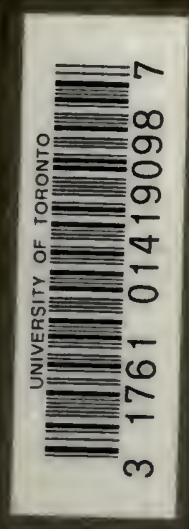





\section{THE PHYSIOLOGY OF STOMATA}

BY

FRANCIS ERNEST LLOYD

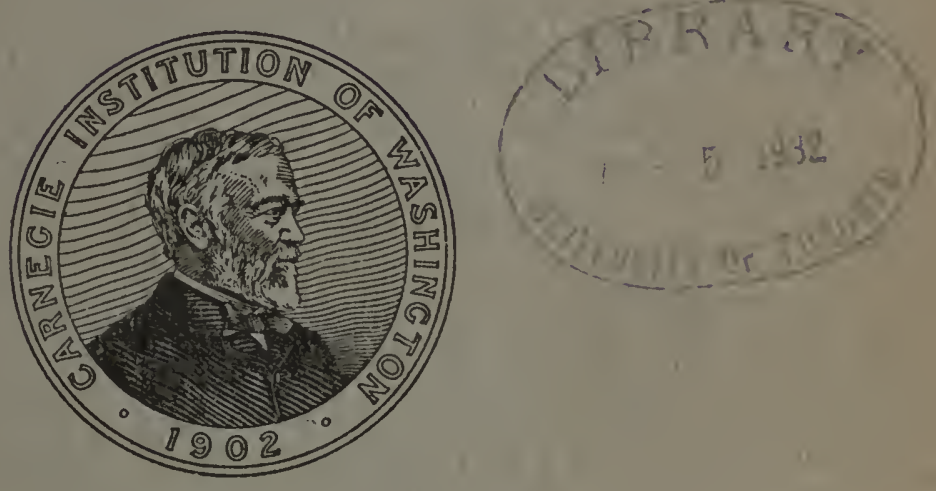

WASHINGTON, D. C.

Rublished by the Carnegie Institution of Washington 1908 




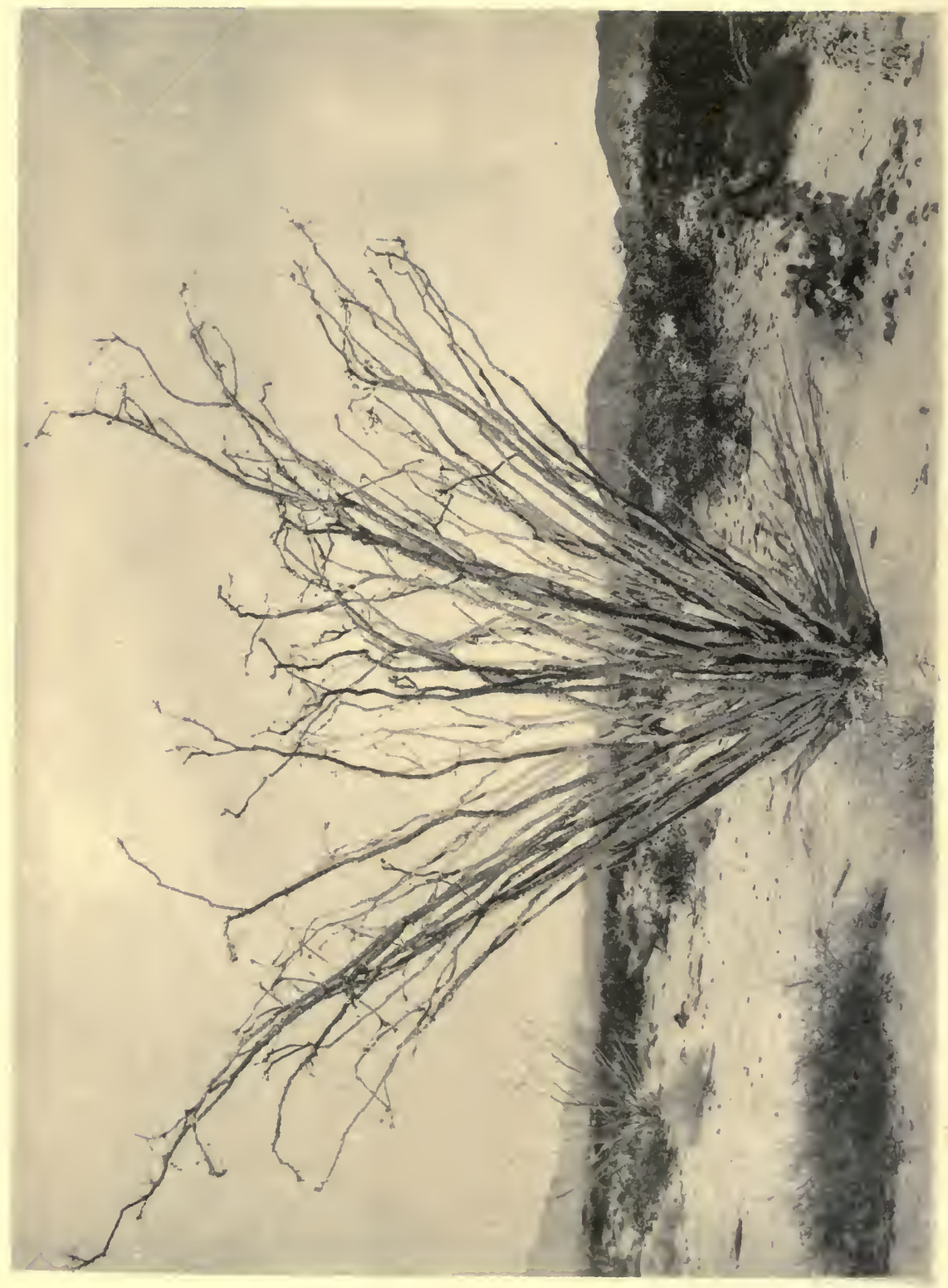

 


\section{THE PHYSIOLOGY OF STOMATA}

BY

FRANCIS ERNEST LLOYD

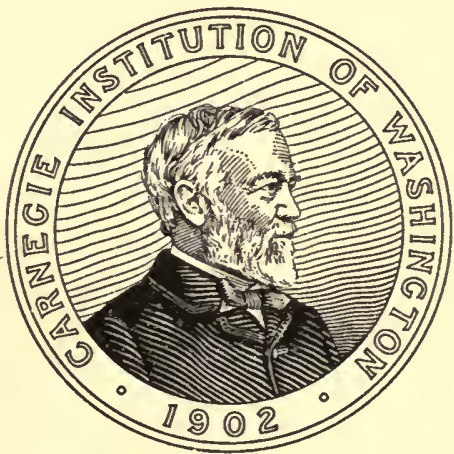

WASHINGTON, D. C.

Published by the Carnegie Institution of Washington 1908 


\section{CARNEGIE INSTITUTION OF WASHINGTON}

Publication No. 82

PRESS OF GIBSON BROTHERS

WASHINGTON, D. C. 


\section{CONTENTS.}

Introduction

The point of view

The plants studied

Meteorology

Methods

Transpiration

Stomatal action

Effect of caustic potash upon stomata

PAGE.

PART I.

Transpiration and stomatal movement

Normal daily periodicity

Responses in transpiration and stomatal movement to sudden changes in illumination

Discussion .

Summary

Induced rhythm in transpiration

Induced rhythm in stomatal movement

Closure of stomata during wilting

Selected experiments

Relative humidity and stomatal movement

Relative humidity-its influence upon the condition of stomata

PART II.

Physiology of stomata, with special reference to the metabolism of guard-cells

Normal diurnal changes in contents of guard-cells Verbena ciliata Stomatal movement Oil

Fouquieria splendens Variation in the starch content of the guard-cells Normal stomatal movement

Summary

Relation of stomata to certain parts of the spectrum, to darkness, and to air devoid of carbon dioxid

Method

The red and blue regions of the spectrum

Red light

Blue light

Darkness

Summary for Verbena

Additional experiments

Experiments with air free of carbon dioxid

Experiments commencing at time of minimum starcl content of guard-cells

Discussion and conclusions

General summary

Transpiration and stomatal movement .

Induced rhythm in transpiration

Induced rhythm in stomatal movement .

Whilting ${ }_{\text {Phiology of the guard-cells }}$.

Bibliography . 
Digitized by the Internet Archive in 2007 with funding from Microsoft Corporation 


\section{THE PHYSIOLOGY OF STOMATA.}

\section{INTRODUCTION.}

\section{THE POINT OF VIEW.}

The critical study of stomata began with von Mohl. Since his time there have been two trends of study, not always separated, to be sure, but in the main distinct enough so that their recognition serves for the moment a useful purpose in enabling us to define the point of view of the present paper. These are the physical trend of thought, the followers of which have sought to elucidate the mechanical aspects of stomata. Although Schwendener did not ignore the physiological problem, his work was chiefly concerned with the mechanism of the stoma, and we may speak, without injustice to him, of a Schwendener school.

There are, on the other hand, those who have sought chiefly to determine the causes which underlie the grosser physical manifestations of stomatal activity. Of this physiological school von Mohl himself was the founder. Of late years the chief contributors to the solution of physiological problems pertaining to the stoma are Kohl and Francis Darwin. The latter, especially in his work "Observations on Stomata" (I898), has most trenchantly criticized our present knowledge. This paper is brief in its discussions, but masterly and pertinent, and we are indebted to Francis Darwin for showing, at a time when the text-books in general voiced an intellectual complacence on the subject, that, beyond the generally accepted view relative to the rôle of photosynthesis in stomatal activity dating from von Mohl, practically nothing is understood, and that this view is inadequate to explain certain known facts in regard to stomata. One of these, the opening of stomata in the absence of $\mathrm{CO}_{2}$, established by Leitgeb and verified by Darwin, may be cited as an example. To be sure, the attempt has been made to explain such activity by referring the stoma to the class of irritable mechanisms, but unfortunately such treatment is not investigation, and does not give us real light.

The common point of view upon which the followers of both the physical and physiological students of the stoma have chiefly and naturally stood is that of biological, or teleological, interpretation. Such obvious and striking structures, common to the epidermis of so great a multitude of vegetable organisms, and having throughout a very uniform construction, have rightly 
been looked upon as important in placing the protoplasts within the leaf or plant in contact with the above-ground environment. To allow chiefly the entrance of light, the exit and escape of gases, or the escape of water-vapor have been emphasized separately or collectively by almost every observer. With the exception of the first, which may now be disregarded, these are to be admitted as qualitatively true. In view of the suppression of gaseous diffusion through the cuticle, the stomata are certainly the sole path by which gases, in wide sense, enter and escape (Blackman, 1895). And that the loss of water by the plant is chiefly through the stomata is also true. The more difficult question of what the exact biological meaning of the stomatal movement is, has not been answered quantitatively. Schwendener's contention that, inasmuch as the plant is normally active only when fully supplied with water, and that, therefore, the stoma has to do with the interchange of oxygen and carbon dioxid, appears rather to avoid the issue. On the other hand, those who see in stomata mechanisms intimately connected with the control and regulation of the passage of water-vapor from the plant, have not succeeded in advancing facts in support of their position. Certain phylogenetic considerations* fail to offer more than suggestions, and can not be expected to do more, since at all times photosynthesis in, and the escape of water from, the aerial parts of green plants, whether gametophytic or sporophytic, have gone on hand-in-hand; and, moreover, the plants of the past are now not available. The problem, in its quantitative aspect, must therefore be solved by physiological methods and the answers to specific questions so attached will bear upon physiological problems, purely considered, and upon the biological question above indicated.

Regarded in this way, the problem of stomatal activity is by no means a slight one. The attempt in the present paper has been made to attack it on two points: (I) Specifically, the supposed relation between stomatal movement and the loss of water-vapor by the plant, in order to determine whether this loss is regulated by the stomata; and (2) the determination, so far as possible, of the cause of stomatal movement, or more particularly, the cause which leads to a rise in turgor greater than that in surrounding cells (Kohl, 1895), which results in the opening movement.

The series of studies which are here brought together was begun in the summer of 1904, under the valued patronage of the Botanical Society of America, at the Desert Botanical Laboratory; at the same place, during the following summer, by means of a grant from the Carnegie Institution of Washington; and during the major portion of the present year (I906), while the author was a member of the staff of the Desert Botanical Laboratory.

*Cf. K. Goebel: The Present-day Problems of Plant Morphology. Transl. by F. E. Iloyd, Science, II. 
In nearly all instances the experiments herein presented were repeated at, roughly speaking, yearly intervals, and in this way a valuable check upon all the work was obtained. If, as it may appear, but a beginning has been made toward the solution of the difficult problems which have been attacked, I may still venture to hope that the results will prove to be a stimulus to further studies in the same direction. If this has been accomplished, it is due in no small part to the personal concern which my colleagues have shown in this work, and to them, as well as to the Institutions mentioned above, I wish at this point to express my most earnest appreciation. Of these, I would especially mention Dr. Daniel Trembly MacDougal, who has throughout taken a most generous interest in my studies. The moral support of one's co-workers is frequently no small element in his success. I wish also to thank Prof. E. M. Blake for his help in making certain mathematical interpretations used in the section on transpiration and stomatal action.

THE PLANTS STUDIED.

The material which has been used has been obtained chiefly from two plants, the ocotillo (Fouquieria splendens, plates I and 2) and a showy desert verbena (Verbena ciliata, plate 3), both of which grow abundantly upon Tumamoc Hill, upon which the Desert Botanical Laboratory stands.

FOUQUIERIA SPLENDENS* WISL.

The ocotillo (Fouquieria splendens, plates I and 2) is one of the most conspicuous and characteristic among the plants of the formation in which it occurs. Its common name, "coach-whip cactus," conveys to the mind two ideas - that the stems appear as a cluster of coach whips, lithe, slender, and unbranched, and so standing at an angle with the ground as to suggest the whip held in the hand, and that it looks much like the cacti which are associated with it in its habitat, the likeness to which is strengthened by the occurrence of thorns of remarkable morphological origin (Robinson, 1904). Nor is this likeness merely superficial, since even a cursory examination of the anatomical structure discovers the occurrence of water-storage tissue, the cortex, the character of which brings the ocotillo very close to the cacti physiologically. Another interesting feature of this plant, in which the likeness is rather to certain other types of desert forms, is the ready manner in which it develops a complement of foliage. So readily does this occur that the growth of leaves may be induced during the course of a few days merely by sufficiently wetting the stem (Lloyd, 1905). Normally a full growth of leaves follows an abundant shower, and accordingly the foliage is present during the two periods of rainfall. It is, however, capable of responding

*Wislezenus: Tour N. Mex., 98. 
much more frequently to an increase of water in the soil. As many as five leaf coverings have been formed during the period from February to August, three of which were induced by irrigation (Cannon, 1905). From these facts it will be appreciated that this plant is a marked desert type, and on this ground it was believed that the study of the stomata and their relation to the loss of water by the plant would be of profit.

Aside from other features which may be at present disregarded the one pertinent to the matter in hand is the anatomical structure of the leaves (fig. I). They are $0.3 \mathrm{~mm}$. thick, small, obovate in form, 2 to 3 (or 4) cm. long, rather light green, and slightly glaucous. The cuticle is not thick, and, save for the

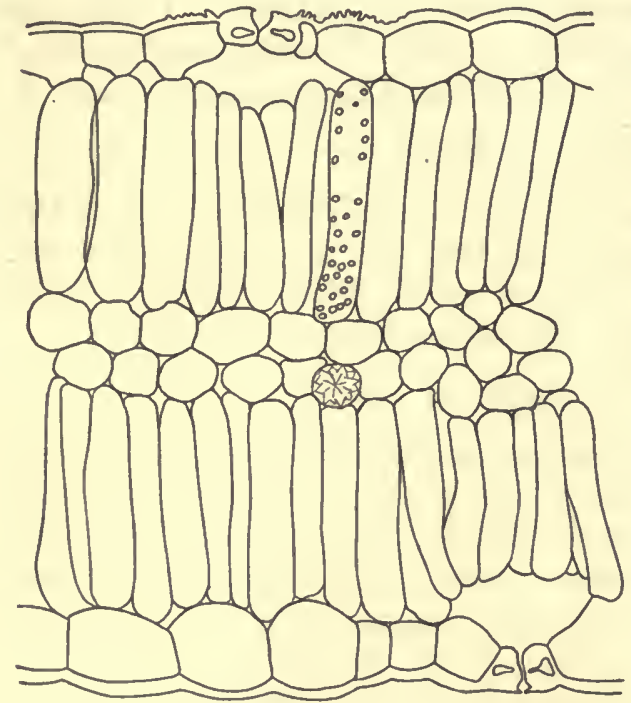

Fig. 1.-Transverse section of portion of leaf of Fouquieria splemtens. isolateral structure, the leaves do not at all strikingly suggest the desert type of foliage (plate 2, fig. 3 ). The chlorenchyma has above and below a relatively thick palisade of, in each case, a single row of deep, columnar cells. Between them lies a spongy chlorenchyma, one-seventh of the total leaf thickness, of rounded cells, with small intercellular spaces.

The epidermis is of a single layer of cells, 30 to 45 micra deep, and of simple tangential outline, the cuticle being more or less readily corrugated from the stomata as a center.* The cuticle is not at all remarkable, since its thickness is no greater than that on the leaf of many mesophytes. A small amount of "bloom" is present, giving a slightly glaucous appearance to the leaf.

The stomata are of very simple character, as seen in fig. 3. The only structural feature which marks it as a supposedly desert type is the somewhat marked outer ridge. There is no inner ridge. When young the dorsal and ventral walls are not markedly thickened, but become very much so with age, and as the secondary thickening proceeds the mobility of the organ is reduced. The lumen, as a result, becomes reduced to a thin space for the inner half of-the guard-cells, but remains approximately cylindrical in the outer half. $\dagger$ The outer wall remains thin, and by its stretching, when the

*A not uncommon character; e. g., it appears in Ampelopsis.

fInner, $i$. $e_{\text {., }}$ adjacent to the pore; outer, adjacent to the epidermis. 


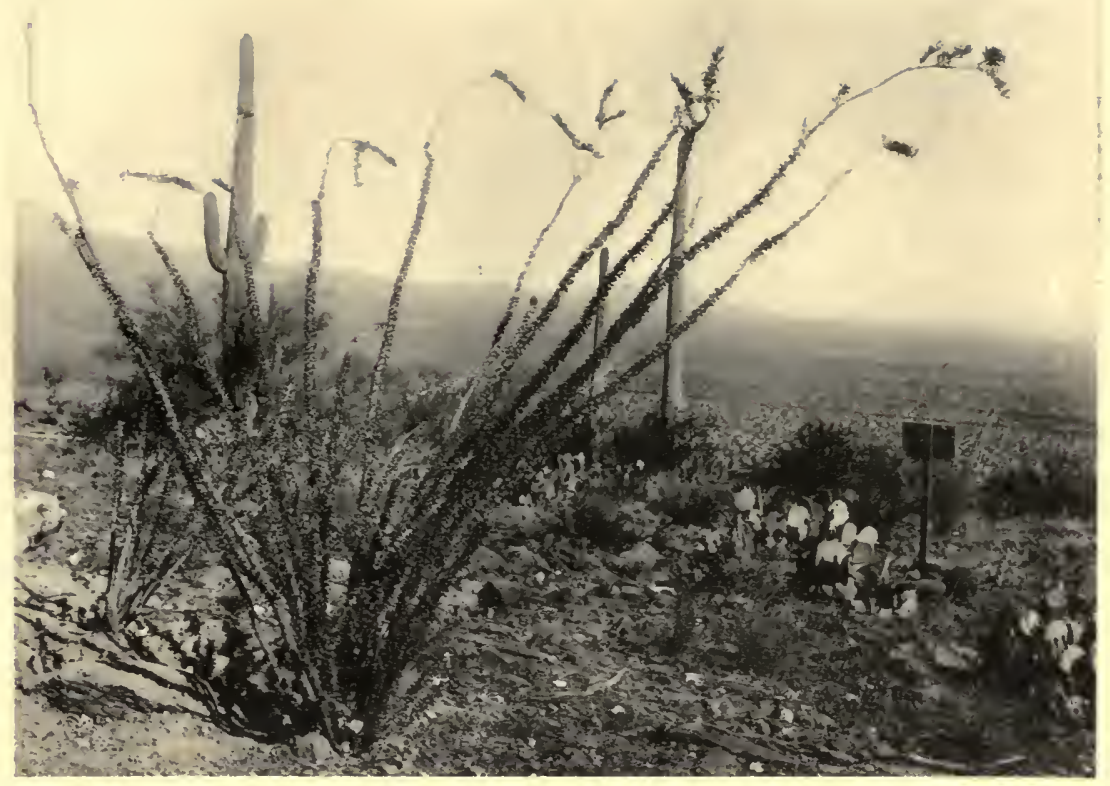

1

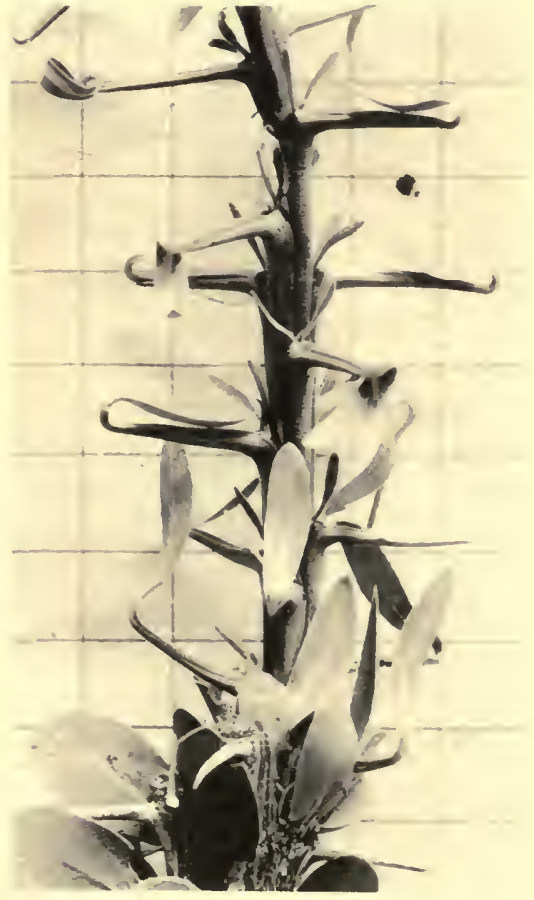

2

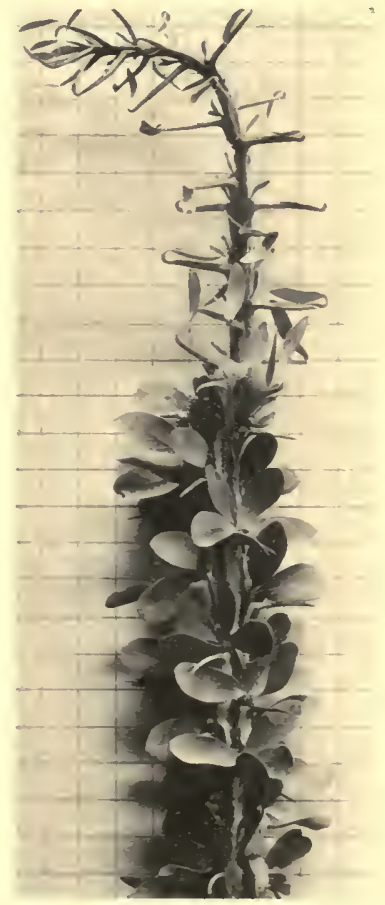

3

1. The Ocotillo, Fouquieria splendens, in leaf and flower, on Tumamoc Hill, April, 1906.

2. Young, rapidly growing shoot of Fouquieria splendens, bearing primary leaves. The developing spines are seen to be formed within the dorsal part of the petioles. On the right, near the base of the shoot, is a leaf-blade withered and partially separated from the spine.

3. Shoot of Fouquieria splendens clothed with primary leaves, secondary leaves, and terminating in a new growth. 


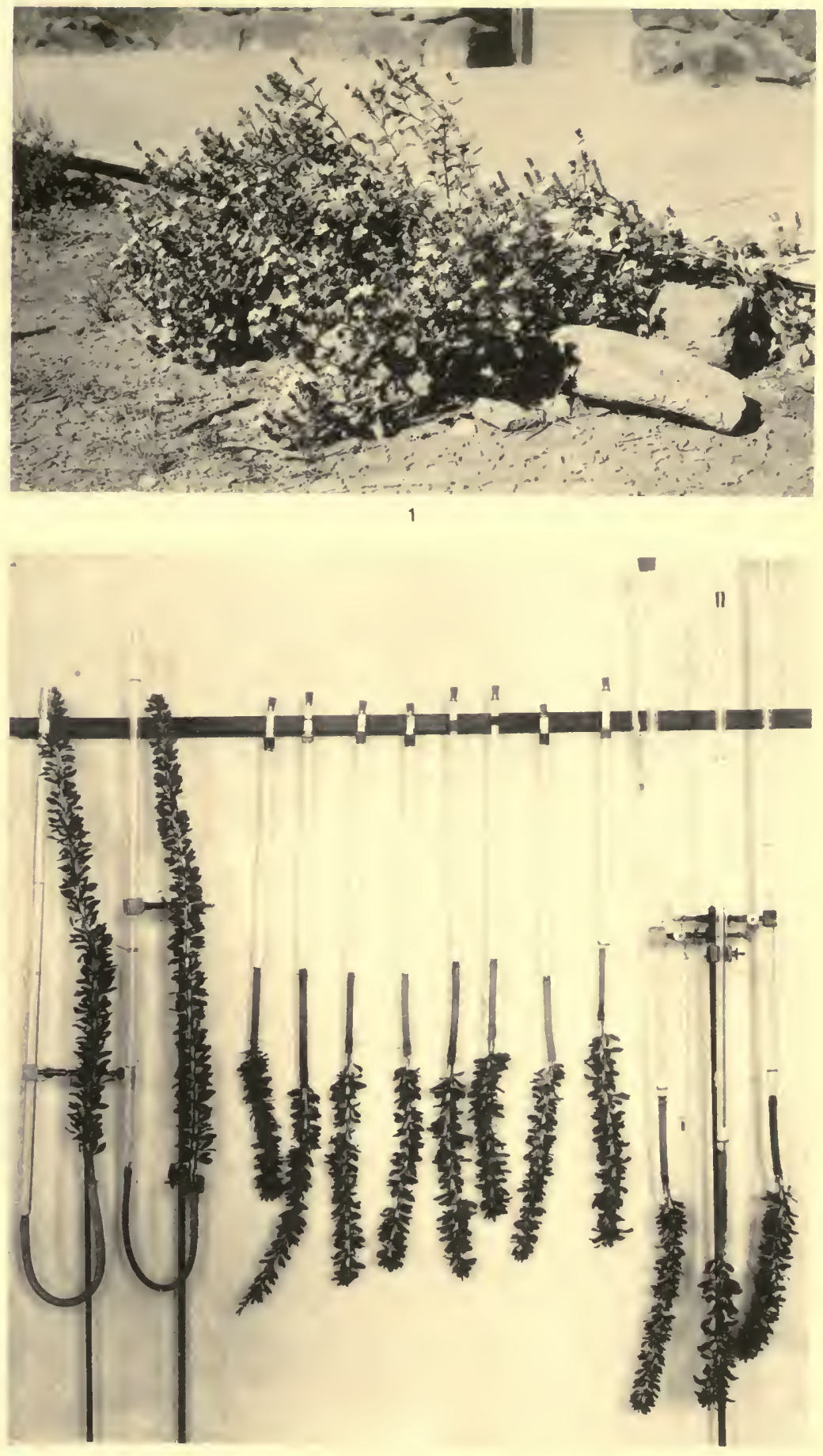

guard-cell is turgescent, provides for such movement as obtains in the old condition.

The dimensions of the stoma of average maturity, in the open and closed positions, are shown in table $\mathrm{I}$.

TABLE I.-Ocotillo measurements of two stomata open and closed.

\begin{tabular}{|c|c|c|c|c|c|c|}
\hline & \multicolumn{3}{|c|}{ Width. } & \multicolumn{3}{|c|}{ Length. } \\
\hline & Stoma. & Pore. & Ridge. & Stoma. & Pore. & Ridge. \\
\hline $\begin{array}{l}\text { Open } \ldots \ldots \ldots \ldots \ldots \ldots \\
\text { Closed . . . . . . . . . }\end{array}$ & $\begin{array}{l}\text { Micra. } \\
30 \\
27\end{array}$ & $\begin{array}{c}\text { Micra. } \\
9 \\
0 \\
0\end{array}$ & $\begin{array}{l}\text { Micra. } \\
12 \\
18\end{array}$ & $\begin{array}{c}\text { Micra. } \\
36 \\
36 \\
\end{array}$ & $\begin{array}{l}\text { Micra. } \\
\text { I } 8 \\
\mathrm{I} 2 \\
\end{array}$ & $\begin{array}{r}\text { Micra. } \\
28.5 \\
28.5 \\
\end{array}$ \\
\hline $\begin{array}{l}\text { Open } . . . \ldots \ldots \ldots \ldots \\
\text { Closed........... }\end{array}$ & $\begin{array}{l}27 \\
27\end{array}$ & $\begin{array}{l}6 \\
0\end{array}$ & $\begin{array}{l}\text { I3.5 } \\
13 \cdot 5\end{array}$ & $\begin{array}{l}33 \\
33\end{array}$ & $\begin{array}{l}13 \cdot 5 \\
12\end{array}$ & $\begin{array}{l}2 \mathrm{I} \\
24\end{array}$ \\
\hline
\end{tabular}

In point of size the stoma is smaller than such monocotyledonous types as Zebrina and compares, mechanically considered, with the more usual dicotyledonous types.
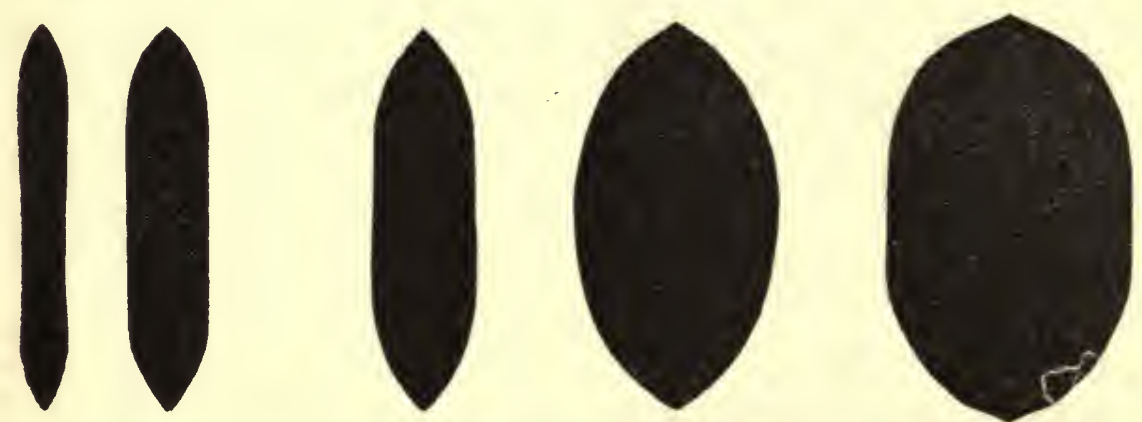

FiG. 2.-Form of stomatal pore of Fouquieria splendens at various degrees of opening. $\times 2450$.

The distribution of stomata, together with that of a few other plants, is given for comparison in table 2.

TABLE 2.-Distribution of stomata of Fouquieria splendens and certain other plants.

\begin{tabular}{|c|c|c|c|}
\hline \multirow{2}{*}{ Plant. } & \multicolumn{2}{|c|}{ Number of stomata per sq. $\mathrm{mm}$. in } & \multirow{2}{*}{$\begin{array}{l}\text { Total per } \\
\text { sq. mm. leaf. }\end{array}$} \\
\hline & $\begin{array}{c}\text { Lower } \\
\text { epidermis. }\end{array}$ & $\begin{array}{l}\text { Upper } \\
\text { epidermis. }\end{array}$ & \\
\hline Ocotillo............. & $160 \quad(100)$ & 160 & 320 \\
\hline Verbena ciliata.............. & 100 to 175 & 100 to 175 & 200 to 350 \\
\hline Celery $\ldots \ldots \ldots \ldots \ldots \ldots \ldots \ldots$ & 175 & 0 & 175 \\
\hline Fuchsia $\ldots \ldots \ldots \ldots \ldots \ldots \ldots$ & 100 to 125 & o & 100 to 125 \\
\hline Parsley. . . . . . . . . . . . . . . . . & 150 & o & 150 \\
\hline 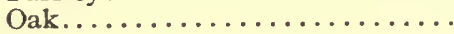 & 346 & o & 346 \\
\hline
\end{tabular}

The change of form taken by the stomatal pore during opening may be seen in fig. 2, which was made by carefully drawing the pores of different 
extent of opening to the same scale. Roughly speaking, the transverse form may be described as elliptical, but this is departed from in the acute apices and flattened sides, the departure being greatest in regard to the apices in the smaller openings and in the sides in the larger.

The plastids of the guard-cells are numerous and very faintly green. The size of the plastid varies with the amount of contained starch, and this doubtless modifies the optical effect of the chlorophyll upon the eye. Even when the amount of starch is low the amount of green color is very small, so that the plastids appear almost colorless. The contrast between the chlorenchyma plastids and those of the guard-cells is in this regard very striking, as also is the difference in the origin and development of the starch granules. In the chlorenchyma plastids the starch appears as small lenticular bodies, two to three or four in number, but never large enough to modify the form of the

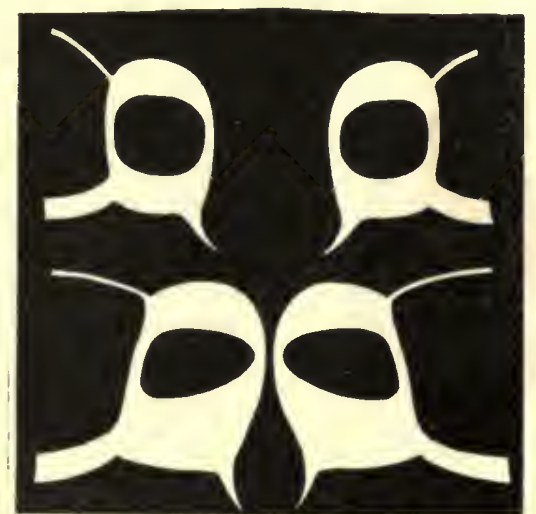

F1G.3.-Transverse sections of stomata of Fouquie ria splendens. Two stomata, one closed and the other open, drawn to the same scale. The black square represents 40 micra on each side. plastids in which they occur. In the guard-cell, however, the starch granules are spherical, except for the contiguous flattened facets caused by mutual contact. They are, moreover, so large that the plastids, when fully loaded with starch, appear as a compound starch grain, such as occurs in certain cereals, while the matricial substance can scarcely be detected.

The application of Molisch's (1896) potash test shows a pronounced reaction, but while the plastids of the chlorenchyma retain their individuality those of the guard-cells do not. This may be due to the swelling of the starch and consequent disorganization of the plastids, which, being crowded together in this condition, would produce a general coloring effect rather than that of distinct bodies similarly colored.

The Molisch test may, however, be misleading, though this must be said with a full appreciation of the care with which he has studied the reaction. Thus, I have succeeded in getting a curious reaction in certain leaf-cells in which no trace of chlorophyll was optically present, while in similar cells in another region of the same leaf no reaction followed. For example, the guardcells of a species of Linum gave a reaction on one side of the leaf, while this did not occur on the other. Epidermal cells also give an appearance of a yellow-green solution, when there are no plastids observably green. 


\section{VERBENA CILIATA* BENTH.}

Verbena ciliata (plate 3 ) is a plant with showy flowers which may persist by means of its roots and by half-withered stems through a rather extended period of drought. Though an annual in type, it therefore often becomes perennial.

The leaves (1 30 micra in thickness) are of a common mesophytic bifacial type, with an arrangement of chlorenchymatous tissues very similar to that in Raphanus (Haberlandt, Physiologische Pflanzenanatomie, p. 256). This is characterized by a 3 -layered palisade tissue. The epidermal cells are of the very generally distributed type, with wavy outlines, and both the epidermis and cuticle are thin (plate 13 , fig. I; plate 7 ).

Both surfaces of the leaf have bristle and glandular hairs, which stand in such scattered positions that they can scarcely be interpreted as mechanical suppressors of water loss. They are more abundant on the lower surface. The

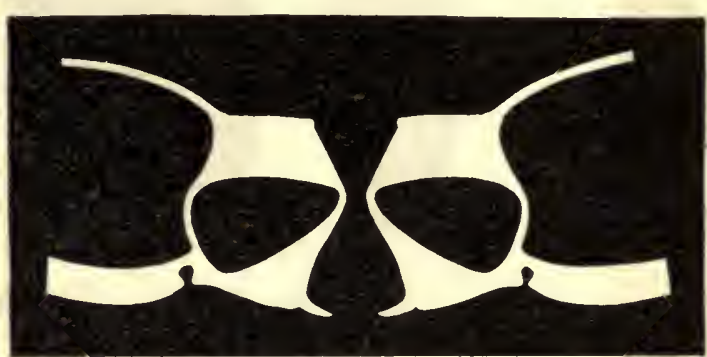

Fig. 4.- Stoma of Verbena ciliata in transverse section. stomata are, like those of the ocotillo, of a simple type, with a very slight inner ridge (fig. 4). The secondary thickening of the guard-cell wall affects chiefly the lower wall. The hinge which, in ocotillo, is replaced by a thinner line of wall in the adjacent epidermal cell, is quite marked in Verbena. The form of the pore at various degrees of expansion is shown in the diagrams in fig. 5, drawn to the same scale. The widest opening is 10 micra in width and' 15 in length. It will be observed that the transverse form of the pore is materially changed after a width of 6 micra has been obtained, and that the geometrical figure departs from the closer approach to the elliptical taken by the pore when it is less than 6 micra in width. These figures, and the similar ones already given of the stomata of Fouquieria, are of much interest, as they suggest a method for the extension of the field of study so ably opened up by Schwendener, in which the methods employed in the work to follow may be of very great aid in pushing the mechanical analysis of stomatal movement to a high degree of refinement. The relation of this change of form to the diffusion capacity of the opening will be referred to later.

In addition to starch there is present, at times, a droplet of oil in each guard-cell. The amount of oil and of starch is subject to certain fluctuations, which will be considered at length beyond. 
An examination of the plastids, even when they are devoid of starch, fails to convince one that chlorophyll is present. I am inclined to believe that they are not chlorophyll-bearing, and it turns out that Kohl (I886, p. 39) sought for and believed that he found chlorophyll-free or chlorophyll-poor stomata on the corolla-like calyx leaves of the verbenaceous Chlorodendron balfouri. and in the white portions of variegated leaves of Euonymus japonicus and the grass Oplismenus imbecillis. Certainly the stomata of Verbena ciliata are chlorophyll-poor, if this substance be not, indeed, absent; but I have not found, as Kohl reports for the species above named, that stomatal activity is correlated with the absence or presence of chlorophyll. Further reference to this point will be made.
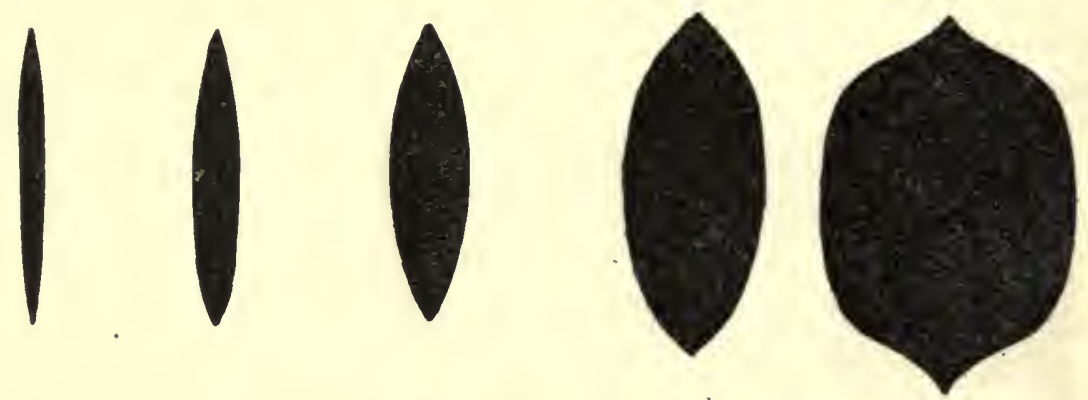

FIg. 5.-Variation of form taken by pore of Verbena ciliata during opening. The widest measured 10 micra broad. All dimensions of drawings are in proportion. $\times 2450$.

The distribution of stomata per unit area of leaf for Verbena ciliata has been given in table 2. Their size and the changes in dimensions undergone during plasmolysis are indicated in table 3 .

TABLE 3.-Range of size of stomata on the same leaf.

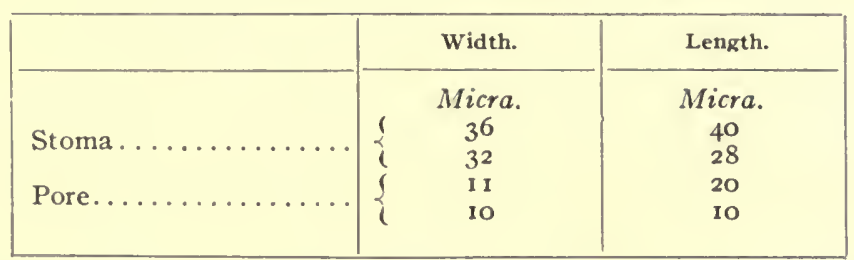

Small stomata can open nearly as widely as large ones, though the length of the pore may vary very considerably.

The degrce of mobility exhibited by these organs is indicated by the figures in tables 4 to 6 .

It is quite evident from the measurements in these tables that, in spite of the very small amount of chlorophyll present, if indeed it is present, the stoma of this plant is by no means immobile or, as shown by certain of the data to be presented later, slow to react. 
TABLE 4.-Mobility of stomata.

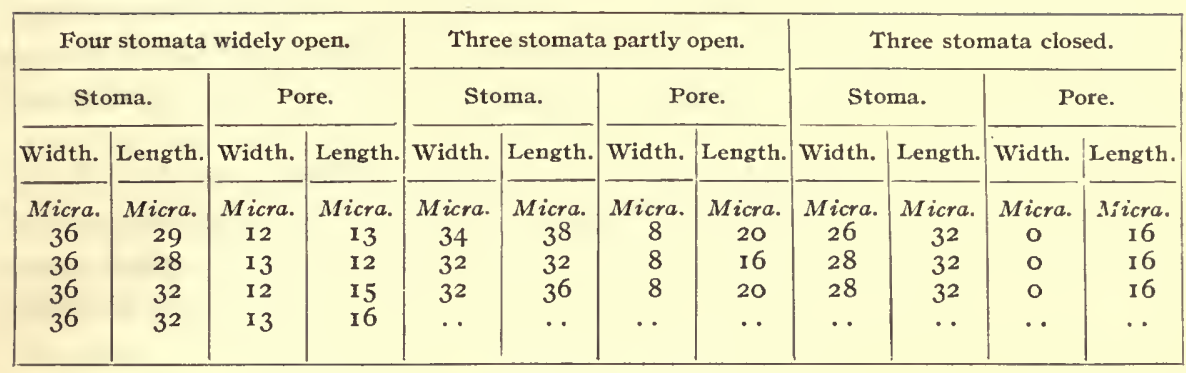

TABLE 5.-Changes in dimensions of stomata irrigated with water after remaining some months in absolute alcohol.

\begin{tabular}{|c|c|c|c|c|c|c|}
\hline \multirow[t]{2}{*}{ - } & \multicolumn{3}{|c|}{ Width. } & \multicolumn{3}{|c|}{ Length. } \\
\hline & Stoma. & Pore. & $\begin{array}{c}\text { Outer } \\
\text { vestibule. }\end{array}$ & Stoma. & Pore. & $\begin{array}{c}\text { Outer } \\
\text { vestibule. }\end{array}$ \\
\hline $\begin{array}{l}\text { Open } . . . \ldots \ldots \ldots \ldots \\
\text { Partly closed............ }\end{array}$ & $\begin{array}{r}\text { Micra. } \\
35.75 \\
-35.75 \\
\end{array}$ & $\begin{array}{c}\text { Micra. } \\
7 \\
4.2 \\
\end{array}$ & $\begin{array}{l}\text { Micra. } \\
15.77 \\
14\end{array}$ & $\begin{array}{l}\text { Micra. } \\
29.5 \\
31\end{array}$ & $\begin{array}{r}\text { Micra. } \\
12.6 \\
9.8\end{array}$ & $\begin{array}{r}\text { Micra. } \\
19.6 \\
19.6\end{array}$ \\
\hline Open $\ldots \ldots \ldots \ldots \ldots \ldots$ & 36 & 6 & I 5 & 36 & 15 & 24 \\
\hline Partly closed........... & $3 I \cdot 5$ & 3 & 12 & 33 & 10.5 & 24 \\
\hline
\end{tabular}

TABLE 6.-Measurements of three freshly taken stomata, open in water and closed, partly or nearly, by iodine (Verbena ciliata).

\begin{tabular}{|c|c|c|c|c|c|c|}
\hline & \multicolumn{3}{|c|}{ width. } & \multicolumn{3}{|c|}{ Length. } \\
\hline & Stoma. & Pore. & Ridge. & Stoma. & Pore. & Ridge. \\
\hline $\begin{array}{l}\text { Open } . . . \ldots \ldots \ldots \ldots \ldots \\
\text { Partly closed } \ldots \ldots \ldots \ldots \ldots \ldots\end{array}$ & $\begin{array}{l}\text { Micra. } \\
36 \\
3 \mathbf{I} \cdot 5\end{array}$ & $\begin{array}{l}\text { Micra. } \\
6 \\
3\end{array}$ & $\begin{array}{l}\text { Micra. } \\
\text { I } 5 \\
\text { I } 2\end{array}$ & $\begin{array}{l}\text { Micra. } \\
36 \\
33\end{array}$ & $\begin{array}{l}\text { Micra. } \\
\text { I5 } \\
\text { 10. } 5\end{array}$ & $\begin{array}{l}\text { Micra. } \\
24 \\
24\end{array}$ \\
\hline $\begin{array}{l}\text { Open } . \cdots \ldots \ldots \ldots \ldots \ldots \ldots \ldots \\
\text { Closed. } \ldots \ldots \ldots \ldots \ldots \ldots \ldots \ldots\end{array}$ & $\begin{array}{l}28 \\
25\end{array}$ & $\begin{array}{l}5 \cdot 6 \\
0.7\end{array}$ & $\begin{array}{r}\text { II. } 2 \\
8.4\end{array}$ & $\begin{array}{l}26.6 \\
25.2\end{array}$ & $\begin{array}{l}9.8 \\
5.6 \\
\end{array}$ & $\begin{array}{l}17 \\
18 \\
\end{array}$ \\
\hline $\begin{array}{l}\text { Open } \ldots \ldots \ldots \ldots \ldots \ldots \ldots \ldots \\
\text { Closed } \ldots \ldots \ldots \ldots \ldots \ldots \ldots \ldots\end{array}$ & $\begin{array}{l}32 \\
27\end{array}$ & $\begin{array}{l}8 \\
1.5\end{array}$ & $\begin{array}{l}\cdots \\
\cdots\end{array}$ & $\begin{array}{l}36 \\
33\end{array}$ & $\begin{array}{l}18 \\
13\end{array}$ & $\begin{array}{l}\cdots \\
\cdots\end{array}$ \\
\hline
\end{tabular}

It will be apparent from the foregoing brief description of the two plants chiefly concerned in the pages to follow that they offer decided advantages for a preliminary study of physiology of the stomata in desert plants.

The ocotillo is a highly specialized spinose type, producing normally at least two complements of leaves annually; these are certainly no more specialized anatomically than those of, say, Lactuca scariola. The verbena is a successful herbaceous desert plant with leaves of no more specialized anatomical characters than those of numerous mesophytes, as, e. g., Raphanus.

In point of size, the stomata of both plants are approximately of the average size, and their numbers per unit of area are not reduced.

In both plants the stomata are of a simple type and have no accessory. 
elaborations of the cuticle or adjacent cells in the form of pits, plugs, or other devices which might be regarded as modifying the effect of the stomatal aperture. We are therefore face to face with the relation of the stomatal openings to the regulation of loss of water, unmodified by other anatomical complications.

The small amount of chlorophyll (or its absence, if this be the case) in the stomata of Verbena, their size and mobility, the relatively small amount of starch present, together with other features, have made this plant most valuable in the pursuit of light upon the internal economy of the stomatal apparatus.

\section{METEOROLOGY.}

A more exact appreciation of the precise degree of adaptive value of the stomatal mechanism of these plants may be had if we glance for a moment at the conditions under which they live. There are introduced for this purpose the tables of temperatures for the year 1906 and of rainfall for 1905 and 1906. The latter are plotted in fig. 6, together with a curve of normal rainfall (Coville \& MacDougal, 1903).

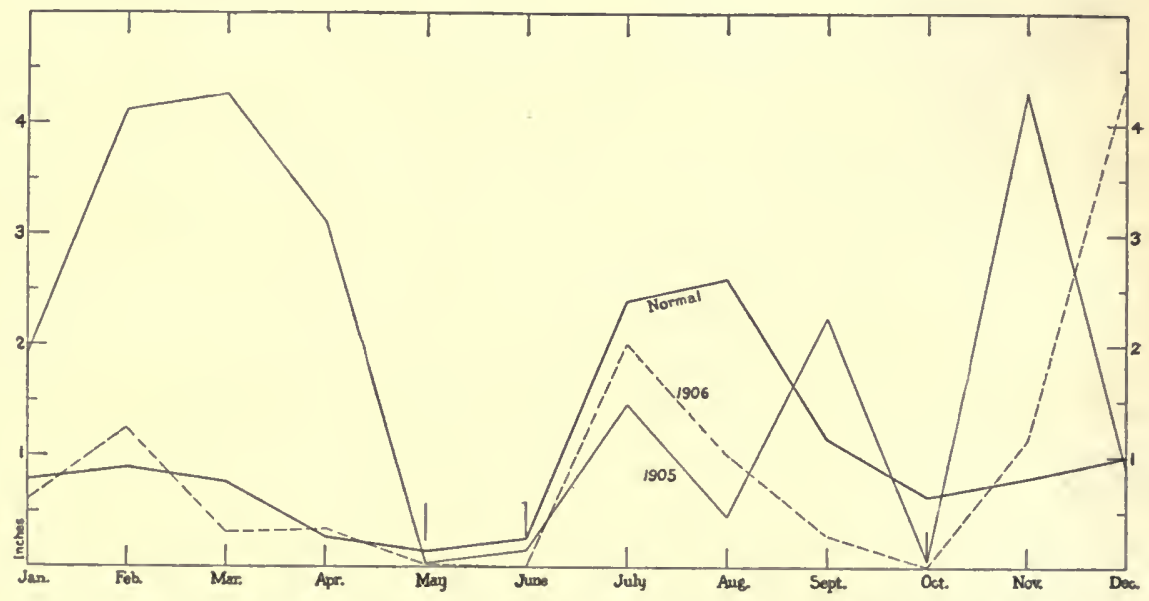

Fig. 6.-Curves of rainfall for 1905 and 1906 at the Desert Botanical Laboratory, together with a curve of normal rainfall, based upon data for 15 years taken at Tucson, Arizona.

With regard to the temperatures it will be noted that extreme cold is not known on Tumamoc Hill, where the plants studied are to be found. Growth is therefore possible for the vegetation of the region at almost any time of the year if the soil-water is sufficient. Thus, the ocotillo began to develop its foliage during the latter half of December, 1906, and by the end of the year many individuals were conspicuous for their abundant green vestiture. During the same period the verbena recommenced its growth and at the close of the month many plants showed a fine development, though of course, owing to the lower general temperatures, the growth was in neither of these 
plants rapid as compared to that which ensues after the spring and summer rains. During the cool and moist period of the winter season the conditions approximate closely those of a northern cool, moist, though not wet spring, when the ground is wet but the air cool, a high relative humidity, with dews and with an abundance of sunshine. The leaves of the plants which grow at this time are in no danger of wilting, and indeed never show it, and, from the teleological point of view, there is no reason why the stomata should not be wide open. I have, however, not found them open more than six-tenths their possible extent of opening during the warm period of the day, though exceptional stomata show a somewhat wider opening.

TABLE 7.-Rainfall, Tumamoc Hill, Tucson, Arizona, for 1906, in inches.

[See fig. 6].

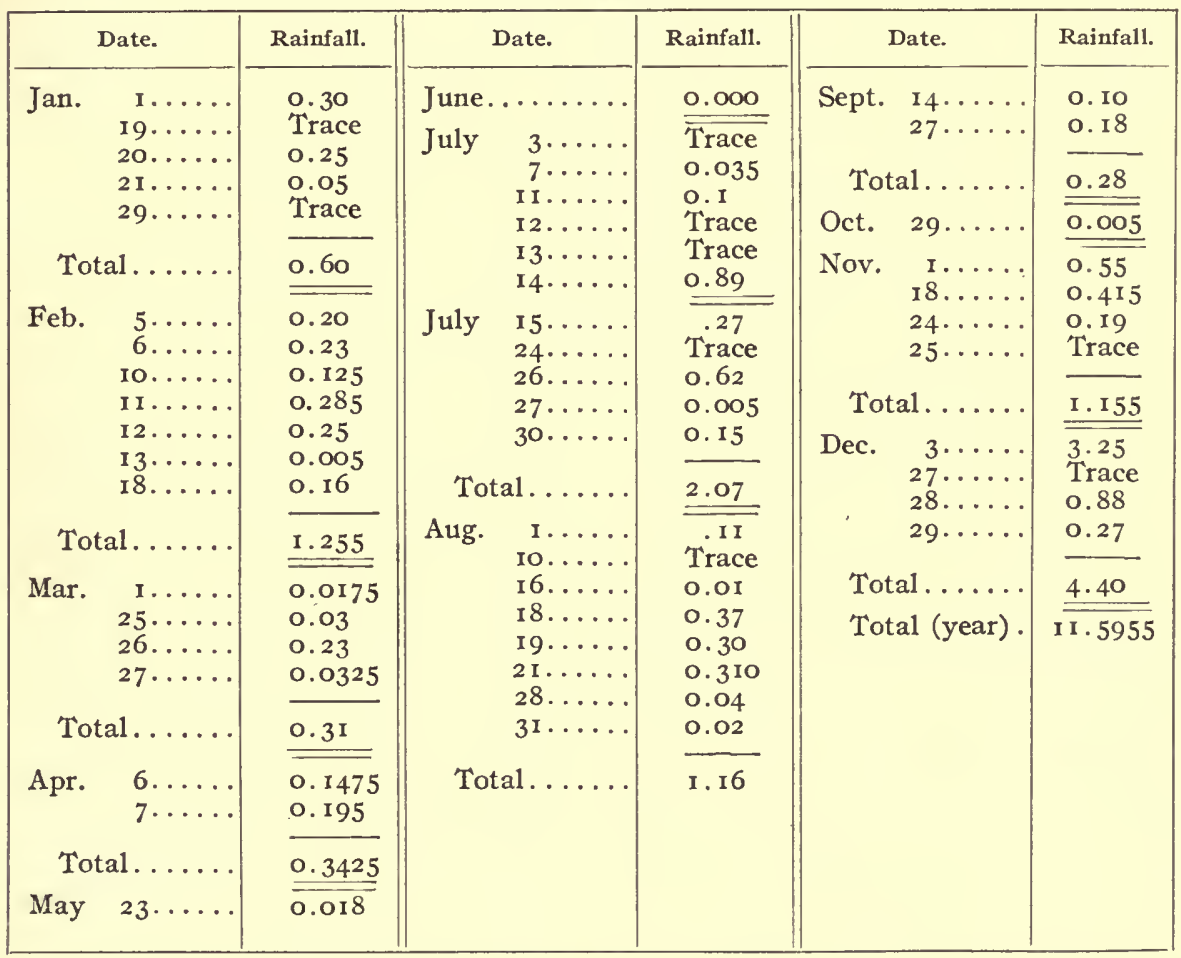

The approach of the summer is marked by cessation of rain, increase of temperature, and lowering of the relative humidity.* At the same time,

* No accurate data for relative humidity for a sustained period are available, so that gen. eral statements must suffice. With reference to the possible high humidities in a given area in the absence of rain see Cannon, 1906. The problem of the desert in this regard is one which commends itself to study. Many areas have a distinctly desert character, but are favored by high atmospheric humidities, and these are contiguous in many places to the desert areas having the opposite condition, e. g., Southern California and Arizona (McGee, 1906). 
the soil-water is depleted (Livingston, I906), though sufficient may be retained to carry some forms of vegetation through to the summer rainy period. Verbena ciliata is in this respect remarkably hardy and, from its anatomical character, quite unexpectedly so. The height of the dry season is one which is trying in the extreme, one would think, and still, with a supply of water

TABLE 8.-Rainfall, Tumamoc Hill, Tucson, Arizona, for 1905, in inches.

[Ste fig. 6.]

\begin{tabular}{|c|c|c|c|}
\hline Month. & Rainfall. & Month. & Rainfall. \\
\hline January . . . . . . . . . . & I.9I & 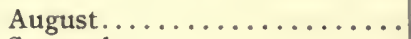 & 0.465 \\
\hline February.............. & 4 . I I & September................ & 2.24 \\
\hline 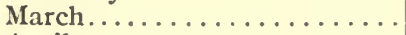 & 4.27 & 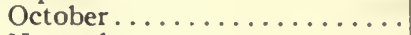 & 0.048 \\
\hline 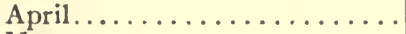 & 3. II & November................ & $4 \cdot 4^{8}$ \\
\hline 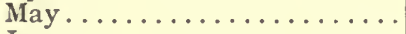 & 0.03 & 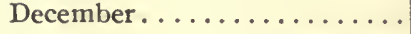 & 0.90 \\
\hline June.................... & 0.15 & & \\
\hline July................ & I $\cdot 47$ & Total.......... & 23.183 \\
\hline
\end{tabular}

TABLE 9.-Temperatures for the year I go6, Tumamoc Hill $\left({ }^{\circ} \mathrm{F}.\right)$.

\begin{tabular}{|c|c|c|c|c|c|c|c|c|c|c|c|c|}
\hline \multirow{2}{*}{ Day. } & \multicolumn{2}{|c|}{ Jan. } & \multicolumn{2}{|c|}{ Feb. } & \multicolumn{2}{|c|}{ Mar. } & \multicolumn{2}{|c|}{ Apr. } & \multicolumn{2}{|c|}{ May. } & \multicolumn{2}{|c|}{ June. } \\
\hline & Min. & Max. & Min. & Max. & Min. & Max. & Min. & Max. & Min. & Max. & Min. & Max. \\
\hline I & $\cdots$ & $4^{I}$ & 50 & 63 & 55 & 70 & 62 & 82 & 45 & 81.5 & 60 & 92 \\
\hline 2 & 27 & $4 I$ & 55 & $5^{8}$ & 39 & $5^{2}$ & 52 & 71 & 50 & 87 & 62 & 93 \\
\hline 3 & 28 & 41 & $5 \mathrm{I}$ & 65 & 34 & 54 & 42 & 71 & 5 I. 5 & 89 & 60 & 86 \\
\hline 4 & 30 & 47 & $4^{8}$ & 67 & 36 & 56 & 40 & 74 & 54.5 & 92 & 53 & 89 \\
\hline 5 & 32 & 59 & 52 & 64 & 47 & 67 & 43 & 77 & $49 \cdot 5$ & 92.5 & 60 & 96 \\
\hline 6 & 40 & 60 & 49 & 55 & 45 & 63 & 49 & 75 & 53 & 85 & 62 & $97 \cdot 5$ \\
\hline 7 & 45 & $6 \mathrm{I}$ & 45 & $6 I$ & 42 & 66 & 50 & 62 & 52.5 & 84 & 67 & 97 \\
\hline 8 & 45 & 60 & 44 & 61 & $5^{I}$ & 68 & 43 & 63 & $57 \cdot 5$ & 96 & 62 & 97.5 \\
\hline 9 & 40 & 60 & 44 & 62 & 52 & 73 & 43 & 71 & $63 \cdot 5$ & 99.5 & 61 & 104 \\
\hline IO & $3^{8}$ & 64 & 49 & 62 & $5 \mathrm{I}$ & 79 & 53 & 79 & 64 & 102 & 69 & 108 \\
\hline II & $34 \cdot 5$ & $64 \cdot 5$ & 47 & $5^{8}$ & $4^{8}$ & 71 & 56 & 83 & 69 & 97 & 69 & 107 \\
\hline 12 & 34 & 64 & 43 & $5^{2}$ & $5^{2}$ & 73 & 57 & 72 & 66 & 95 & 71 & 107.5 \\
\hline I 3 & 47 & 58 & 42 & 55 & 61 & 69 & 50 & 70 & 57 & 86.5 & 74 & 107.5 \\
\hline 14 & 39 & $5^{8}$ & 42 & 59 & 54 & 67 & 48 & 77 & 62 & 88.5 & 73 & 106.5 \\
\hline I5 & $4 I$ & $6 I$ & 43 & 59 & 50 & 67 & 55 & 83 & 62 & $95 \cdot 5$ & 72 & 104.5 \\
\hline 16 & $4^{I}$ & 63 & 43 & 62 & 47 & 71 & 55 & 77 & 70.5 & 96 & 71 & $104 \cdot 5$ \\
\hline 17 & 42 & 59 & $4^{6}$ & 69 & 50 & 72 & 50 & 76 & 64 & 95 & 74 & 104 \\
\hline 18 & 42 & 64 & 47 & 67 & 50 & 70 & 55 & 83 & 70 & 97 & 74 & 102.5 \\
\hline 19 & 45 & 68 & $5^{I}$ & 68 & 43 & $5^{8}$ & 62 & 82 & 65 & 98 & 69 & 104.5 \\
\hline 20 & $5 I$ & 70 & 47 & 66 & $4 I$ & 67 & $5^{8}$ & $8 I$ & 67 & 99 & 69 & 104.5 \\
\hline 21 & 46 & 51 & 52 & 69 & 46 & 74 & 62 & 83 & 64 & 94 & 73 & 106.5 \\
\hline 22 & 28 & 49 & $4^{8}$ & 70 & 50 & 71 & 65 & 85 & $6 \mathrm{I} \cdot 5$ & 95 & 72 & 108.5 \\
\hline 23 & 29 & 47 & $5 \mathrm{I}$ & 62 & 53 & 74 & 66 & 90 & 62.5 & 89 & 71 & IOI \\
\hline 24 & 32 & 52 & 42 & 57 & 54 & 76 & 66 & 85 & $7^{8}$ & 77 & 69 & 102. \\
\hline 25 & 40 & 62 & 40 & 64 & 59 & $8 I$ & 59 & 78 & $\cdots$ & 83 & 70 & 102 \\
\hline 26 & 43 & 64 & 43 & 65 & 60 & 71 & 52 & 86 & 63 & 83 & 68 & 102.5 \\
\hline 27 & $4^{6}$ & 66 & 56 & 73 & 56 & 68 & 55 & 85 & 67 & 89 & 71 & 99.5 \\
\hline 28 & 47 & 68 & 53 & 76 & $5 \mathrm{I}$ & 71 & 54 & 86 & $6 i$ & 96.5 & 69 & 94.5 \\
\hline 29 & 47 & 68 & . & . & $4^{8}$ & 70 & 59 & 75 & $6 \mathrm{I}$ & 88.5 & 56 & 96 \\
\hline 30 & 50 & 62 & .. & . & 47 & 73 & $5 \mathrm{I}$ & 72 & 54 & 83.5 & 68 & 98 \\
\hline 3 I & 45 & 66 & $\cdots$ & . & $5^{8}$ & 83 & .. & $\cdots$ & 54 & 9 I. 5 & $\cdots$ & $\cdots$ \\
\hline
\end{tabular}


TABLE 9. -Temperatures for the year 1905, Tumxmoc Hill $\left({ }^{\circ} \mathrm{F}.\right)$-Continued.

\begin{tabular}{|c|c|c|c|c|c|c|c|c|c|c|c|c|}
\hline \multirow{2}{*}{ Day. } & \multicolumn{2}{|c|}{ July. } & \multicolumn{2}{|c|}{ Aug. } & \multicolumn{2}{|c|}{ Sept. } & \multicolumn{2}{|c|}{ Oct. } & \multicolumn{2}{|c|}{ Nov. } & \multicolumn{2}{|c|}{ Dec. } \\
\hline & Min. & Max. & Min. & Max. & Min. & Max. & Min. & Max. & Min. & Max. & Min. & Max. \\
\hline I & $\ldots$ & 100 & 76 & 98 & 64 & 95 & 76 & 94.5 & 57 & 80 & 34.5 & 49 \\
\hline 2 & 71 & 104 & 70 & 9I & 68 & 95 & 72 & 99 & 63 & 68 & 39 & 50 \\
\hline 3 & 74.5 & Io6 & 74 & 98 & 67 & 95 & 70 & 98 & $5^{I}$ & 78 & 47 & $5^{8}$ \\
\hline 4 & 77 & 100 & $7^{8}$ & 103 & 68 & 97.5 & 69 & 100 & 55 & 84 & $5 \mathrm{I}$ & 58.5 \\
\hline 5 & 60 & 93.5 & 77 & 104 & 72 & & 66 & 95 & 64 & 83.5 & 44 & 53.5 \\
\hline 6 & 71.5 & 91.5 & 75 & 100 & & IOI & $6_{4}$ & 89 & 60 & 87 & 39.5 & 53.5 \\
\hline 7 & 71 & 96.5 & 75 & 95.5 & $7 \mathrm{I}$ & 102.5 & 65 & $9 \mathrm{I}$ & 55 & $8 \mathrm{I}$ & $4 \mathrm{I}$ & 63 \\
\hline 8 & 71.5 & 95.5 & $73 \cdot 5$ & 87 & 74 & 96 & 67 & 94.5 & 51.5 & 87 & 47.5 & 73 \\
\hline 9 & 69 & IOI. 5 & 70 & 100 & 71 & 98 & 63 & 94.5 & 59 & 90.5 & 45 & 74 \\
\hline Io & 74 & 99 & 74.5 & 100 & 73 & 98 & 59 & 95.5 & 57 & 90.5 & $4^{2} \cdot 5$ & 72 \\
\hline I I & 74 & 102.5 & 77 & 102 & 72 & 99 & 73 & 95 & 55 & 85 & 49 & 74 \\
\hline 12 & 72.5 & 102 & 72 & 99.5 & 68 & 99 & 71 & 95 & 51 & 85 & 59.5 & 76 \\
\hline 13 & 77 & 104 & 79 & 99 & 67 & 99 & 62 & 89.5 & $55 \cdot 5$ & 90 & 56 & 68 \\
\hline 14 & 75 & 97.5 & 78.5 & 102.5 & 68 & 94 & $65 \cdot 5$ & 86 & 52 & 84 & 44.5 & 57.5 \\
\hline 15 & 73 & 97 & 79.5 & 99.5 & $7 I$ & 90 & 55 & 84 & $5^{6}$ & 82.5 & 39.5 & 57 \\
\hline 16 & 70 & 97 & 73.5 & 97 & 67 & 88 & 50 & 87 & 53 & 88 & 37 & $5^{6} .5$ \\
\hline 17 & 70 & $\ldots \ldots$ & 72.5 & 94 & 62 & 86 & 59 & 92 & 61 & 77 & 37 & 61 \\
\hline 18 & $\ldots$ & 103.5 & 71.5 & 94.5 & 59 & 9 I. 5 & $6 \mathrm{I}$ & 94.5 & 55 & 68 & 39.5 & 60 \\
\hline I9 & 73 & 104.5 & 68.5 & 79.5 & 63 & 98 & $6+5$ & 92.5 & 39.5 & 57 & 43 & $6 \mathrm{I}$ \\
\hline 20 & $75 \cdot 5$ & 103 & 67.5 & 90.5 & 67 & 100.5 & 63 & 88.5 & 38 & 47 & 39 & $6 I$ \\
\hline $2 \mathrm{I}$ & 79 & 106.5 & 67.5 & 83.5 & 69 & 100 & 62.5 & 79.5 & 28.5 & $5^{I}$ & $37 \cdot 5$ & 67 \\
\hline 22 & $77 \cdot 5$ & 106 & 70 & $9 \mathrm{I}$ & 69 & 97 & 45 & 64 & 31 & 58 & $4 \mathrm{I} \cdot 5$ & 74 \\
\hline 23 & 76 & 108 & 68 & 91.5 & 71 & IOI & 39.5 & 59.5 & 39 & 60 & 55 & 74 \\
\hline 24 & 80 & 108 & 67 & 93.5 & 76 & 98 & 38 & 66.5 & 53 & 63 & $53 \cdot 5$ & 77 \\
\hline 25 & $8 I$ & I05.5 & 68 & 94 & 74 & 94 & +7 & 78 & 42 & 53 & $4^{8}$ & 75 \\
\hline 26 & 79 & IOI.5 & 73 & $95 \cdot 5$ & 70 & 90 & $5 \mathrm{I}$ & 85 & 36 & 50 & $4^{8}$ & 76.5 \\
\hline 27 & 66 & 92.5 & 71 & 95 & 63 & 93 & $5^{2}$ & 87 & 30 & 66.5 & 54 & 70 \\
\hline 28 & 73 & 97 & 71.5 & 94.5 & 66 & 96 & 54 & $9 \mathrm{I}$ & 49 & 72.5 & 52 & 65 \\
\hline 29 & 74.5 & 103 & 70 & 95 & 70 & 97 & 60 & 71.5 & 37 & 60 & 50 & 56 \\
\hline 30 & 76.5 & 103.5 & 65 & $9 \mathrm{I}$ & 75 & 97 & $5^{6.5}$ & 72.5 & $34 \cdot 5$ & 63.5 & 40.5 & 56 \\
\hline $3 \mathrm{I}$ & 79.5 & 105.5 & 65 & 93 & $\ldots$ & & $54 \cdot 5$ & & $\ldots$ & $\ldots$ & 40 & 62 \\
\hline
\end{tabular}

not obviously great; the foliage of the ocotillo and of Verbena will continue normal for a fairly extended period. When the soil-water is sufficient there is no evidence in the behavior of the stomata that even the highest temperatures and strongest insolation affect the plants unfavorably. As I shall show, when the conditions are so trying as to bring about wilting, the stomata then close; otherwise they open to their full extent during certain portions of the day, maximum dimensions having been observed day after day during the hottest weather. And, moreover, as will appear, the differences of temperatures are not without relation to the physiological processes evident within the guard-cells, although these are not in the direction of reducing the transpiration rate when, aside from the condition of wilting, the danger from transpiration would appear to be greatest. 


\section{METHODS.*}

In order to answer the questions which I set before myself, it was necessary to study separately the phenomena of transpiration and of stomatal action. The methods employed will now be described.

\section{TRANSPIRATION.}

Inasmuch as it was impossible to use potted plants or to dig up and start complete individuals, the method of weighing, so insistently maintained by some as the only strictly reliable method of measuring the transpiration, was not feasible. The use of such indicators as cobalt chlorid, as used by Stahl and others, while useful for certain kinds of comparative study, was not adapted to the conditions surrounding the experiments, the small leaf area of the ocotillo, the extremely low relative humidity, and the high temperatures all contributing to make it very difficult or impossible to arrange a small closed chamber suitable to the method, which is, moreover, not at all adapted, at least as at present carried out, to the demands of quantitative work. For similar reasons, and others which will be discussed later, the type of hygroscope used by Francis Darwin was not available. Two other methods were tried. One is that inaugurated by MacDougal and elaborated by Cannon ( $1905 b$ ), in which a Lamprecht polymeter is used to indicate the rise of relative humidity within a closed chamber in which is confined the whole or an attached portion of the plant to be studied. Knowing the capacity of the chamber and the temperature and having taken readings of the hair hygrometer at constant intervals, it is then possible, theoretically at least, to calculate the amount of water-vapor which has escaped into the chamber from the surface of the plant or part inclosed. While the method offers the advantage of allowing transpiration to be studied while the plant remains undamaged and growing in the normal surroundings, the objection may still at this time be raised that the hair hygrometer is an inadequate instrument, as at present constructed. It may, however, be quite possible to construct an instrument of great delicacy and accuracy, and this will probably be accomplished in the future. For the purpose of my work this method proved to be of only limited value, and, while a few of the results have been used, they are considered to be of less value than those obtained in the way now to be described.

The second means at hand was the potometer, an instrument which has been repeatedly criticized on well-known grounds. $f$ For some time the MacDougal potometer, consisting of a horizontal tube of small caliber graduated to $100 \mathrm{mg}$. was used. A considerable number of experiments were made with this type of potometer, but the form of the whole instrument was at length found to be too cumbersome and unwieldy to lend itself to my purposes. I could not move the instrument about without difficulty, and it was very easy

*The main points were presented before the Botanical Society of America at its meeting in December, 1904.

†Burgerstein (1904) and Clements (1905). 
to disturb the parts. Furthermore, it was difficult to get records of a large enough series of experiments carried out through a long enough period without the most laborious business of making rery frequent readings at unequal intervals, a burden quite out of proportion to the amount of data gained. For my purpose it was quite necessary that I should have evidence that the parts studied were behaving normally, and, under the circumstances, the only way to be sure of this was to have a number of experiments going on at the same time under the same conditions, so that each might act as a control on all the rest. I was led to meet this demand by substituting, in a particular experiment, a vertically placed burette for the horizontal calibrated tube when I wished it to run all night. Since the supply of burettes happened to be limited, I substituted, for the time, ordinary glass tubes. Later on, I used blue-line burettes which could be read quickly and accurately. The arrangement used then was this: A glass tube or burette of suitable length was attached to the cut end of a piece of ocotillo stem by means of rubber tubing, always with the precaution that the cut surface of the stem was clean. The possible stoppage of the pores of the wood was avoided, at least for the time during which the piece was to be used, by a filter consisting of a firm plug of absorbent cotton placed in the rubber tube in contact with the cut surface. It was found also that it was important to trim off the green cortex, which quickly decayed when exposed to the water, so that only the wood was inserted into the rubber tubing.

Undoubtedly, as Ewart (I905) has recently shown with more accuracy than heretofore, the rate of flow of water through cut stems is gradually reduced by clogging bacteria, probably both in the cut surface and throughout the length of the piece. Having had due regard to this circumstance, there is abundant reason, for believing that potometer experiments conducted within reasonable time limits (about 24 hours) and set up carefully, as above described, give accurate enough results for my particular purpose.

The piece of stem having been cut under water and adjusted to the potometer, it may then be supported in a vertical position by tying it up to the tube and the whole suspended from a rack; or the piece might equally well be allowed to hang down, as comparative readings showed no difference in the behavior in the two positions. It will be seen that the number of separate experiments which might be set up was limited only by the materials available and the time necessary to make the readings. It was found by experience that one can hardly attend profitably to more than from 8 to ro such (plate 3, fig. 2), hence I confined myself to the results of several series in these numbers.

The results obtained from a battery of potometers were in almost all cases so uniform that I have little hesitation in saying that they depart but little from those which would be obtained by any other method, at least so far 
as the relative rates of transpiration in successive periods are concerned. Whether the absolute amount of water transpired may safely be measured in this way can not be settled until comparative results based upon experiments with rooted plants are available. It will be seen, however, that my object, namely, to record sudden changes of rate in transpiration, was attained. It may be noted in this connection that of 38 experiments conducted in batteries, only one had to be disregarded.

One obvious objection had to be met, namely, that the rate of transpiration might not be equal to the rate at which the water leaves the potometer. This objection was answered first by comparative weighing and absorption experiments and also by the comparison of the synchronous experiments of a battery. The former discovers the absolute error and also its distribution, and therefore whether it affects the character of the curve or not; the latter by comparison, point by point, gives the probability of error in any one or more of the series. The data in tables io to 12 illustrate the former for ocotillo.

'АABLE 10.-Ocotillo-Error due to use of potometer, June 19, 1904.-Two pieces.

\begin{tabular}{|c|c|c|c|c|}
\hline No. & Period. & $\begin{array}{c}\text { Volume } \\
\text { absorbed. }\end{array}$ & $\begin{array}{l}\text { Difference } \\
\text { weight. }\end{array}$ & $\begin{array}{l}\text { Water retained } \\
\text { by plant. }\end{array}$ \\
\hline $\mathbf{I}$ & $1 \mathrm{oh}^{\mathrm{h}} 4^{\mathrm{m}}$ a. m. to $3^{\mathrm{h}} \mathrm{o} 5^{\mathrm{m}}$ p. m.. & $\begin{array}{c}\text { Grams. } \\
3.5\end{array}$ & $\begin{array}{c}\text { Grams. } \\
3.2\end{array}$ & $\begin{array}{c}\text { Grams. } \\
0.3\end{array}$ \\
\hline 2 & 943 a.m. to 2 56 $\quad$ p. m. & 3.0 & 2.7 & 0.3 \\
\hline
\end{tabular}

* 8.6 per cent of water drawn from potometer was absorbed by plant. $\dagger 10$ per ceut of water drawn from potometer was absorbed by plant.

In piece No. I, table 10, 8.6 percent of the water drawn from the potometer was absorbed by the plant, while in the second piece, the amount retained was Io per cent.

In table 11 , of all the water retained (viz, 3.7 per cent of the whole amount absorbed) 92.6 per cent was retained during the first 8.5 hours, the rest during the last II hours. The hourly readings taken showed an abnormally high rate between $9 \mathrm{p}$. m. and $3 \mathrm{a}$. m., a behavior out of harmony with nearly all my experiments. Even then the total error is small, and if distributed

TABLE 11.-Ocotillc-Error due to use of a potometer, July 18-19, 1904; continual darkness.

\begin{tabular}{|c|c|c|c|}
\hline l'eriod. & $\begin{array}{l}\text { Volume } \\
\text { absorbed. }\end{array}$ & $\begin{array}{c}\text { Difference, } \\
\text { weight. }\end{array}$ & $\begin{array}{l}\text { Water retained } \\
\text { by plant. }\end{array}$ \\
\hline 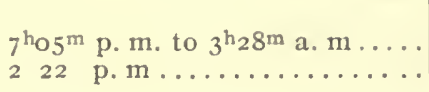 & $\begin{array}{l}\text { Grams. } \\
37.5 \\
35.7\end{array}$ & $\begin{array}{l}\text { Grams. } \\
35.0 \\
35.5\end{array}$ & $\begin{array}{l}\text { Grans. } \\
2.5 \\
0.2\end{array}$ \\
\hline
\end{tabular}

during the entirc period would be quite negligible for any of my own purposes. Under the conditions of this experiment the last ro lours of the curve show the rate of loss of water by the plant. With very few exceptions 
the only part of an experiment of this type which has been used, and upon which conclusions have been based, has been the latter half.

That the error found in the above experiment is properly explained appears true from the data derived from a similar experiment carried on at the same time, in which the rate curve between $9 \mathrm{p}$. m. and $3 \mathrm{a} . \mathrm{m}$. follows the normal course, as indicated by my experiments in general.

TABLE 12.-Ocotillo-Error due to use of a potometer.

\begin{tabular}{|c|c|c|c|c|}
\hline Period. & $\begin{array}{l}\text { Volume } \\
\text { absorbed. }\end{array}$ & $\begin{array}{l}\text { Difference } \\
\text { in weight. }\end{array}$ & $\begin{array}{l}\text { Water } \\
\text { retained } \\
\text { by plant. }\end{array}$ & Water lost. \\
\hline 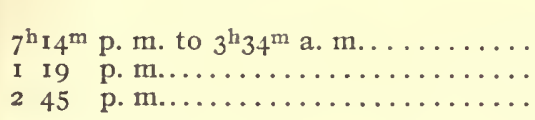 & $\begin{array}{l}\text { c. c. } \\
39 \cdot 4 \\
22.9 \\
27 \cdot 5\end{array}$ & $\begin{array}{l}\text { Grams. } \\
37.1 \\
24.6 \\
28.4\end{array}$ & $\begin{array}{l}\text { Grams. } \\
2 \cdot 3 \\
\quad \cdots \\
\cdots\end{array}$ & $\begin{array}{l}\text { Grams. } \\
\quad \cdots \\
\text { I. } 7 \\
0.9\end{array}$ \\
\hline Total... & 89.8 & $\ldots$ & $\ldots$ & $\ldots$ \\
\hline
\end{tabular}

In the experiment displayed in table 12 , approximately the same error occurs, 2.3 grams of water having been held back by the plant in the first 8 hours. After ro a. $\mathrm{m}$. it was noted that the piece commenced to wilt rapidly, the rate falling hourly as follows: I I.2, 8.3, 7.3, 5.6, 4. I grams, and evidently lost more water than was taken up. The total error, however, was within 3 per cent and was distributed over several hours.

TABLE 13.-Tests made with Verbena ciliata, June I4 and 16, 1905.

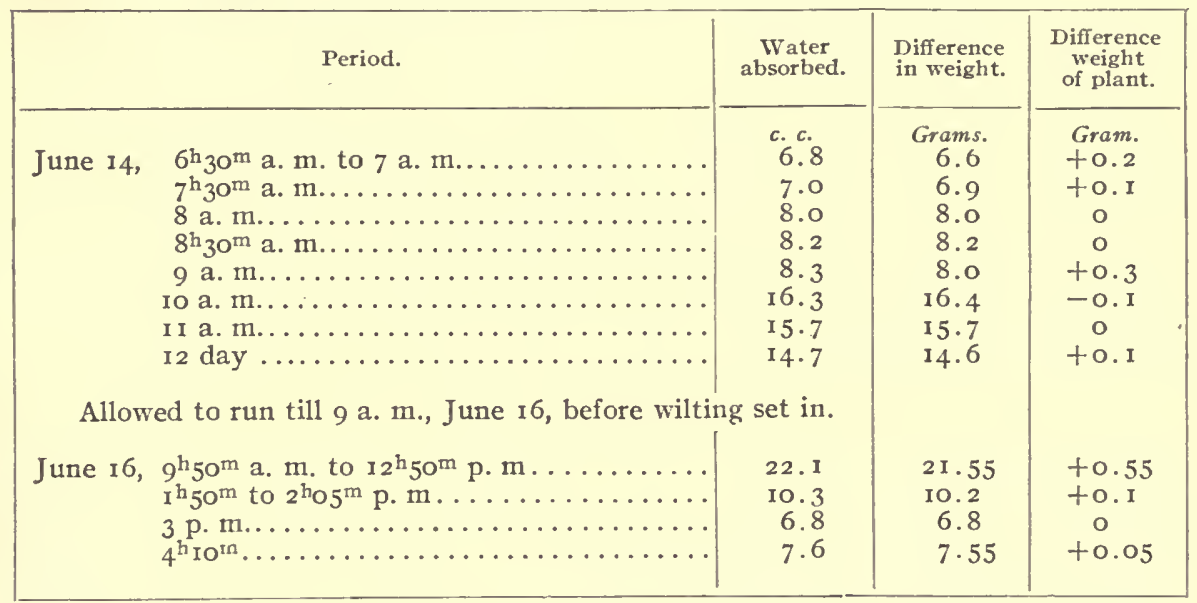

Table 13 embodies the data derived from a similar test made with Verbena ciliata, in which plus and minus differences were observed. Doubtless such errors of observation creep in when a single observer tries to make as nearly as possible simultaneous readings and weighings. Nevertheless the error 
was only 3.6 per cent in the most extreme case. The data in table 14 are by way of comparison, not without interest.

TABLE 14.-Experiment 19.-Covillea mexicana, June 19.

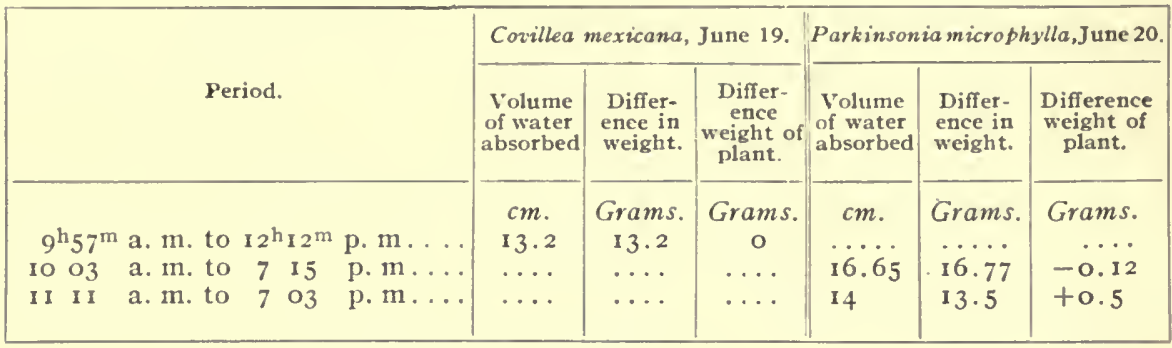

In the last instance the positive error was 3.7 per cent.

The figures displayed in tables 13 and 14 indicate that the error in ocotillo is higher in general than in the other plants tried, a difference which is referable, it is not unlikely, to the absorbing power of the water-storage tissue, which designation may be applied to indicate the function, in part, of the cortex, or wholly, perhaps, the function of certain clear islands of tissue within the cortex.

Evidence of this kind, it must be said, does not prove what another plant or piece will do, so that it would remain an untrustworthy method for certain purposes, including my own (and must remain so in the case of quantitative problems involving comparisons of root activity, absolute transpiration of plants, etc.), were it not for the system of controls afforded by a good number of the same kind of experiments carried on synchronously. This condition, in potometer work, must not be overlooked. If from 6 to ro experiments, running side by side, give identical results, the degree of probability that their behavior is normal is very high. Especially when sudden changes in the environment are followed by sudden changes in the rate of transpiration may importance be attached to the data. Thus, if the rate falls immediately on the plant being placed in darkness, this fall is due to the change, and not to irregularities of flow in the stem. The truth of this will appear clearer upon the inspection of the curves presented in Part I.

\section{STOMATAL ACTION.}

For the study of stomatal action none of the means heretofore used appeared adequate. To assume the condition of the stomatal openings from the behavior of either the physical or chemical indicators of water-vapor is to assume what is to be proved, if it be the case, namely, that there is a constant relation between the size and number of the openings and the rate of transpiration (Burgerstein, I 904, p. 32), and upon this point I take issue with Burgerstein. Merget's statement, made as a result of the palladium chlorid 
paper test, that on the white parts of leaves the stomata do not function, illustrates the invalidity of arguing from the behavior of such indications. In many plants with non-chlorophyllous areas, the stomata are known to function, $i$. e., to open and shut, and their guard-cells are often provided with chlorophyll.

Francis Darwin very properly admitted the inadequacy of the hygrometer methods devised by him, and classified them with other methods for demonstrating stomatal as contrasted with cuticular transpiration. Among these, however, we find regarded by Darwin as the least accurate, "microscopic examinations of the unipjured leaf," a method clearly to be used for the determination of the condition of the stomata, unless we assume what must rather be proved. It seems perfectly clear that Darwin's hygroscopes are available for demonstrating sharp contrasts in transpiration, as occurs, e.g., when the hygroscope is pushed from a white to a green portion of the leaf. But it would seem improper to draw conclusions as to the condition of the stomata, except when a rough contrast of the closed and open conditions is to be determined. Weiss (I878) may be perfectly right in asserting that the stomata on non-green parts behave as normal ones, because, as I have satisfied myself by personal examination, the stomata on white, and on colored but nonchlorophyllous, parts of many variegated leaves are normal (Zebrina, Poinsettia, certain grasses, etc.), while Kohl's ( 886, p. 39) non-chlorophyllous stomata, I am equally persuaded, are not incapable of movement. Instructive and suggestive as Darwin's work with stomata is, and in spite of the fact that I have found his the most suggestive of essays on the general subject, I nevertheless feel urged to insist that the only way to know what stomata are doing, and to know the relation between their condition and the diffusion of matters into and out of the leaf, is to determine these quite independently, and above all to know exactly what the condition of the stomata is. To do this we must see the stomata, not one or a few, but many, and on different leaves. On this point Copeland (r902, p. 330) is correct.

All of the methods above referred to may properly be used for certain purposes, as, $e . g$. , to determine roughly the ratio of transpiration of the upper and lower surfaces of the same leaf, but for exact work on stomata some method of direct observation was needed.

Immediate microscopic study of the stomata on a leaf in situ, as has been carried on by Kohl (I 895 and earlier) and others, was practically, though not wholly, impossible in both of the plants studied. To study the living stomata in epidermis removed alone, or in thick tangential sections of the leaf, and mounted in water, offered difficulties and sources of error which could not be overcome.

Air bubbles, which cling so persistently, prevent accurate measurement; and it would have defeated my purposes to have used the method of mounting the epidermis or sections in boiling water, which, upon standing, will take up 
the air by solution (Copeland, 1902). Furthermore, stomata, when mounted for observation in water, may, as others, including myself, have found, suffer sudden changes in contour (von Mohl), a possibility fatal to my object. Indeed, I found that invariably the stomata of Verbena ciliata suddenly enlarge their transverse (tangential) measurements when water reaches them. This may be determined without very great difficulty if a piece of epidermis is mounted* for microscopic observation first without the addition of any medium. After observing the size of certain stomata, these, upon running water under the cover, will be found to open wider. Thus, 5 closed stomata in different pieces of epidermis taken at $6 \mathrm{p}$. $\mathrm{m}$. opened so that their pores became 6 micra broad. In another case, the outside transverse measurement of 4 neighboring stomata, all of which were closed, were taken. These were, in micra, 28, 26, 24, and 27. Upon the addition of water, the measurements were $34,32,28$, and 30 , respectively.

By means of a stop-watch the rate of opening may be determined with but fair though sufficient accuracy. Thus a stoma opened o to 7 micra in somewhat less than 3 seconds. It will be appreciated that, to mount epidermis in water and, after placing on the stage, then to examine the stomata, might result in hopeless error. Nothing can be said of stomata mounted in water, as regards their condition in situ, unless it is known that placing in water does not effect them in the least, which is unlikely in any case.

Again, the removal of epidermis has been objected to on the ground that this results in a release of tensions which are responsible in part for the size of the stomatal openings. I have suspected this to be true in the case of a plant, Chrysoma pauciflosculosa (Lloyd, 190I), which has a very peculiar leaf anatomy, though it may be possible that a local shrinkage of the thickness of any flattened leaf, as might occur in the areas between the vascular tissues during wilting, may effect the ratio between the size of the outer and inner opening of the stomata. This, however, is a different case from a general tangential stretching of the epidermis due to the turgidity of the leaf. There is, quite probably, upon removal of a piece of epidermis, a slight shrinkage of general dimensions. The effect, it would seem, upon the condition of the stomata, must be exceedingly small, so that the differences before and after removal would be inappreciable.

The upward curving of the leaf of Verbena ciliata (see beyond, p. 8I) during the early stages of wilting implies that the upper epidermis is reduced in tangential dimensions, but this is only in a very small amount. If we assume a shrinkage of 5 per cent during this time, a very liberal estimate, it would mean in a single stoma a corresponding percentage of shrinkage. A stoma widely open measures, say, ro micra across the pore. This would mean a reduction in size from ro to 9.5 micra, a scarcely measureable amount, and within the personal error of observation. In the absence of special structural

\footnotetext{
* On account of the numerous hairs, epidermis of Verbena should in this operation be viewed from the under side.
} 
conditions which conceivably might affect the size of the stomatal openings, there are no reasons to believe that stripping the epidermis leads to permanent distortion or change in dimensions. That a local temporary distortion. occurs during the stripping is certain, but this has no more permanent effect than pressure on a rubber ball, upon the release of which it reassumes its rotundity. I have satisfied myself by direct observation that this holds true in Fouquieria splendens and Verbena ciliata, and on this point I am in full agreement with Czeck (I869). Thus, when a piece of epidermis is removed, there is frequently an unharmed portion of the leaf taken with it. If properly observed, the stomata on the unharmed area will accord in size with those in the free epidermis. But if mounted in water, differences may be seen, due not to the release of tensions, but to the access of water into the guard-cells.

Another form of the objection that tearing off the epidermis produces mechanical disturbances has been urged by Kohl (1885). He found that, on placing epidermis in water, the stomata which were placed near and with

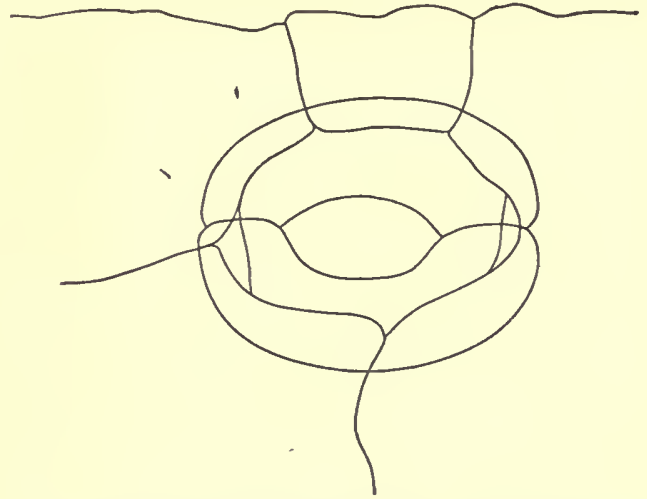

Fig. 7.-Stoma of Verbena ciliata, from epidermis torn from leaf and examined in water. The torn edge is above.

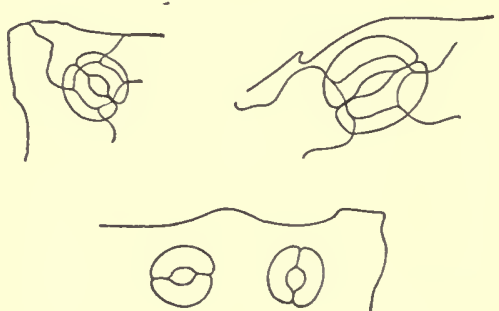

FIG. 8.-Stomata of Verbena ciliata, in epidermis torn from leaf and fixed in absolute alcohol.

their major axes parallel to the edge of the removed piece of epidermis had larger openings than those removed some distance from the edge or had their major axes perpendicular to it ( $c f$. his plate I, fig. 4). Such changes of form might conceivably occur as the result of released pressures near the margin of a torn piece of epidermis. If this were true it might be taken as evidence of the mechanical effect of adjoining epidermal cells upon the form of the stomata, as Kohl indeed holds. But I have not found that, either in ocotillo or Verbena, the form of stomata in such position is changed, for I have repeatedly observed, as is exemplified in figs. 7 and 8 , that the shape of the stomata and the sizes of their openings are not changed in any way by the tearing or by the resulting setting free of tensions, for, when pieces of epidermis are at once fixed in absolute alcohol, the stomata are as uniform as to the size of their openings and as to their form along the edge of the piece as elsewhere. 
Having satisfied myself that the mechanical disturbances incidental to removing the epidermis do not affect the form of the stomata, at least in the plants with which I was concerned, it remained to find some method of fixing these organs in the form assumed at any particular time, so that they might be studied later at any length desired. Only in this way, if we can be certain of the value of the method employed, can we be informed of the actual condition of the stomatal openings scattered over relatively large areas of the plant surface, unless, indeed, direct observation of the living plant is possible. Such a method I have been able to perfect in its application to the plants ocotillo and Verbena (plates 4 and 6), and I have tested it also on several other species of common cultivated plants with entire success. Since all our ordinary experience leads away from accepting a method of this kind, I shall discuss it in some detail.

TABLE 15.-Transverse measurements, ocotillo.

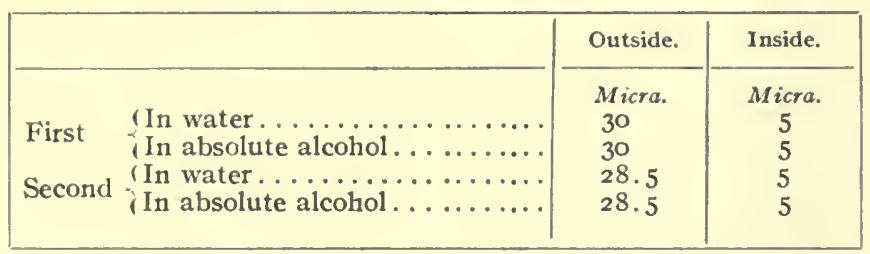

The method is based upon the fact that if the cell-wall is robbed of its water it becomes inelastic, and it will therefore remain in any position it happens to be in when enough water has been extracted to produce inelasticity.* If, then, it were possible to extract the water fast enough before any appreciable change in the form of the walls of the guard-cells intervenes, this is all that is needed. I have determined to my satisfaction that if the epidermis of the leaf be removed and plunged at once into absolute alcohol, this agent removes the water rapidly enough so that no measurable change in the dimensions of the stomata takes place. It is, then, quite easy to preserve in permanent form for later study the material thus gained, either in vials without further treatment or by adding to the absolute alcohol a suitable stain, which must be soluble in the absolute ( 99.8 per cent) alcohol. In this the tissue is allowed to remain till deeply enough stained, which occurs in about 12 hours, when it may be passed through clove oil $\dagger$ into balsam. None of these operations affects the form of the stomata in the least, a fact which I have verified time and again both by eye measurements and scale, which in many cases was applied before and after each step was taken in the process.

*I was led to see the force of this principle in its possible relation to the fixation of stomata during a conversation with Professor de Vries, who recalled that during his student days under Sachs, his preceptor pointed out that if a wilted plant is placed in alcohol it will remain in the wilted form. This is clearly due in large part to the loss of elasticity by the cell-walls.

†The fully formed though young stomata of Agave are properly fixed by absolute alcohol, but become distorted upon being placed in clove oil. 


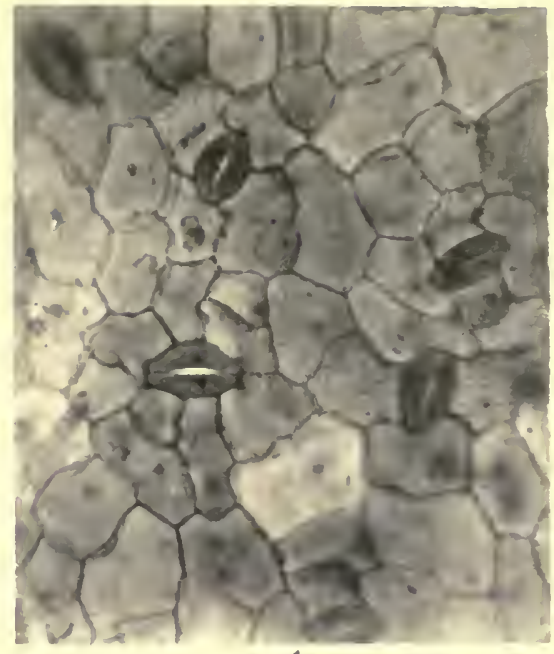

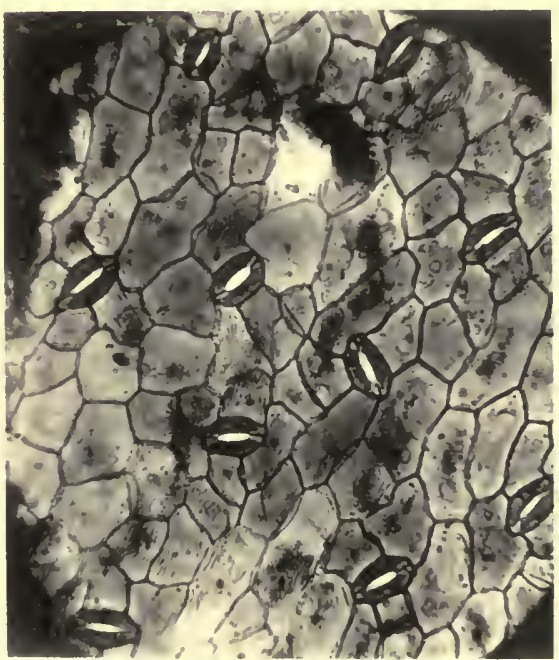

2

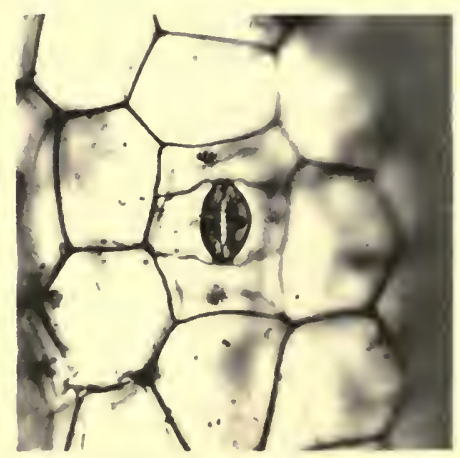

4

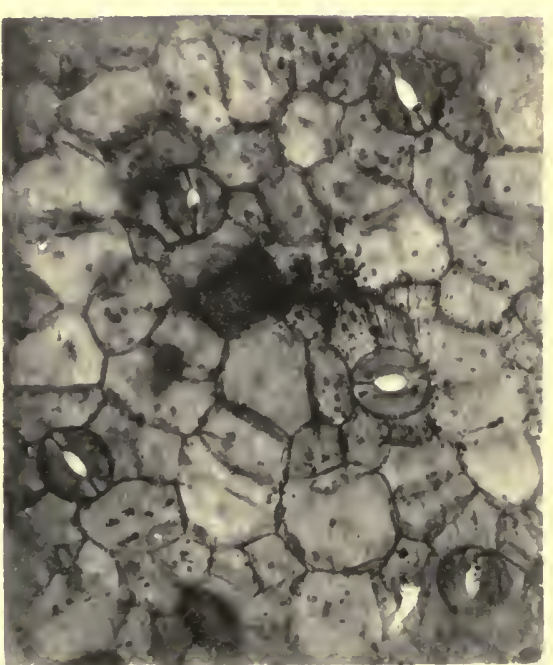

3

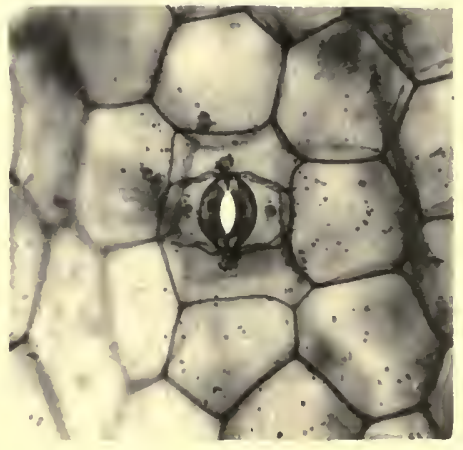

5

1. Stomata of Fouquieria splendens nearly closed, 4 h34m a. $\mathrm{m}$.

2. Partly open, 7 a. m.

3. Open, noon.

4 and 5. Stomata of Tradescantia zebrina in closed and open condition. 


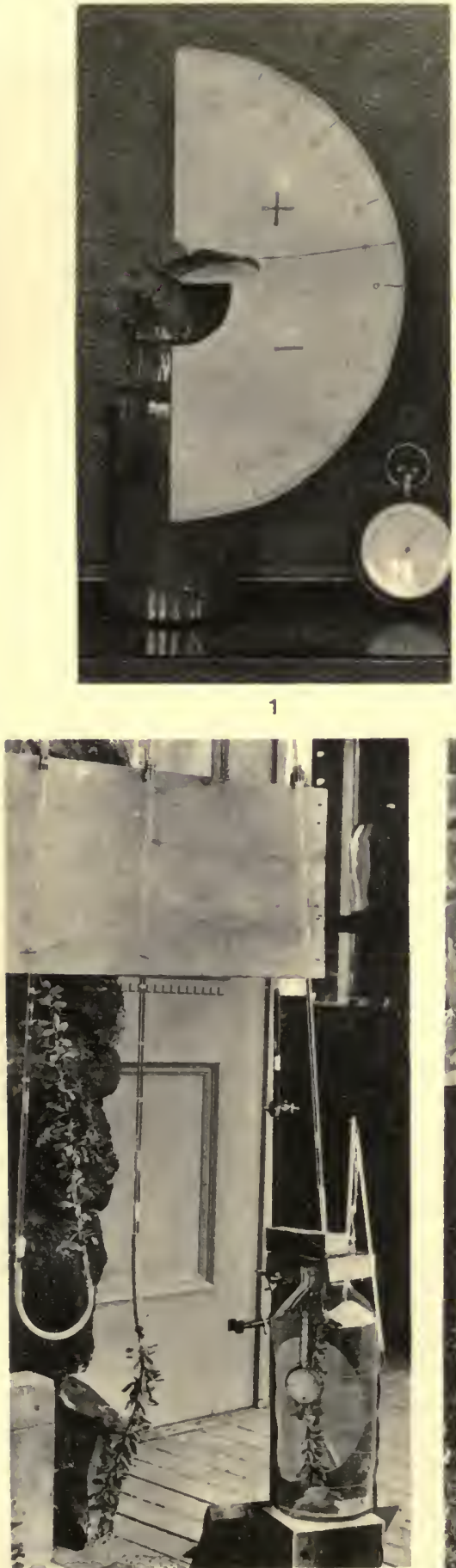

3

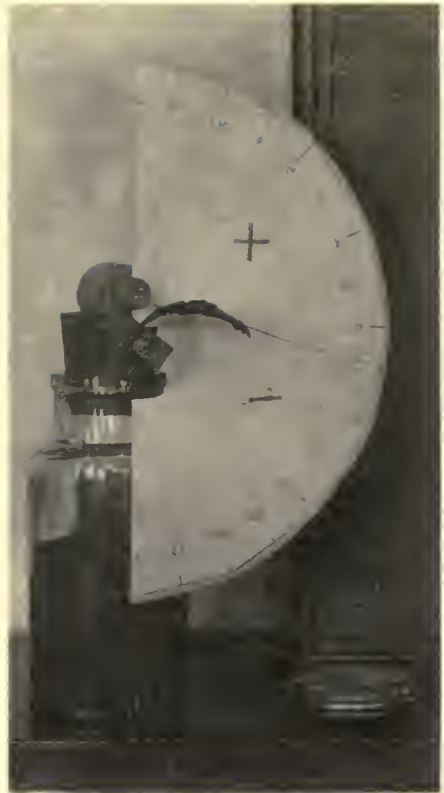

2

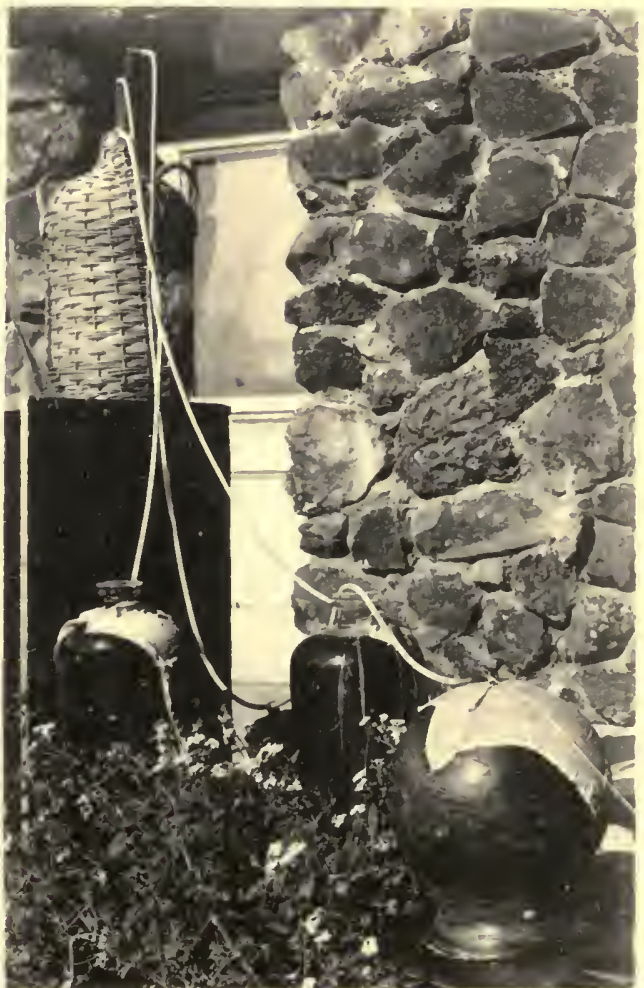

1 and 2. A simple apparatus for detecting changes in tissue tensions in the leaf during wilting. In the experiment in progress when photographs were made the leaf had bent upward during a short interval (fig. I). It then moved downward (fig. 2). The index was set at 0 at the beginning of the experiment.

3. Method of studying the effect of different degrees of relative humidity on transpiration, using vertical tube potometer.

4. Bell-jars and "olla" in place during experimentation upon Verbena ciliata. 

Tradescantia zebrina.- Large mechanically sensitive stomata; stontata at edge of piece flooded by running absolute alcohol under the cover, and constantly watched.

That the preservation of the form of the stomata is due to the rapid extraction of the water is shown by the fact that, if a piece of epidermis is fixed in alcohol and then mounted for examination in the same fluid, the opening may be made to close by the addition of water.

The movement will take place just as in life, so that one who is not aware of the conditions will at once suppose that the closure is due to plasmolysis. This of course has really occurred in the dead tissue; what happens now is merely the restoration of the water to the walls, this being accompanied by the return of the elastic condition. The change occurs, therefore, because the shut condition is the normal one when the turgor of the cell is low.

TABLE 16.--Transverse measurements, Tradescantia zebrina.

\begin{tabular}{|c|c|c|c|c|}
\hline & \multicolumn{2}{|c|}{ Outside. } & \multicolumn{2}{|c|}{ Opening. } \\
\hline & Length. & Breadth. & Length. & Breadth. \\
\hline \multirow{3}{*}{ 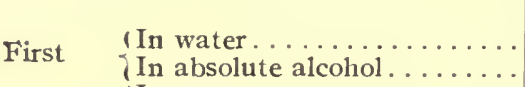 } & Micra. & Micra. & Micra. & Micra. \\
\hline & 36 & 21 & 24 & 5 \\
\hline & 36 & 21 & 24 & 5 \\
\hline \multirow{3}{*}{$\begin{array}{l}\text { Second }\{\text { In water .................... } \\
\text { Measurements made of outer and inner } \\
\text { openings, by appropriate focusing:* }\end{array}$} & 20 & I 5 & 12 & 5 \\
\hline & 20 & I 5 & $11 \cdot 5$ & 5 \\
\hline & & & & \\
\hline \multirow{2}{*}{ 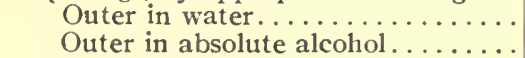 } & $\cdots$ & $\cdots$ & 13.5 & $3 \cdot 5$ \\
\hline & $\cdots$ & . & $13 \cdot 5$ & $3 \cdot 5$ \\
\hline Inner in water $\ldots \ldots \ldots \ldots \ldots$ & 18 & 14 & $9 \cdot 5$ & 2 \\
\hline \multirow{2}{*}{$\begin{array}{l}\text { Inner in absolute alcohol } \ldots \ldots \ldots \\
\text { Specimen passed through- }\end{array}$} & 18 & I 5 & $9 \cdot 5$ & 2 \\
\hline & & & & \\
\hline Absolute alcohol............... & I 8 & I 3 & 9 & 3 \\
\hline \multirow{2}{*}{ 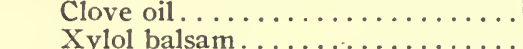 } & 18 & $12 \cdot 5$ & 9 & 3 \\
\hline & 18 & I 2 & 9 & 3 \\
\hline
\end{tabular}

* Plate 4 , figs. 4 and 5 .

The application of the absolute alcohol method to other plants must be made with due caution. I have recently tried it with Brodiaa, with some degree of uncertainty. I found that when the epidermis is strippedandexamined in water the stomata expand. Upon being placed in absolute alcohol the epidermis, which is made up of long, slender cells, shrinks longitudinally and apparently presses the stomata in this direction, so that the pores become distorted. When the epidermis is placed in the alcohol immediately upon stripping the stomata are preserved nearly as in normal condition.

Most beautiful preparations may be made by the above means. Thus, the fine large stomata of our cultivated Zebrina, usually referred to as Tradescantia zebrina, may be preserved in any condition. The illustrations in plate 4 from photomicrographs made from my own preparations bear sufficient evidence of the results. 
The stains which have been used are Congo red and Bismarck brown. The former gives very superior results, as it stains much more deeply. No doubt there are others just as good.

It would seem that this method will enable us to study, with great accuracy, the mechanical aspects of stomata-a matter with which I am at present, however, not concerned. With regard to my own purposes, it enabled me to study the conditions of large numbers of stomata at my leisure and with a high degree of certainty. As a result, however, I found that there are other sources of error inherent in the behavior of the organs themselves. The stomata in a piece of epidermis are seldom of a uniform degree of opening. In the same piece some stomata may be quite shut and others as wide as 6 micra, or even more. In one which would be said to have stomata wide open, a glance shows a variation in width of 4 micra, between the extremes of 6 and Io micra.

In making my observations, therefore, I was compelled to follow a course which should give me the requisite degree of accuracy without too great an expenditure of time. For a while I measured ro stomata as they came in a line, moving the preparation by means of a mechanical stage. Again I tried to estimate the size of a hundred stomata taken at random, having an eyepiece micrometer scale in position as a standard of comparison.

I finallydecided that I could get as nearthe truth by the following method as by any way available. This is, to examine the whole of the piece of epidermis, to see what the range of size is, and to determine whether the majority of the stomata are near the mean size. The extremes are then measured accurately and the measurement recorded. Not infrequently a single stoma may be found shut, or wide open, among a hundred or many more in neither condition. This is disregarded or recorded in parenthesis. In plotting curves the extremes may be given, together with a curve of the mean. This method has been found sufficiently accurate for the work, though I can well understand that for further investigation a still more refined method may be found desirable.

When pieces of epidermis are placed in absolute alcohol it is to be noted that they become more or less twisted. This is due apparently to the cuticle which prevents the synchronous action of the fixing agent on all parts of the tissue. The effect on any one cell is, however, infinitesimal and may be disregarded. It should be further pointed out that it does not do to place the whole leaf or even a small part of it in the alcohol and expect the result obtained by using the removed epidermis. It appears that there is quite sufficient water in the tissue of the leaf to dilute the alcohol to the extent that it is made inefficient in rapidity of action, and hence the stomata close more or less.

I have repeatedly found, especially when large portions of the uninjured 
leaf were taken, that the stomata in this were less open than in the epidermis. This must, I feel sure, be attributed to the dilution of the alcohol by the escaping water from the chlorenchyma of the leaf, since I have shown, conclusively I believe, that the absolute alcohol, when properly used, does the work expected of it. Wilson \& Greenman (1892) used absolute alcohol for fixing the leaves of Melilotus, and believed that the stomata were fixed as in the living condition, but these authors did not attempt to demonstrate that this was the case. They may properly have been justified in believing that the stomata were not shut, but, if found half open, they could not have been sure that they had not been wholly so before treatment. Even this, however, may be questioned, for Copeland (1902) found that "alcohol" (when applied beneath the cover-glass, I presume) caused the stomata of certain plants to close. I can believe that this was the result of the killing action in the protoplasm of alcohol too dilute to fix the cell-wall. Farmer \& Chandler (I902), however, noted that in plants (Kalanchoe) treated with an excess of $\mathrm{CO}_{2}$ the stomata were gorged with starch and the guard-cells remained open even when killed with "spirit." Those of the control plants were found shut.

In studying the contents of the guard-cells, the well-known methods of Böhm (1856, potash and iodine) and of Meyer (I885, chloral hydrate and iodine used together), as also the simple I + KI reagent, were used. Boiling, as an additional means of swelling the starch granules, was employed. Experience taught, however, that the simple iodine test was sufficient.

The transverse diameter measurement given is the distance across the pore, ${ }^{*}$ that is, the opening between the bodies of the guard-cells and not the distance between the ridges, inner or outer.

\section{EFFECT OF CAUSTIC POTASH UPON STOMATA.}

Incidentally to making certain other observations, it was found that the stomata of Verbena, when subjected to boiling in water, often remained as a result quite widely open, while those of a dead and dried leaf were not affected in this way. This was attributed to the swelling of the starch, which might be expected to produce a result simulating turgor by raising the internal pressure of the cell. An attempt to produce a like result with potash obtained an effect which was a great deal more striking. Stomata treated with strong potash open remarkably (fig. 9) to an extent similar to that seen by Leitgeb in the moribund stomata of Galtonia candicans. When, however, the stoma has become widely open it then very suddenly closes, as with a snap, so that unless one is actually observing the effect of the reagent the closed condition only may be seen.

*I have adopted Copeland's (1902) term and usage. 
A similar result, excepting the sudden closure, may be obtained with the stomata of Fouquieria splendens, and in an even more marked degree than

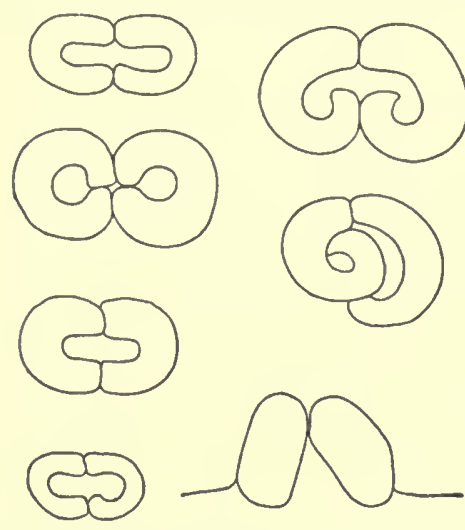

F1G. 9.-Forms assumed by stomata on treatment with strong potassium hydrate. Uppermost left-hand figure from Verbena; others Fouquieria. Lowest right-hand figure shows that the guard-cells become tilted with respect to epidermis.

the same as in the case here recorded. in those of Verbena. They not only open widely, but the guard-cells frequently separate from each other at one or both ends, enlarge greatly, and become tilted with reference to the epidermis. This enlargement and the distortion which accompanies it appears to be due, not to the swelling of the starch-grains, but of the thickened cellwalls, as these changes are often quite as great, even if the starch is in small amount or is absent from the stoma.

The behavior of the stomata of Galtoniu was induced by Leitgeb by killing with iodine vapor and chloroform, and the opening under these reagents was quite as marked as in my fig. 9, which shows the forms assumed by stomata on treatment with strong potassium hydrate. It would seem, however, that the immediate cause of the opening is not 


\section{PART I.}

\section{TRANSPIRATION AND STOMATAL MOVEMENT.}

The problem here considered has, as I conceive it, two aspects:

(I) The degree of correlation between the normal rates of transpiration and the normal changes in the size of the stomatal openings. There is, however, a logical difficulty to be encountered in that, even should a close correlation be shown to occur, it would remain unproved that the movements of the stomata were immediately related, in the causal sense, to the rise and fall of transpiration rate. This must be fully reckoned with in attributing a regulatory function to the stomata, for, unless marked quantitative differences between the functions of the chloroplasts of the chlorenchyma and those of the stomata exist, it would bequite possible that the photosynthetic activity of the chlorenchyma and of the guard-cells would run parallel without a necessary causal relation between stomatal movements and changes in transpiration rate. That such a causal relation exists is to be doubted from the consideration that the stomata, in very many cases at least, have a greater capacity for the outward diffusion of water-vapor than actually has been found to occur (Brown \& Escombe, I900) and this may be true at any given diffusion capacity of the stomata, depending upon their dimensions.

(2) Since, in the final analysis, light, above all other factors, influences stomatal movement, and since also appropriate illumination is the condition par excellence under which photosynthesis takes place, if the supposed causal relation under consideration exists, wide and sudden changes in the degree of illumination should be accompanied by changes in transpiration rate, and these, at the same time, by corresponding changes in the diffusion capacity of the stomatal openings.

If such changes of transpiration rate occur unaccompanied by stomatal movement, the answer to the problem is clear. If, however, any changes in the stomata occur, due consideration must be given, in the interpretation of the data, to the law of diffusion through a perforated septum as formulated by Brown \& Escombe (loc. cit.), whose study of the static diffusion of gases through membranes perforated by minute openings led them to the surprising result that the rate of diffusion through such openings is much greater than would at first be expected. 
Diaphragins perforated at regular intervals with holes $0.38 \mathrm{~mm}$. in diameter may be so arranged as to produce but little obstructive influence on the diffusive flow of a gas when the total area of the apertures amounts only to about ro per cent of the area of the septum, and that nearly 40 per cent of the full diffusive flow may be maintained when the number of the apertures is so far reduced as to represent an area of only 1.26 per cent of the full area of the septum.

The structure of a typical herbaceous leaf illustrates in a striking manner all the physical properties of a multiperforate septum.* Regarded from this point of view, it is shown that the stomatic openings and their adjuncts constitute even a more perfect piece of mechanism than is required [italicizing mine] for the supply of carbon dioxid for the physiological needs of the plant, and instead of expressing surprise at the comparatively large amount of the gas which an assimilating leaf can take in from the air, we must in future wonder that the intake is not greater than it actually is.

The large amounts of water-vapor which pass out of the leaf by transpiration are well within the limits of diffusion.

The authors, assuming circular openings $\dagger$ in the application of their mathematical deductions, stated that the maximum observed rate of transpiration for a plant of Helianthus was one-sixth of the possible rate or $\frac{-276}{1730} \mathrm{c}$. c. per square meter per hour, in view of the number of stomata and their distribution.

It will be of interest to compare the leaves of Helianthus and of Fouquieria splendens with respect to the physical conditions which are related to stomatal diffusive capacity. $\ddagger$ Brown \& Escombe found that in Helianthus there are 33,000 stomata per square centimeter of leaf surface. The area of the pore was calculated to be 0.0000908 square millimeter, which is equal to the area of a circle of 0.0107 millimeter diameter. The depth of the pore is 0.014 millimeter. In Fouquieria splendens there are $\frac{160}{16}(=320)$ per square millimeter, or 32,000 per square centimeter of leaf. The depth of the stomatal pore is 9 to 15 micra. Their areas in various conditions were found by making careful drawings to scale of openings of different dimensions on standard ruled paper. The figures so obtained (figs. 2 and 5) were cut out and

*In their longer paper ( 1900 a) Brown \& Escombe say that the perforations, if 8 or 9 diameters apart, do not interfere with each other, in which case they act as separate tubes; and this condition is approximated in the leaf.

$\dagger$ Of areas equal to those of the elliptical stomata, since the evaporation from an elliptical surface is equal to that from a circular surface of the same area (Stefan). The area of a stoma was taken to be $\frac{\text { length }}{2} \times \frac{\text { breadth }}{2} \times \pi\left(=l . b \frac{\pi}{4}\right)$ as sufficiently close. Since, however, the openings are not true ellipses (fig. 2) and are sometimes (Verbena) quite aberrant (fig. 5), the area may perhaps better be deduced empirically, at least in many cases.

¥ This comparison does not extend to the form of the intercellular spaces, which are narrower, it is quite probable, in Fonquieria. It will be evident, lowever, that this does not vitiate the comparison, since, in spite of the small intercellular spaces, the maximum transpiration rate is fully as great as in Helianthus. The probable greater thickness of the leaves of Fouquieria may tend to offset the shorter transverse dimensions of the intercellular spaces by their greater extent. (Bergen, 1904.) 
weighed, the weight being compared to that of the whole piece. The measurements are presented in table 17 .

It will be seen that the largest areas here used, those of pores with dimensions 6 by 19.5 and 9 by 16 micra, are fully as great as the area obtained for the stomatal pore of Helianthus. The largest possible pore dimensions, which do not exceed 10 by 20 micra, give us an area of 157.5 square micra, equal to a circle of a diameter of 14.24 micra, quite in excess of the stoma of Helianthus.

TABLE 17.-Measurements of stomatal pores, and areas determined by the method of proportional areas of weighing and by computation, together with the diameters of circles of equal areas.

\begin{tabular}{|c|c|c|c|c|c|}
\hline Width. & Length. & $\begin{array}{l}\text { Area by com- } \\
\text { parative weight. }\end{array}$ & $\begin{array}{l}\text { Area by compu- } \\
\text { tation, pore as- } \\
\text { sumed to be } \\
\text { elliptical. }\end{array}$ & $\begin{array}{l}\text { Diameter of } \\
\text { circle. }\end{array}$ & $\begin{array}{l}\text { Diameter of } \\
\text { circle by com- } \\
\text { putation. }\end{array}$ \\
\hline $\begin{array}{l}\text { Micra. } \\
6 \\
3 \\
1.75 \\
9 \\
5 \\
1.4 \\
7 \\
6.5\end{array}$ & $\begin{array}{l}\text { Micra. } \\
\text { 19.5 } \\
\text { 19.5 } \\
\text { 19.5 } \\
\text { 16 } \\
\text { 16 } \\
\text { 15 } \\
\text { 14 } \\
\text { 14 }\end{array}$ & $\begin{array}{c}\text { Sq. micra. } \\
94 . x \\
48.5 \\
24.8 \\
104.65 \\
57.56 \\
11 . x \\
72 \\
\ldots \ldots\end{array}$ & $\begin{array}{l}\text { Sq. micra. } \\
93.6 \\
46.8 \\
27.296 \\
\text { 115.2 } \\
64 \\
16.8 \\
78.4 \\
71.66\end{array}$ & $\begin{array}{c}\text { Micra. } \\
\text { ro.94 } \\
7.8 \\
5.6 \\
\text { 11.4 } \\
8.4 \\
3.6 \\
9.4 \\
\ldots \ldots\end{array}$ & $\begin{array}{c}\text { Micra. } \\
\text { I0.9 } \\
7.6 \\
5.8 \\
\text { I1.5 } \\
9 \\
4.6 \\
9.8 \\
9.4\end{array}$ \\
\hline
\end{tabular}

The depth of the Fouquieria pore-tube is from 9 to 15 micra; so it may be concluded that, aside from slight differences possible in the form of the tube (fig. 3), the diffusion capacity of the stomata of Fouquieria is certainly not inferior to that of Helianthus stomata. How far the geometrical form of the area may modify the calculation we can not say, but, as in the case of the poretube, it may be assumed to be but little. Since the stomata of both plants conform closely to a very common type of this apparatus, the main results of the comparison will not be vitiated by the trifling differences which must of course exist.

By means of a potometer experiment, the maximum rate of transpiration for a Fouquieria shoot $27 \mathrm{~cm}$. long, having a leaf surface of 299 sq. cm., was found to be 3 I 2 c.c. per square meter per hour,* a rate between one-sixth and one-fifth the stomatal diffusion capacity of Helianthus and, on the basis of the above comparison, approximately that of the Fouquieria leaf.

\footnotetext{
*It should be noted that due caution has been exercised in obtaining this rate, allowance having been made for the probable inaccuracy of the potometer method. The rate without the correction was 390 c.c. per square meter per hour. By weighing (vide ante) a correction for absorbtion of Io per cent was determined to be necessary during the earlier hours of the experimental period. In order to be well within the truth a correction equal to the volume of the twig used has been applied. This correction proved to be about 20 per cent. The average rate per hour for 24 hours was found to be about 90 c.c. per square meter per hour, this being a high rate for a xerophyte. As has been shown, however, the leaves under consideration are not markedly xerophytic.
} 
The diffusion capacity of the stomata considered as openings with no depth varies directly with the linear dimensions* which are derived, for purposes of computation, by comparing the stomata with circles of equal area. The actual rate of diffusion through stomata will depend upon the length of the tube, the gradation of density of the water-vapor between the surface of the cells of chlorenchyma, and the outer air, modified by air-currents. $\dagger$

It seems clear from Brown \& Escombe's experiments (cf., p. 259, fig. 6) that there exists such a gradation of density, from which it follows that under conditions of rapid transpiration the vapor-pressure within the leaf-cavities is less than when a low rate occurs, assuming the evaporation capacity of the cells to be constant. As in the case of $\mathrm{CO}_{2}$, the pressure of the water-vapor within the leaf, though much greater, must vary with the size of the stomatal pores, but here the relative humidity without is a very variable factor and will therefore modify the rate of transpiration independently of the pores.

It is also to be noted that the evaporating capacity of the surface of the chlorenchyma cells of the leaf is less than that of the pure water, so that the cell-walls tend to hold back the water. This, combined with a high relative humidity, would produce a high vapor-pressure within the leaf and a low rate of transpiration, even though the stomata are widely open. A low vapor-pressure within the leaf would follow on a low relative humidity, so that with open or partially open $\ddagger$ stomata the rate of transpiration may be high, but because of the incapacity of the cells to give up water-vapor, the capacity of the stomata to allow its escape may not be made full use of. If this argument be sound we should expect that the rate of transpiration will vary independently of the size of the stomatal openings.

This view is borne out by the facts obtained during the progress of this investigation. As an illustration experiment 54 will serve, the full data of which are given beyond. In this the transpiration rate was found to be, at $9^{\mathrm{h}} \mathrm{I} 5^{\mathrm{m}}$ a.m., $2 \mathrm{I} 6$ grams, and at $\mathrm{II}^{\mathrm{h}} \mathrm{I}^{\mathrm{m}} \mathrm{a}$ a.m. $22 \mathrm{I}$ grams per hour per square meter of leaf. At $9^{\mathrm{h}} 5^{\mathrm{m}}$ a.m., the stomata were open, and measurements showed that the average width to be 6.5 micra and the average length 14 micra. The average area, by computation, was $71.66 \mathrm{sq}$. micra, and the

*This Brown \& Escombe inferred from experiments with openings with diameters 40 to 2000 times the diameter of the stomata.

$\dagger$ Increase beyond a slight movement of air will not make the increase of outward diffusion of water-vapor greater, because this slight movement will be sufficient to remove the density shells. The ratio between diffusion in still and moving air in a Helianthus leaf is 1 to 1.23 (Brown \& Escombe, 1905. p. 65). In 1904 experiments were conducted to determine the effect of wind upon the transpiration in ocotillo, with a result which practically substantiates Brown \& Escombe's figures. There are no such great differences as are commonly supposed to occur. (For ratios of diffusive capacity in still and moving air see table I8.)

tThe diameters of stomata might be reduced to from one-fifteenth to one-twentieth of their length, and still allow a sufficient amount of $\mathrm{CO}_{2}$ to pass for maximum assinilation, provided the absorption was perfect [italicizing mine]. (Brown \& Escombe, loc. cit.) 
diameter of a circle of equal area would be 9.4. At $\mathrm{II}^{\mathrm{h}} \mathrm{I} 5^{\mathrm{m}} \mathrm{a} . \mathrm{m}$. the pores were found to be smaller by not more than 2 micra in transverse measurement, reducing the area to 49.6 I square micra, equal to that of a circle with a diameter of 7.8 micra. The length of the pore-tube was 12 micra. The ratio of these two observed rates of transpiration is $\mathrm{I} .02$, while that of the diffusive capacities of the stomata is 0.62 approximately. If the rate of transpiration followed the diffusion capacity of the stomata, the change at approximately the sizes given would be in the neighborhood of from unity at $9^{\mathrm{h}} \mathrm{I} 5^{\mathrm{m}}$ to 0.60 at $I^{\mathrm{h}} \mathrm{I}^{\mathrm{m}}$ a. $\mathrm{m}$. That is, from the data as they stand, the change of transpiration rate should, it is obvious, have been decreased, and the calculation shows that this decrease should have been of about 40 per cent. During the period, however, on account of exposure to darkness, the rate had fallen in

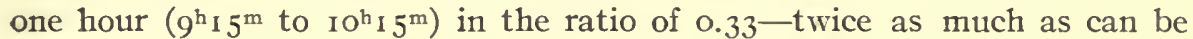
accounted for by the ratio of stomatal diffusion at the beginning and end of the I-hour period.

There can of course, be no doubt at all that complete closure of stomata, if this occurs, reduces transpiration to or near to the cuticular rate, so that thick or peculiarly impregnated cuticles and plugged stomata, etc., such as have been described by various authors, would act as a constant, more or less effective, preventive of water loss. Our problem relates, however, to stomatal movement, and, further, takes no account of anatomical elaborations, as pits, partial diaphragms, canaliform passages, etc., such as may be believed to influence the total amount of water loss, though perhaps not to regulate it,* during successive intervals of time. Conservation depends upon anatomical peculiarities, regulation upon physiological activity.

It has been the purpose of this part of the study to determine if considerable differences in the rate of transpiration are or are not constantly accompanied by corresponding stomatal movements. When a change in the dimensions of the stomata have been observed, the possible change in their diffusion capacity may be known by the change in linear dimensions by the use of a formula of Brown \& Escombe's, by which the proper correction for the length of stomatal tube is introduced. This, compared with the actual change in transpiration rate, will give us the data desired.

For the sake of convenience in estimating the relative diffusive capacity of the stomata of Fouquieria splendens $\dagger$ at different degrees of opening, I have arranged a table of calculations based upon the formula of Brown \& Escombe above mentioned. In this table the longitudinal diameter ( $2 a$ ) has been taken as a constant at about the average stomatal-pore length, namely, I 5

\footnotetext{
*The effect of such structures would be represented, in a mathematical expression of the physical processes in which they are involved, as a constant, and this would exclude any regulatory function.

$\dagger I$ have depended upon the data below for Verbena ciliata, as they are approximately true for this plant also.
} 
micra. $a$, therefore, equals 7.5 micra. The transverse diameters have been taken in geometrical progression from $2 b$ equals 2 micra up, increasing in the ratio 1.30 , the areas increasing in the same ratio. The length of the stomatal tube (the curved sides of which can not be taken into account) is taken at I5 micra and is, then, a constant. When the air-currents are sufficient to remove the outer density shells the diffusive capacity is increased. The formula, then, is

$$
Q=\text { constant } \frac{A}{l+x} \cdot . \quad . \quad . \quad . \quad .
$$

and when the two, outer and inner, density shells are present, as would be the case in perfectly still air, the formula would be modified to read

$$
Q^{1}=\text { constant } \frac{A}{l+2 x}
$$

where

$$
\begin{aligned}
& A=\text { transverse area of stomatal tube. } \\
& l=\text { length of stomatal tube. } \\
& x=\frac{\pi}{8} \times \text { diameter of a circle of area equal to } A .
\end{aligned}
$$

also

$$
x=\frac{\pi r}{4}=0.7854 r
$$

where $r=$ radius of a circle of area equal to that of the stomatal tube $(A)$. Since $A$ is equal to $\pi r^{2}$ formulas (I) and (2) may be written

$$
\begin{aligned}
& Q=C \frac{r^{2}}{l+0.7854 r} \text { for one shell . . . } \\
& Q^{\mathrm{l}}=C \frac{r^{2}}{l+\mathrm{I} .5708 r} \text { for two shells . . . . }
\end{aligned}
$$

where $C$ is a constant.

Assuming the stomatal pores to be elliptical,

$$
A=\pi a b \text {. }
$$

where $a$ and $b$ are the semi-axes. Also, since $A=\pi r^{2}$ we have $\pi a b=\pi r^{2}$ and

$$
r=\mathrm{v} \bar{a} \bar{b} \text {. }
$$

Table 8 contains the numbers which show, for stomata of several different dimensions, the ratios of diffusion capacities for these dimensions, when the air is still $\left(Q^{1}\right)$ and in motion $(Q)$. These ratios are smaller than the ratios between the areas, which are proportional to the transverse diameters $(b)$ and larger than those (ratio of $r$ ) between the radii $(r)$ of circles of areas equal to the areas of the stomata. The effect of the wind upon the diffusion capacity of a stoma of any given dimension is shown in the ratio $\frac{Q}{Q^{1}}$ and it 
is seen that as the opening increases the effect of the wind increases. In using the table, the longitudinal diameter has been assumed to be constantly 15 micra. The transverse diameters may then be applied to numbers under $2 b$. If the areas are calculated, the values of $r$ may be deduced and these applied to the numerals under the column $r$, but I have not proceeded on this method. The ratios desired may then be read in column $Q$ or $Q^{1}$.

TABLE 18.-Ratios of diffusion capacities for stomata of several different dimensions.

\begin{tabular}{|c|c|c|c|c|c|c|c|c|}
\hline \multirow{2}{*}{$\begin{array}{l}\quad b \\
\text { Ratio } \\
\text { areas. }\end{array}$} & \multirow{2}{*}{$\begin{array}{c}2 b \\
\text { Transverse } \\
\text { diameter. }\end{array}$} & \multirow{2}{*}{$\begin{array}{c}\frac{r^{2}}{l+0.7854 r} \\
\text { See }(3) .\end{array}$} & \multirow{2}{*}{$\begin{array}{c}\frac{r^{2}}{l+1.5708 r} \\
\text { See }(4) .\end{array}$} & \multicolumn{2}{|c|}{ Ratio of quantities. } & \multirow{2}{*}{$\frac{Q}{Q^{1}}$} & \multirow[b]{2}{*}{$r$} & \multirow{2}{*}{$\begin{array}{c}\text { Ratio } \\
\text { of } r\end{array}$} \\
\hline & & & & $Q$ (wind). & $Q^{1}$ & & & \\
\hline$x .00$ & 2.00 & 0.437 & $0.3^{89}$ & $x .00$ & 1.00 & I . 125 & 2.74 & $x .00$ \\
\hline$x \cdot 30$ & 2.60 & o. 559 & 0.490 & I. 28 & I. 26 & I. 140 & 3.12 & $x \cdot x_{4}$ \\
\hline$x .69$ & $3 \cdot 3^{8}$ & 0.712 & 0.615 & I. 63 & I. 58 & I. 157 & $3 \cdot 56$ & $x \cdot 30$ \\
\hline 2.20 & $4 \cdot 40$ & 0.907 & 0.771 & 2.07 & I. 99 & I. I 75 & 4.06 & I. $4^{8}$ \\
\hline 2.86 & $5 \cdot 72$ & I. I 5I & 0.963 & 2.63 & 2.48 & I . I 95 & 4.63 & I. 69 \\
\hline $3.7 x$ & $7 \cdot 42$ & I. 453 & x. $\times 94$ & $3 \cdot 32$ & 3.07 & I. 217 & 5.28 & I. 93 \\
\hline 4.83 & 9.66 & I. 836 & I $.48 \mathrm{r}$ & 4.20 & $3.8 x$ & I. 240 & 6.02 & 2.20 \\
\hline 6.28 & I 2.56 & $2 \cdot 310$ & I. 827 & 5.28 & $4 \cdot 70$ & x. 265 & 6.86 & $2 \cdot 50$ \\
\hline
\end{tabular}

\section{NORMAL DAILY PERIODICITY.}

\section{EXPERIMENTS.}

The following experiments upon Verbena ciliata afford us data upon the problem of the possible regulatory action of stomata upon transpiration. The rate of transpiration was determined by the method described by Cannon (I905). A suitable branch of the plant was selected, and a waterproofed wooden base was built about it for the support of a bell-jar of known capacity. The increase in the relative humidity of the interior of the jar when placed over the branch to be studied was recorded by means of a hygrometer (the Lamprecht polymeter). Each rate amount given is based upon the initial three readings made at 4 -minute intervals. Initial temperature and hygrometer readings are given in the table, but for the calculation of the rate those at the close of the selected intervals had, of course, to be used. The measurements of the stomatal pores were derived by taking the averages of the observed dimensions of both upper and lower epidermis.

The data afforded show that the daily opening of the stomata commences quite early in the morning, at dawn. The rise in the curve between $\mathrm{I}^{\mathrm{h}} 3 \mathrm{O}^{\mathrm{m}}$ and $2^{\mathrm{h}} 3 \mathrm{O}^{\mathrm{m}}$ a. $\mathrm{m}$. signifies in this regard probably nothing, as 0.5 micron is no greater than the error in the measurement. There seems, however, to be a tendency for stomata to open a little during the night, as Darwin observed. From the hour of dawn on till about 8 a. m. the opening goes on steadily, until at this hour the maximum size of the pore has been reached. This has been 
repeatedly verified by daily observation for several weeks. During the cooler weather of early spring, the opening appears to take place more slowly (see table 49, p. 100). From 8 a. m. till 12 day or 1 p. m. the maximum opening is maintained, but at about $\mathrm{x}$ p. $\mathrm{m}$. the closure of the stomata commences and proceeds till the minimum average opening of about 1.5 micra is reached at about $5 \mathrm{p} . \mathrm{n} 1$. The data obtained on two different days are consistent.

The rate of transpiration commences to increase at about 2 a. m., a phenomenon of very general occurrence. For the first few hours the increase is slow. After 5 a. $\mathrm{m}$. the rate increases much more rapidly and continues to do so till the maximum is reached, in one case at $10 \mathrm{a} . \mathrm{m}$. and in the other somewhat later. After the hour of maximum transpiration is passed the rates fall till midnight or later, but the decrease is interrupted between $I$ and 4 p. m., during which period the decrease is less rapid, or there may be a slight

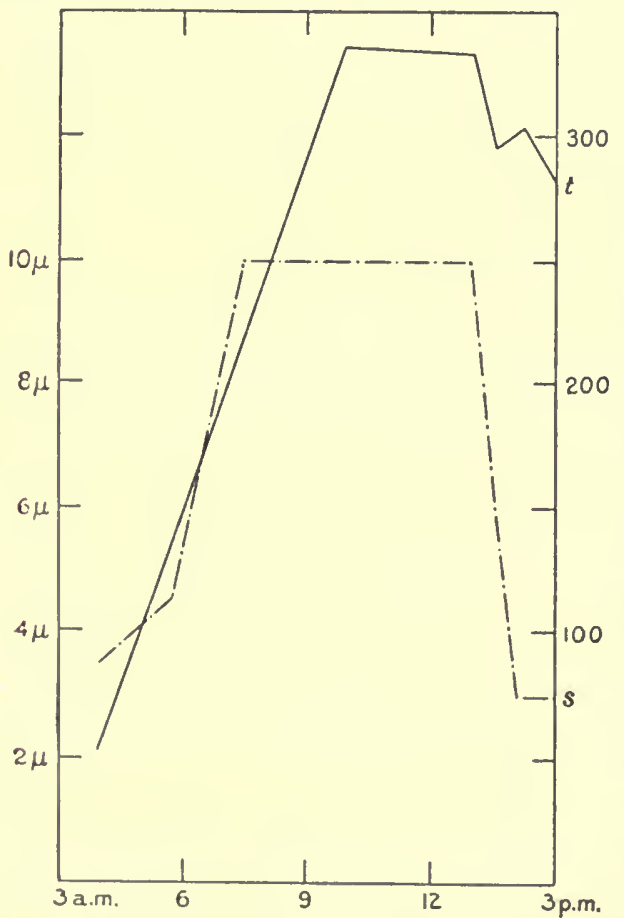

F1G, 10.-Experiment 139. Verbena ciliała. Curves of transpiration $(t)$ and of stomatal movement $(s)$. increase.

Figure ro shows the curves of transpiration and stomatal movement for the period between 4 a. n1. and 3 p. ni., constructed upon the data of experiment I39, Verbena ciliata. Numerals oppositeabscissas on the left are to be applied to the curve of stomatal movement; on the right to the transpiration curve.

If, now, we compare the curves constructed to represent the two sets of data, it will be seen that the maximum stomatal dimensions are reached 2 to 3 hours earlier than the maximum transpiration rate. That the rise in transpiration during the morning is not due in the main to the opening of the stomata is indicated by the continued rise in the curve of transpiration after $8 \mathrm{a} . \mathrm{m}$., the hour of maximum stomatal opening. The slight change in the transpiration curve of experiment 140 at this hour might be regarded as due to the static condition of the stomata, but there are other facts which deny this.

Again, a decrease in stomatal dimensions commences, in experiment 140, about 2 hours later than the decrease in transpiration rate, though in experi- 
ment 139 both commence simultaneously. The stomatal decrease is steady, and is completed by 5 or $6 \mathrm{p}$. m., while the transpiration rate continues to fall after this for several hours. The possible interpretation presents itself, that were it not for the early decrease of the stomatal dimensions in the afternoon, the rate of transpiration would continue high; and this suggestion draws importance from the fact that the danger from wilting is reaching its maximum at about mid-afternoon. It seems hardly likely, however, that the stomata are mainly responsible for the decrease in transpiration, because, in the cases before us, (I) the rate did not fall during the period of greatest reduction of stomatal dimensions, and (2) the rate fell steadily for 5 hours after the minimum openings had been reached.

That the transpiration rates are not related within wide limits to the dimensions of the stomata appears from the observed differences in the rate of transpiration accompanied by constant condition of the stomata; or by direct variation of the stomata too small to explain the changes in transpiration rate; or by inverse differences, which offer still more striking evidence. Thus, with a narrow opening of I to $x .7$ micra, the stomata allow observed differences in the rate of transpiration from unity to 5 .

In experiment 139 the total increase in the rate of transpiration during the morning of July 2 was from 54 to 336 units, while the transverse diameter of the stomata increased from 3.5 to Io micra. In experiment 140 the change from $\mathrm{I}_{4}$ to 90 units in transpiration rate was accompanied by a change in transverse stomatal dimension of from 2 to 9 micra. Assuming the data in table 18 as approximately correct for Verbena ciliata, the ratios between the maximum and minimum diffusive capacities for stomata with these measurements are presented in table 19.

TABLE 19.-Ratios beiwzen transpiration rates and diffusion capacities of stomata compared.

\begin{tabular}{|c|c|c|}
\hline & Exp. 139. & Exp. 140 . \\
\hline $\begin{array}{l}\text { Maximum transpiration } \div \text { minimum transpiration..... } \\
\text { Maximum stomatal diffusive capacity } \div \text { minimum sto- } \\
\text { matal diffusive capacity } \ldots \ldots \ldots \ldots \ldots \ldots \ldots \ldots\end{array}$ & $\begin{array}{l}6.22 \\
2.5+\end{array}$ & $\begin{array}{l}6.43 \\
4.00 \pm\end{array}$ \\
\hline
\end{tabular}

An observed increase in the rate from 54 to 133 units (i. e., in the ratio 2.46) can not be explained by an increase in the average transverse diameter of the stomata from 3.5 to 4.5 micra $\left(i . e_{\text {. }}\right.$, in the ratio 1.28 ); or diffusive capacity ratio $1.27 \pm$. The increased rate from 296 to 304 units is, of course, not connected with the static condition. And, while the stomata decreased from 6 to 2.5 micra, the transpiration rate increased somewhat (experiment I $40,12^{\mathrm{h}} 3^{8^{\mathrm{m}}}$ to $4^{\mathrm{h}} 2 \mathrm{O}^{\mathrm{m}}$ p. m.). 
THE PHYSIOLOGY OF STOMATA.

TABLE 20.-Experiment 139, June 27, 1905. (Fig. 10.)

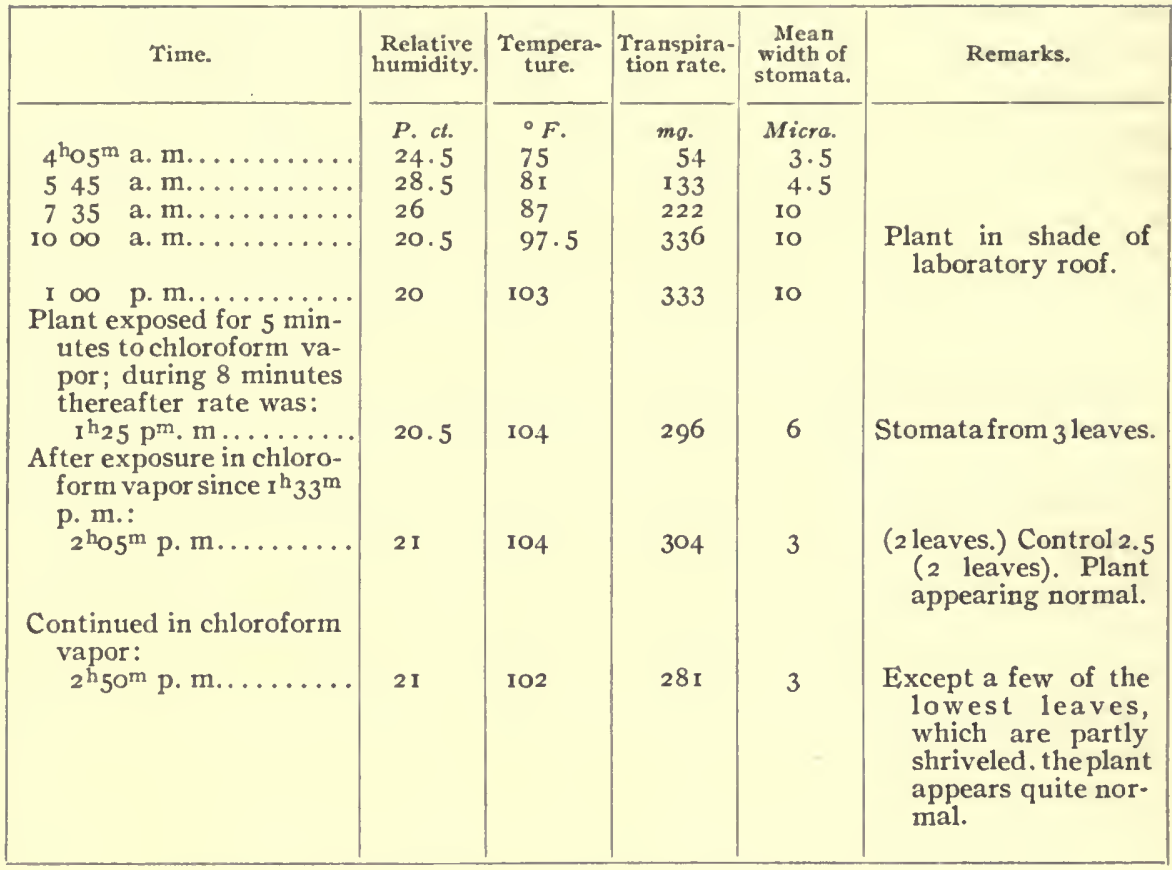

TABLE 21.-Experiment 140, July 1, 2, and 3, 1905. (Fig. I1.)

[Leaf surface reduced to approximately one-fourth by removal of leaves.]

\begin{tabular}{|c|c|c|c|c|c|}
\hline & Time. & $\begin{array}{l}\text { Relative } \\
\text { humidity. }\end{array}$ & $\begin{array}{c}\text { Tempera- } \\
\text { ture. }\end{array}$ & $\begin{array}{l}\text { Transpira- } \\
\text { tion rate } \\
\text { in } 8 \text { min. }\end{array}$ & $\begin{array}{l}\text { Mean width } \\
\text { of stomata. }\end{array}$ \\
\hline \multicolumn{2}{|c|}{ 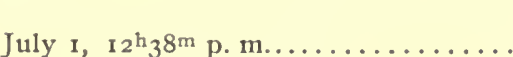 } & $\begin{array}{l}\text { P. ct. } \\
24.5\end{array}$ & $\begin{array}{l}\circ F . \\
\text { 103 }\end{array}$ & $\begin{array}{l}m o . \\
6 \mathbf{1}\end{array}$ & $\begin{array}{c}\text { Micra. } \\
6\end{array}$ \\
\hline 420 & p. m............... & 26 & 99.5 & 63 & 2.5 \\
\hline 716 & p. m............... & 27 & 92 & 28 & 1.5 \\
\hline July 2, I 58 & a. m................ & $33 \cdot 5$ & 79 & 14 & 2 \\
\hline 430 & a. $m \ldots \ldots \ldots \ldots \ldots$ & 33.5 & 75 & 18 & 4 \\
\hline 520 & a. $m \ldots \ldots \ldots \ldots \ldots$ & & $\ldots$ & & 6 \\
\hline 745 & a. $m \ldots \ldots \ldots \ldots \ldots$. & 30.5 & 94 & 70 & 8.3 \\
\hline 800 & a. m.............. & & & & 9 \\
\hline IO $2 \mathrm{I}$ & a. $m \ldots \ldots \ldots \ldots \ldots$. & $27 \cdot 5$ & 107.5 & 90 & 9 \\
\hline \multirow{2}{*}{\multicolumn{6}{|c|}{ Passes into shadow at $12^{\mathrm{h}} 3 \mathrm{O}^{\mathrm{m}}$. }} \\
\hline & & & & & \\
\hline 117 & p. m.................. & $\ddot{27}$ & $99 \cdot 5$ & 65 & 8 \\
\hline I 30 & p. m............... & & & & 7 \\
\hline 436 & p. m.............. & $25 \cdot 5$ & 98.5 & 62 & 2.4 \\
\hline 726 & p. m............... & 28.5 & 92 & 33 & 1.5 \\
\hline 1017 & & 30.5 & $85 \cdot 5$ & $\mathrm{I} 2$ & \\
\hline \multirow{2}{*}{\multicolumn{6}{|c|}{ 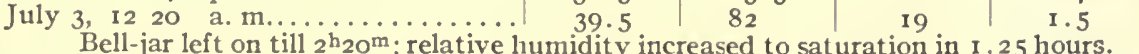 }} \\
\hline & & & & & \\
\hline $2^{\mathrm{h}} 2 \mathrm{O}^{\mathrm{m}}$ & a. $m \ldots \ldots \ldots \ldots \ldots \ldots$ & 48 & 80 & 43 & 1.5 \\
\hline & a. $m \ldots \ldots \ldots \ldots \ldots \ldots$ & 57 & 76 & 37 & I. 5 \\
\hline 606 & a. $m . \ldots \ldots \ldots \ldots \ldots$ & 53 & 82.5 & 71 & $5 \cdot 7$ \\
\hline 642 & a. $m \ldots \ldots \ldots \ldots \ldots$ & & $\ldots$ & 58 & $\ldots$ \\
\hline
\end{tabular}


A sustained attempt was made by the same method to obtain similar data for Fouquieria splendens. Observations were carried on for several days, but upon the examination of the stomata it was found that there had been during the whole period but a small amount of movement, as indicated by the following data: Range of stomatal size, $0-I$ to $2-6$ micra; range of transpiration rate, 4.84 grams to 0.2 gram. This was later suspected to be due to the age of the leaves, resulting in the loss, in great measure, of the power of movement by the stomata. The only conclusion to be drawn was that

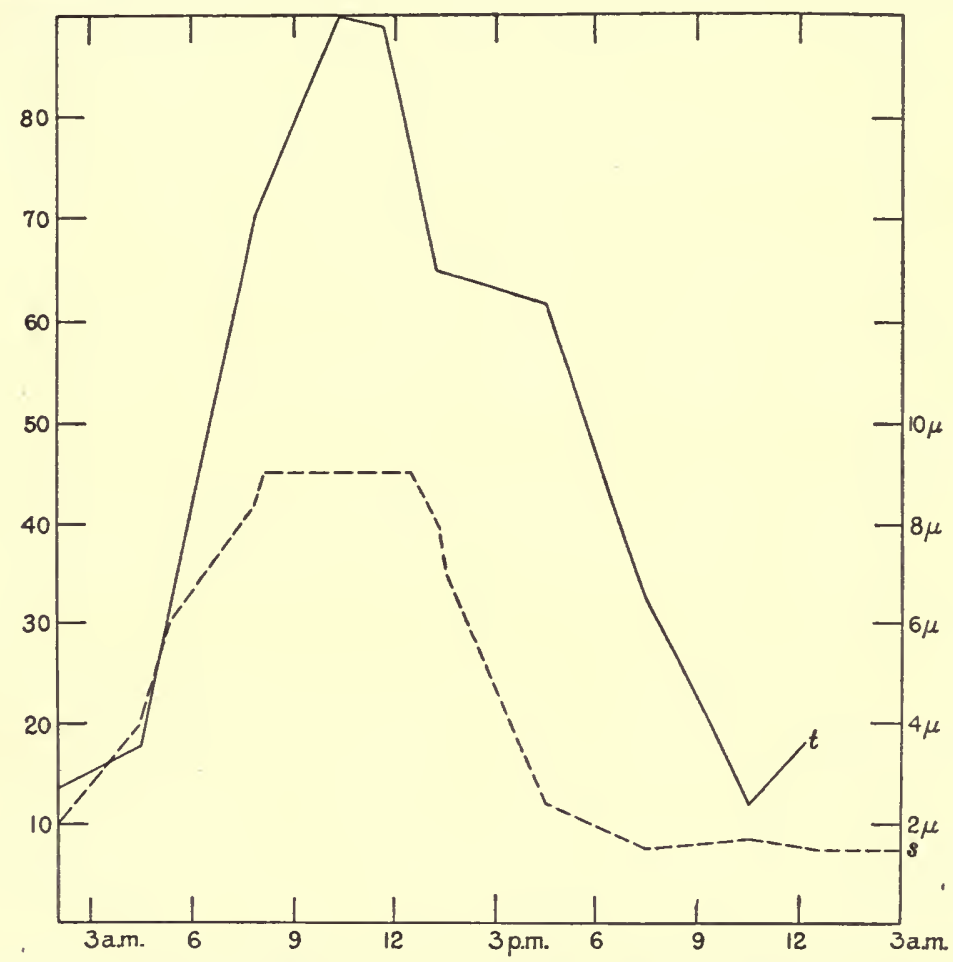

Fig. 11.-Curves of transpiration and stomatal movement for a period of 24 hours, Verbena ciliata, experiment 140. Numerals opposite abscissas on left to be applied to the transpiration curve $(t)$, those on right to curve of stomatal movement $(s)$.

with an amplitude of stomatal movement no greater than I to 3 micra, the maximum opening being about 4 or 5 micra (in one case only, 6 micra), there was still maintained a daily rise and fall of transpiration rate, apparently very nearly, if not wholly, normal. The relative immobility of stomata, due to the secondary thickening of their walls, would make them less effective as regulatory organs, and that their functions are not regulatory appears to follow from the progress of transpiration when they are inactive. Though from a different cause, young stomata are also relatively immobile; yet it is 
very unlikely that the course of transpiration in the growing leaf is less liable to the usual fluctuations observed in day and night.

From data obtained from other experiments and observations hereafter presented, the daily maximum rate of transpiration is shown to occur at or between the hours of I I a.m. and $3 \mathrm{p}$. m., while the maximum stomatal opening is attained at 8 to $10^{\mathrm{h}} 3 \mathrm{O}^{\mathrm{m}}$ a. $\mathrm{m}$. The minimum rate of transpiration falls in the night later than $8 \mathrm{p}$. m., while stomatal closure proceeds to its minimum at about sunset. It thus appears that, as in Verbena, the maximum stomatal opening is reached usually about 2 hours before the maximum transpiration rate occurs, and the evidence makes it probable also that the transpiration rate often begins to fall before the stomatal closure commences. It is not clear that the course of the stomatal movement comports wholly with that of Verbena, since the maximum opening may be maintained by some stomata as late as 3 p. m., as has been occasionally observed.

According to the summary given by Burgerstein (1887, p. 53) the transpiration maxima of various plants occur between I I a. m. and $3 \mathrm{p}$. m., though Sorauer ( 1880 ) found that in seedlings of apple, pear, and cherry it occurs as early as 9 a. m., the rate falling more slowly thereafter than it rose in the morning.

Curtis (1902), in accurate weighing experiments, found that the maximum transpiration was attained (by potted plants) at or between the hours of 12 day and 2 p. m., and in plants kept under constant illumination (electric light) this maximum was attained as early as i $\mathrm{a}$ a. $\mathrm{m}$. The minimum was nearly reached at sundown.

Cannon (1905) has recorded observations on the ocotillo, finding that the maximum occurred, in April, at about noon. The minimum was reached at about sundown. The low rate then reached was maintained till sunrise, though the details of the course during the night are not given.

Livingston (1906) found that in a desert species of Euphorbia the maximum occurred from ro a.m. to $2 \mathrm{p} . \mathrm{m}$. The minimum rate was reached somewhat after 2 a. m., but this rate was nearly reached at or about sundown.

With the permission of my colleague, Dr. B. E. Livingston, to use certain of his data prior to their publication, I am able to add that in two plants of Verbena ciliata studied by him during the present year (1906) the maximum rate of transpiration occurred at $3 \mathrm{p} . \mathrm{m}$. The data were obtained at 3 -hour intervals (by weighing), and it may very well be that the maximum occurred before $3 \mathrm{p}$. m., but certainly not before noon. The character of the curves derived from Livingston's data consists well with the curves which I have obtained. All of them have been plotted together for the sake of ease of comparison.

By calculating the ratios between transpiration rate and evaporation rate, as determined by a new type of evaporimeter elaborated by himself, Living- 
ston (loc. cit.), constructed a curve of "relative transpiration," the character of which, as compared with the "absolute transpiration" curve, led him to the belief that "some physiological change in the plant (Euphorbia) effective during certain hours" brings about a regulation of evaporation from the leaf which results in a course of events different from that which takes place in physical evaporation. Among other suggestions, the "response of the stomatal mechanism" is the one which concerns us in particular. The case of Euphorbia will be referred to further on. With respect to Verbena, the issue may be approached by means of the data given in the table 22. In it are to be found the transpiration rates (absolute transpiration), the relative transpiration rates, and the rates of evaporation, all collated by Dr. Livingston in July of the present year. The appropriate curves for relative transpiration and rate of evaporation are included in fig. $I 2$.

TABLE 22.-Transpiration and evaporation rates, Verbena ciliata.

\begin{tabular}{|c|c|c|c|c|c|c|}
\hline & \multirow[b]{2}{*}{ Period. } & \multicolumn{2}{|c|}{ Plant 40.} & \multicolumn{2}{|c|}{ Plant 36.} & \multirow[b]{2}{*}{$\begin{array}{c}\text { Evapora- } \\
\text { tion. }\end{array}$} \\
\hline & & $\begin{array}{l}\text { Absolute } \\
\text { transpira- } \\
\text { tion. }\end{array}$ & $\begin{array}{c}\text { Relative } \\
\text { transpira- } \\
\text { tion. }\end{array}$ & $\begin{array}{c}\text { Absolute } \\
\text { transpira- } \\
\text { tion. }\end{array}$ & $\begin{array}{c}\text { Relative } \\
\text { transpira- } \\
\text { tion. }\end{array}$ & \\
\hline $6^{\text {hoom }}$ & to 9 a. $\mathrm{m} . . . \ldots \ldots$ & $2 \cdot 52$ & 0.93 & I. 79 & 0.66 & 2.70 \\
\hline 10 30 & to 12 day.......... & $3 \cdot 73$ & I. Io & 2.92 & 0.86 & $3 \cdot 39$ \\
\hline I 30 & to 3 p. m......... & 4.17 & I.OI & 3.84 & 0.93 & 4.15 \\
\hline 430 & to $6 \mathrm{p} . \mathrm{m} . . . \ldots$ & 0.65 & o.19 & I. 08 & 0.33 & 3.23 \\
\hline 730 & to 9 p. m........ & $0.2 \mathrm{I}$ & 0.17 & 0.35 & o. 27 & I. 29 \\
\hline 1230 & to 4 a. m......... & o. 19 & 0.19 & 0.32 & 0.32 & 0.99 \\
\hline 530 & to 7 a. m......... & I.OO & I. OO & 1.00 & I. OO & 1.00 \\
\hline
\end{tabular}

It is to be noted that the maximum absolute transpiration rate falls at the same hour as that of evaporation. It is to be inferred from this that the conditions which produce a high rate of evaporation cause the proportionally rapid removal of water-vapor from the surface of the plant. It is significant, too, that the rate of absolute transpiration is checked after the noon hour, and that at this time is to be found the maximum of relative transpiration; or the check is to be noted in the decreased rate after this time. The rapid fall of absolute transpiration after 3 p.m. is clearly due to the rapid decrease in the rate of evaporation, but there is evident, also, a retarding influence at work on the plant which brings the rates of absolute and relative transpiration closer together than those of evaporation and absolute transpiration. To what extent may this regulation be referred to stomatal activity, however?

The closed condition of the stomata, assuming complete closure, which, as Francis Darwin believed, scarcely obtains, inhibits intercellular transpiration. The total escape of water-vapor from the leaf must then occur through the cuticle. Conversely, the fully open condition of the stomata permits a diffusion which, under optimum conditions for internal physiological processes, 
and for maximum evaporation rate, will be the maximum. No more watervapor may then escape than does so under these conditions. Such fluctuations in transpiration rate as may occur can never transgress the upper and lower limits, and in this degree the stomata of the plant must affect the loss of water. But this is far from attributing to stomata the intimate regulatory function, as is said to

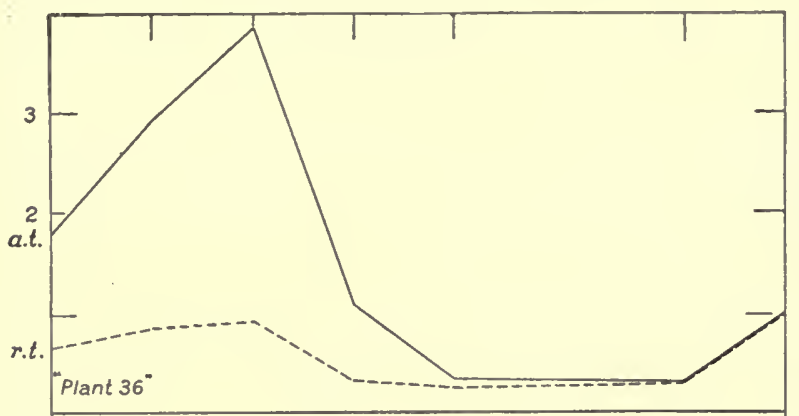
obtain under a very low relative humidity. Repeated observations have convinced me that so long as a water-supply is available at the roots of Verbena and ocotillo, there is no such adaptive change. If the plant wilts from any cause, the stomata, suffering like any other cell, though not quite as rapidly, close, but this is purely a passive behavior.

The low rate of transpiration induced by a high relative humidity may occur in any state, open or nearly closed, of the stomata. In a state of nature, and so long F1G. 12.-Curves of absolute (a.t.) and relative transpiration (r.t.) of as the plant is normal, two plants of Verbena ciliata for 24 hours. A curve of evaporation it is probable that selrate $(e)$ is also plotted. (From data supplied by $\mathbf{B}$. E. Livingston.)
dom, if ever, are the stomata used to their full capacity. This is shown by the readily observed fluctuations in the rate of transpiration which may be induced, accompanied by little or no change in the form of the stomata. So long as these fluctuations in transpiration rate may occur, the regulatory effect of the stomata must be small, and this in inverse ratio to the amplitude of these fluctuations. Curves of transpiration constructed from data taken at short intervals always show such positive and negative changes in successive periods. Some investigators liave, indeed, referred them to stomatal activity (e. g., Curtis, I 895), but without evidence. The low rates of nocturnal transpiration are, it is highly probable, not due to stomatal closure, since very narrow openings have 
a large diffusion capacity. Considerations of this sort make it extremely difficult to account for the course of transpiration in Livingston's experiments by stomatal movement.

There appears to be, therefore, warrant for the view that if such fluctuations occur in the rate of transpiration, unaccompanied by corresponding changes in the dimensions of the stomata, the regulatory function is almost nil. The following experiments are presented as affording data on this point.

\section{RESPONSES IN TRANSPIRATION AND IN STOMATAL MOVEMENT TO SUDDEN CHANGES IN ILLUMINATION.}

\section{EXPERIMENTS.}

The following experiments were designed to determine (a) whether an induced rhythm in transpiration can be shown to exist, and (b) whether sudden changes in the rate of transpiration resulting from the removal of the plant from light to darkness, or vice versa, are accompanied by stomatal movements which may be regarded as quantitatively correlated. The latter we have under immediate consideration, the question of induced rhythm being treated at page 64. The experiments are roughly classified for convenience, according to the change, whether from light to darkness, or vice versa, but can not be completely segregated.

\section{LIGHT TO DARKNESS.}

Experiments 172-179. Ocotillo. July 18-19, 1905. (Fig. 13.)

Eight cuttings were adjusted to burettes, and after standing for an hour or more they were paired off and readings were begun. One pair of cuttings was confined to the dark room permanently; another pair was confined to the dark room for $\mathrm{I} 7$ hours and then placed in diffused light on the porch of the laboratory; a third pair was placed upon the porch, but protected from direct sunlight during the day; the fourth pair remained under similar conditions, except that it was placed in the dark room for an hour. Rates are cubic centimeters per hour.

Aside from the first few hours the deportment of the plants was remarkably uniform, the rise and fall in rate in successive periods being the same for all, with few exceptions. To be noted are the maxima at 4 a. m. (I 74, I 76-1 79) and 9 a. m. (Nos. $173^{-1} 74$, I 76-I 79), aside from the great day maximum at I I a. $m$. The absence of a maximum in the curves of the plants kept in the dark at the time when it normally occurs ( I $\mathrm{a}$. m.) is also to be noted. Nos. I 72 to 175 show each a distinct maximum at 4 to $7 \mathrm{a}$. $\mathrm{m}$. and this behavior may be compared with that of the other pieces (Nos. I76 to I79) which produced each a maximum at 4 a. $\mathrm{m}$.

After a prolonged exposure to darkness, the plants exposed to moderate illumination increased their rate of transpiration in the ratios 6.25 ( 174 ) and 3.5 (175) rising to nearly the normal rate for the particular hour. Con- 
TABLE 23.-Rates of transpiration.

[172-173, dark roum throughout; 174-175, dark room till 12 day.]

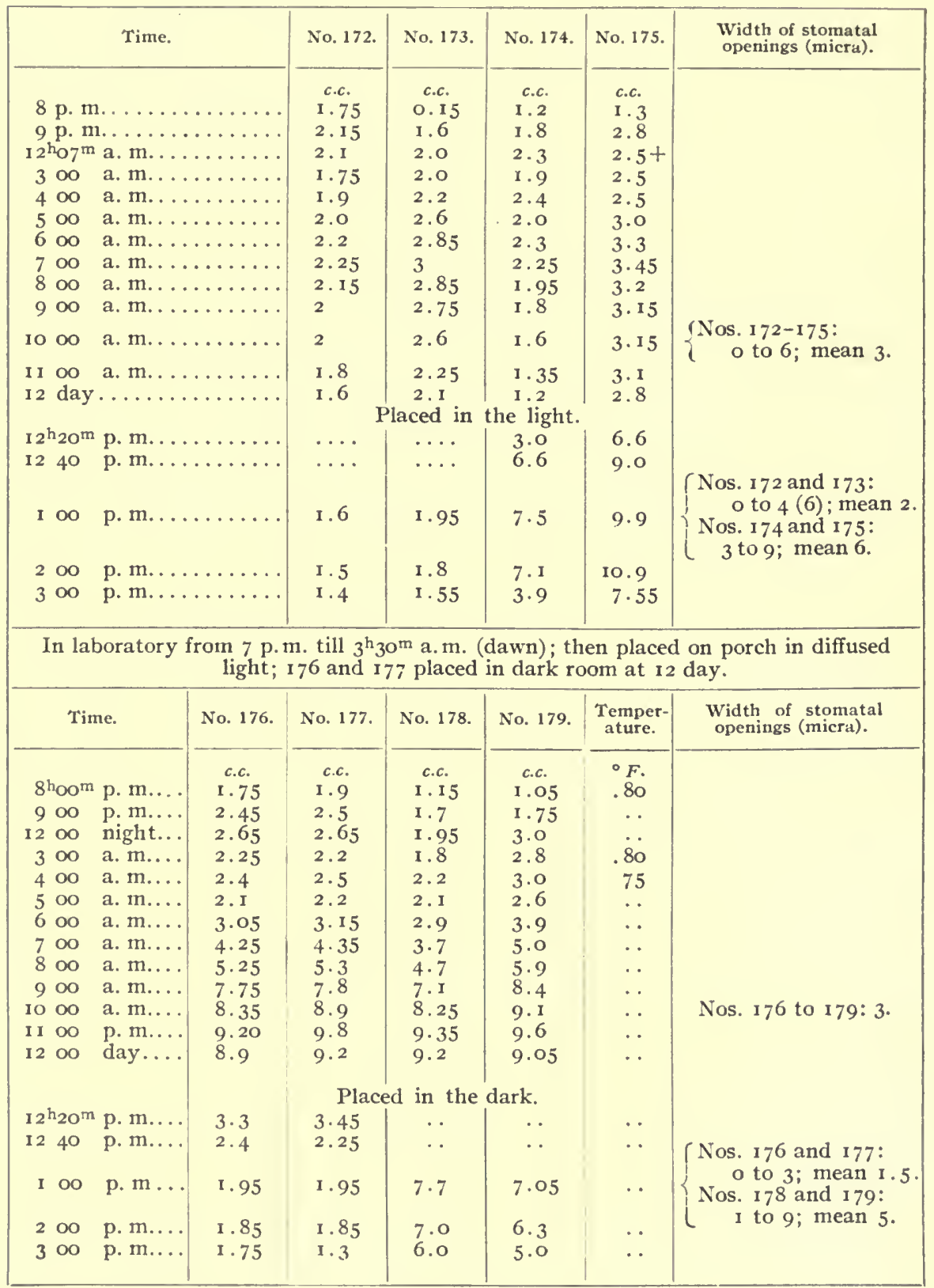




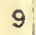




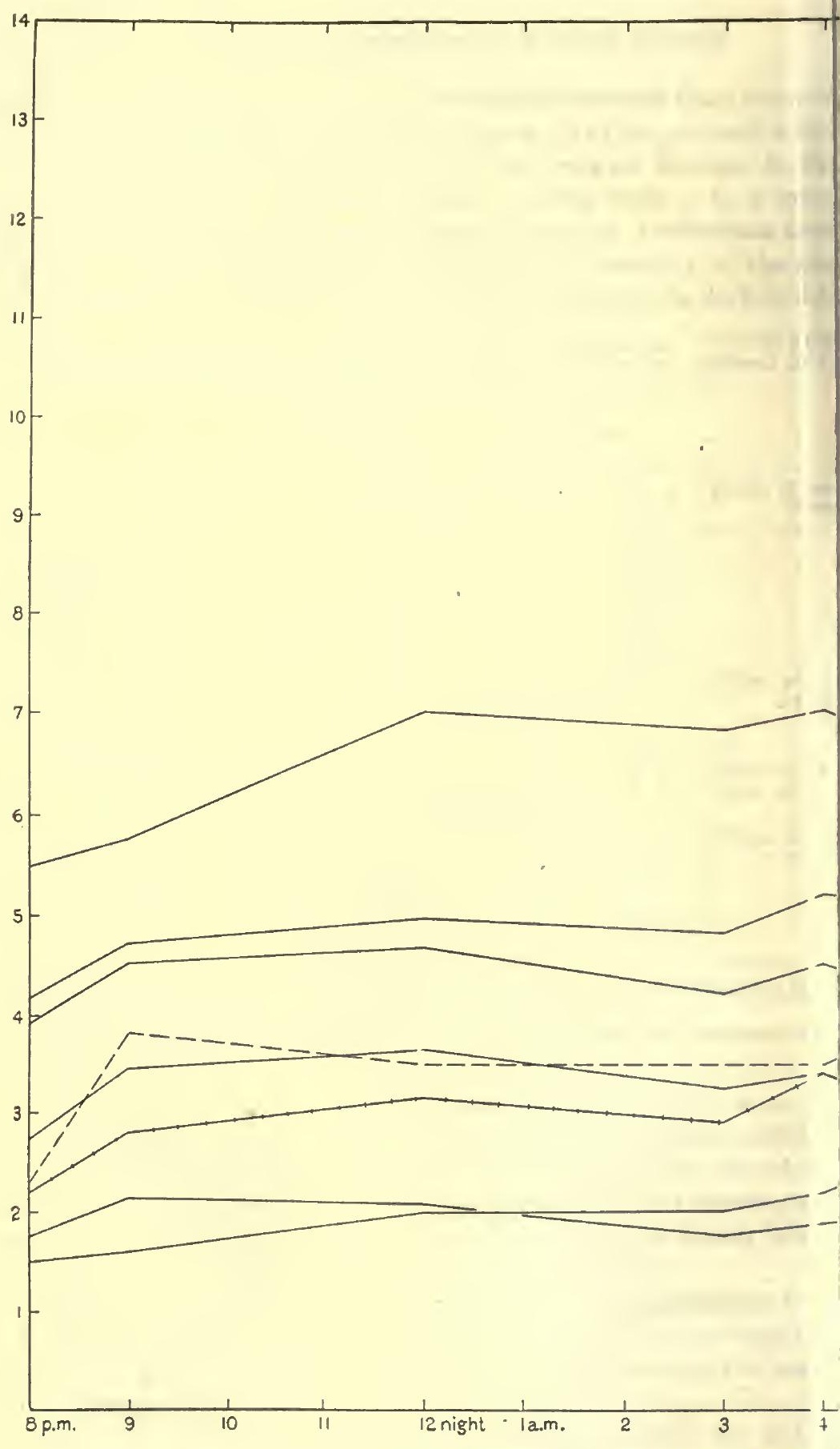

Facing page 46

Fig. 13.-Curves of experiments 172 to 179 inclu iv 


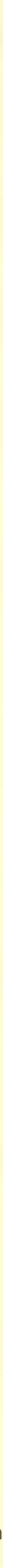

sive Fouquieria splendens. The curves are plotted so as not to intersect each other. 

versely, those exposed to normal illumination reduced their rates of transpiration when placed in the dark in the ratios 0.22 (No. I 76) and 0.21 (No. I 77). During the hour of exposure to light there was an increase in the average transverse dimensions of the stomatal opening from 3 to 6 micra. Conversely, the change from light to dark resulted in a reduction from 3 to I.5 micra. That is, approximately, the diffusive capacity of the stomata increased in the light in the ratio I.8, and decreased in the dark in the ratio o. 6.

Experiments 46, 47, and 54.-Ocotillo, July I6, I7, I904 (fig. I4). Vertical tube potometer placed on porch at 9 p. m.; placed in dark at $9^{\mathrm{h}} 5^{\mathrm{m}}$ a. m.; replaced in the diffused light at $10^{h} 5^{\mathrm{m}}$ a. m. Hourly rates.

TABLE 24.- Rates of transpiration.

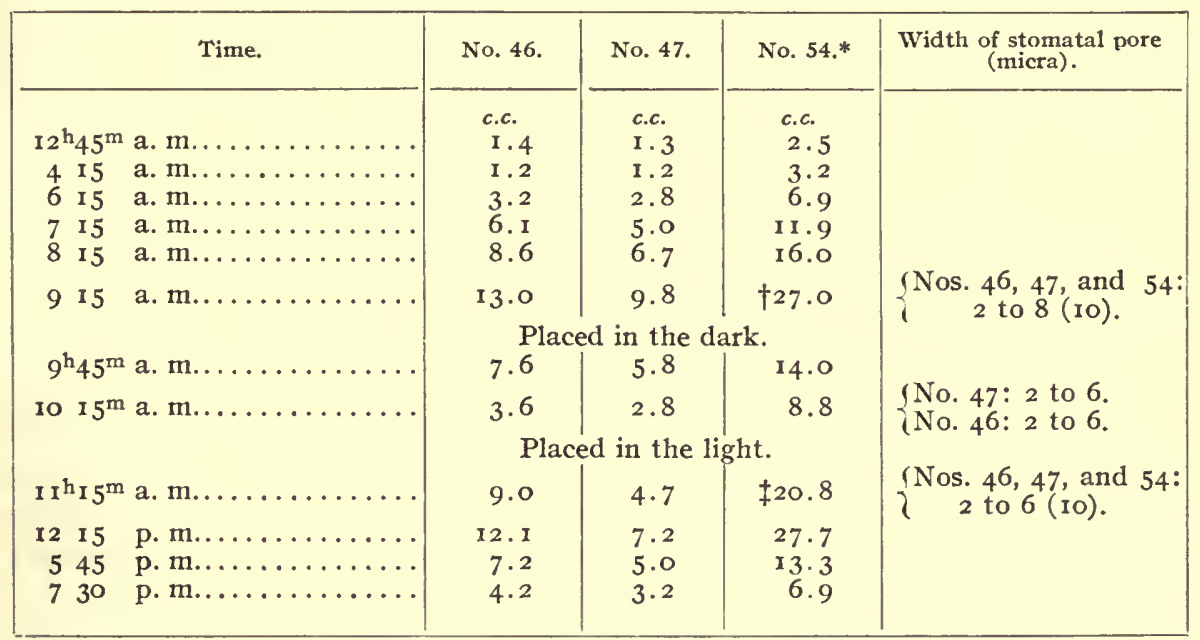

Eipidermis of plant used for experiments 47 and 54 was fixed at 20 -minute intervals after $9 \mathrm{~h}_{15} \mathrm{~m}$. All specimens showed the stomata 2 to 6 micra open.

* $40 \mathrm{~cm}$. tube-length contained 8.7 c.c. of water. Leaf-surface $272 \mathrm{~cm}^{2}$. Maximum transpiration rate per square meter per hour, 221 c.c.

$\dagger=5.87$ c.c. $\ddagger=\mathrm{L} .52$ c.c.

The transpiration curves took a normal course till $9^{\mathrm{h}} \mathrm{I} 5^{\mathrm{m}}$ a. m., when, upon being placed in the dark, the rate fell in I hour to about one-third $(46,47$, and 54). Readings which were made at $9^{\mathrm{h}} 45^{\mathrm{m}} \mathrm{a} . \mathrm{m}$. show that the change is more rapid during the first part of the period. During the following hour $\left(\mathrm{IO}^{\mathrm{h}} \mathrm{I}^{\mathrm{m}}\right.$ to $I^{I^{h}} I^{m}$ a. $m$.) in the light the rates again rose to within one-third (two cases) and two-thirds (one case) of the rate at $9^{\mathrm{h}} \mathrm{I}^{\mathrm{m}}$.

Measurements of the stomata show an average diminution in size during I hour of darkness from 5 or 6 micra at $9^{\mathrm{h}} \mathrm{5}^{\mathrm{m}} \mathrm{a}$. m. to not less than 4 micra at ${ }^{1} \mathrm{O}^{\mathrm{h}} \mathrm{I} 5^{\mathrm{m}} \mathrm{a} . \mathrm{m}$., after which, when exposed to light during the hour following, they remained the same.

Broadly speaking, a negative change of about 60 per cent in transpiration rate was accompanied by a negative change in diffusion capacity of the stomata of about 30 per cent. 
Experiment 45.-Ocotillo, July 14-15, 1904 (fig. 15). Placed in dark room at 12 day and returned to diffused light at $\mathbf{x}$ p. $\mathrm{m}$; ; burette potometer.

TABLE 25.-Rates of transpiration.

\begin{tabular}{|c|c|c|c|c|}
\hline & Time. & Rate. & Temperature. & $\begin{array}{l}\text { Width of stomatal } \\
\text { opening. }\end{array}$ \\
\hline $10^{1 / 20} \mathrm{~m}$ & p. $m \ldots \ldots \ldots \ldots \ldots \ldots$ & $\begin{array}{l}\text { c.c. } \\
\text { I. } 4\end{array}$ & $\begin{array}{l}{ }^{\circ} \mathrm{C} . \\
25.5\end{array}$ & 1 to 3 Micra. \\
\hline 1240 & 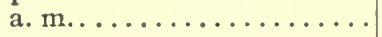 & I. 16 & $\ldots$ & 2 to $6(7.5) ; 1$ to 2 \\
\hline $3 \times 5$ & 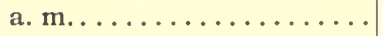 & 0.82 & 23 & o to 4 \\
\hline 500 & 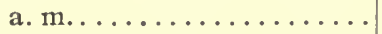 & 0.7 & 23.3 & \\
\hline 600 & 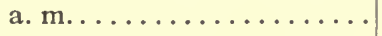 & 0.8 & $\ldots$ & \\
\hline 700 & 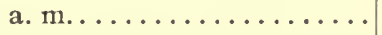 & I. 2 & 26 & \\
\hline 800 & 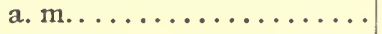 & $2 \cdot 3$ & 28.5 & \\
\hline 900 & 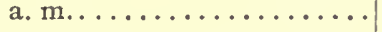 & $4 \cdot 4$ & 30 & \\
\hline 1000 & a.m........... & 6.1 & $33 \cdot 5$ & \\
\hline I I OO & 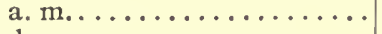 & 6.6 & 33 & \\
\hline 1200 & day $\ldots \ldots \ldots \ldots \ldots \ldots$ & $\begin{array}{l}7 \cdot 4^{4} \\
\text { Placed in }\end{array}$ & $\begin{array}{c}33 \\
\text { the dark. }\end{array}$ & 3 to 9 \\
\hline 1220 & p. m............ & $4 \cdot 2$ & $3 \mathrm{r}$ & \\
\hline 1240 & 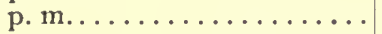 & 3.0 & $\ldots$ & \\
\hline I 00 & 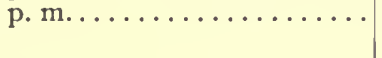 & $\begin{array}{l}2.4 \\
\text { Placed in }\end{array}$ & the light. & 3 to 9 \\
\hline I 30 & 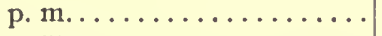 & 3.2 & 33 & \\
\hline 200 & 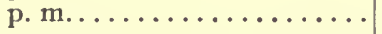 & 5.0 & $\ldots$ & 2 to $4 \cdot 5$ \\
\hline 230 & 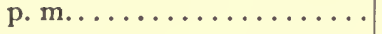 & 6.0 & $\cdots$ & \\
\hline 300 & 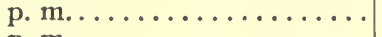 & 7.8 & $\ldots$ & \\
\hline 430 & 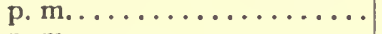 & 6.5 & $\cdots$ & \\
\hline 1000 & 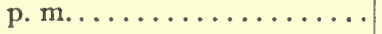 & I. I & 25 & \\
\hline
\end{tabular}

The stomata at noon showed measurements of 2 to 6 micra, which, upon being exposed to darkness for I hour, remained unchanged. Upon being replaced in the light for the same interval ( $I$ hour), the sizes of the stomata decreased to 2 to 4.5 micra. The change in average transverse dimensions during the second hour was, therefore, from 4 to 3.25 micra. The rate of transpiration was reduced in I hour from $7.4 \mathrm{c}$. c. per hour to $2.4 \mathrm{c}$. c. (or to about one-third) and was again advanced to $5 \mathrm{c}$. c. in one hour, or about twofold. That is, a reduction of about 60 per cent in transpiration rate occurred, with no change in the stomata; and a rise in transpiration of roo per cent occurred in spite of a lowering of the diffusion capacity of the stomata in the neighborhood of 40 per cent.

Experiment 68.-Ocotillo, July 20, $\mathrm{r}_{9}$ (fig. 15). Cutting in potometer; set up at 9 a. m. ; placed in dark room for one hour at $3 \mathrm{p} . \mathrm{m}$.; stomata examined at $3 \mathrm{p}$. m. and $4 \mathrm{p} . \mathrm{m}$. Measurements in micra.

TABLE 26.-Rates of transpiration.

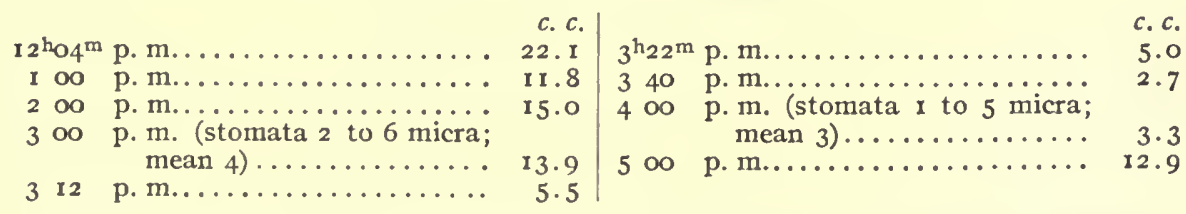

The transpiration rate was reduced to about one-fourth in $I$ hour, while the stomata reduced their transverse dimensions to only three-fourths, in the ratios for transpiration of 0.24 and for stomatal diffusion capacity of 0.8 . 


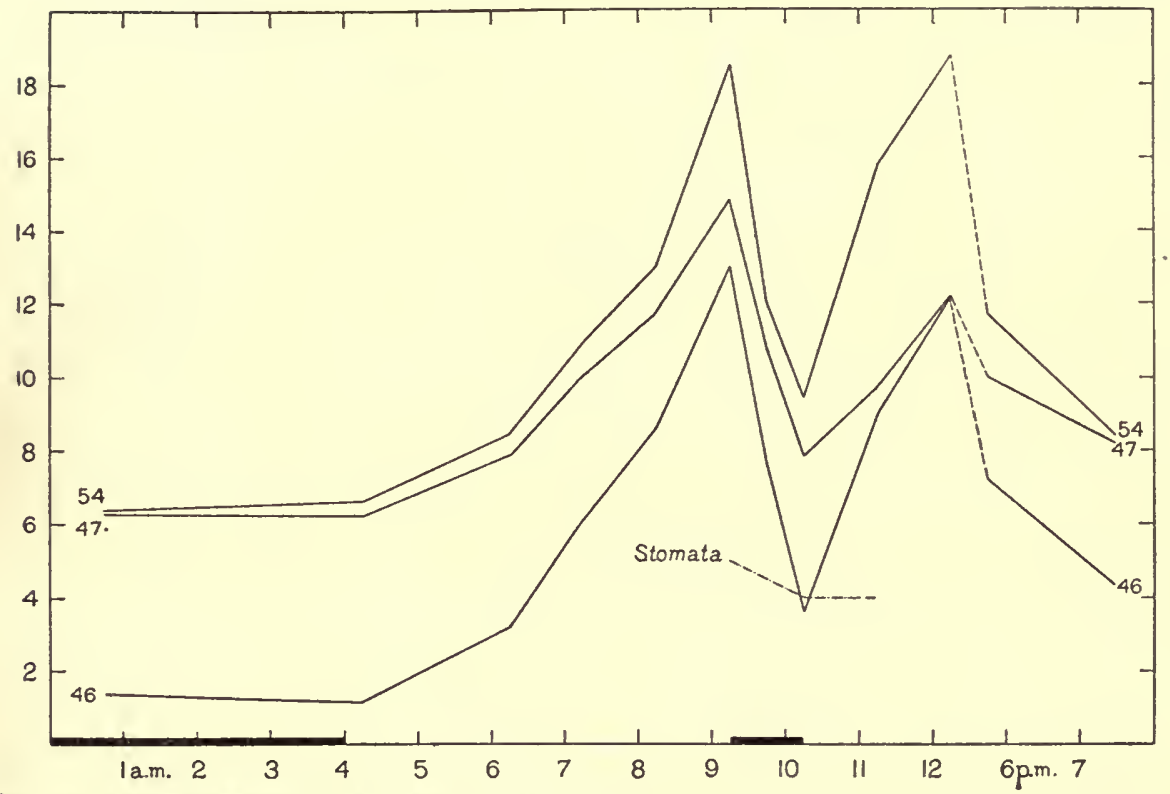

Fro. 14. - Curves of experiments 46,47 , and 54, Fouquieria splendens. Plotted so as not to intersect.

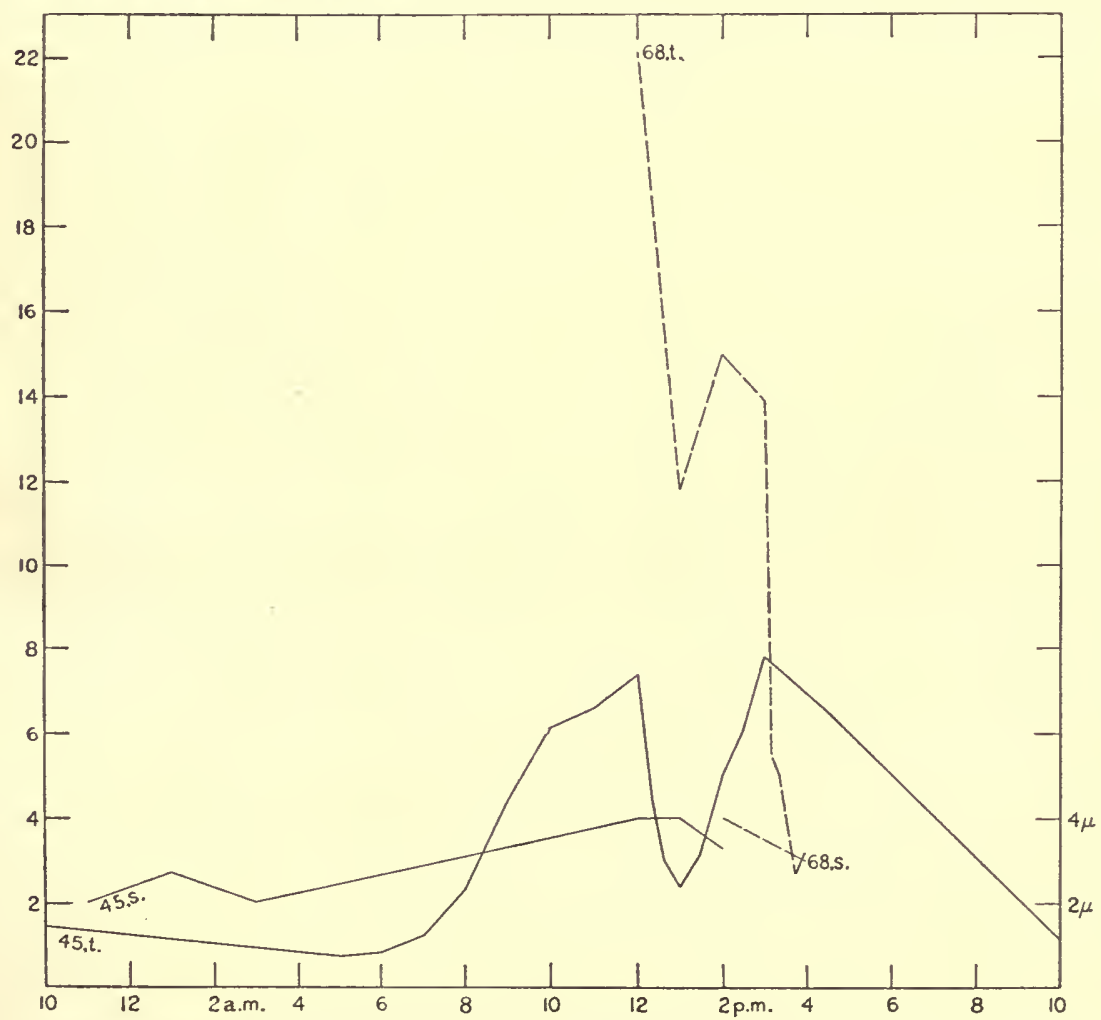

Fig. 15.-Curves for experiments 45 and 68 , Fouquieria splendens. $s$, curves of stomatal movement; $t$, transpiration curves. 


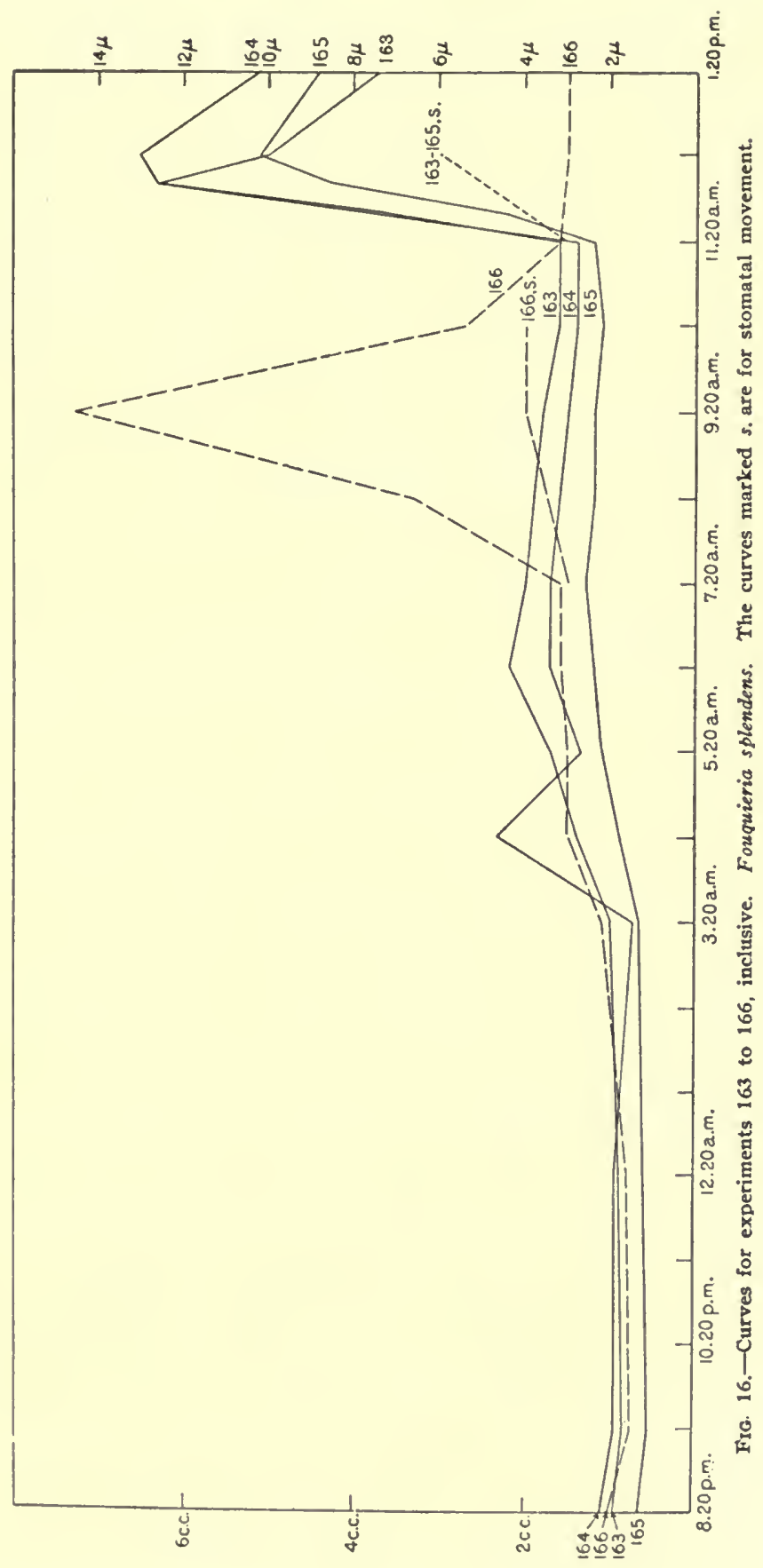


Experimen! 117.-Verbena ciliata, June I7, 1905; burette potometer; volumetric readings and weighings compared.

TABLE 27.-Rates of transpiration for 15 minutes.

\begin{tabular}{|c|c|c|c|c|}
\hline Hour. & Rate. & Weight. & $\begin{array}{l}\text { Difference } \\
\text { in weight. }\end{array}$ & $\begin{array}{l}\text { Width of stomatal } \\
\text { openings. }\end{array}$ \\
\hline 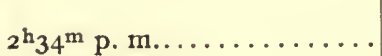 & $0_{0}^{c . c .}$ & $\begin{array}{l}\text { Grams. } \\
100.5\end{array}$ & $\begin{array}{c}\text { Grams. } \\
\ldots \ldots\end{array}$ & Micra. \\
\hline 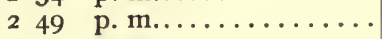 & I. 3 & 99.2 & 1. 3 & \\
\hline p. m........... & I. 4 & 97.8 & I. 4 & \\
\hline 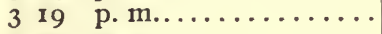 & I. 45 & 96.35 & I .45 & \\
\hline p. $m \ldots \ldots \ldots \ldots \ldots$ & I. 4 & $\begin{array}{l}94.95 \\
\text { in dark }\end{array}$ & om. & 3 to 9. \\
\hline 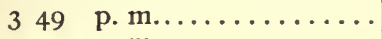 & I. I 5 & $\ldots \ldots$ & $\ldots$ & \\
\hline 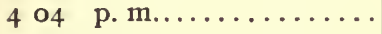 & 0.9 & $\cdots \cdots$ & $\cdots$ & 3 to 9. \\
\hline 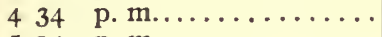 & 0.9 & $\cdots \cdots$ & $\cdots$ & 3 to 9 ; mean 6 . \\
\hline 504 p. m.............. & 0.9 & $\cdots \cdots$ & $\cdots$ & 2 to 7.5 ; mean 4.7 . \\
\hline
\end{tabular}

A reduction of one-third in the rate of transpiration occurred in 30 minutes, unaccompanied by any change in the size of the stomata (for curve in which the rates are given per hour, see fig. 17). After the lapse of an hour, the stomata were reduced to about three-fourths $(0.78)$ the original dimensions, or, in terms of diffusive capacity, $0.8+$.

Experiments 163 to 165 inclusive, July 14-15, Ig05 (fig. I6). Ocotillo, with young and mature foliage. Placed in dark room at midnight, where they remained till $\mathrm{I}_{\mathrm{I}} \mathrm{h}^{\mathrm{m}}$ a. m., when they were placed in strong diffused light for I hour; temperature of dark room constant $\left(28^{\circ} \mathrm{C}\right.$. $)$

TABLE 28.--Rates of transpiration per hour.

\begin{tabular}{|c|c|c|c|c|c|}
\hline & Time. & No. 163. & No. 164 . & No. 165 . & Width of stomatal pores. \\
\hline $8^{h_{20}} \mathrm{~m}$ & p. m............ & $\begin{array}{l}\text { c.c. } \\
0.95\end{array}$ & $\begin{array}{l}\text { c.c. } \\
\text { I. I }\end{array}$ & $\begin{array}{l}c . c . \\
0.65\end{array}$ & \multirow{17}{*}{2 to $4(8)$; mean 3 . } \\
\hline 920 & 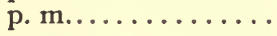 & 0.85 & 0.95 & 0.55 & \\
\hline 1220 & a. m............. & 0.9 & 0.93 & 0.6 & \\
\hline 320 & a. m.............. & 1.0 & 0.73 & 0.67 & \\
\hline 420 & a. m............ & I. 4 & 2.35 & 0.9 & \\
\hline 520 & a. m............ & 1. 7 & I. 35 & I. I & \\
\hline 620 & a. $m \ldots \ldots \ldots \ldots$ & 2.2 & I. 7 & 1.2 & \\
\hline 720 & a. $m \ldots \ldots \ldots \ldots$ & 2.0 & I. 7 & I. 3 & \\
\hline 820 & a. $m \ldots \ldots \ldots \ldots \ldots$ & I. 9 & 1. 6 & 1.2 & \\
\hline 920 & a. $m \ldots \ldots \ldots \ldots$ & 1.8 & I. 5 & 1.2 & \\
\hline 10 20 & a. $m \ldots \ldots \ldots \ldots$ & 1. 6 & I. 4 & I. I & \\
\hline II 20 & a. m............. & \multicolumn{3}{|c|}{ Placed in the light. } & \\
\hline II 40 & a. $m \ldots \ldots \ldots \ldots$. & 3.6 & $3 \cdot 75$ & 2.25 & \\
\hline 1200 & day.............. & 6.3 & 6.3 & $4 \cdot 2$ & \\
\hline \multirow[t]{2}{*}{1220} & p. m............ & $5 \cdot 0$ & 6.5 & 5.1 & \\
\hline & & \multicolumn{3}{|c|}{ Placed in the dark. } & \\
\hline I 20 & p. m........... & $3 \cdot 7$ & $5 \cdot 1$ & $4 \cdot 4$ & \\
\hline
\end{tabular}


Experiment 166.-July 14-15, 1905 (fig. I6). Ocotillo, with young and mature leaves. In laboratory till $7^{\mathrm{h}} 2 \mathrm{O}^{\mathrm{m}}$ a. m., July 15 , when it was placed in the shade on porch for 2 hours, then returned to the laboratory; placed in dark room at $10^{\mathrm{h}} 2 \mathrm{O}^{\mathrm{m}} \mathrm{a} . \mathrm{m}$.; temperature $28^{\circ} \mathrm{C}$. in laboratory and on porch at $7^{\mathrm{h}} 2 \mathrm{O}^{\mathrm{m}}$ a. $\mathrm{m}$.

TABLE, 29.-Rates of transpiration per hour.

\begin{tabular}{|c|c|c|c|c|c|c|}
\hline \multicolumn{2}{|r|}{ Time. } & \multirow{2}{*}{$\begin{array}{l}\text { Rate. } \\
\text { c.c. } \\
\text { I .o }\end{array}$} & \multicolumn{2}{|r|}{ Time. } & \multirow{2}{*}{$\begin{array}{l}\text { Rate. } \\
\text { c.c. } \\
\text { I. } 6\end{array}$} & \multirow{2}{*}{ 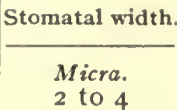 } \\
\hline $8^{\mathrm{h}_{2} \mathrm{O}^{\mathrm{m}}}$ & p.m........ & & $7^{\mathrm{h}_{20} \mathrm{~m}}$ & a.m........ & & \\
\hline 920 & p. m.......... & 0.75 & 820 & a. m.......... & $3 \cdot 3$ & 2 to 6 \\
\hline 1220 & a.m........ & 0.80 & 920 & a. m.......... & $7 \cdot 3$ & 2 to 6 \\
\hline 320 & a. m....... & I . I & 1020 & a. $m \ldots \ldots \ldots$ & 2.7 & 2 to 6 \\
\hline 420 & a.m. $\ldots \ldots \ldots \ldots$ & I. 5 & I I 20 & a. m.......... & 1.6 & $\ldots \ldots$ \\
\hline 520 & a. $\boldsymbol{n}_{\mathbf{i}}, \ldots \ldots \ldots \ldots$ & I. 5 & 1220 & p. m........ & 1.5 & $\ldots \ldots$ \\
\hline 620 & a.m......... & I. 6 & I 20 & 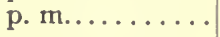 & I. 5 & $\ldots \ldots$ \\
\hline
\end{tabular}

Experiments 163 to 165 , inclusive.

At the end of 16 hours of darkness the rate of transpiration, during a 1 -hour exposure to light, increased three to four fold, while the increase in the size of the stomata was an average size of 3 micra to 6 micra, $i$. e., an increase in diffusive capacity of 80 per cent. In three cases a steady rise in the curve is seen after midnight. The stomata of the pieces which had been exposed to prolonged darkness ( 6 hours), when suddenly exposed to strong midday diffused light, responded more rapidly than those exposed earlier in the morning.

\section{Experiment 166.}

During an exposure from $7^{\mathrm{h}} 2 \mathrm{O}^{\mathrm{m}}$ a. $\mathrm{m}$. to $9^{\mathrm{h}} 3 \mathrm{O}^{\mathrm{m}}$ a. $\mathrm{m}$. to relatively strong illumination, the rate of transpiration increased 4.5 times. The average size of the stomata increased from 3 micra to 4 micra (an increased diffusive capacity of about 30 per cent), and thus remained without further change.

SUDDEN CHANGE FROM DARKNESS TO LIGHT.

Experiment 115.-June 17, 1905 (fig. 17). Verbena ciliata. Cutting placed in dark room at $3^{\mathrm{h}} 3 \mathrm{o}^{\mathrm{m}}$ p. $\mathrm{m}$.

TABLE 30.-Rates of transpiration per 15 minutes.

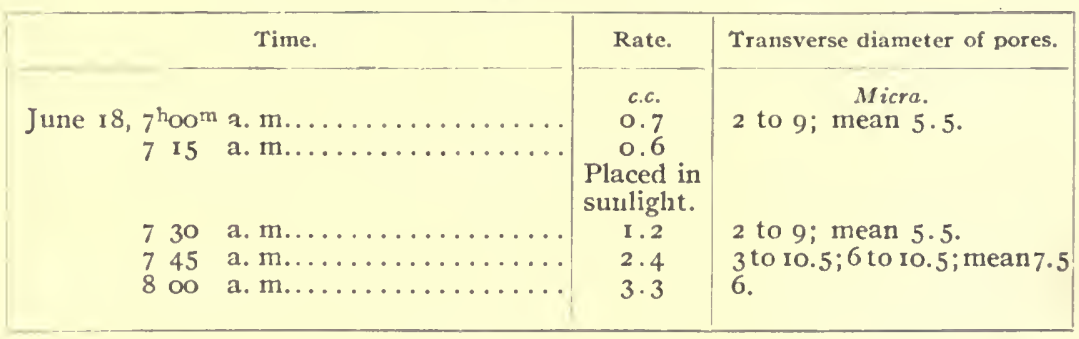

The rate of transpiration in 45 minutes was increased fivefold, while the average transverse dimensions of the stomata increased in 30 minutes from 5.5 micra to 7.5 micra, an increase of about 30 per cent. 


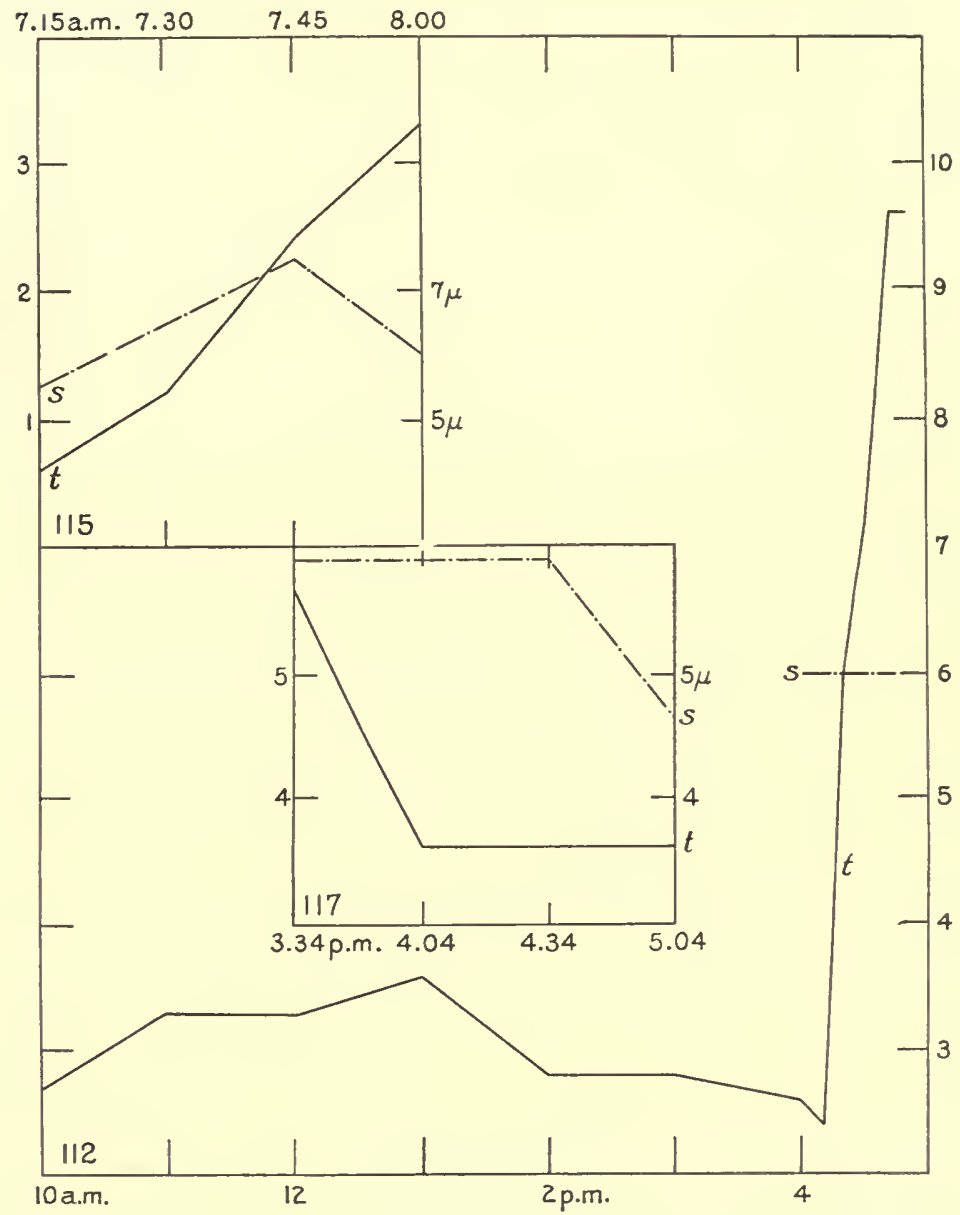

FIG. 17.-Curves for experiments 112,115, and 117. Verbena ciliata. The lines marked $s$ are curves of stomatal movement.

Experiment 112.-June 19, 1905(fig. 17). Verbena ciliata. Burette potometer. Placed in dark room at $9 \mathrm{a} . \mathrm{m}$.

TABLE 31.-Rates of transpiration.

\begin{tabular}{|c|c|c|c|c|c|c|c|}
\hline & Time. & 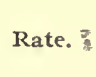 & $\begin{array}{l}\text { Size of } \\
\text { stomatal } \\
\text { openings. }\end{array}$ & & Time. & Rate. & $\begin{array}{c}\text { Size of } \\
\text { stomatal } \\
\text { openings. }\end{array}$ \\
\hline $10^{h} \mathrm{OO}^{\mathrm{m}}$ & a. $m \ldots \ldots \ldots \ldots$ & $\begin{array}{l}c . c . \\
2.7\end{array}$ & $\begin{array}{l}\text { Micra. } \\
\ldots \ldots\end{array}$ & $4^{\mathrm{h}} \mathrm{O}^{\mathrm{m}}$ & p. m........ & $\begin{array}{l}\text { c.c. } \\
2.4\end{array}$ & $\begin{array}{l}\text { Micra. } \\
2 \text { to } 10\end{array}$ \\
\hline 1100 & a. $m \ldots \ldots \ldots$ & $3 \cdot 3$ & $\ldots \ldots$ & & & Placed in & \\
\hline 1200 & day $\ldots . . . \ldots$ & $3 \cdot 3$ & $\ldots \ldots$ & & & sunlight. & $F$ \\
\hline 100 & p. m......... & 3.6 & $\ldots \ldots$ & 410 & p. $m \ldots \ldots \ldots \ldots$ & 6.0 & $\ldots \ldots$ \\
\hline 200 & p. m......... & 2.8 & $\ldots \ldots$ & 415 & p.m.......... & 7.2 & $\ldots \ldots$ \\
\hline 300 & p. m........... & 2.8 & $\ldots \ldots$ & 420 & p. m.......... & 9.6 & $\ldots \ldots$ \\
\hline 400 & p. m......... & 2.6 & 2 to 10 & 425 & p. m.......... & 9.6 & 2 to 10 \\
\hline
\end{tabular}


In 20 minutes the rate of transpiration increased fourfold, with little or no change in the size of the stomata. The behavior of these organs is apparently anomalous in this instance. It is certainly surprising to find that some of them remain so widely open after 7 hours' darkness.*

Experiment 74.-July 21, 1904 (fig. 18). Ocotillo. Burette potometer; plant used in experiment 69 , July 20 ; placed in dark room at $10^{\mathrm{h}} 3 \mathrm{o}^{\mathrm{m}} \mathrm{p} . \mathrm{m}$. ., July 20 , and no records taken till $6^{\mathrm{h}} 3 \mathrm{O}^{\mathrm{m}}$ a. m.. July 21 , plant remaining in dark room till $12^{\mathrm{h}} 4 \mathrm{O}^{\mathrm{m}}$, then placed in light till $12^{\mathrm{h}} 55^{\mathrm{m}}$; replaced in dark till $1 \mathrm{p} . \mathrm{m}$.

TABLE 32.-Rates of transpiration.

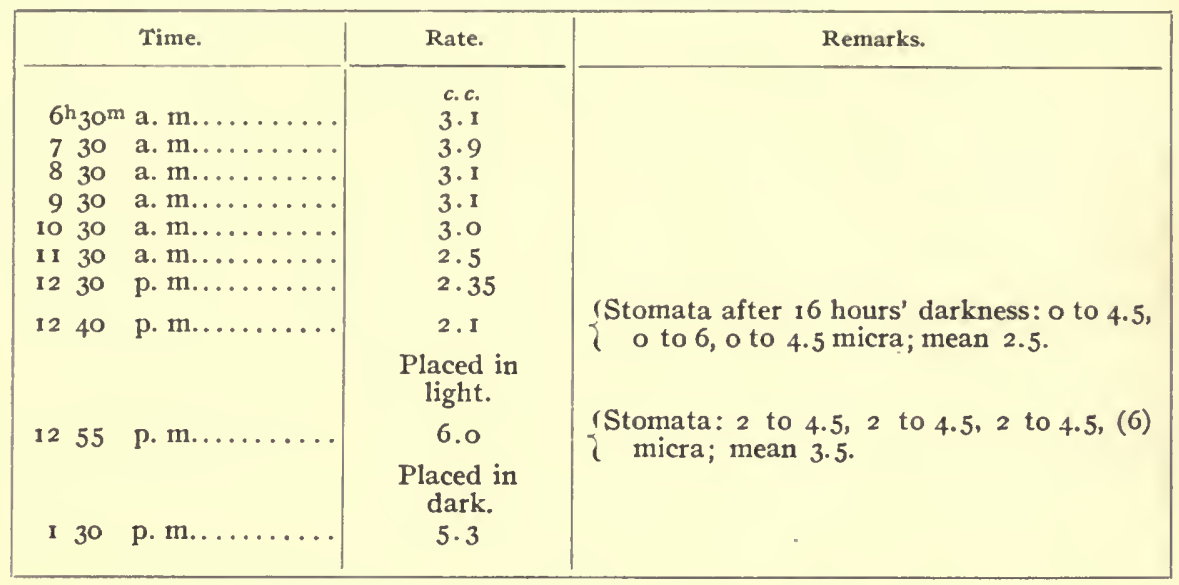

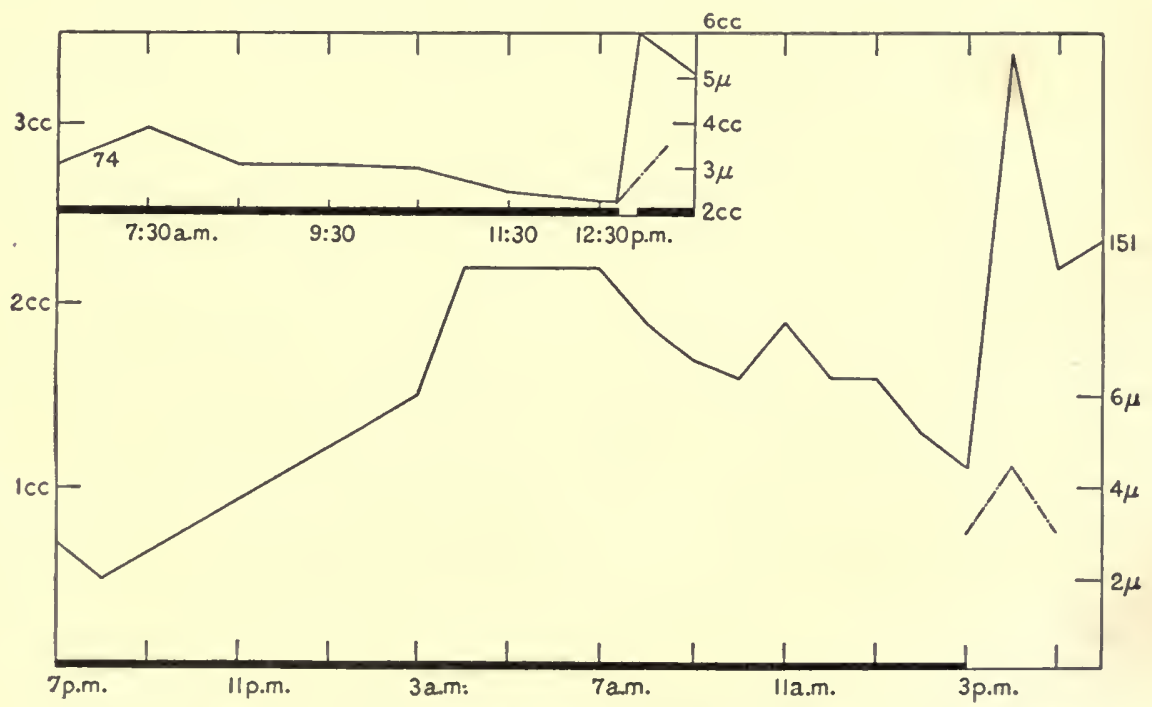

Fig. 18.-Curves for experiments 74 and 151. Fouquieria splendens. The dot-and-dash curves are of stomatal movement.

*I have later (Dec., 1906) found the stomata in a verbena kept in total darkness for 48 hours (2) 4 to 6 micra open. 
During a I 5-minute interval, after nearly 7 hours' exposure to darkness, the average opening of the stomata increased from 2.5 micra to 3.5 micra. This increase was due to the opening of the closed stomata, those having the wider openings being scarcely affected. The failure of stomata already partially open to increase their dimensions may not indicate lack of physiological response, but rather that the mechanical advantage in closed stomata is greater, and that, therefore, the result is more quickly expressed. The rate of transpiration at the close of the same interval of exposure to light (I 5 minutes) was nearly trebled. The average transverse linear dimensions of the stomata increased in the same period somewhat less than one-third. Otherwise stated, transpiration ratio, 2.9; that of diffusion capacity, I.3.

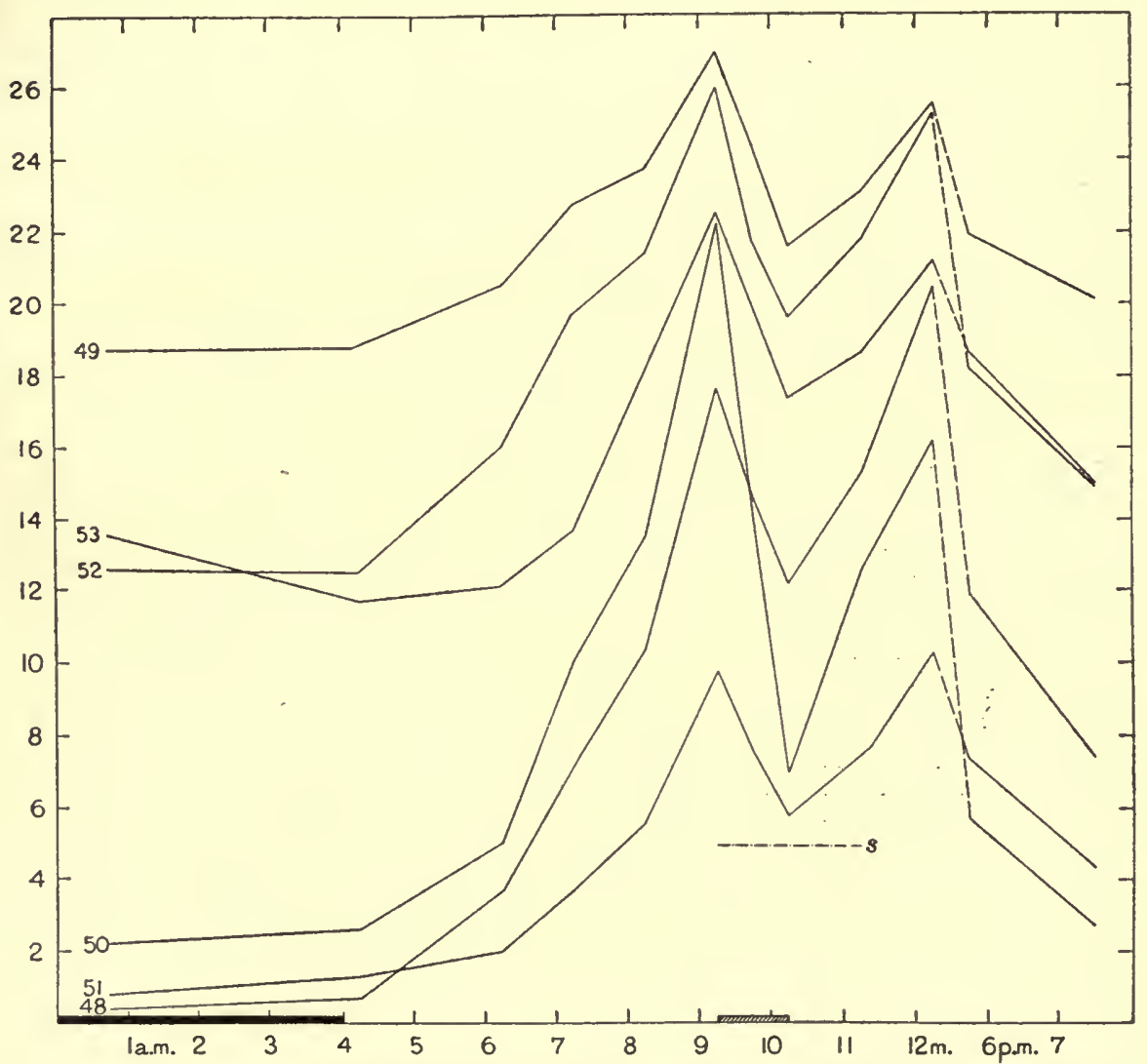

Fig. 19.-Curves for experiments 48 to 53 , inclusive. Fouquieria splendens. Curves are arranged so as to intersect but seldom. 
Experiment 151.-July 9, 1905 (fig. 18). Ocotillo. Burette potometer; in dark room.

TABLE 33.-Rates of transpiration per hour.

\begin{tabular}{|c|c|c|c|c|}
\hline Time. & Rate. & Time. & Rate. & Width of stomatal pore \\
\hline & c.c. & & c.c. & Micra. \\
\hline 7 p.m........... & 0.7 & 12 day............ & 1.6 & \\
\hline 8 p. m............ & 0.5 & I p. m........... & 1.65 & \\
\hline 3 a.m............ & 1.2 & 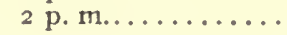 & $1 \cdot 3$ & \\
\hline 4 a.m........... & 2.2 & 3 p. m........... & 1.1 & 3. \\
\hline 5 a.m.......... & 2.2 & & Placed in & \\
\hline 7 a.m........... & 2.2 & & diffused & \\
\hline 8 a.m........... & 1.9 & & light. & \\
\hline 9 a.m........... & I. 7 & 4 p. m........... & 3.4 & 2 to 7 ; mean 4.5 . \\
\hline 10 a.m.......... & I. 6 & 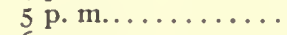 & 2.2 & o to 6 ; mean 3 . \\
\hline I 1 a. $m \ldots \ldots \ldots \ldots$ & 1.9 & 6 p.m............ & 2.9 & \\
\hline
\end{tabular}

The stomata exposed to diffused light in the mid-afternoon opened in an hour from 3 to 4.5 micra wide, returning to the former dimensions during the succeeding hour. The rate of transpiration rose threefold in I hour and fell to two-thirds its rate in the succeeding hour.

Experiments 48 to 53.- July 16, 1904 (fig. 19). Ocotillo. Vertical tube potometers all placed on porch at $9 \mathrm{p}$. m. July 16; placed in laboratory at $9^{\mathrm{h}} \mathrm{I}^{\mathrm{m}} \mathrm{a} . \mathrm{m}$. July 17 ; replaced on porch at $\operatorname{lo}_{1} 5^{\mathrm{m}}$ a. $\mathrm{m}$.

TABLE 34.-Hourly rates of transpiration.

\begin{tabular}{|c|c|c|c|c|c|c|c|}
\hline \multirow{2}{*}{\multicolumn{2}{|c|}{$12^{\mathrm{h}} 45^{\mathrm{m}}$ a. $m \ldots \ldots \ldots \ldots \ldots$}} & No. 48 . & No. 49. & No. 50. & No. 51. & No. 52. & No. 53 . \\
\hline & & $\begin{array}{c}\text { c. } c . \\
\text { I. } 4\end{array}$ & $\begin{array}{l}\text { c. c. } \\
\text { I. } 7\end{array}$ & $\begin{array}{c}\text { c. c. } \\
3.2\end{array}$ & $\begin{array}{c}\text { c. } \\
1.8\end{array}$ & $\begin{array}{c}\text { c. } c . \\
\text { I. } 6\end{array}$ & $\begin{array}{c}\text { c. } c . \\
5.6\end{array}$ \\
\hline 415 & a. $m \ldots \ldots \ldots \ldots$ & 1.7 & $1 \cdot 7$ & 3.6 & $2 \cdot 3$ & I. 5 & $3 \cdot 7$ \\
\hline $6 \times 5$ & a. m.............. & $4 \cdot 7$ & $3 \cdot 5$ & 6.0 & 3.0 & 5.0 & $4 \cdot 1$ \\
\hline 715 & a. $m \ldots \ldots \ldots \ldots$ & 8.5 & $5 \cdot 7$ & 11.5 & $4 \cdot 7$ & 8.7 & $5 \cdot 7$ \\
\hline 815 & a. $m \ldots \ldots \ldots \ldots \ldots$ & I1. 4 & 6.8 & $14 \cdot 5$ & 6.6 & 10.4 & 10.2 \\
\hline 915 & 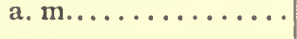 & 18.7 & 10.0 & 23.2 & 10.8 & 15.0 & $14 \cdot 5$ \\
\hline 045 & a. $\mathrm{m}$. & I 5.6 & 7.4 & I 5.2 & 8.6 & 10.8 & I I . 4 \\
\hline I0 15 & 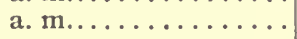 & I 3.2 & 4.6 & 8.0 & 6.8 & 8.6 & 9.4 \\
\hline & & & & eplaced & porch. & & \\
\hline I I 15 & 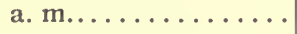 & 16.3 & 6.0 & 13.6 & 8.7 & 10.8 & 10.6 \\
\hline 1215 & 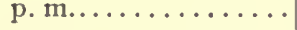 & $21 \cdot 5$ & 8.6 & 17.2 & 11. 3 & $14 \cdot 3$ & 13.1 \\
\hline 545 & 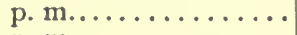 & 12.9 & $4 \cdot 9$ & 6.7 & 8.4 & 7.2 & 10.6 \\
\hline 730 & 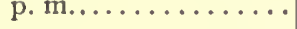 & 8.4 & $3 \cdot 1$ & $3 \cdot 7$ & $5 \cdot 3$ & 3.9 & $7 \cdot 3$ \\
\hline
\end{tabular}

Stomata at $9^{\mathrm{h}} 15^{\mathrm{m}}$ a. m., 2 to 8 (1o) micra; at $9^{\mathrm{h}} 4 \mathrm{O}^{\mathrm{m}}$ a. m., 2 to 8 micra; at $10^{\mathrm{h}} 25^{\mathrm{m}}$ a. $\mathrm{m}$. 2 to 8 nicra.

These experiments differ from the preceding only in having been placed in the reduced light of the laboratory instead of in the dark room. The reduction of the rate of transpiration under these circumstances amounted, approximately, to from one-third to one-half (in one case thr e-fourths), rising again about one-sixth when the stomata were examined. No change was found in their dimensions. 
TABLE 35.-Ratios between transpiration rates and stomatal diffusive capacities.

IIGH'T TO DARKNESS.

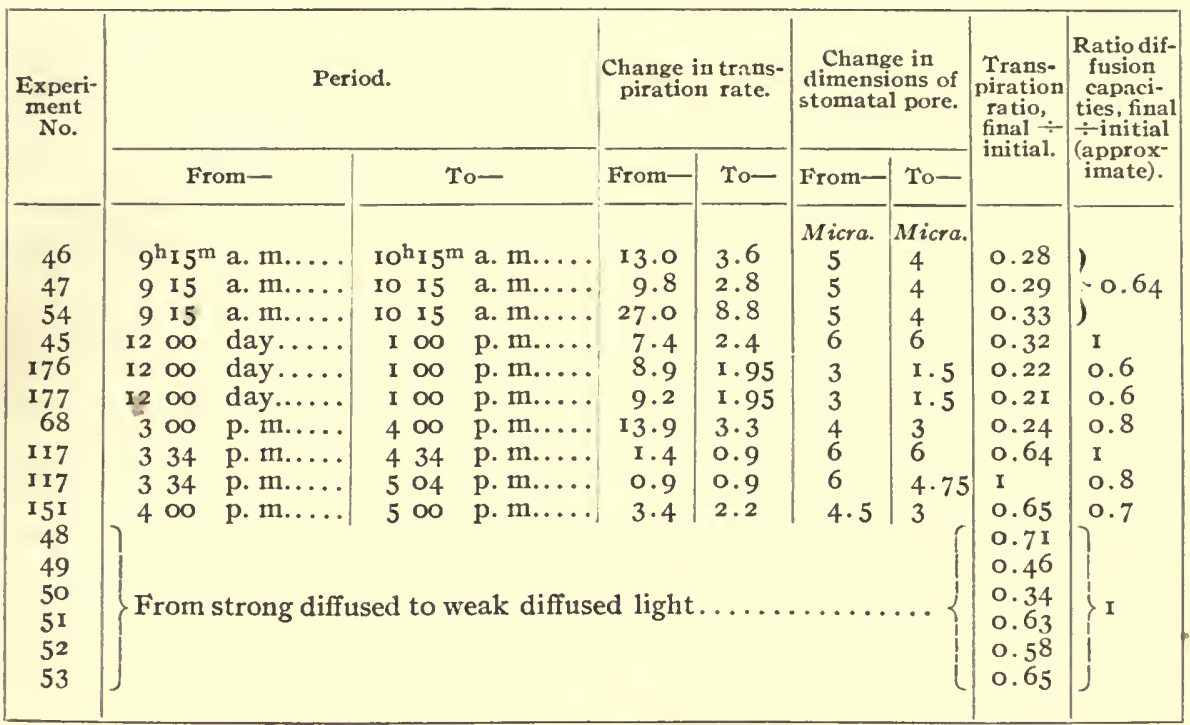

TABLE 36.--Ratios of change in transpiration rate and diffusive capacity of stomata.

DARKNESS TO LIGHT.

[All experiments are with ocotillo, excepting those marked with an asterisk (*)]

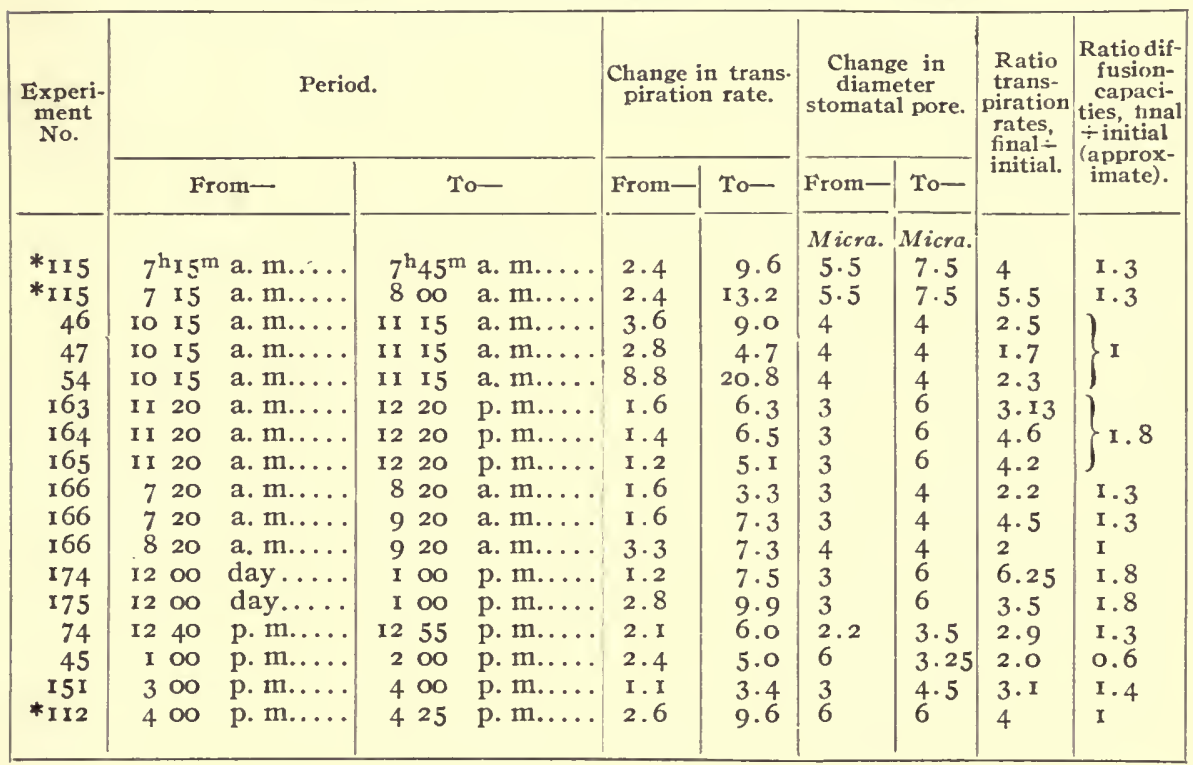




\section{DISCUSSION.}

According to the data above presented, the inference may be drawn that the movements of the stomata are not the causes of the recorded whole differences in the rate of transpiration. Such part of each change of rate in particular as might be referred to the change in stomatal dimensions is so small that it becomes negligible in its effect on the economy of water by the plant, and a regulatory effect on the transpiration by stomata in Fouquieria and Verbena amounts to nothing.

One of the commonest and at the same time least understood phenomena of transpiration is the fluctuation in the rate in successive short periods. They may be observed only when the periods are brief enough; they are, fowever, readily seen to occur when hourly observations are made. When the periods are reduced in length to a few minutes, this constant variation in rate, though involving only small absolute amounts, becomes very striking. When the periods between the hours of observation become longer, the fluctuations are gradually lost sight of, until only the general diurnal rate values are encountered, which give the data of daily maximum and minimum.

It is further to be noted that it appears to make no difference how constant the conditions surrounding the plant may be, or whether light be present or absent, the fluctuations above mentioned still occur, though it may be in less amplitude. Curtis (1902) has conducted very carefully guarded experiments, which displayed this variation in transpiration rate. Some of these experiments were placed under continual constant illumination for 12 hours; others in the absence of light. Nearly all of the plants used in my own experiments exhibit the same behavior. In the absence of synchronous variations in relative humidity and temperature, it seems impossible to avoid referring such minor fluctuations in transpiration rate to the internal economy of the plant, but what phase of this it may be is quite obscure. Among the more obvious explanations, and one which has been invoked as the cause, is the expansion and contraction of the stomata.

Thus, spcaking of the transpiration of plants in the dark, Curtis (loc. cit.) expressed surprise at the amount of water-vapor transpired in view of the fact that we usually consider the stomata as closed under this condition, but later on, in reference to the behavior of Ficus elastica, he regards the evidence offered by him as warranting the conclusion "that the stomata are sufficiently open to permit transpiration during the night," and, still again, suggests that the variation of minor amplitude in the rate of transpiration may be due to the activity of stomata. He says, "It is possible that, owing to the activity of the secreting cells and the accumulation of intracellular water, the stomata may open at varying periods, and, after the escape of the vapor, close again." 
The following sentence from Haberlandt (1904, p. 404) may be regarded as a summary of a rather generally entertained opinion on this point:

Die Spaltöffnungen sind zufolge ihrer Fähigkeit, sich zu öffnen und zu schliessen, nicht blosse Ausführungsgänge des Durchluftungssystems, sondern zugleich auch Regulatoren des Gasaustausches, in erster Linie der Abgabe von Wasserdampf, der Transpiration.

But what sort of evidence do we find to underlie this generalization? We need not recapitulate the arguments based upon comparative and genetic grounds, since conclusions drawn therefrom are subject to examination by experimental methods.

It has been shown by blocking the stomata with appropriate agents, the surfaces of leaves, by means of papers sensitive to water-vapor (Stahl, Merget), and by direct measurement of collected water (Garreau), that the amount of water-vapor passed off from the stomatal surface of a leaf is greater than that from the astomatal, and that large differences in the numbers of stomata on the two faces are related to observable differences in the amount of transpiration. Upon similar evidence also, low and high rates of transpiration have been coupled with a "closed" or "open" condition of the stomata, though the possible accompaniment of differences in the rates by constant stomatal condition has, of necessity, escaped observation by these means.

The change in rate of transpiration following reversal of the normal position of a bifacial leaf, maintained to occur by Meissner (1894) but denied by Francis Darwin (1898), was ascribed by Meissner to the closing of the under stomata upon exposure to direct sunlight. Similarly, Lidforss (I 896) referred the low rate of transpiration in evergreens in winter to the closed condition of the stomata, a conclusion believed by Francis Darwin to need "further research." But the studies of this author, based upon the readings of a hygrometer, provided data which are often open to two interpretations, since, in the absence of direct observation of the stomata, the horn hygroscope may be depended upon to record transpiration rate, and not the condition of the stomata. Thus, this instrument remained at zero on the red, chlorophyll-free leaves of Poinsettia of the greenhouses. "The difference in the green and non-green parts seems to depend upon the aperture rather than the number of stomata, but on this point more observations are needed," Darwin concluded, for he also observed, "the stomata in the white and in the yellow part of at least some variegated leaves close in darkness and as the leaf withers." The behavior of the hygroscope on the Poinsettia bract may be taken to mean a low transpiration rate merely, or a closed condition of the stomata, and hence a low transpiration rate. But there is no direct evidence that the stomata of the non-green parts are at all different from those found elsewhere (Weiss, 1898). I myself find the stomata of the red bracts of Poinsettia provided with chlorophyll and open in daylight, though I have not made careful quantitative measurements of transpiration nor measurements 
of the stomata. Some half dozen other plants with white areas gave similar facts. The closure of the stomata in non-green parts "in darkness and as the leaf withers" is quite to be expected, and, as I show later, the absence of chlorophyll from, or a very small amount in, the guard-cells indicates nothing at all as regards their ability to function.

In many instances, however, the stomata of non-green organs and of the non-green portions of variegated leaves have been stated to be "chlorophyllfree" or immobile, and, for either or both these reasons, non-functional (Czeck, Kohl), or conversely, because of the relatively low rate of transpiration of non-green parts, the non-functional condition of the stomata has been believed to be demonstrated (Merget). Of interest in this connection is Kohl's criticism of Wiesner's views, based upon the latter's experiments with green and etiolated maize plants. The differences in the rates of transpiration which he observed were referred to the presence or absence of chlorophyll and not to the condition of the stomata, which he found to be almost closed in both green and etiolated plants. He noted also that although the stomata of Hartwegia comosa are wide open in the dark, nevertheless the transpiration rate is low. He concluded, therefore, "dass die Oeffnung der Stomata die Verdunstung der Pflanze im Lichte etwa zu verstärken vermag soll nicht geläugnet werden," but that his experiments showed the fluctuations of transpiration rate noted by him "auf anderen Ursachen beruhen müsse." But Kohl denied the validity of Wiesner's observation, stating that he himself found the stomata in green maize plants in all stages of opening. He goes on to say "da nun an etiolirte Maizplanzen wie der Augenschein lehrt den Schliesszellen der Stomata das Chlorophyll fehlt, so kann das Ausbleiben der starken Beschleunigung der Wasserverdunstung an solchen Pflanzen ebensowohl von der Unthätigkeit der Spaltöffnungen berühren." Kohl, on the ground of direct observation, further denies Wiesner's statement that the stomata of Hartwegia remain open in the dark.

It is obvious that in this controversy, as in the other arguments previously presented, the assumption is made, usually tacitly, that if the stomata are "closed," which must be taken to mean nearly closed, a low rate of transpiration must ensue, and if a high rate is observed, that the stomata are open.

So far as I am aware, in those cases in which the stomata have lent themsalves to direct observation, the attention has been directed rather to the responses of these organs to different stimuli than to their condition as related to different rates of transpiration, and when this point has been raised the same assumption has been made-that the amount of water transpired is conditioned chiefly by the size of the stomatal openings.

There is, however, evidence to indicate that Wiesner's view is the correct one. Unger (r 862) showed that when the transpiration of one surface of a 
leaf is stopped, the rate of transpiration in the other surface becomes great enough to remove all the water-vapor which otherwise would have escaped from both sides; and similar evidence was offered by Comes (I878), who found that the total amount of water lost through both sides separately was greater than through both sides at once. It is, however, in the light of Brown \& Escombe's work, not at all necessary to assume a change in the stomata to account for Unger's and Comes's results, since the diffusion capacity of the stomata was probably still greater than was necessary to allow the observed rates. The increased vapor tension within the leaf following on the blocking of stomata on one side would account for a higher rate on that side (Comes) than would be found if the stomata on both sides were free. Yet in these instances, as in all the others, while conclusive evidence that considerable changes in the rate of transpiration is given, evidence of equal value that the stomata undergo, or do not undergo, correlated changes is lacking.

By means of the foregoing data, a summary of which follows, this lack is to some extent supplied. The light responses are chiefly depended upon, since light affects both transpiration and the activity of stomata.

\section{SUMMARY.}

The rate of transpiration may increase after the maximum size of the stomatal pores is reached, and continue to fall after the stomatal closure (short of entire closure) is complete. This occurs normally during the daily course of events. That the stomata commence to close in the early afternoon might be regarded as the cause of the fall in transpiration, were it not for the fact that an increase in the rate of transpiration may occur (as it did, e.g., under the influence of chloroform) while a static stomatal condition prevails. This conclusion accords with the calculation of Brown \& Escombe, which showed that the maximum diffusion of water-vapor from the leaf of the sunflower (Helianthus) was only one-sixth of the possible maximum in view of the number and size of the stomata. W This clearly indicates that changes in the rate of transpiration within certain wide limits is determined, when the stomata are not shut, not by these organs, but by some other means or condition.

Wide fluctuations in the rate of transpiration may occur without change in the size of the stomatal pores when the period of stimulation is brief. These fluctuations may be, as they usually are, accompanied by incommensurate changes in the pores, when the period of stimulation is sufficiently prolonged.

The slow opening of the stomata as compared with the rapid rise in the transpiration rate (as seen, e.g., in experiments 63-66) when the plant is placed in the light might be interpreted as a check on the transpiration, if, at any moment during opening, the greatest possible rate of transpiration occurred. 
This, however, is probably not true, since positive change in transpiration rate in the same amplitude may occur without stomatal change, or the rate may continue to increase after cessation of stomatal opening. The limitation of the transpiration rate at its maximum in the daily program might also be interpreted as due to the maximal stomatal opening but for the same objection, the truth of which is indicated by Brown \& Escombe's observations on Helianthus and my own on Fouquieria.

The rate of transpiration in the plants here studied also varies in successive time units under constant external conditions, and without illumination, as was recently observed in certain other plants by Curtis (1902). The rates are, however, not correlated with stomatal movements, which are very slow, if they occur at all, in darkness. The slight normal opening might be called upon to interpret a commonly occurring rise in transpiration rate after midnight or somewhat later, but it is impossible to believe that the lowering of the transpiration rate, after the hour of the maximum of induced rhythm (see, e.g., figs. $2 \mathrm{I}, 22$, and 23), is caused by stomatal regulation.

The possibility of such fluctuations occurring independently of stomatal changes makes it impossible that in these plants stomatal regulation of an effective kind may be said to take place. Livingston suggested that the regulation which he believed to occur in a desert species of Euphorbia, resulting in the maximum transpiration rate being reached before the maximum evaporation rate (of water from a porous shell) may perhaps be due, among other things, to stomatal activity. I have examined the stomata of this plant with a view to obtaining evidence on this point, but to my surprise I

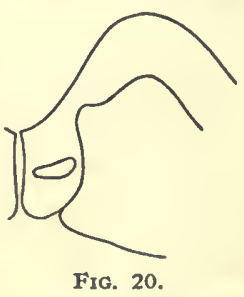
find very little observable stomatal movement. The cuticle of this plant is very thick indeed, and the upper and under walls of the stomata are similarly indurated. So thick are the walls of the stomata that but a small amount of movement seems possible. Fig. 20 shows the stomata of Euphorbia sp. in transverse section. The profile of one guard-cell is shown. The distribution of the stomata (upper epidermis, 75 to Ioo per square millimeter; lower epidermis, I 50 to I 75 per square millimeter) would indicate that the leaf movements might be more effective if they occur at the proper times, thus lending weight to Livingston's further suggestion that these movements may be regulatory, and in this way be a factor in determining the rates of relative transpiration.

Stomatal movement, correlated with that of the leaf or leaflet, may, however, occur. Wilson \& Greeman (1892) report that in Melilotus on a "very hot morning" the stomata of the vertically placed leaflets were "all without exception" closed, while under alum and ice screens, with a temperature of $8^{\circ}$ C. lower than without, the stomata were "well open." The authors believe 
that the vertical position of the leaflet greatly lessens the transpiration; and if the stomata were tightly closed, the same end would be furthered.

A further consideration of the facts which pertain to plants like the $E u$ phorbia* here mentioned leads me to the belief that all is not said on the subject of the regulatory effect of stomata, when we have in mind openings as wide as a micron or more. In view of Brown \& Escombe's data it may very well be that the problem of stomatal regulation relates to stomata with very minute openings, and perhaps to larger stomata when nearly closed. There are facts which would seem to exclude the latter, as these minute openings are not found, when the plant is normal, at the times when regulation is supposed to occur. This does not exclude, however, the possibility that stomata, the openings of which are beyond the present practical limits of micromeasurement, may not exert a regulatory effect upon transpiration. Such a problem as this involves a most rigorous physical research of the type of Brown \& Escombe, but pushed to far more refined limits and applied extensively to the actual conditions found in the plants themselves.

*The stoma of this plant measures about i 5 by 9 micra; pore, 4 micra long. In water the pore opens to about I micron wide. 


\section{INDUCED RHYTHM IN TRANSPIRATION.*}

Although it was no part of the contemplated scope of the present paper to pay attention to transpiration as such, it has happened that a not inconsiderable amount of evidence bearing upon the phenomenon of induced rhythm has been gathered, especially from experiments with Fouquieria splendens. By "induced rhythm" is meant an autogenic fluctuation in the rate of transpiration corresponding to the daily fluctuation in the normal rate, or periodicity, as ordinarily conceived, or as Kohl (I886, p. 48) puts it "eine von äusseren Einflüssen unabhängige Periodicität." A résumé of the literature pertinent to the question may be found in Kohl (loc. cit.) and in Burgerstein (1887, pp. 53, 449; 1904, p. 150). Briefly summarized, the positive view of Unger, as formulated in $185^{2}$, has been supported by Sachs (1859), Sorauer ( 1880 ), Kohl (loc. cit.), and Curtis (1902), and has been denied, on apparently slender grounds, by Barenetsky (1872) and Eder (1875). $\dagger$ But little unequivocal evidence has, however, been offered, that supplied by Curtis being, in the light of my own work, by far the most important. For my purpose I need not dwell upon any of the data furnished by previous students, except those of Curtis, and, in view of the support offered by him to certain conclusions advanced by Francis Darwin (1898), upon the work of this investigator also.

Curtis's views on this point are based upon two series of experiments carried out upon (a) several plants kept under constant conditions in darkness, their hourly rate of transpiration being determined by weighing; and $(b)$ plants kept under the same conditions, but exposed to given periods of illumination in the morning and in the afternoon.

Of the latter series of experiments (loc. cit., p. 37I) all but two must be regarded as insufficiently critical for the present purpose. These two consisted of exposing two plants (Aucuba japonica and Justicia elegans) to electric illumination of constant value for the period of one hour in the morning and in the afternoon. Otherwise, the plants were kept under the constant conditions above mentioned. It was found that the response in the morning hour was absolutely and relatively greater for both plants than in the afternoon hour.

Curtis prefers to refer this behavior to "a pronounced periodicity in the stomata" and comes in this regard to the support of Francis Darwin (1898). Of this phase of the question I speak elsewhere (p.74). Similarly, I believe that Francis Darwin's own experiments must be interpreted as bearing rather

*Presented in brief form before the Botanical Society of America, Dec., 1904.

†Other authors have found induced rhytlim in absorption of water and bleeding (see Kohl's work, loc. cit.) but their results have no direct bearing on the present problems. 
upon the question of transpiration than stomatal response. Regarded in this light they become open to the objection, equally applicable to the majority of Curtis's experiments (though not to those above mentioned), that the difference in normal morning and afternoon illumination introduces a source of error. Nor is the element of fatigue considered at all by either. I must say further that I believe Burgerstein is quite mistaken in his evaluation of the evidence above considered (loc. cit., p. 153) and appears to have overlooked that which we shall now consider.

The data which Curtis (loc. cit., p. 367) derived from plants kept in constant darkness are, however, distinctly pertinent. I quote his conclusions as formulated by himself :

Occasionally there is apparent rhythm corresponding to the daily periodicity, but on the other hand it not frequently happens that there may be an irregular decline from the start, or the curve may be characterized by a rise or fall without reference to the period of the day.

It would appear that Curtis was expecting, on a priori grounds, a rhythmic maximum to fall at or about the hour at which the normal daily maximum occurs. This is what Unger believed to occur, but as Burgerstein has pointed out (loc. cit., p. I5 I), his experiments were not carried out with sufficient rigor. That at present unexplainable fluctuations of transpiration rate occur even under conditions as constant as we have been able to get them is a matter of general observation, and that for some plants some maxima will fall at or about the hour of the normal maximum is, so far as our understanding at present goes, a matter of chance, and must be so regarded. A few instances in different plants of a time correspondence of this kind may or may not be properly regarded as rhythm. From my own experience, however, it seems more logical to look for a maximum nearer to the hour at which the stimulus which leads to the increased transpiration response of daytime is normally applied, namely, at or somewhat later than at sunrise.* This I had satisfied myself to be, in fact, the case, and on examining Curtis's data I found that he too had noted on several occasions that pronounced maxima may be found early in the morning, between 5 and 9 o'clock, an observation which Curtis seemed to have attached but little importance to, but which in the light of the evidence now to be presented appears to be of great importance as bearing on the problem under discussion.

This evidence, as will be manifest upon examination, possesses a remarkable degree of uniformity. The manner by which it was obtained has been fully described (see p. I8).

*The fact that Fouquieria splendens produces a crop of leaves in December and January should enable us to test this view, for, since the sun rises at this time about 2 hours later than in the summer, the maximum of induced rhythm in the winter leaves should be pushed forward accordingly. 
Only one species, Fouquieria splendens, was used, and while the conclusions drawn may at present be applied solely to this form, the data which support them appear unequivocal. The only apparent source of criticism lies in the fact that the dark room in which the experiments were conducted had to be entered, thereby admitting a little light, and that a candle was used in making the readings. The dark room was, however, entered through another small room, to which but little light was admitted, and further, the experimental room was entered as rapidly as possible. That neither the entrance of a very small amount of light nor the use of the candle vitiated the results would seem clear from the character of the curves derived. Had the light affected the transpiration sensibly it would have been discovered in a repeated positive response, which I failed to detect. This answer is again strengthened by the fact that, as will be seen from the data below, several pieces on different occasions behaved in the same way simultaneously.

\section{EXPERIMENTS.}

In all experiments cut shoots of Fouquieria splendens set in vertical burette potometers were used. The temperature of the dark room* was controlled within $\mathrm{I}^{\circ} \mathrm{C}$. during the whole period and no appreciable variation of temperature took place during the several critical hours, say from 3 a. m. till 9 a.m. The relative humidity was also constant, as indicated by a hair hygrometer (Lamprecht polymeter).

Experiment 56.-July I8, 1904 (fig. 21). Placed in shade of laboratory porch till II p. m., July 18, when it was placed in dark room and there remained till 2 p. m., July 19; then replaced in the light.

TABLE 37.-Hourly transpiration rate.

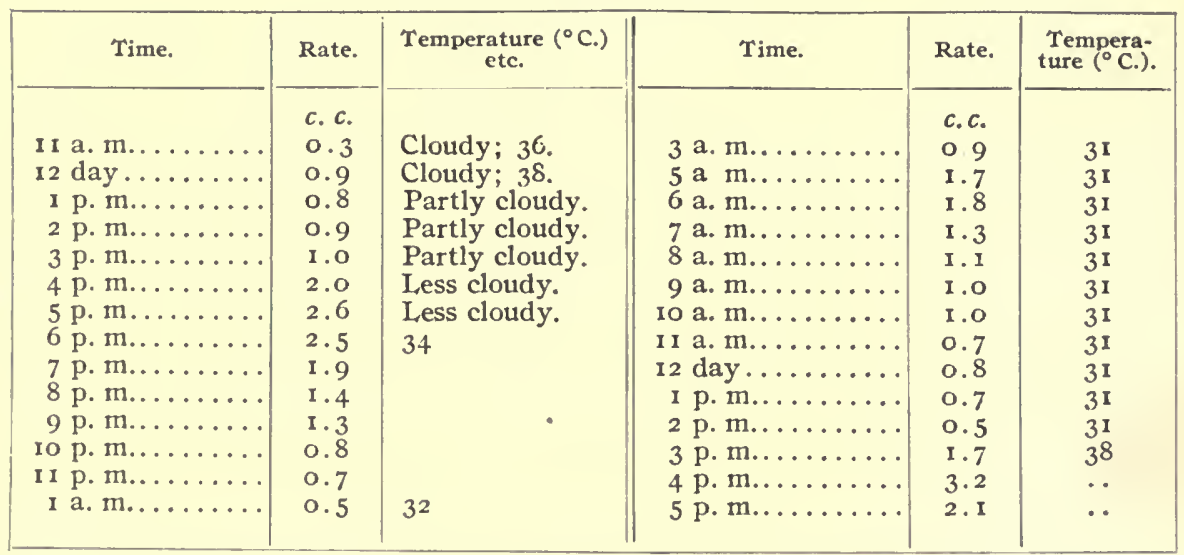

*Experiments 75 to 79 (p. 71 ) were not placed in the dark room. 
The rate commenced to increase shortly after $\mathrm{I}$ a. $\mathrm{m}$. and rose to an early morning maximum at 6 a. m., July 19.

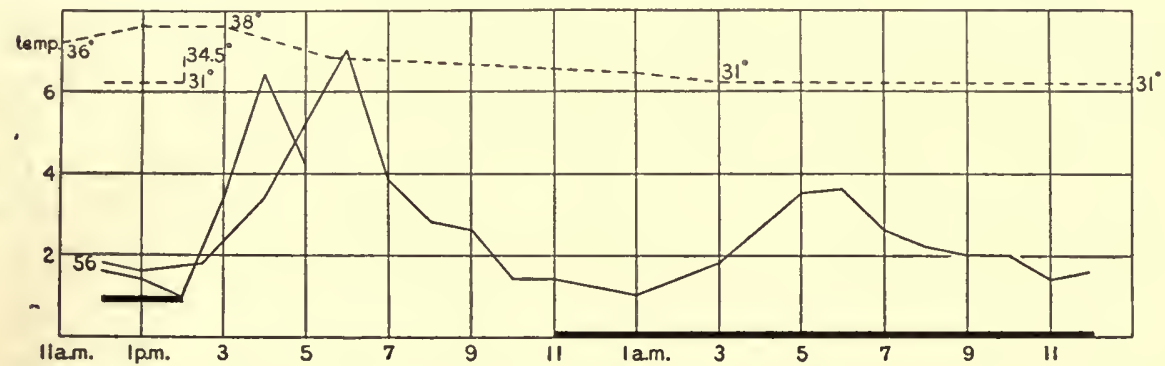

Fig. 21.-Curve for experiment 56. Fouquieria splendens. The temperature during the experiment is shown by the broken line.

Experiments 58, 59, and 60.-July I8-19, I904 (fig. 22). Set up at 5 p. m.; on laboratory porch till I p. m., then placed in dark room, of which temperature was $32.5^{\circ} \mathrm{C}$., the same as without; dark room remained open until $3 \mathrm{a}$. m., when it was closed; no variation at this time $\left(32.5^{\circ} \mathrm{C}\right.$.) until close of experimentation.

Experiments 62,63, and 64 (fig. 23) were conducted simultaneously with the above, but remained without on laboratory porch till $3 \mathrm{a} . \mathrm{m}$.

Experiments 65 and 66 (controls) were identical with the foregoing in all respects, but were alıwed to remain on laboratory porch under normal diffused illumination.

NoTE. - The maxima occurring in experiments 58 to 60,62 to 64 , at I p. m., toward the close of the experiment, were due to brief exposures to light.

\section{TABLE 38.-Hourly rates of transpiration.}

[The hourly rates given are derived by measurements of uncalibrated tube potometers.]

\begin{tabular}{|c|c|c|c|c|c|c|}
\hline Time. & No. 58 . & No. 59. & No. 60 . & No. 62 . & No. 63. & No. 64 . \\
\hline 8 p.m......... & 2.0 & I. 8 & 1. 8 & I. 5 & 2.0 & 2.2 \\
\hline 9 p. m.......... & 2.0 & I. 7 & 1. 65 & I. 4 & I. 8 & I. 8 \\
\hline Io $\mathrm{p} . \mathrm{m} . \ldots \ldots \ldots$ & I. 7 & I. 5 & I. 5 & 1.2 & I. 6 & I. 5 \\
\hline I $\mathrm{p}, \mathrm{m} \ldots \ldots \ldots$ & I. 7 & I. 6 & I. 55 & I. 2 & I. 7 & I. 5 \\
\hline I a.m......... & 2.0 & I. 6 & 1.6 & I. I & I. 55 & I. 4 \\
\hline 3 a.m......... & 3.2 & I.9 & 3.0 & I.O & I. 5 & I. I 5 \\
\hline 5 a.m.......... & $7 \cdot 4$ & 4.0 & 5.6 & 2.0 & 2.35 & $2 . I$ \\
\hline 6 a.m.......... & 8.7 & $4 \cdot 9$ & 5.2 & $3 \cdot 4$ & 2.5 & $2 \cdot 4$ \\
\hline 7 a.m......... & $7 \cdot 3$ & $4 \cdot 3$ & 4.0 & $2 \cdot 3$ & $2 \cdot 3$ & 2.2 \\
\hline 8 a.m........... & 7.0 & 4.0 & 3.8 & 2.4 & 2.4 & 2.2 \\
\hline 9 a.m......... & 6.0 & $3 \cdot 5$ & $3 \cdot 4$ & 2.0 & 2.1 & I. 8 \\
\hline Io a. m.......... & $4 \cdot 9$ & 2.9 & $2 \cdot 7$ & I. 7 & I. 9 & I. 45 \\
\hline I I a. m......... & $4 \cdot 4$ & 2.6 & 2.2 & I. 5 & I. 7 & I. 35 \\
\hline 12 day.......... & $3 \cdot 9$ & $2 \cdot 3$ & I. 9 & I. 3 & I. 6 & 1.2 \\
\hline I p. $111 \ldots \ldots \ldots$ & $3 \cdot 5$ & 2.4 & I. 9 & I. 6 & 2.1 & I. 85 \\
\hline 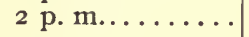 & 2.9 & 1.9 & I. 7 & I. 2 & I. 8 & I. 75 \\
\hline 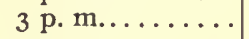 & 8.0 & $4 \cdot 3$ & 5.0 & 2.7 & 3.8 & 4.0 \\
\hline 4 p. m.......... & 10. 8 & 6.4 & $7 \cdot 7$ & 4.1 & 5.6 & 5.6 \\
\hline 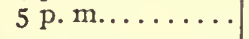 & $9 \cdot 9$ & 5.8 & 6.2 & 4.0 & $5 \cdot 5$ & $5 \cdot 1$ \\
\hline
\end{tabular}

Stomatal pores measured at 9 a.m., 2 to 6 micra wide in all; at ${ }_{1} 2^{\mathrm{h}} 15^{\mathrm{m}}$ p. m., 2 to 6 micra wide in all; at $12^{\mathrm{h}} 45^{\mathrm{m}}$ p. m., 2 to 6 micra wide in 64 . 


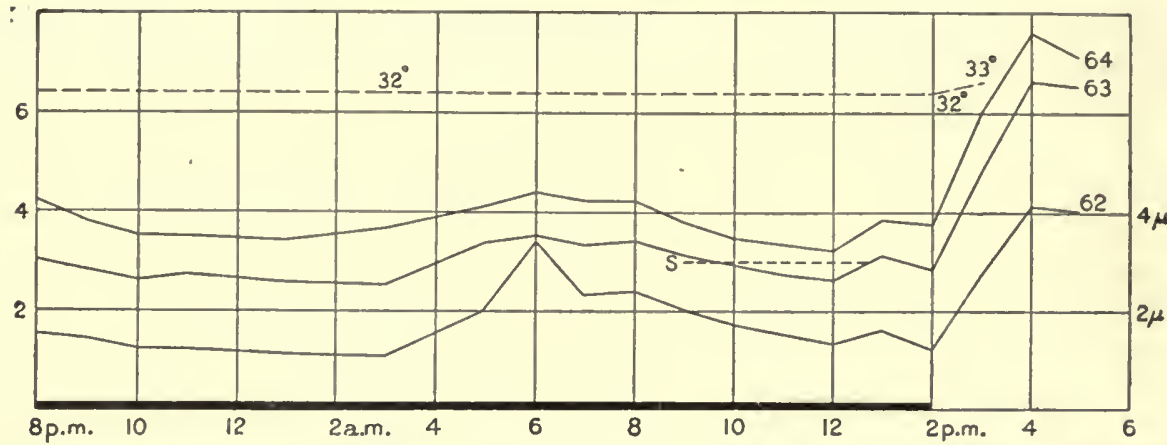

FiG. 22.-Curves for experiments 62,63 , and 64 . Fouquieria splendens, s, curve of stomatal condition.

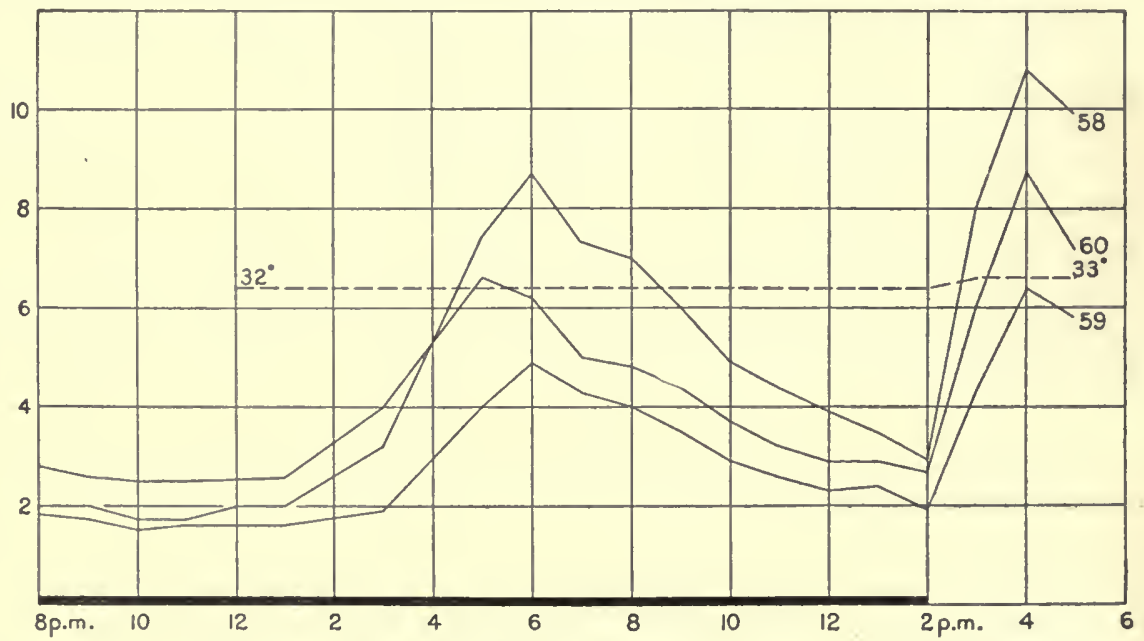

F1G. 23.-Curves for experiments 58, 59, and 60. Fouquieria splendens.

Experiments 65 and 66.-July 18, 19, 1904 (fig. 24). The curve of 65 is normal throughout; 66 was placed in dark room at $\mathrm{II}^{\mathrm{h}} \mathrm{I}^{\mathrm{m}}$ and replaced in light at $\mathrm{II}^{\mathrm{h}}{ }^{\mathrm{m}} 5^{\mathrm{m}}$, 10 minutes later. Readings in tube-lengths reduced to hourly rates.

TABLE 39.-Rate of transpiration.

\begin{tabular}{|c|c|c|c|c|c|c|c|}
\hline \multirow{2}{*}{ Readings taken at- } & \multicolumn{2}{|c|}{ Experiment. } & \multirow{2}{*}{$\begin{array}{l}\text { Tem- } \\
\text { pera- } \\
\text { ture } \\
\left({ }^{\circ} \mathrm{C} .\right) .\end{array}$} & \multirow{2}{*}{ Readings taken at- } & \multicolumn{2}{|c|}{ Experiment. } & \multirow{2}{*}{$\begin{array}{l}\text { Tem- } \\
\text { pera- } \\
\text { ture } \\
\left({ }^{\circ} \mathrm{C} .\right) .\end{array}$} \\
\hline & 65 & 66 & & & 65 & 66 & \\
\hline 8 p. m........... & I. 5 & I. 8 & $\ldots$. & ro a. m........... & 5.6 & 6.9 & ... \\
\hline 9 p. m......... & I. 3 & I. 7 & $\ldots$ & I I a. m........... & 7.0 & 8.5 & $\ldots$ \\
\hline Io p. m........... & I. I 5 & I. 3 & $\ldots$ & $\mathrm{II}^{\mathrm{h}}{ }_{1} 5^{\mathrm{m}}$ a. m........ & $\ldots \ldots$ & 9.2 & $\ldots$ \\
\hline I I p. m............ & I. 2 & I. 3 & $\ldots$ & 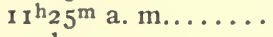 & $\ldots$ & 6.6 & $\ldots$ \\
\hline 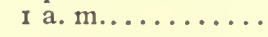 & I. I & I. 2 & 29 & 1 2 day............ & $7 \cdot 4$ & $7 \cdot 7$ & ... \\
\hline 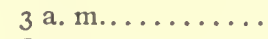 & I.O & 0.95 & 28 & I p. m........... & 7.0 & $8 \cdot 5$ & $\cdots$ \\
\hline 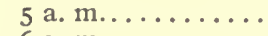 & I. 4 & 1. 75 & $\ldots$ & 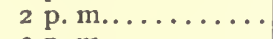 & 6.9 & 8.7 & $\cdots$ \\
\hline 6 a. m............ & 2 & 2.7 & $\ldots$ & 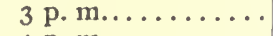 & $7 \cdot 9$ & $\cdots$ & $\cdots$ \\
\hline 7 a.m........... & $2 \cdot 35$ & 3.1 & ... & 4 p. m.......... & 6.3 & $7 \cdot 7$ & 33 \\
\hline 8 a. m........... & 2.9 & $3 \cdot 7$ & $\cdots$ & 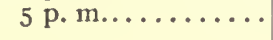 & 5.6 & 6.6 & $\cdots \cdots$ \\
\hline 9 a. m........... & 4.2 & $5 \cdot 3$ & 32 & & & & \\
\hline
\end{tabular}




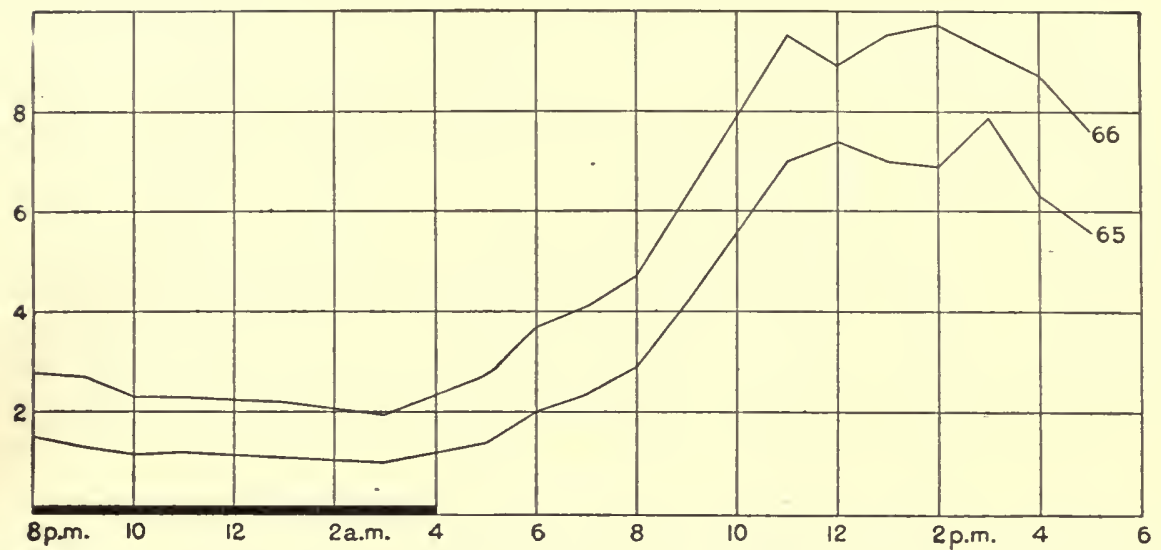

FIG. 24.-Curves for experiments 65 and 66. Fouquieria splendens,

In all the above eight cases the rate commences to increase shortly after midnight and rises to an early maximum, in five cases at $6 \mathrm{a} . \mathrm{m}$., and in one (60) at $5 \mathrm{a} . \mathrm{m}$. In the controls a normal behavior is shown, the maximum being reached at 12 day and $3 \mathrm{p}$. $\mathrm{m}$. The drop in 66 between I $\mathrm{a}$. $\mathrm{m}$. and I 2 day was due to a i 5 -minute exposure to darkness.

Experiments 73, 74.- July 21, 1904. Ocotillo. Burette potometer; pieces placed in dark room at $10^{\mathrm{h}} 3 \mathrm{O}^{\mathrm{m}} \mathrm{p}$. m., reading commenced at $6{ }^{\mathrm{h}} 3 \mathrm{o}^{\mathrm{m}} \mathrm{a} . \mathrm{m}$., a maximum was developed at $7^{\mathrm{h}} 3 \mathrm{O}^{\mathrm{m}}$ a. $\mathrm{m}$. (See fig. 18 , of experiment 74 only.)

Experiments 80, 81, and 82.- Aug. IO-II, I904 (fig. 25). Placed in dark room at 9 p. m.; placed in light at ro a. m., after 15 hours of total darkness; temperatures given during these hours are those of dark room.

Experiment 83 , fig. 26 , differed only in being placed in the light for 5 minutes, at $9^{\mathrm{h}} 3 \mathrm{om}^{\mathrm{m}}$ a. m., Aug. II.

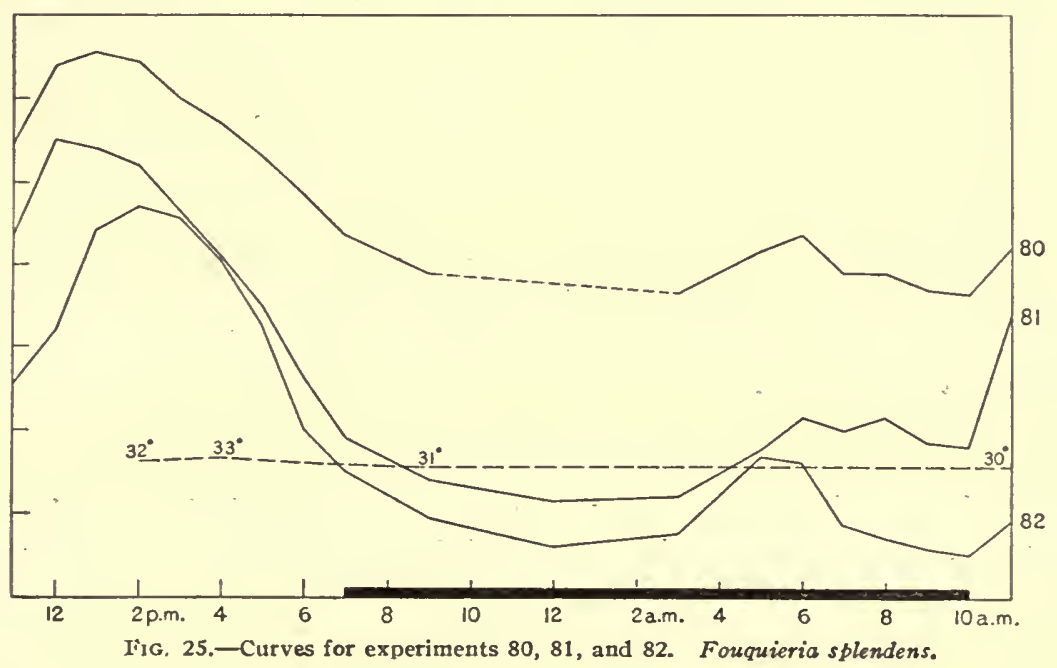




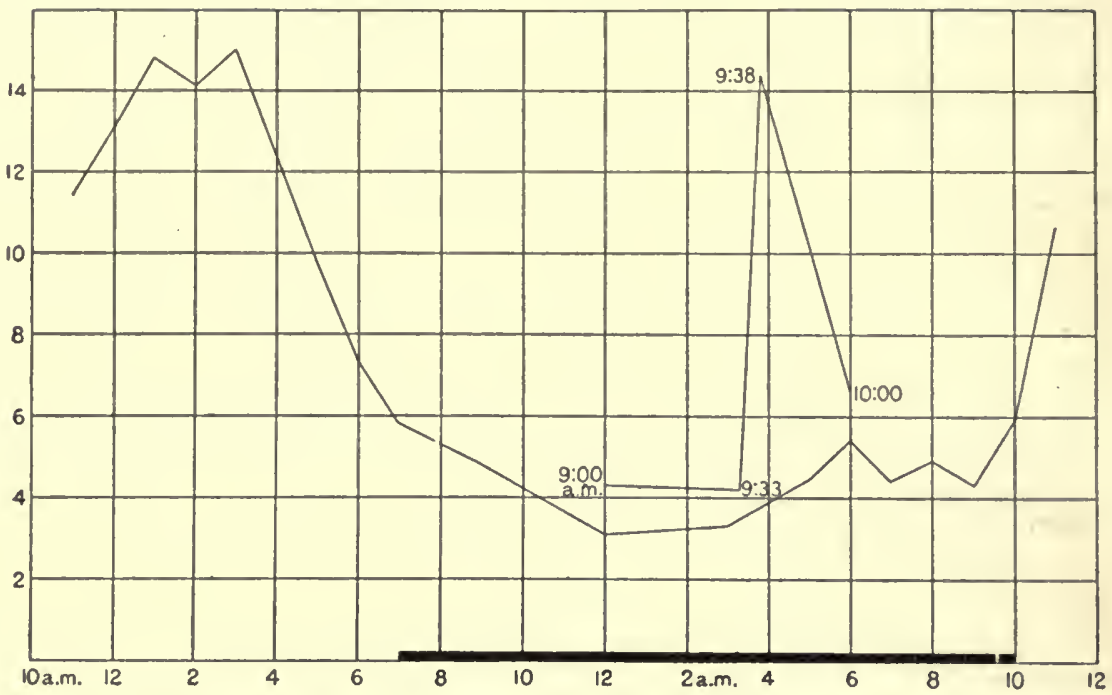

FIG. 26.-Curve for experiment 83. Fouquieria splendens. The short curve shows the response when the piece was placed for a brief interval in the light between 9 and $10 \mathrm{a} . \mathrm{m}$.

TABLE 40.-Rates of transpiration.

\begin{tabular}{|c|c|c|c|c|c|c|c|c|c|c|c|}
\hline Time. & No. 80 . & No. 81 . & No. 82 . & No. 83 . & $\begin{array}{l}\text { Tem- } \\
\text { pera- } \\
\text { ture } \\
(\text { 'or.). }\end{array}$ & Time. & No 80 . & No.81. & No. 82 . & No. 83 . & $\begin{array}{l}\text { Tem- } \\
\text { pera- } \\
\text { ture } \\
\left.\text { ("o }{ }^{\circ} \mathrm{C} .\right)\end{array}$ \\
\hline I I a. m. . & $4 \cdot 9$ & $7 \cdot 7$ & $5 \cdot I$ & I I . 4 & $\cdots$ & 3 a. m..... & I. 3 & I. 4 & I. 5 & $3 \cdot 3$ & 31 \\
\hline I 2 day. . & 6.8 & 10.0 & 6.4 & 13.1 & . & 5 a. m..... & $2 \cdot 3$ & 2.5 & $3 \cdot 35$ & $4 \cdot 45$ & 3 I \\
\hline I p. m.... & 7.1 & 9.8 & 8.8 & 14.8 & . . & 6 a. m..... & 2.7 & $3 \cdot 3$ & 3.2 & $5 \cdot 4$ & 31 \\
\hline 2 p. m.... & 6.9 & 9.4 & 9.4 & 14.1 & 32 & 7 a.m..... & I. 8 & 3.0 & I. 75 & $4 \cdot 4$ & 31 \\
\hline 3 p. m.... & 6.0 & 8.3 & 9.1 & 15.0 & . & 8 a.m..... & I. 8 & $3 \cdot 3$ & I. 4 & $4 \cdot 9$ & 3 I \\
\hline $4 \mathrm{p} \mathrm{m} . .$. & 5.4 & 7.1 & 8.1 & 12.4 & . & 9 a. m.... & 1.4 & 2.7 & I. I 5 & $4 \cdot 3$ & 3 I \\
\hline 5 p. m.... & 4.6 & 6.0 & 6.5 & $9 \cdot 7$ & . & $9^{\mathrm{h}} 33^{\mathrm{m}}$ a.m. & $\cdots$ & ... & $\ldots$ & 4.2 & - \\
\hline 6 p.m... & $3 \cdot 7$ & 4.15 & 4.0 & $7 \cdot 3$ & - & $9^{\mathrm{h}} 3^{8^{\mathrm{m}}}$ a.m. & ... & $\cdots$ & $\cdots$ & $14 \cdot 4$ & . \\
\hline 7 p. m.... & 2.7 & 2.85 & 3.0 & 5.8 & . & Io a. m..... & I. 3 & 2.6 & I .O & 6.6 & $3^{I}$ \\
\hline 9 p: m... & I. 8 & I. 8 & I. 9 & 4.8 & $3 I$ & I I a. m..... & 2.4 & 6.7 & I.9 & 10.7 & 33 \\
\hline 12 night. & $\cdots$ & I. 3 & 1.2 & $3 \cdot I$ & 31 & & & & & & \\
\hline
\end{tabular}

In all cases an early morning maximum was developed at 6 o'clock, except in No. 82 , in which the maximum falls at 5 o'clock. The rates commence to increase at about $\mathrm{I}$ a. $\mathrm{m}$.

Experiment 15I, 1905.

The early morning maximum was attained at 4 o'clock and the rate remained constant till 7 o'clock, after which it fell off till 3 p. m. (see fig. 18). 
Experiments 163, 164, and 165.-July 14, 15, 1905(fig. 16). Pieces in vertical tube potometers (burettes) set up in the afternoon; readings commenced at $8 \mathrm{~h}_{2} \mathrm{~m}$ p. m. Placed in dark room at midnight, where they remained under constant conditions of temperature, relative humidity, and darkness.

In all three curves the early morning maximum is clearly shown as follows: I63 at $6^{\mathrm{h}} 2 \mathrm{O}^{\mathrm{m}}$ a. m. ; 164 at $4^{\mathrm{h}} 2 \mathrm{O}^{\mathrm{m}}$, and at $6^{\mathrm{h}} 2 \mathrm{O}^{\mathrm{m}}$ a. m.; 165 at $7^{\mathrm{h}} 2 \mathrm{O}^{\mathrm{m}}$ a. $\mathrm{m}$. No. 164 shows a marked irregularity at $4^{\mathrm{h}} 2 \mathrm{O}^{\mathrm{m}}$ a. m., producing a maximum which is unusual if not abnormal. Otherwise the character of the curve consists well with that of the other two. It is significant, however, that the irregularity occurred in the early morning, near the time when the maximum of induced rhythm is to be expected in the plant.

Experiments 172 to 175 , inclusive.-July 18, 1905.

These four pieces, attached to burette potometers, were in the dark room from 8 p. m., July 18 , till i 2 day, July i9. All showed early morning maxima as follows (see fig. I3): I 72 at 7 a. m.; 173 at 7 a.m.; 174 at 4 and 6 a.m. (cf. experiment 164, p. 51 ); 175 at 7 a. m.

TABLE $4 \mathbf{r}$.- Hourly rates of transpiration.

\begin{tabular}{|c|c|c|c|c|c|c|c|}
\hline \multirow{2}{*}{ Readings taken at- } & \multicolumn{3}{|c|}{ Experiments 75 and 76.} & \multicolumn{4}{|c|}{ Experiments 77 to 79 . } \\
\hline & No. 75. & No. 76. & $\begin{array}{l}\text { Tempera- } \\
\text { ture }\left(^{\circ} \mathrm{C} .\right)\end{array}$ & No. 77. & No. 78. & No. 79. & $\begin{array}{l}\text { Tempera- } \\
\text { ture }\left({ }^{\circ} \mathrm{C} .\right)\end{array}$ \\
\hline I $\mathrm{r}$ a. m....... & 51.8 & 18.8 & 30 & 23.4 & 23.1 & 9.3 & $\ldots$ \\
\hline 12 day......... & 47.8 & $\ldots$ & $\ldots$. & 26.8 & 28.7 & I I. 3 & $\ldots$ \\
\hline I p. m........ & 41.8 & $* 33.1$ & ... & 19.7 & I5. I & II. 2 & $\ldots$ \\
\hline 2 p. m........ & $35 \cdot 3$ & 14.8 & $\ldots$ & 14.2 & 11.2 & 10.5 & $\ldots$ \\
\hline 3 p. m......... & 20.2 & 10.4 & $\ldots$ & 10. 3 & $9 \cdot 4$ & $9 . I$ & $\ldots$ \\
\hline 4 p. m........ & 17.8 & 9.6 & 33 & 10.2 & 8.0 & $7 \cdot 4$ & ... \\
\hline 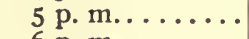 & 14.6 & 8.9 & $\cdots$ & 8.4 & 6.5 & $6 . x$ & $\cdots$ \\
\hline 6 p. m......... & $9 \cdot 4$ & $7 \cdot 4$ & ... & 6.7 & $4 \cdot 75$ & $4 \cdot 4$ & $\ldots$ \\
\hline 7 p. m......... & $4 \cdot 4$ & $4 \cdot 9$ & $\ldots$ & $4 \cdot 9$ & 3.0 & 2.9 & $\ldots$ \\
\hline 8 p. m........ & 2.2 & 2.8 & $3 I$ & 3.2 & I. 5 & I. 7 & $\ldots$ \\
\hline 12 night. ....... & 1.7 & I. 8 & $\ldots$ & 2.6 & I. 7 & I . 2 & $\ldots$ \\
\hline 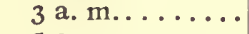 & 2.5 & 1.9 & $\cdots$ & $3 \cdot 5$ & 2.0 & I. I & $\cdots$ \\
\hline 5 a. m......... & $5 \cdot 7$ & $2 \cdot 3$ & 28 & $4 \cdot 4$ & 2.7 & 2.7 & $\ldots$ \\
\hline 6 a.m........ & 10.9 & 3.8 & $\cdots$ & $5 \cdot 2$ & $2 \cdot 3$ & 5.2 & $\cdots$ \\
\hline 7 a. m........ & 10.0 & 3.8 & $\cdots$ & $4 \cdot I$ & $2 \cdot 7$ & 4.0 & $\cdots$ \\
\hline 8 a.m........ & 15.0 & 4.65 & $\cdots$ & 5.2 & 2.45 & 4.6 & $3 I$ \\
\hline 9 a.m......... & 17.05 & $4 \cdot 4$ & 30 & $5 \cdot 3$ & $2 \cdot 5$ & $5 \cdot 5$ & $3 \mathbf{I}$ \\
\hline $9^{h_{1} 8^{m}}$ a.m..... & 21.6 & $(\dagger)$ & $3 \mathbf{I}$ & $\cdots$ & $\cdots$ & $\cdots$ & $\cdots$ \\
\hline $9^{h_{2} 6^{m}}$ a. m..... & $12 \cdot 75$ & $(\dagger)$ & $\cdots$ & $\cdots$ & $\ddot{\theta}$ & $\cdots$ & $\cdots$ \\
\hline Io a. m....... & 21.0 & $4 \cdot$ I 5 & 32 & $5 \cdot 5$ & 2.6 & 7.0 & 3 I \\
\hline I I a. m......... & 8.4 & 2.04 & 33 & $3 \cdot 3$ & I. 7 & $2 \cdot 4$ & $3 I$ \\
\hline
\end{tabular}

* Total for two hours. † Data lost.

The following are experiments with plants which were exposed to normal illumination, and are of interest in the present connection because of certain irregularities in rate which occur in the early morning hours. 


\section{Experiments 75 to 79, inclusive-August 10-1 I, 190.4 (fig. 27).}

Experiments 75 and 76 remained in the sunlight till 2 p. m., when the sky became overcast. Placed in the dark room at $9^{\mathrm{h}} \mathrm{I} 8^{\mathrm{m}}$ a. m., on August II; replaced in the light at $9^{\mathrm{h}} 25^{\mathrm{m}} \mathrm{a} . \mathrm{m}$.

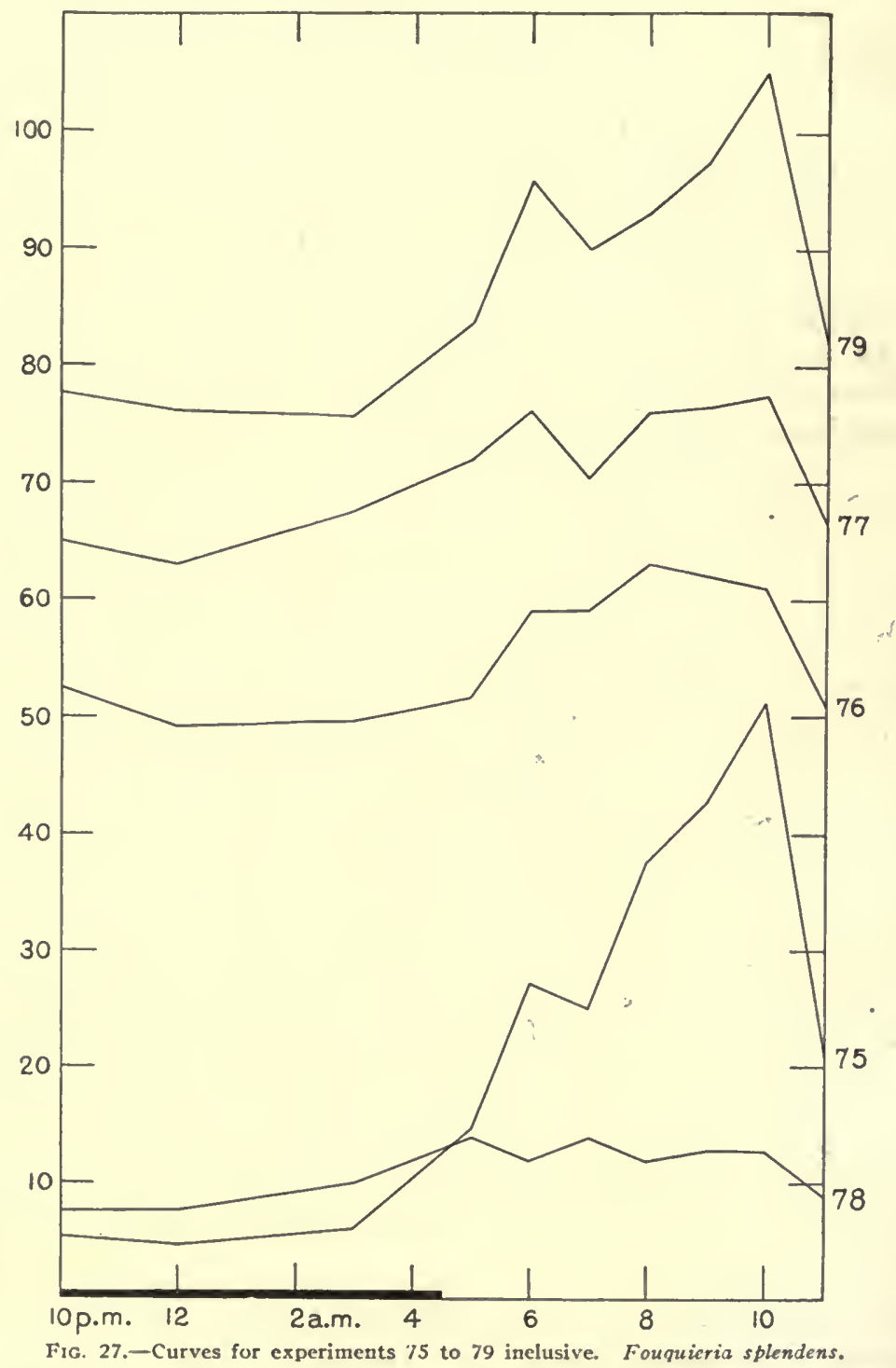

Experiments 77,78 , and 79 remained in the diffused light of the laboratory till I I a. m., August II, and then placed in the dark room.

In table $4 \mathrm{I}$ only hourly rates are given, in centimeters of tube length. 
In studying the behavior of the plants of experiments 75 and 79 it must be borne in mind that the conditions to which the pieces were exposed were quite normal for the time of year, that is, the temperature was steadily rising and the relative humidity, which is always low, steadily decreasing. In all cases an early morning low maximum is developed. Following the reduction of rate after the low maximum has been attained, there is a steady rise to the normal daily maximum.

$$
\text { Experiments } 176 \text { to } 179 \text {, inclusive.-July 18, 19, } 1905 .
$$

Exposed to normally increasing illumination, but all showed a low maximum at 4 a. m. (see fig. 13 and accompanying data).

\section{CONCLUSIONS.}

As I have shown under another caption (pp. 59 and 62), the evidence is lacking that the behavior of the ocotillo, as regards the fluctuations in the transpiration rate in the early morning when in total darkness, is due to stomatal activity with corresponding fluctuations. Similar changes of rate under normal illumination would seem, alone, to indicate this. Even should a small increase be shown to occur in the dimensions of stomata, it would still remain to show that this caused the fluctuation in transpiration rate, though the important question of a possible induced rhythm in stomatal movement would be answered.

It is possible that a slow increase in the dimensions of the stomata, such as probably occur during prolonged darkness, may account for the frequently seen slow increase in transpiration rate after midnight, but this will not explain, I believe, the production of a maximum followed by a reduction of rate. That such a change, though more pronounced, occurs in plants exposed to normal conditions would also be an objection to the explanation based on stomatal activity.

The constant occurrence of the early morning maximum in pieces kept in total darkness is very remarkable, and would seem to be properly interpreted as the expression of an induced rhythm. It would also appear, however, that the physiological changes which lead to the maximum commence long before the hour of normal daily stimulation at dawn. This rhythm appears to be quite independent of the rhythm in water absorption by the roots (Eberdt) and in bleeding (Hofmeister and others).

The best we can say at present is that the plant behaves qualitatively the same in total darkness as under normal conditions until an hour (usually near 6 a. m.) when, the normal stimulation being absent, the plant relapses to a low condition of activity characteristic of its darkness condition. Undoubtedly the early morning maxima observed by Curtis are the same thing. For the lack of a real explanation we must refer the behavior to the category of induced rhythm. 


\section{INDUCED RHYTHM IN STOMATAL MOVEMENT.}

Darwin favors the conclusion that there is exhibited by stomata an induced rhythm of movement. The evidence cited by him is found in the more rapid closure of stomata when darkened in the morning than in the afternoon, and conversely, the more rapid opening when, after being darkened, they are illuminated in the morning than when the illumination takes place in the afternoon.

Curtis (1902) supports Darwin (1 898), offering in evidence the data obtained in the study of transpiration. The exposure of plants when kept in the dark and subjected to a given period of illumination (this being a constant in the two cases in which electric light was used) in the morning and in the afternoon resulted in a greater response in the morning. This is interpreted by Curtis as an expression of stomatal response, but as the stomata were not examined directly the conclusion seems scarcely justified. The same objection may be urged, too, against Darwin's conclusions, for we may hold that the effect upon the hygroscope was due to a greater response in transpiration, without any change in the condition of the stomata. The evidence may, then, be regarded as evidencing induced rhythm in transpiration and not in stomatal action. Nevertheless, I am inclined, on a priori grounds, to support Darwin's view. The occurrence of rhythm in other processes (I believe that I have shown it to occur in transpiration) would lead us to expect it in the behavior of stomata, and there appears to be no reason why it should not. The evidence here presented bearing on this question is, however, rather more confusing than convincing.

TABLE 42.-Verbena ciliata.-Transverse diameter measurement of stomatal pores.

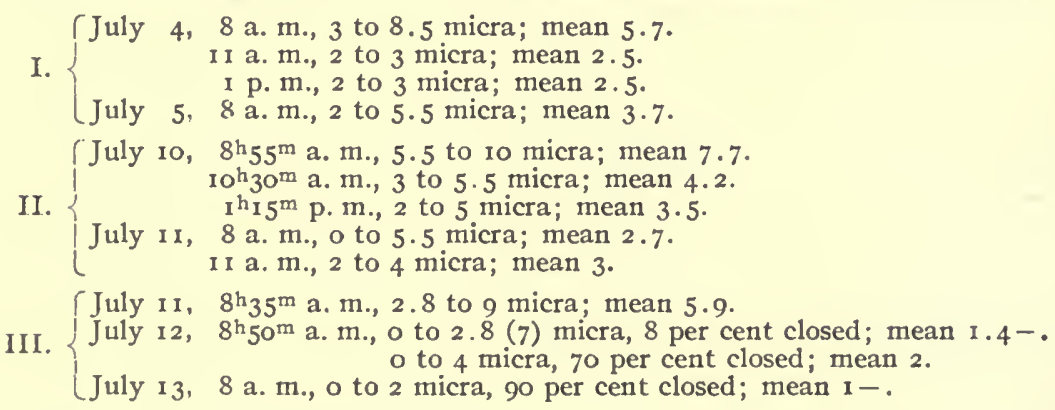

I was led to look for the occurrence of periodicity in stomatal movement upon finding a maximum in the transpiration curve at an early hour in the morning. The regularity of its occurrence in total darkness and with other conditions constant can only with difficulty be explained in any other way 
than by attributing it to induced rhythm. For reasons which I have insisted upon above it would be improper to infer stomatal periodicity from the transpiration curve. It is, on the other hand, very difficult to draw conclusions in these instances from measurements of the stomata, since the error in counting and measuring may well be greater than the total movement which it is the endeavor to measure. This, I think, is shown by the data in table 42 , obtained by placing verbena cuttings in the dark room.

The increase in size indicated in I and II, on the second morning in each case, might be interpreted as indicating a slight opening. The differences are not great, however, and must be accepted with caution, for the reason stated above. The fact that a few stomata on July $\mathrm{r} 2$ (III) were rather wide open, is not surprising, as occasional extremes are frequent. Disregarding the exceptional stomata, the personal error and the variation between leaves may be as great as the slight differences obtained, and thus we are forced to discard the data as unconvincing. On the other hand, the almost complete closure at the end of $\mathrm{I} 2$ hours (III) indicates that, if a tendency to rhythm is present, it is almost, if not quite, inappreciable by our means of measurement. Being dissatisfied with observations of this kind, I have attempted to get evidence of the sort employed by Francis Darwin.

Francis Darwin's method of examining stomata, by means of his hygroscope, after exposure to illumination and to darkness for the given period in the morning and afternoon, was modified in the fixation of pieces of epidermis at brief intervals during the observational periods and taking measurements. My method of making preparations should be mentioned here. The piece of epidermis to be examined, after sufficient fixation in absolute alcohol, was mounted in the same medium, and observed with a Leitz No. 7 objective and a micrometer eyepiece. The whole area of epidermis was rapidly surveyed to find the largest and smallest stomatal openings and the measurements of these taken. The average of these extremes was then applied, by eye, to a large number of stomata, and by this means a close estimate was made of the average size of the openings. If the measurements of the extremes are, say, $o$ and $8 \mathrm{micra}$, and the average opening found to be 4 micra, these extremes are given. Not infrequently, however, one or two in a hundred or more stomata are found to be, say, I 2 micra, while the remainder range between, say, 4 and 8 micra. These few exceptions are disregarded in plotting the data, though I have generally mentioned the extreme cases, putting the figures in parenthesis.

\section{EXPERIMENTS.}

The experiments were made with well-irrigated plants which showed no signs of wilting and chiefly with Ampelopsis quinquefolia, a "mesophytic" vine which is readily grown for ornamental purposes at Tucson. Other plants (Solanum sp., Iris sp.,) gave purely negative results. The transverse 
measurements given are maximum and minimum in eyepiece parts ( $\mathrm{I}$ part $=$ 3.5 micra) and are correct within an error of 0.25 part, and the averages deduced are very nearly correct. For darkening the parts to be studied, I used covered tin pails, sheathed with white cloth which could be kept wet, so keeping the temperature nearly normal.

June $2 \mathrm{r}$, r906.-Ampelopsis quinquefolia. Leaves attached to plant darkened in evening and illuminated for whole period indicated, forenoon $\left(9^{\mathrm{h}} 3 \mathrm{O}^{\mathrm{m}}\right.$ to $\left.\mathrm{I}^{\mathrm{h}} \mathrm{O}^{\mathrm{m}}\right)$ and afternoon, $\left(\mathrm{I}^{\mathrm{h}} 4 \mathrm{O}^{\mathrm{m}}\right.$ to $\left.3^{\mathrm{h}} 3 \mathrm{O}^{\mathrm{m}}\right)$. A different leaf was used for morning and afternoon. Plants on eastern exposure normally receive sunlight till i I a. m., while those on the west are shaded till that hour. Measurements given in parts ( 1 part $=3.5$ micra).

TABLE 43.-Stomatal pore dimensions. (Fig. 28.)

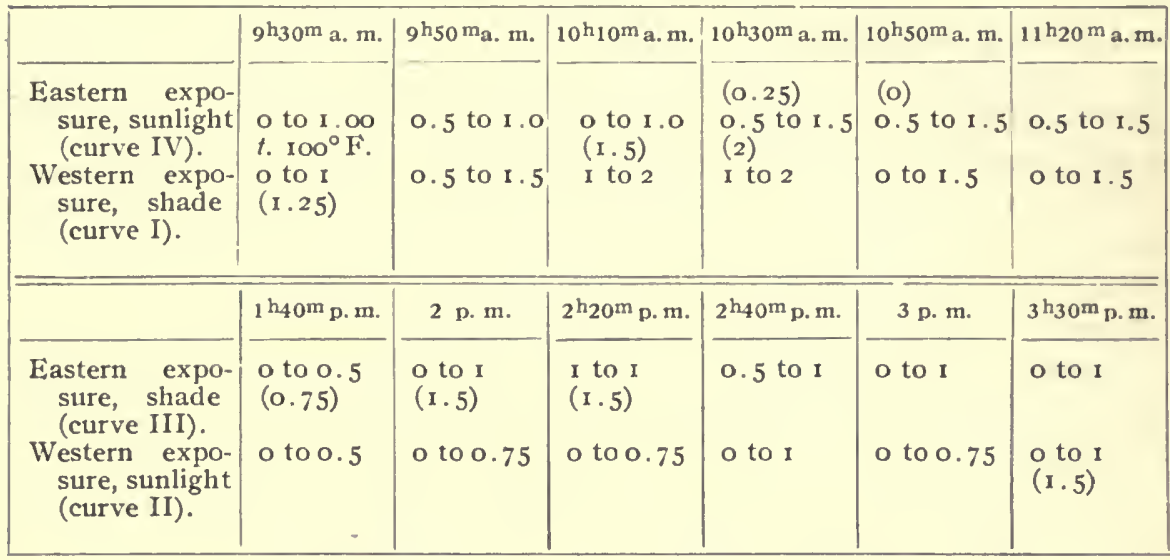

The measurements show that the average initial opening in the afternoon period of illumination was about one-half that of the morning period. Relatively to the initial opening, the greatest opening attained (in I hour) was the same. The ratios between the initial and maximum openings for the morning hours are I (shade), 2; IV (sun), 3. For the afternoon hour they are III (shade), 3; II (sun), 2.

The total average amount of movement was, however, greater in the morning, although case I (a.m.) and case II (p. m.) showed the same amount. It seems possible, from a mechanical point of view, that it would take longer to effect the same amount of opening when the stoma is closed, or nearly so, than when it is already well started in opening. It is usually easier to cause closing in a wide open than in a slightly open stoma. The amount of movement is, of course, a measure of internal forces, and these are the expression of protoplasmic activity. If this mechanical consideration is the fact, then we have no evidence that induced rhythm is present, the opposite of which would seem to be true at first glance, and which must be admitted as the possibly proper view and in agreement with Francis Darwin's interpretation of his experiments. 
Another point of interest is suggested by the fact that the stomata which were exposed to diffused light in the afternoon opened more than those on the sunny exposure. The plant is not a desert plant, and this result may be due to a masking effect of a heat reaction upon the light reaction. The temperature in direct sunlight at the time of the year when the data were obtained is great, and greater on the western exposure than upon the eastern, so that plants exposed to the western sun often show signs of wilting. Care was, however, taken to avoid using wilted material, the difficulty of which has been referred to elsewhere.

When, however, the stomata examined are taken from the plants under the normally increasing illumination and temperature, the reverse is found to

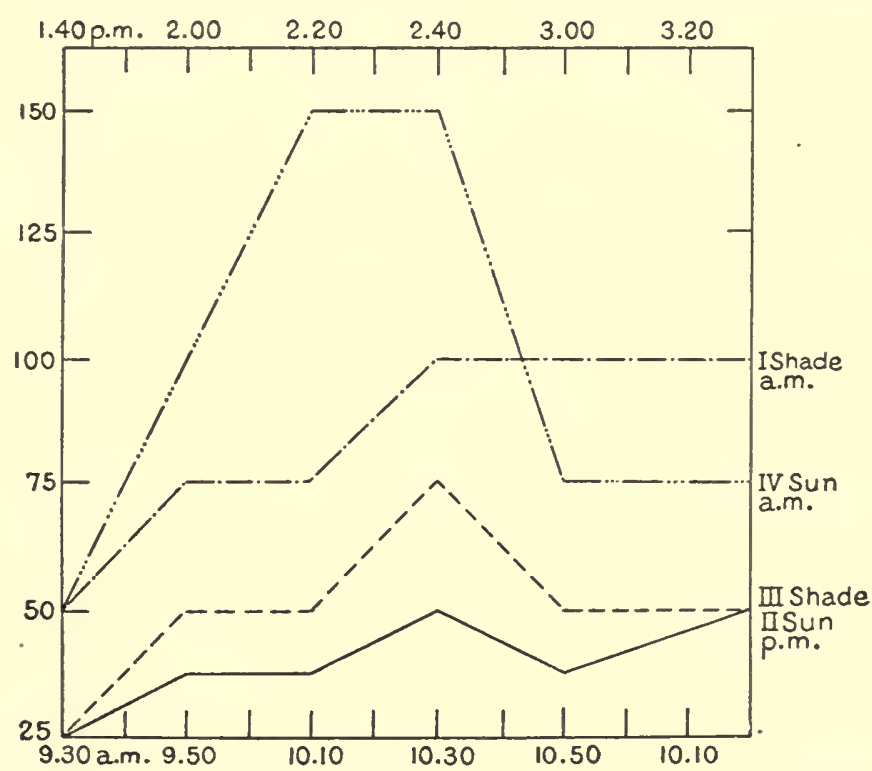

FIG. 28.-Curves constructed on data of table 43. Ampelopsis quinquefolia.

obtain, as shown by the measurements given. Stomata were collected at the same hours from the eastern and western exposures of the building. The plants on the eastern side were exposed to direct sunlight till about i I a. m.; that on the west side began to be illuminated directly at that hour. The stomata exposed to the early morning sun opened more rapidly than those in diffused illumination, and the maximum was attained an hour earlier. Ampelopsis appears to accord with Fouquieria and Verbena in having a sustained maximum opening, lasting for about 3 or 4 hours (fig. 29). The data further indicate that in the plant exposed to the western sun the stomata began to close earlier, again a result, possibly, of wilting. The reverse condition, namely, submitting the plant to a given period of darkness, has been experimented with, with more uniform results. 
June 21, 1906.-Ampelopsis quinquefolia. (Fig. 29.) Stomatal movement during day ; plant on east side of building in sunlight till II a. m.; on west side in shade till that hour. I eyepiece part $=3.5$ micra.

TABLE 44.

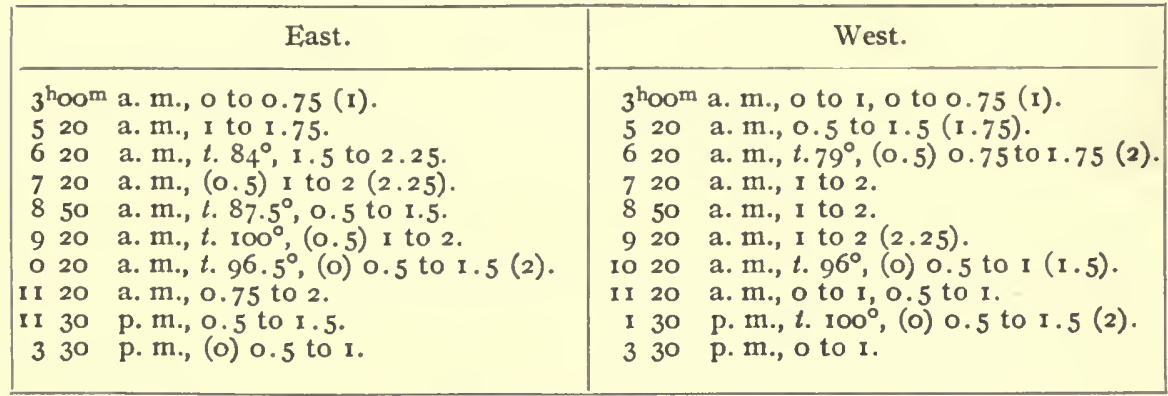

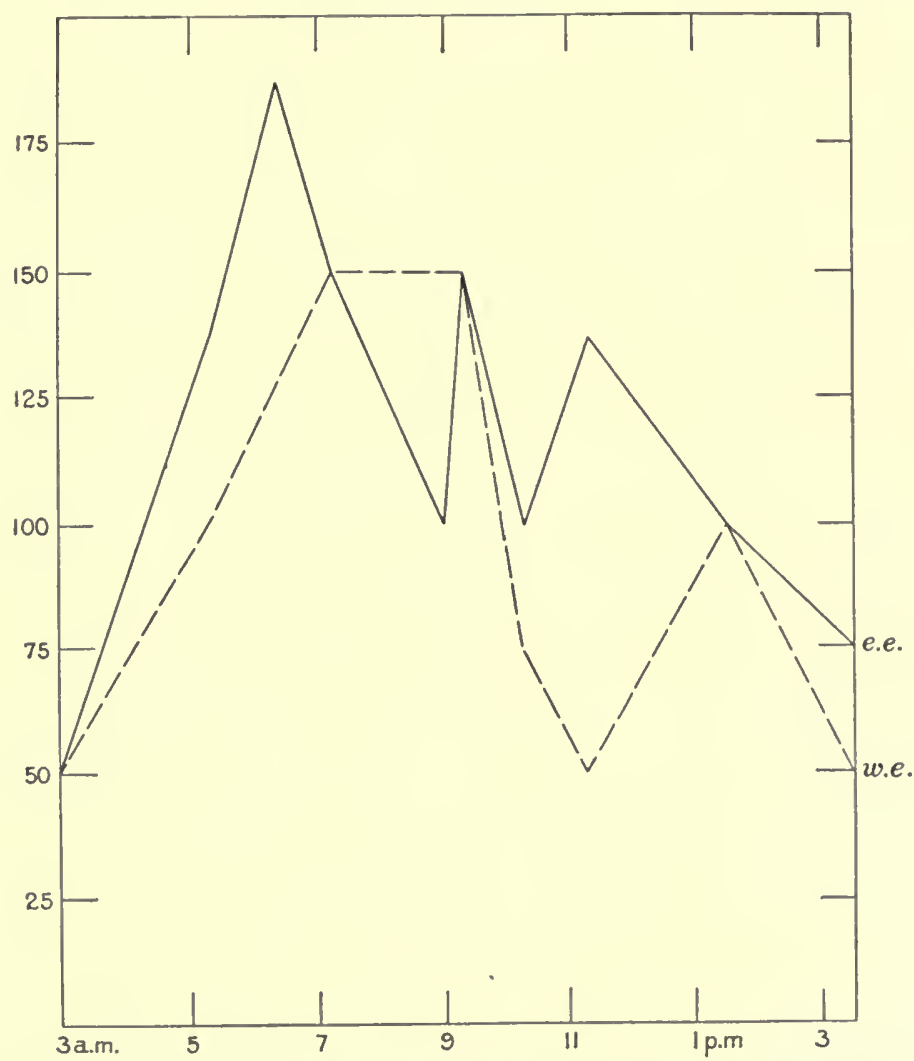

Fic. 29.-Curves of stomatal movement, between the hours of 3 a. m. and 3 h $30 \mathrm{~m}$ p. m., for Ampelopsis quinquefolia. 100 parts on the ordinates=1 part in table 44. e. e., eastern exposure of building; w.e., western exposure. 
June 19, 1906.-Four species experimented on, by darkening leaves or twigs in situ by means of tin vessels; period of darkness 1.5 hours, beginning at 1o a. $\mathrm{m}$.

Three species showed no change in the measurements of the stomataa begoniaceous vine, pepper-tree, and rose.

Ampelopsis quinquefolia showed the following results ( $\mathrm{r}$ part $=3.5$ micra): Io a. m., 0.75 to $\mathrm{I} .5$ (2) parts; $\mathrm{II}^{\mathrm{h}} 3 \mathrm{O}^{\mathrm{m}}$ a. m., 0.25 to I part; 3 p. m., 0.5 to I.O, I to I.75, 0.5 to I part; 4 p. m., O to I.75, I to $2,0.5$ to I.33 parts.

A simple calculation shows that in the morning exposure to darkness for I hour was followed by a reduction in the average size of the stomata from I 2 units (transverse diameter) to 62 units; that is, to not quite one-half their original size. In the afternoon, however, there was but little difference. According to Darwin's results, closure should be much more rapid in the afternoon, and therefore my own data do not accord with his.

June 22 and 23, 1896.-Ampelopsis quinquefolia. Plants darkened for 30 minutes in morning and in afternoon; matured leaf used in each case. I part $=3.5$ micra.

Eastern exposure:

June $22: 8$ a.m., 2-4 (I), to $8^{\mathrm{h}} 3^{\mathrm{m}}$ a. m., o-r $; 3^{\mathrm{h}} \mathrm{r}^{\mathrm{m}}$ p. m., (o) $0.5^{-1}$, to $3^{\mathrm{h}} 53^{\mathrm{m}}$ p. m., $0-0.5$.

June 23: $6^{\mathrm{h}} \mathrm{O}^{\mathrm{m}}$ a. m., $0.5^{-1.5}$, to $6^{\mathrm{h}} 3^{\mathrm{m}}$ a.m., o-I; II a.m., $*-0.5,(0) 0.5^{-1}$, to $\mathrm{Ir}^{\mathrm{h}} 3 \mathrm{O}^{\mathrm{m}}$ a. m., o-0.5.

June 25, 1906.-Leaves darkened.

Ampelopsis quinquefolia:

$6^{\mathrm{h}} 45^{\mathrm{m}}$ a. m., I-2, to $7^{\mathrm{h}} 3 \mathrm{O}^{\mathrm{m}}$ a. m., (o) O.5-1.5; $\mathrm{I}^{\mathrm{h}} 3 \mathrm{O}^{\mathrm{m}}$ p. m., o-0.5, to $2^{\mathrm{h}}{ }_{1} 5^{\mathrm{m}}$ p. m., o-0.5. Hairy-leaved composite:

$7^{\text {ho }} 8^{\mathrm{m}}$ a. m., (o) $\mathrm{I}-2$, to $7^{\mathrm{h}} 53^{\mathrm{m}}$ a. m., o-I; $\mathrm{I}^{\mathrm{h}} 3^{\mathrm{m}}$ p. m., o-I to $2^{\mathrm{h}} \mathrm{I}^{\mathrm{m}}$ p. m., o-r.

Ricinus communis:

$7^{\mathrm{h}} 5 \mathrm{O}^{\mathrm{m}}$ a. m., o-1.5, to $8^{\mathrm{h}} 3 \mathrm{O}^{\mathrm{m}}$ a. m., o-I; $\mathrm{I}^{\mathrm{h}} 3 \mathrm{O}^{\mathrm{m}}$ p. m., o-1.5, to $2^{\mathrm{h}} 5^{\mathrm{m}}$ p. m., o-I.

A plant of Iris sp. showed no difference in the morning and afternoon.

The foregoing experiments are diagrammatically summarized in fig. 30, from which, for the sake of simplicity, certain details have been omitted.

Data derived from experiments with ocotillo give a negative answer to the question. In experiments $I 6_{3}$ to $I 66$, as will be seen by consulting fig. I 6 , the stomata opened more readily at $\mathrm{II}^{\mathrm{h}}{ }^{2} \mathrm{O}^{\mathrm{m}}$ a. $\mathrm{m}$. than at $7^{\mathrm{h}} \mathrm{O}^{\mathrm{m}}$ a. m., by 3 times or more. The measurements given in the tabular summaries on page 57 are quite discordant and will, therefore, not allow affirmation or denial. One thing appears to be true, namely, that at about noon the amount of opening movement is greater than earlier or later, and this may indeed be regarded as supporting the view that an induced rhythm exists, except for the objection that the stimulus was, under the circumstances, beyond control.

The tendency of stomata to open slightly during prolonged darkness may also be looked upon as affirmative evidence, in the absence of knowledge to the contrary. 
The very obvious difficulty which intervenes to prevent the drawing of any safe conclusion is the variation in the size of the stomata, and the consequent large error in measurement as compared with the amount of movement which we may expect. Another objection which obtains in my own as well as in Darwin's experiments is the unequal stimulus applied. To be certain of the data, therefore, a large number of stomata must be accurately measured, and the changes in the condition of these stomata must be induced by a known constant stimulus. This is, then, a subject which awaits further inquiry,

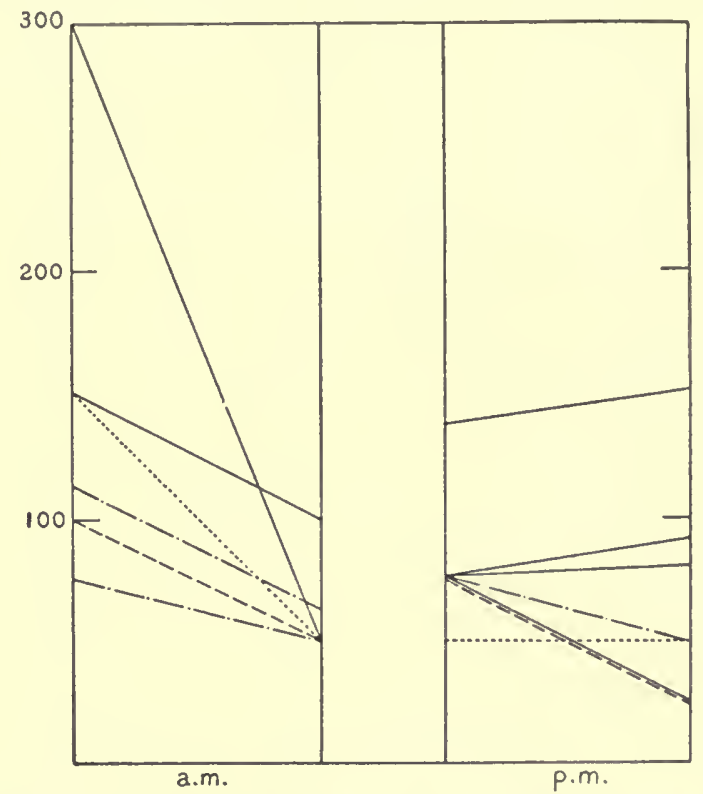

FIG. 30.-Diagram illustrating stomatal responses when placed in total darkness for given periods in the morning and in the afternoon. A particular species is represented by one kind of line.

which, however, may be expected, by means of a refinement of the method here used, to afford an answer to the problem. The method of the hygroscope, on the other hand, certainly can not be relied upon to give us safe evidence, since the possible variation in rate of transpiration, with a given stomatal opening somewhere between the extreme limits is so great that the rhythmic movements of the stomata, if present, might not be detected. Darwin's results, interpreted to mean an induced rhythm in transpiration, receive the support of Curtis's work; but neither of these observers may interpret their data as indicating stomatal behavior. 


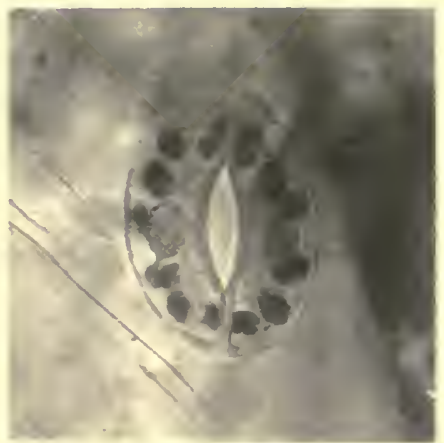

1

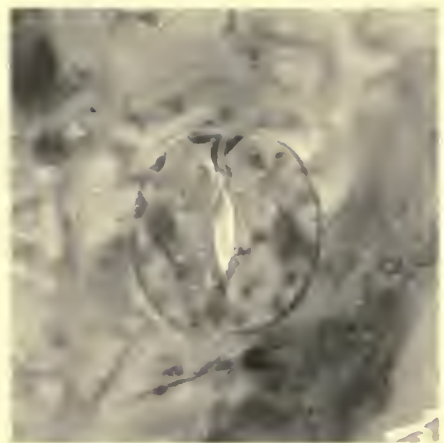

2

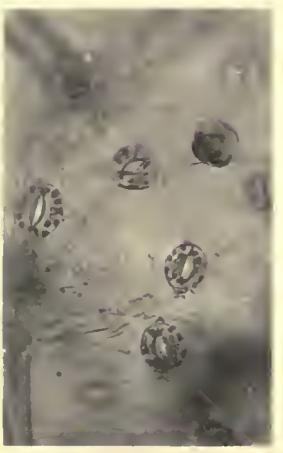

3

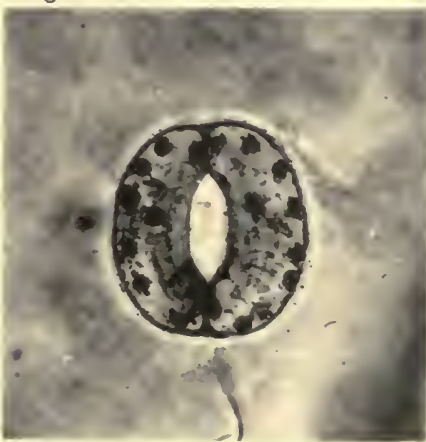

6

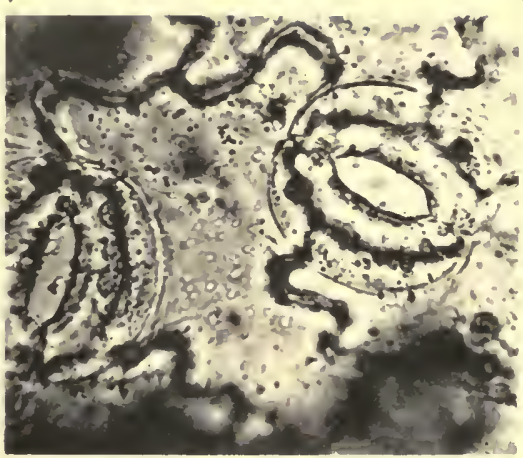

5

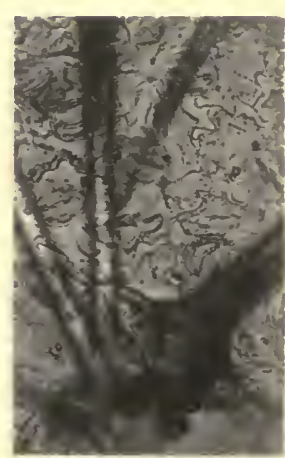

4

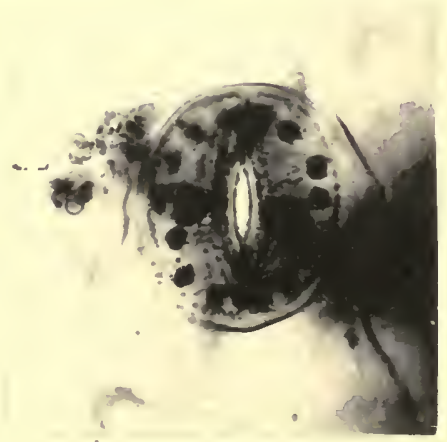

7

Stomata of Verbena ciliata taken at periods of maximum and minimum starch content. 1. Stoma at sunrise; starch abundant.

2. Stoma at about $9 \mathrm{a} . \mathrm{m}$.; starch none. Plastids at minimum size. These two stomata were in the pieces figured in 3 and 4 , respectively, at lower magnification.

5. This is from stomata fixed by absolute alcohol, and photographed while in this medium. The oil drops may be seen, one in each cell.

6. Stoma at 9 a. m., showing starch present, but in reduced amount, while in 7 the amount of starch is high. This was taken at $6 \mathrm{p} . \mathrm{m}$. on the same day. 



\section{CLOSURE OF STOMATA DURING WILTING.}

Francis Darwin (1 898, p. 543) inferred from a series of experiments upon a dozen or more plants that, upon the removal and consequent withering of the leaf, there occurs during the first few minutes (from 3 to Io, according to his data) a temporary opening of the stomata, followed by the gradual closure ordinarily expected.* It is obvious that, if such a temporary opening occurs within the first few minutes of withering, it might easily have escaped attention, both on account of the difficulty of recognizing the early stages of wilting, and especially because of the difficulty of determining exactly what the stomata do without seeing them. Darwin's method was to apply the horn hygroscope to the leaf just removed and record the readings. The initial readings may well be imagined to have been caused by an increased outpour of water-vapor caused by an initial reduction of tensions, and not by the increase in the size of the stomatal openings. That this may indeed have been the case, I am led to believe by the results obtained by me with a simple apparatus (pl. 5, figs. I and 2) designed to give some idea, approaching exactness, of what occurs during wilting as regards the leaf as a whole, and what the rate of wilting for a particular leaf may be. 'This consisted of a suitable stand, with an arrangement of pins and corks, together with a graduated index, so that a leaf, having just been removed from the plant, might be oriented in such a way that the movements during wilting could be recorded by watching the deflection of a bristle or glass-thread indicator, previously fastened to the apex of the leaf by means of shellac. The previous constant position of the leaf was insured by watching the indicator for some time after its attachment and while the leaf was not yet removed from the plant.

By studying the process of wilting in Verbena by means of this apparatus, I found that in leaves of fair or full maturity the period of wilting embraced two distinct phases. Thus, if a leaf, with the ventral surface up, be so oriented that the indicator is placed in a horizontal position, this will at first move upwards for some time, after which it will begin to drop. This is illustrated by the following readings at $\mathrm{I}$-minute intervals, the plus sign indicating upward and the minus sign downward movement.

$$
\text { o, }+\underset{1}{+} \mathrm{x} .5,3,4.5,6,7,7,6.5,5.5,4,2,0, \overline{2} .5,5,8,10.5,12,14 .
$$

The total length of the whole period and the ratio between the two phases will depend upon the maturity of the leaf and the consequent interactions of the mechanical tissues present. In quite young leaves there is no upward movement at all. Not all kinds of leaves show an upward movement upon wilting, though I have noted it in the so-called sensitive fern Onoclea sensi-

\footnotetext{
*Darwin records experiments showing this general wilting and stomatal closure (loc. cit.).
} 
bilis (Lloyd, 1902), and the inrolling on grass leaves may be regarded as a similar movement, clearly due to mechanical conditions resident in the tissues.

Though the experiment is very simple it nevertheless helps one to form a conception of what goes on in the verbena leaf during wilting.* It seems probable that during the first few minutes the loss of water results in a general lowering of tensions produced by high turgidity, the particular kind of movement of any leaf being one brought about as the result of its particular arrangement of tissues. This lowering of tensions means also a squeezing together of the cells and a reduction of the inter-cellular spaces, which again will result in the sudden forcing out of the contained gases, and therefore water-vapor. We should, then, find a sudden increase in the rate of transpiration, if we may call it such, due to a mass movement of water-vapor, and not necessarily a change in the condition of the stomata. A change of this kind is purely a mechanical matter, and can hardly be regarded as of any significance.

Having satisfied himself that the temporary opening occurred, Darwin sought to determine whether the degree of this opening differed in the morning and afternoon, and he obtained positive results, chiefly with Poinsettia, which showed a temporary opening in the morning but none in the afternoon. The explanation of this difference Darwin referred to the induced periodicity of the stomata, reference to which has been made elsewhere (p. 74). Assuming Darwin to be perfectly right in his belief that a temporary opening occurs, it is possible that the movement of the guard-cells is purely a mechanical result of the lowering of tissue tensions in the epidermis, and not a physiological process having anything in common with the different responses obtained by exposure to light or darkness in the morning and afternoon, though the differences in turgor in morning and afternoon may be common factors in both. This assumption, while justified upon speculative grounds, does not seem in this matter to lead to a definite conclusion. What is essential is to determine without doubt whether such a temporary opening occurs or not, and this I have tried to do. Two methods have been used-direct observations through the microscope of the living stomata, and the measurements of stomata after fixation in absolute alcohol at suitable intervals. In the case of ocotillo the latter method alone has been used. A sufficient number of leaves were removed from the plant and the epidermis from one of them fixed at certain periods. In the case of Verbena, in which the leaves are opposite in position, it is possible to obtain two leaves of the same age and degree of maturity. One of them may be used for the control, the epidermis being fixed at once, and the other allowed to wilt for any suitable period and its epidermis fixed at the close. By taking a sufficient number of pairs of leaves, observation may be taken so as to give a series, say of 1 minute or more

*'This method should prove useful in studying mechanical tensions in the leaf during extended periods. 
or less apart. In the method of direct observation of the living stomata, the epidermis was removed and mounted under a cover-glass, either in water or not, and a particular stoma was watched under the microscope during a complete period of wilting. The objection may be urged that in the separated epidermis the stomata may act differently than when attached to the leaf, but I have offered evidence elsewhere to show that they do not. Besides, the two methods act as mutual checks, and as they comport with one another I feel reasonably certain of my results.

\section{SELECTED EXPERIMENTS.}

A selected stoma of Verbena was measured and found to be 8 micra wide at $\mathrm{I}^{\mathrm{h}} 5 \mathrm{O}^{\mathrm{m}} \mathrm{p} . \mathrm{m}$. It was watched constantly till $2^{\mathrm{h}} \mathrm{O} 3^{\mathrm{m}} \mathrm{p} . \mathrm{m}$. The closure was continuous, without any increase in the size of the opening. The epidermis was still moist upon removal from the slide.

Another instance: $2^{\mathrm{h}} 28^{\mathrm{m}}$ p. m., Io micra; $3^{\mathrm{h}} 8^{\mathrm{m}}$ p. m., o micra; irrigated with water: $3^{\text {ho }} 9^{\mathrm{m}}$ p. m., 4 micra.

The closures were without previous opening, as I satisfied myself by continual observation. The ease with which stomata take up water is shown by the opening, when irrigated, in I minute. No doubt the epidermis as a whole does the same thing, but if the access of water to the stomata upon irrigation had taken place only through the adjoining epidermal cells, we should scarcely expect that the opening would be so rapid. The experiment seems to indicate that the closing of stomata during wilting is the result of a general wilting of the leaf and not an independent reaction of the stomata, and as during the general wilting the concentration of solution of all the cells is gradually raised, it would be difficult to account for the opening of stomata under this condition. The higher degree of concentration within the guard-cells in the morning than in the afternoon, as indicated by the wider condition of the stomata, may possibly be called into account for the greater reactions of stomata in the morning than in the afternoon (as is believed by Darwin to occur), if they occur. I have contributed data on this point under the head of induced rhythm in stomata.

TABLE 45.-Closure of stomxta during wilting. Io a.m., July, 1906. (Fig. 3r.)

\begin{tabular}{|c|c|c|c|c|}
\hline Leaf wilted for- & \multicolumn{2}{|c|}{ Leaf $I$. } & \multicolumn{2}{|c|}{ Leaf II (control). } \\
\hline 1 minute $\ldots \ldots \ldots \ldots \ldots \ldots \ldots \ldots \ldots \ldots$ & \multicolumn{2}{|c|}{$\begin{array}{l}\text { Micra. } \\
5.7 \text { to to }\end{array}$} & \multicolumn{2}{|c|}{$\begin{array}{l}\text { Micra. } \\
5.7 \text { to } 10\end{array}$} \\
\hline 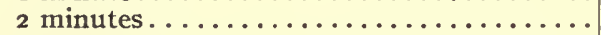 & 4.2 & 8.5 & 5.7 & 10 \\
\hline 3 minutes . . . . . . . . . . . . . & $5 \cdot 7$ & 8.5 & 5.7 & 8.5 \\
\hline 4 minutes . . . . . . . . . . . . . . . . & 4.2 & 8.5 & 8.5 & 12.8 \\
\hline 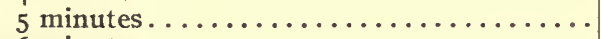 & 4.2 & 7 & $5 \cdot 7$ & 8.5 \\
\hline 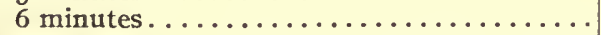 & o & 8.5 & 8.5 & 12.8 \\
\hline 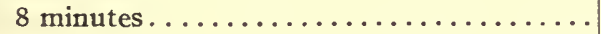 & $\mathbf{I}$ & 7 & 2.8 & 8.5 \\
\hline 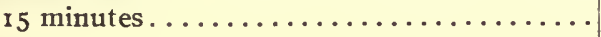 & I & 2 & 2.8 & 8.5 \\
\hline
\end{tabular}


By using paired leaves of Verbena, as above described, the observations shown in table 45 were made. In each case the control measurement was obtained from one leaf of the pair; the other, at the close of the indicated period of wilting, from the other leaf.

In the last case some stomata were open as widely as 6 micra, though they were few. Extreme flaccidity was usually reached in 15 minutes at the latest, under the severe but normal conditions to which they were subjected.

Ocotillo.-August 6, 1906. Primary leaves. Closure of stomata during wilting.

Different leaves taken in a series, the first to be regarded as control.

${ }^{\mathrm{h}}{ }^{\mathrm{H}} 3^{\mathrm{m}}$ p. m., $\quad 3$ to 9 micra.

2 p. m., $\quad 3$ to 9. Another piece of epidermis from the same leaf gave at ${ }_{2} \mathrm{~h}_{4^{\mathrm{m}}}$ p. m., $\quad 3$ to 9 , wilting evident.

$2^{\mathrm{h}} \mathrm{O} 7^{\mathrm{m}}$ p. m., $\quad 3$ to 7.5 , but more stomata measuring 3 micra than before.

$2^{\mathrm{h}}{ }_{1} 2^{\mathrm{m}}$ p. m., $\quad$ to 8 , wilting marked, leaf curling.

$2^{\mathrm{h}} 18^{\mathrm{m}}$ P. m., $\quad$ o to 4.5 .

$2^{\mathrm{h}}{ }^{2} 3^{\mathrm{m}}$ p. m., $\quad$ o to 2 .

It is to be noted that the opening of the narrowest stomata is not increased, but is steadily decreased concomitantly with the widest open.

Watermelon.-Unirrigated plant. 8 a. m, October 6, 1906.

The stomata, which are small (measuring 18 by 6 and 4.5 by 1.5 micra), measured at this hour from o to I.5 micra. A leaf was wilted for 50 minutes. Measurements were made at I-minute intervals for 6 minutes, followed by 2-minute intervals, then by 3 -minute intervals, and a final measurement at 50 minutes. The greatest measurements were steadily decreased by 0.5 micron per minute for 3 minutes, after which it remained at less than 0.5 micron for the 6 minutes. All stomata were closed at the end of 50 minutes. There was, moreover, no increase in the number of open stomata, as would be expected should closed ones open, which might occur though the open ones failed to increase their size. At 13 minutes a single stoma measuring 2 micra was found. This was one in hundreds examined.

This experiment has the advantage of having been made in the morning, when presumably the stomata were in condition for opening both physically and physiologically. No temporary opening, however, occurred, as the closure was constant and gradual.

The conclusion to be drawn is that no matter whether stomata are open or closed, neither in the morning nor in the afternoon does a temporary opening occur during wilting.

In any particular plant closure does not commence in all stomata at the same time. Local conditions may account for this. Thus, in Verbena no change was noted in one case for I minute, in another for 3 minutes. 
We may not deny that the closed condition of the stomata, such as may occur as the result of the loss of water during wilting, is an advantage to the plant, and this will be greater as the cuticular transpiration is smaller.

During the ordinary life processes there may be variations of turgor within certain limits without affecting the onward progress of these processes, and inasmuch as we may not consider these turgor variations abnormal, we are scarcely justified in regarding wilting, as Schwendener has (I88I), as a phenomenon quite apart from the conditions of normal vegetation. Certainly very many plants wilt regularly each day under the conditions under which they grow, yet it is very possible, or rather probable, that the stomata are of advantage in limiting to some degree the loss of water. We may therefore separate the wilted condition, an abnormal one, from the activity of stomata during wilting. This latter we should not relegate to the same category, at least until the closure during wilting is shown clearly to be abnormal. During the early stages of wilting (see data above) the stomata close gradually, during and somewhat more slowly than the wilting. If the leaf is totally cut off from a source of water, as in my experiment, the wilting continues without further opening;-but in life, many times a source of water may be great enough to supply the need, if the stomata are shut, till more is available.

It would seem that the "prelimi-

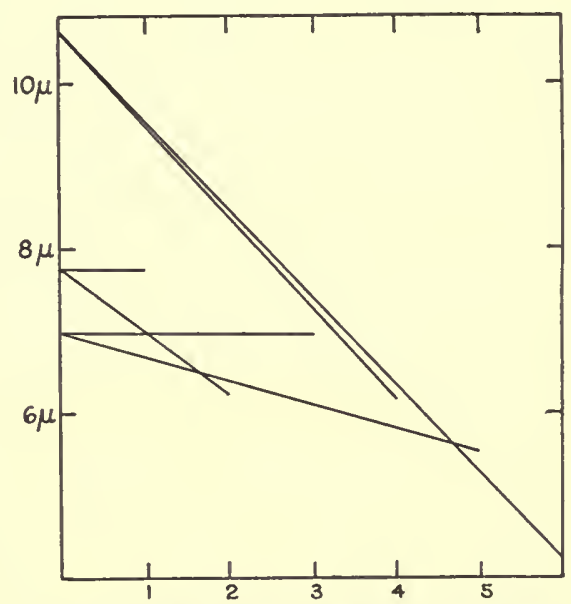

FIG. 31.-Diagram illustrating closure of stomata in six different leaves wilted for periods varying from 1 to 6 minutes. Verbena ciliata. nary opening" of Darwin is a disadvantage if it occurs, but why it should occur is not at all clear. It so happens that, so far as my own experience shows, it does not. To this extent at least, the stomata might be regarded as better regulating mechanisms of water loss than other facts about them would lead us to believe.

Schimper (1903-4, p. 12) has said:

Most xerophytes, also, have the property of closing their stomata when they begin to wilt, and thus of considerably depressing their transpiration; this is, however, not quite universal. Undoubtedly, under direct insolation, the protection offered by the closing of stomata is much less than is often imagined.

We might add that this property of closing during wilting of which Schimper speaks is not peculiar at all to xerophytes, and further that, while normal 
closing in many plants may indeed take place under direct insolation, the "protection afforded" is less than "is often imagined." Thus, Bergen has found that the older leaves "of the Myrtus type" transpire more than the younger $(1904 b)$ and that, in a number of thick, xerophylous-leaved evergreens, the sun leaves transpire more than the shade leaves, and as much or more than many mesophytes (1904a). These rather unexpected results were attributed by Bergen to differences in the physical conditions within the leaf, such as the more highly developed vascular tissues and more extensive evaporation surface of the sun leaves as compared with the shade leaves, though it was believed by him that this explanation is not wholly adequate. The conclusion was drawn, which accords well at all points of contact with my own studies, that "xerophytic leaf structure is not always incompatible with abundant transpiration, but sometimes exists only for use in emergencies to protect the plant from injurious loss of water." Aside from the consideration that shade leaves may cease to transpire before they show any signs of wilting, in which, however, wilting may have proceeded far enough to result in the closure of the stomata, if this did not intervene from other cause, Bergen's observations indicate the truth of Schimper's above-quoted remark, and that the stomata are not by any means as effective in suppressing transpiration as supposed. In a word, the protection of the plant as regards its water content, by stomata, is chiefly or entirely confined to their closed condition.

Haberlandt (1904, p. 407) sees a difficulty in regarding the closure of stomata during wilting as a simple result of the reduction of turgor within the guard-cells, since, he observes, this concentration would, because of the reduction of the amount of water, lead to a higher concentration of sap, which would in turn lead to opening. It is evident, however, that wilting robs all of the cells of water, and this alone would lead to a concentration of solution in all cells at the same time. The resultant lowering of tensions would, then, be shared by the stomata, and there would result a closure. 'This closure may, however, not be as rapid as the wilting itself, though it is not long delayed. This delay may perhaps be referred to a slightly slower loss of water by the stomata. If, then, in conclusion of this portion of the study, the behavior of stomata in respect to regulation of water loss, both during the normal daily march of events and during wilting, is such as described, it is very natural to ask what is the function of these organs. The answers which have been given at various times have already been indicated. More recently C. E. Bessey (1898) has argued that the stomata have made possible the exchange of gases which would otherwise have been suppressed by the means adopted by the plants for conserving the water supply upon their emergence from a watery environment, and that therefore we must regard them primarily as organs for the interchange of oxygen and carbon dioxid. 
He states:

The epidermis which prevents the escape of water-vapor also prevents the absorption of carbon dioxid. This difficulty was surmounted by the formation of stomata. A leaf without stomata, or what is the same thing, with its stomata permanently closed, as with wax, will not lose water, but it will starve for want of carbon dioxid. The stomata are open so long as there is no danger of such a water loss as would result in loss of turgidity, but when the cells show an approach to flaccidity the stomata close [italicizing mine].

Originally the loss of water was harmful, but many plants have in a secondary way made use of the stomata for the purpose of obtaining with the transpiration stream a supply of materials for use in building up the tissues and for other purposes. To the support of Bessey's view may be brought the lack of regulatory function of water loss by the stomata, at least to the extent that, though they allow the escape of water, they have not become so far adapted secondarily to regulate it. But, after all, the harmfulness of water loss by primitive plants is an assumption, as there may never have been a time in the history of plants when sometranspiration was not a useful process, the hindrance of which would have delayed the progress of necessary physiological change within the plant. It seems to be simpler and more in accord with the known facts to regard the stomata as a means of communication between the interior of the plant and the gaseous environment, and that their function is to allow the exit and entrance of gases, inclusive of water-vapor. 


\section{RELATIVE HUMIDITY AND STOMATAL MOVEMENT.}

\section{RELATIVE HUMIDITY-ITS INFLUENCE UPON THE CONDITION OF STOMATA.}

In some previous experiments (Sudden Change, p. 45) we have been concerned especially with the responses of transpiration and of stomata to change of illumination. In subjecting the plants to such changes other conditions should remain constant, or as nearly so as circumstances will permit. During the times when the experiments were made the relative humidity was very low, often as low as 5 per cent, while the difference between the dark room and the outside was, in this regard, not more than a very few per cent, a negligible amount. The fact that the stomata are found quite open during a very high temperature and a very low relative humidity-a typical desert conditionleads one to suspect that the latter has very little influence upon the stomata themselves, though, of course, the rate of transpiration may be very greatly influenced by it, just as the rate of evaporation is. If the conditions are such as to bring the plant nearly to the point of wilting, a high relative humidity will have the effect of making it easier for the plant to recover than if a low relative humidity prevailed; so that a plant may be so far wilted that the stomata are closed, when a rise in the relative humidity may then afford the condition for a returgescence and a consequent opening of the stomata.

The supposed regulatory effect of stomata upon transpiration is said to rest upon their great sensitiveness to changes of humidity (Haberlandt, I904, p. 406) but neither the opening of stomata during returgescence, because of the dampening effect of humidity upon transpiration, nor the closure of stomata during wilting, which may but does not necessarily follow a low relative humidity, may be regarded as an expression of irritability. Indeed, from a teleological point of view, the stoma should, at any rate, close before the danger of water loss has become felt, or, as it has been expressed, before visible wilting cnsues (Leitgeb). "Visible wilting" is, however, a purely artificial criterion. The danger-point, which, during wilting, we do not know much about, may be reached and passed before visible wilting is manifest. This phase of the subject is, however, treated in another place. The consideration before us is the supposed sensitiveness of stomata to change in relative humidity.

There is a small amount of evidence that a high relative humidity favors, as a condition, the wider opening of the stomata in the ocotillo. This plant has, as has been already noted, two kinds of leaves, distinguished by their position as regards the chief shoot and by their thorn metamorphosis. The primary leaves are of a briefer life than the secondary leaves, possessing less power of resistance. It is also true that in general the stomata are larger and open more widely, and it may readily be supposed that this may con- 
tribute to the brevity of the life span of the primary leaf, though I do not for my own part believe sn.

In table 46 measurements are given of the stomata of both primary and secondary leaves.

TABLE 46.-Measurements of stomata of primary and secondary leaves.

\begin{tabular}{|c|c|c|c|}
\hline \multirow{2}{*}{ Time. } & \multirow{2}{*}{ Primary leaves. } & \multicolumn{2}{|c|}{ Secondary leaves. } \\
\hline & & Upper surface. & Lower surface. \\
\hline $\begin{array}{l}9^{\mathrm{h}} 2 \mathrm{O}^{\mathrm{m}} \text { a. m., July } 25 \ldots \\
8^{\mathrm{h}} 3 \mathrm{o}^{\mathrm{m}} \text { a.m. } \mathrm{m} \text {. July } 26 \text { (high } \\
\text { relative humidity fol- } \\
\text { lowing shower in the } \\
\text { night). }\end{array}$ & $\begin{array}{l}\text { o to } 9 ; \text { mean } 4.5 \ldots \\
6 \text { to } 12 ; \text { mean } 9 \ldots\end{array}$ & $\begin{array}{l}\text { o to } 3 \text {; mean } 1.5 \text {. } \\
\text { o to } 3 \text {; mean } 3 . .\end{array}$ & 2 to 6 ; mean 4 . \\
\hline $\begin{array}{l}8^{h} 30^{m} \text { a. m., July } 27 \ldots \ldots \\
9 \text { a. m., July } 28 \ldots \ldots \ldots\end{array}$ & $\begin{array}{l}3 \text { to } 9 ; \text { mean } 6 . . . . \\
4 \text { to } 9 ; 4 \text { to ro; mean } 7 \text {. }\end{array}$ & $\begin{array}{l}5 \text { to } 6 \text {; mean } 5.5 . \\
4 \text { to } 8 \text {; mean } 6 . .\end{array}$ & $\begin{array}{l}2 \text { to } 6 \text {; mean } 4 . \\
4 \text { to } 9 ; \text { mean } 6.5 \text {. }\end{array}$ \\
\hline
\end{tabular}

I was unable to take the relative humidity in these days, but judging from other experiences a difference of 30 per cent between July 25 and 26 would be a very conservative guess, and it is not improbable that it was as great as 60 per cent. By the morning of the 28 th the humidity would have dropped back to 20 per cent or thereabout. Assuming these figures to be in the main correct, it would appear that, after a showery night, the high relative humidity made possible, on July 26 , the opening of the stomata of both. primary and secondary leaves to an average transverse measurement twice. that on the day previous at the same hour. It is, of course, possible that this was the result of an increased supply of soil-water or of water in the stem. absorbed through the areas immediately contiguous to the basis of the rosettes of secondary leaves, or, again, of a conservation of the supply of water in the stem by the wetting and relative humidity. Facts are already at hand to show that the ocotillo is especially sensitive to increased soil-water (Cannon, I905), to meteoric water (Lloyd, 1905), and probably also to a high relative humidity independently of these (Cannon, 1906). It will be seen, however, that on the following two days, July 27 and 28 , the stomata of the secondary leaves gradually increased their dimensions at the same hour (from 3 to 6 micra) while those of the primary leaves decreased (from 9 to 7 micra), and this under a much reduced relative humidity. Even allowing for individual differences in leaves and errors of measurement, it appears conclusive that the two sets of stomata behaved differently, and this is difficult to explain. The behavior of the stomata of the secondary leaves suggests the effect of soil-water, but why this factor did not influence the primary-leaf stomata similarly is quite unaccountable. It is possible that the formation of scission tissue had set in, which results in the separation of the leaf-blade from the endogenously formed spine (Robinson, I904), but I endeavored to guard against this possibility 
by choosing mature but not moribund leaves. The plant itself was in vigorous condition, and by its strong growth indicated a plentiful supply of soilwater, and this makes any explanation involving an increase of soil-water improbable. On the other hand, that such a difference in the relative humidity as above described should affect the stomata of a plant well supplied with water seems, in the light of other experiments, even more improbable. The following data will be seen to bear out this view:

On July 13, 1904, there was a hard shower lasting an hour, during which I.I inches of rain fell. In spite of this, however, the stomata showed no change in dimensions, measuring o to 3 micra before and after the shower. The plant had previously been irrigated.

A few days before this (July 8) an attached branch was allowed to remain covered by a bell-jar for one hour and a quarter, during which the relative humidity rose from $4^{2}$ per cent to 87 per cent. At the close of the period, at $4^{\mathrm{h}} 24^{\mathrm{m}}$ p. m., the stomata measured exactly as those of a control branch.

On July I I, I904, at $9^{\mathrm{h}} 3 \mathrm{O}^{\mathrm{m}} \mathrm{p}$. m., the stomata of the same branch measured o to 2 micra. The branch was left covered by the bell-jar for 12 hours, when at $9^{\mathrm{h}} 3 \mathrm{O}^{\mathrm{m}}$ a. $\mathrm{m}$. the stomata measured 2 to 6 micra, as also did, however, the stomata of the control. It is to be concluded, therefore, that the opening was normal and unaffected by the continuous high relative humidity.

The same behavior has been shown by Verbena ciliata. An exposure of 2 hours to a high humidity under a bell-jar on July 3, 1905, at mid-day (experiment 140) failed to produce any changes in the stomata, though at the close of the period the rate of transpiration was apparently greater. This result, it is true, may be incorrect, since there may have been moisture deposited on the leaves or absorbed by the glandular hairs, which, upon exposure to the day air beneath a fresh bell-jar, was sufficient to affect the hygrometer.

The same behavior of the stomata was shown also by all the Verbena experiments in the 1906 series (200 to 300 ), in which bell-jars were used. In no case was I able to detect obvious differences between the experimental part, detached from the plant, and the control part.

Similarly the method used in my experiments with Ampelopsis to determine the presence or absence of an induced rhythm in stomatal movement made it necessary to confine leaves in a small chamber, which, while lighttight, produced a high relative humidity. After 12 to 14 hours under these conditions, in the total absence of light, no tendency on the part of the stomata to open was observed, while exposure to darkening was followed by closure in spite of increasing humidity. One instance only (July 19, 1905) shows a behavior which, if not attributable to personal error, might have been due to the increased humidity.

It is evident, though, that the further opening of stomata under increased humidity is of less importance, for the teleological point of view, than closure 
due to a reduced relative humidity would be, and it is quite conceivable that the stomata would be more sensitive to a reduced than to an increased humidity.

On this part of the subject Francis Darwin has offered results (1 898, p. 557):

The fact that many plants close their stomata when brought from a greenhouse to a laboratory can not be doubted by anyone who investigates the subject; nevertheless it does not seem to be widely recognized that this is the case, and that it occurs in cases where there is not the slightest visible flaccidity.

This observation is supported by suitable evidence, and inasmuch as the drier air would tend to increase the transpiration, the behavior of the hygroscope would seem here to indicate stomatal behavior, approximately at least.

With such evidence as I have available I am able only to say that in the plants which are here under consideration such is not the case. This may be wholly due to the fact that these are desert plants living often under a very low relative humidity for long periods, and are therefore "attuned" to the rigorous conditions to which they are subjected. But even at times of high relative humidity no obvious effect of this condition has been observed. Two other experiments may be added, with, however, negative results.

Verbena ciliata.-December, 1906: After 1.25 hours in a nearly saturated atmosphere, showed no decrease in stomatal size when exposed to a relative humidity of about 50 per cent.

December 29, 1906: After 48 hours' darkness in a saturated atmosphere, on exposure to light, and to a relative humidity of 50 per cent, the stomata were as in the normal.

Mentha piperita.--December 5, 1906: 'Two plants in pots were removed from outdoors, where the relative humidity was very high, after drenching rains on the $2 \mathrm{~d}$ and $3 \mathrm{~d}$ ( 3.25 inches), into a sunny window in a warm, dry room at noon. One was covered with a glass bell-jar arranged to keep the humidity high, while the other was left uncovered to the dry air of the room. At the end of 2 hours the stomata of the latter were, if anything, more open than those exposed to high humidity.

The conclusion is, in these plants, that, as long as wilting does not take place, a low relative humidity does not reduce the stomatal opening. 



\section{PART II.}

\section{PHYSIOLOGY OF THE STOMATA, WITH SPECIAL REFERENCE TO THE METABOLISM OF THE GUARD-CELLS.*}

NORMAL DIURNAL CHANGES IN THE CONTENTS OF THE GUARD-CELLS.

(Plate 6.)

Repeated examination at short intervals, during a period of several days, of the stomata of Verbena ciliata revealed the fact that the amount of starch in the guard-cells was not constant, and further sustained observation persuaded me that these changes were regular and of such extent that it was possible for one to distinguish with reasonable ease between the stomata taken at one time of the day and another. This result, though borne in upon me only after a prolonged study of the structures in question, was so surprising and so at variance with the published results of former observers, so far as I was then acquainted with them, that it was only after about three weeks of further systematic observation that I was finally persuaded of the correctness of my earlier examination. It should be said that at first, at any rate, it is quite difficult to arrive at this result, in part on account of the inability to get a standard of comparison for such small objects as the plastids and their amyloid inclosures, and in part on account of one's natural skepticism when such slight changes are observed. I have, however, taken occasion to show preparations to my colleagues, with the result that the differences were readily seen by them. These differences are, however, great enough to be demonstrable by means of photography, so that the reader has at least representative optical evidence before him. Similar observations have been made, also, upon the ocotillo, but the phenomena in this species are still more difficult of observation.

\section{VERBENA CILIATA.}

Beginning at sunrise, in the summer time, we find that the amount of starch in the guard-cell is at its maximum. The whole of each plastid, when iodine is applied, colors deeply blue-black. Each plastid contains several, usually from 5 to 7 , starch grains, which lie in close contact, the apposed faces of adjacent grains being flattened. The whole group of granules may

*Presented in brief form before the Botanical Society of America, December, 1905. 
be regarded as a compound grain, this condition being secondary, since the whole is built up from several centers which appear distinct at other times. The diameter of such a compound starch grain is nearly as great as that of the nucleus and one-third to one-half the transverse measurement of the guard-cell. Their size, together with their number, give the interior of the cell a crowded appearance which often makes the observation of the nucleus difficult. After sunrise, during a period of 4 to 7 hours, according to the season, and, as I believe, according to the temperature, the amount of starch is gradually reduced till a minimum is reached, which may mean its entire absence, or a small quantity. In any event, the minimum amount is so small that the plastids come to be comparatively insignificant in size, and often lie in profile on the periphery of the cell, as seen from above (see plate 6 , fig. 2 , of stomata taken at $8^{\mathrm{h}} 3 \mathrm{o}^{\mathrm{m}}$ a. m.). The difference in the amount of starch is less marked when lower temperatures prevail. Indeed, I have found it rather difficult, on cold days in early spring, to be assured that any difference at all was observable, but this would be expected under such conditions. At this time the iodine test results in a brown stain of the plastid; and when applied with great care, in the event that starch is present, this will be revealed as minute granules lying separately within the plastid. When the material is boiled in the iodine solution the swelling of the starch granules results in a lakey appearance of the plastid, best represented by a medium shade of the "neutral tint" of water color of Windsor \& Newton.

The period of minimum starch content lasts, according to my notes made in July, 1905, for 3 or 4 hours, this probably varying with the temperature. At its close the granules increase in size until the maximum is again reached. This occurs in a comparatively short time when once begun. As the middle of the afternoon is approached, the amount of starch is obviously increased, until at about 5 o'clock the maximum is nearly if not quite reached.

During the night there seems to be no change, or if any occurs it is inappreciable. This accords with the movements of the stomata during the same time and, in fact, the correlation between the stomatal action and the variation in the amount of starch in the guard-cell is so constant and striking under all circumstances that the former may well be now described, after which we may return to consider the other cell contents.

STOMATAL MOVEMENT.

At sunrise the stomata are all nearly or quite closed (plate 7, fig. 1). There is seldom to be found a complete uniformity in the size of aperture. Measurements, as seen by the accompanying tables and notes, show that there is a variation of size between o and 4 micra, transverse pore measurement. Often the variation is much less, and cases have been observed in which only, say, 5 per cent of the stomata show a sensible opening. The 

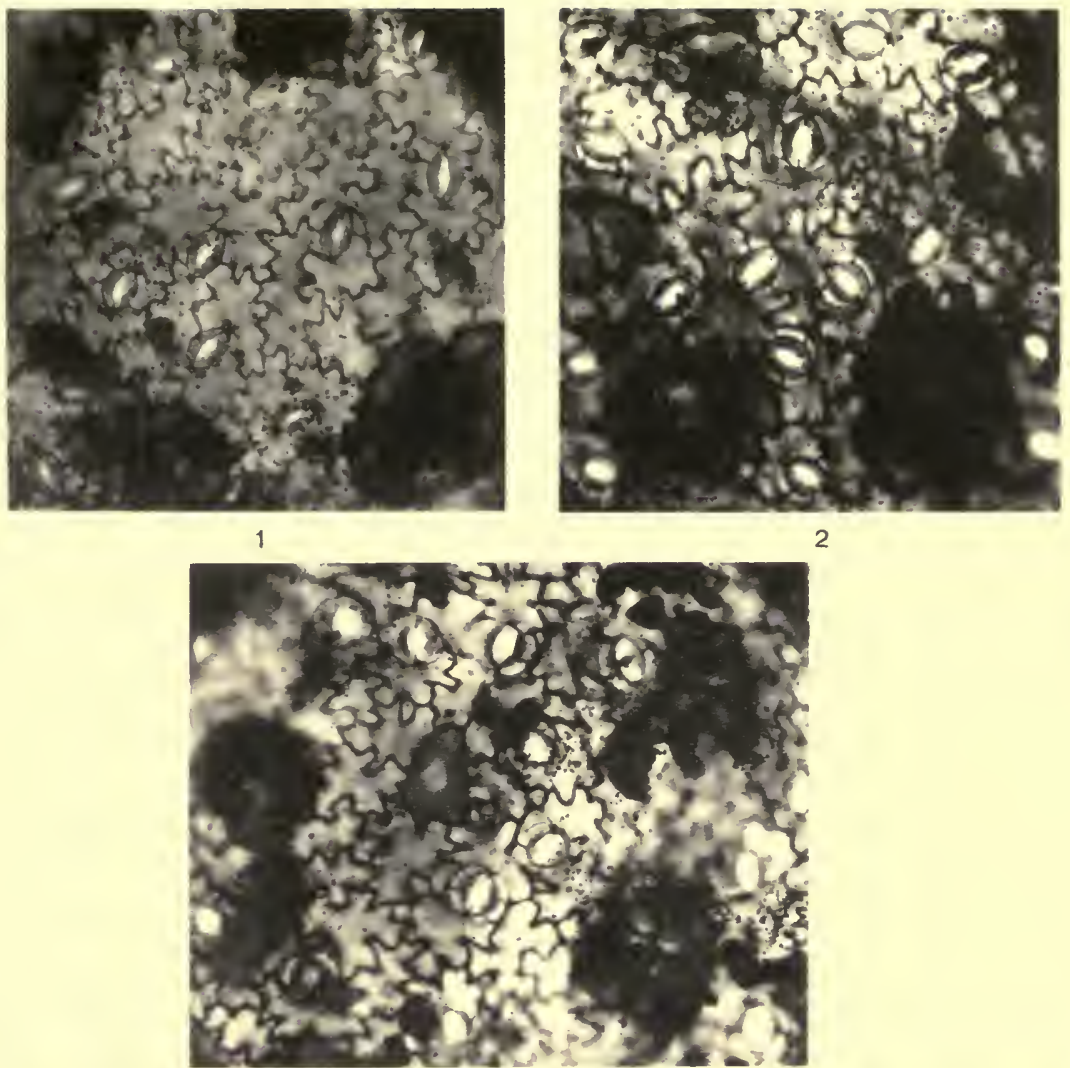

2

3

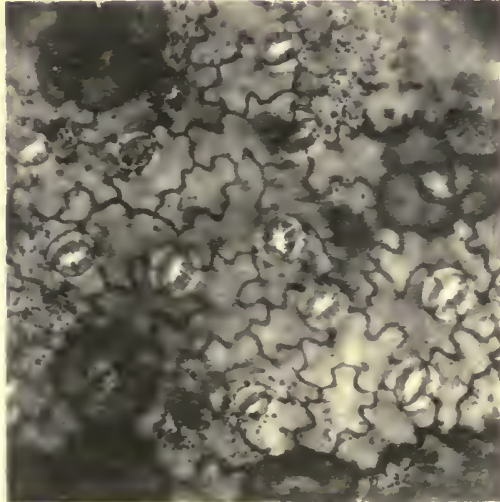

4

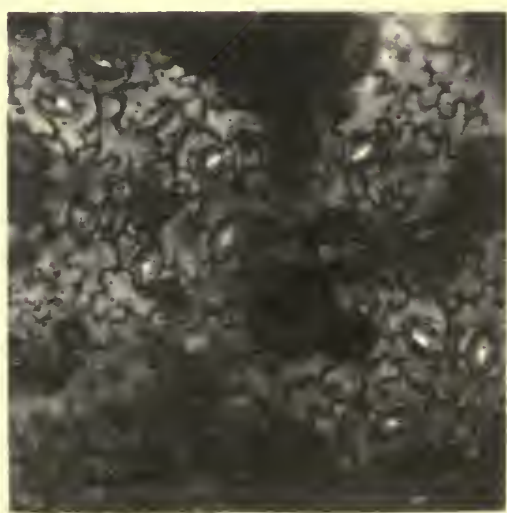

5

Stomata of Verbena ciliata (fixed in absolute alcohol, stained with Congo red, and mounted in balsam). Fig. 1, at 4 a. m. Fig. 2, at $6 \mathrm{~h} 20 \mathrm{~m}$ a. m. Fig. 3, at $9 \mathrm{~h} 30^{\mathrm{m}}$ a. m. Fig. 4 , at $2 \mathrm{~h} 30^{\mathrm{m}}$ p. $\mathrm{m}$. Fig. 5 , at $5 \mathrm{~h} 30^{\mathrm{m}}$ p. m. 

series of photomicrographs herewith presented shows an average degree of uniformity.

The opening of the stomata begins at dawn and proceeds slowly till Io a. $\mathrm{m}$. in the early spring and till about $8^{\mathrm{h}} 3 \mathrm{O}^{\mathrm{m}}$ a. m. in the summer (plate 7, fig. 3 ). The openings measure, in average-sized stomata at this time, 6 to i 2 micra, although in many cases the opening is still larger, reaching the extreme size of 16 micra. Generally, in an average piece of the epidermis, the transverse measurements will vary between 6 and Io micra, but frequently the variation

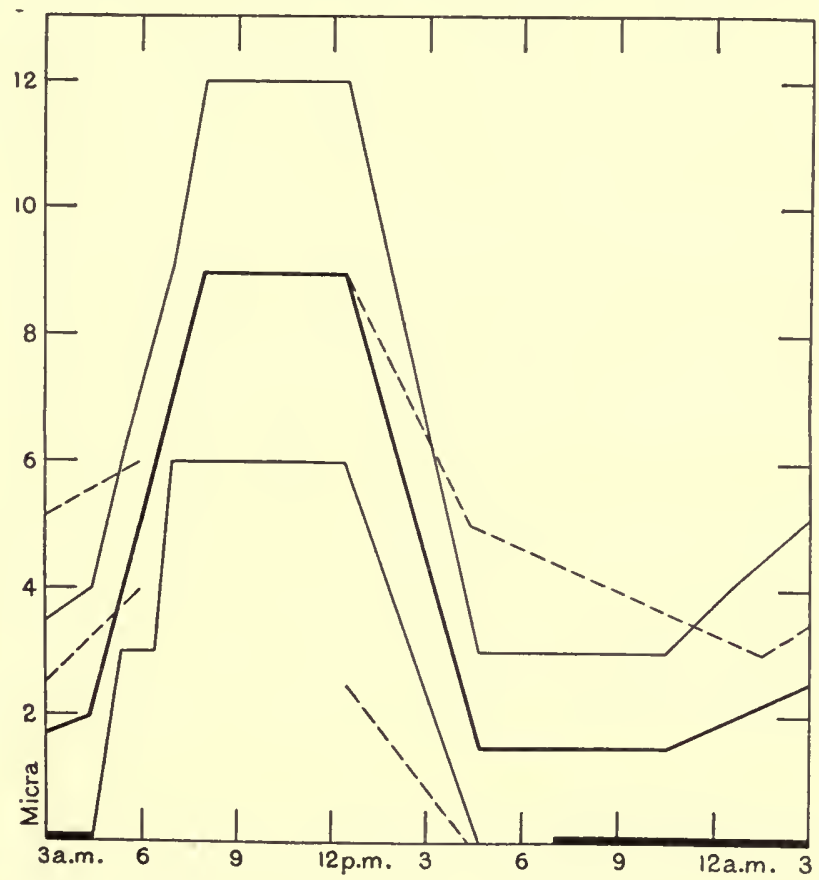

Frg. 32.-Daily periodicity of stomatal movements in Verbena ciliata. Extreme measurements are plotted by thin lines, and means in a heavy line. July 2, 1906. Broken lines are curves for parts of other days (July 1 and 3 ).

will be much less. To the eye often a remarkable degree of uniformity of size obtains, as indeed the illustrations show (see plate 7 , fig. 2). It may be remarked that the illustrations are from pieces taken at random, the only consideration having been, on account of the curvatures in the mounted epidermis, to get as many stomata in one optical plane as possible.

The maximum opening is maintained for about 3 hours, after which closure sets in (plate 7 , figs. 4 and 5). It seems that the initial closure is somewhat rapid, though the total movement occupies about the same length of time 
as the opening, so that by about 4 p.m. many stomata are closed and the range of size is between o and 3 or 4 micra. I have attempted to represent these facts graphically in diagram, fig. 32 , which will serve to bring at once to the mind the whole course of action of the stomata. On the ordinates have been laid off the limits of size, and a curve is laid off so as to embrace, in a gencral way, the average sizes. Such a curve is true within a reasonable limit of error. Indeed, it would be of little profit to attempt a more exact representation, inasmuch as two sets of material would vary from each other to as great an extent as the error involved.

The conclusion to be drawn from the facts summarized in this curve is that the opening and closing of the stomata do not proceed rapidly upon the advent of day and of night, respectively, but are on the contrary rather slow processes. The evidences indicate that the opening, as we shall see elsewhere, is inaugurated as a response to the stimulus of light during the early hours of the day. The cause of the closure, which, it should be especially noticed, occurs early in the afternoon, and, as I have shown, independently of wilting, of rate of transpiration, and not on the advent of darkness, is less obvious, but I believe is explicable on the theory of processes within the cell of the nature of enzymatic activity. Inasmuch as this general question must be treated beyond at greater length, it will be unnecessary to speak of it further at this point.

The only attempt which, so far as I am aware, has been made to represent the beliavior of stomata in graphic form is that recorded in Francis Darwin's paper (1898, p. 595). A comparison of his curves with that here given discovers certain differences, which may indeed be due to the different plants used by him, and the widely different conditions of experimentation. Darwin's curves appear to me, however, to resemble transpiration curves much more closely.

The rise of the curve in the morning and its fall in the evening are "fairly steep," indicating a correspondingly rapid opening and closure of the stomata; that is, within the space of an hour or a trifle over. This conclusion is based on the readings of the hair hygroscope of Darwin's contrivance, a device which undoubtedly responds to changes in transpiration, but does not at all prove that the movements of the stomata are responsible for the changes in the rate of transpiration. My own experiments compel me to question the conclusion that these rather sudden changes, caused by temporary meteoric changes, are the expression of stomatal action. Rather would I hold that no stomatal movements take place at all, or at any rate, if changes occur, they are far too small to be recorded. I show elsewhere that wide variations in the transpiration of a plant may occur without any observable stomatal movement, a result which makes it unsafe to infer stomatal action from the rate of transpiration. 
According to the same data, Darwin concludes (loc. cit., p. 594) that-

The maximum opening of the stomata is not reached till the day is well advanced, $i . e$, at times between II a. m. and $3 \mathrm{p} . \mathrm{m}$. But the stomata reach a fair aperture, $i . e$., twothirds of the maximum reading, at from half an hour to two and a half hours after sunrise. The time of closure is usually from three-quarters of an hour to one hour after sunset, but Narcissus was shut . . . . more than half an hour before sunset, and

Cineraria was shut ten minutes after sunset.

Aside from minor details, my own conclusions differ from those of Darwin in ( $\mathrm{r}$ ) the maintenance of the maximum opening for a rather definite period; (2) the early closure, 2 to 3 hours before sunset; and (3) the slower movement, aside from that of the mid-day period in Darwin's plants, whether opening or closing. To be sure, the maximum opening "is not reached till the day is well advanced" according to Darwin, which maximum is, however, not maintained. In making the comparison, however, if we regard the "fair aperture" in Darwin's curves as the maximum, then the chief facts are the rather rapid opening and closing of the stomata and the marked period of maximum aperture.

Table 47 contains typical data for Verbena ciliata, giving the range and average size of the stomatal apertures. The measurements, in micra, were made in connection with a study of the transpiration, the results of which are given elsewhere (experiment 140, p. 40).

TABLE 47.-Measurements of stomatal pores, Verbena ciliata, 1905. (Fig. 32.)

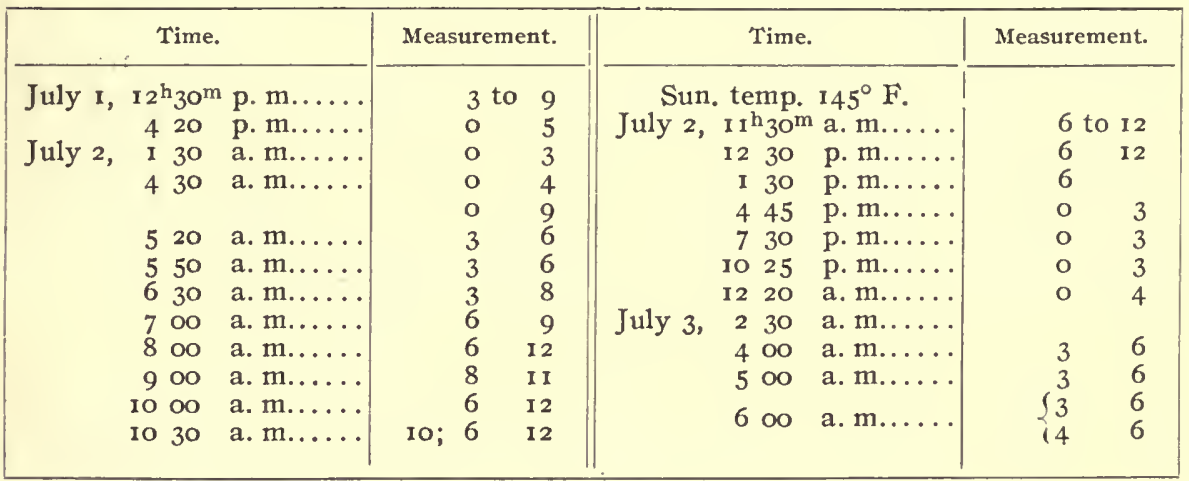

OIL.

The variation in the amount of starch in the guard-cells has its complement in the variation in the oil content. The occurrence of oil in stomata has been several times noted, in $A$ lö̈ (Strasburger, Practicum, pp. 167, 168), in Galtonia (Leitgeb), and I have myself found them in Buxus, Agave, lilac, privet (apparently not noted by Pirotta), and in another species of Verbena.* This substance is undoubtedly of quite common occurrence in stomata. In

* Occurs also in the chlorenchyma cells (as, too, in the pomegranate) and in some other plants in the epidermal cells. 
the plant Verbena ciliata the oil is present in the stomata in appreciable quantities only for a small portion of the day. At sunrise the amount is very small and optically quite inappreciable, except as minute droplets, which would defy identification by the casual observer except by refined methods. During the period in which the stoma is opening, however, the droplets increase greatly in size until usually one, but of ten two, large drops are found in each guard-cell. Smaller ones, too, may frequently be seen. One large drop near the end of the guard-cell is the characteristic condition (plate 6, fig. 5). Their nature is demonstrated by their behavior in potash, in which they become irregular in shape, and apparently of a soapy texture. They take up alcannin readily; potassium iodide-iodine renders them very transparent and difficult to see, ultimately becoming shriveled and dissolved, while alcohol renders them opaque, often with a slightly crenate or irregular margin. After treatment with alcohol they may sometimes appear as if cracked on one side, suggesting that a hardening or coagulating effect has been induced. In the afternoon, $i$. e., during the closure of the stomata, the drops wane, until by ${ }^{\mathrm{h}} 3 \mathrm{O}^{\mathrm{m}}$ or $2 \mathrm{o}^{\prime}$ clock they have been reduced to minute droplets of the size seen at daybreak. Nor do they at any time reappear till the following day. The constancy of these changes is so marked under normal conditions that, in view of the similar but reversed changes in the starch content, the suggestion presents itself that there is a direct connection between these two substances. This is, however, entirely unlikely, as will later be shown. It is of very considerable interest in this connection to note that Leitgeb (1888) found that the oil-drops of Galtonia stomata gradually disappear when starved by isolation, and it is probable that further study of this plant would throw light on the difficult problem of the significance of this substance in the stoma.

The data in table 48 , extracted from notes recorded in July, 1905, serve to indicate the basis for the foregoing description of the changes which occur within the guard-cell, as well as to present the results in summary form. The original wording has been preserved in condensed form.

TABLE 48.-Changes in contents of guard-cells and of pore.

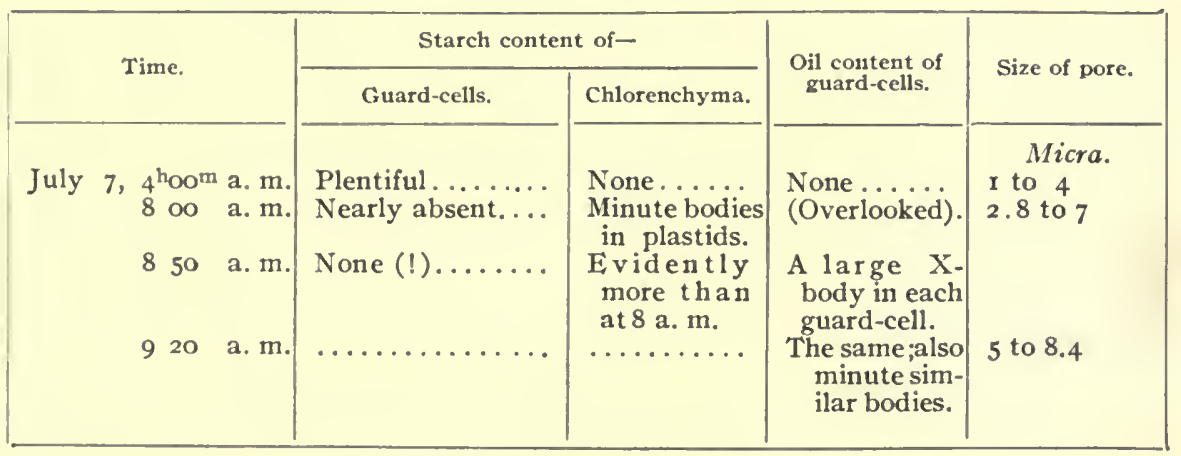


TABLE 48. - Changes in contents of guard-cells and of pore-Continued.

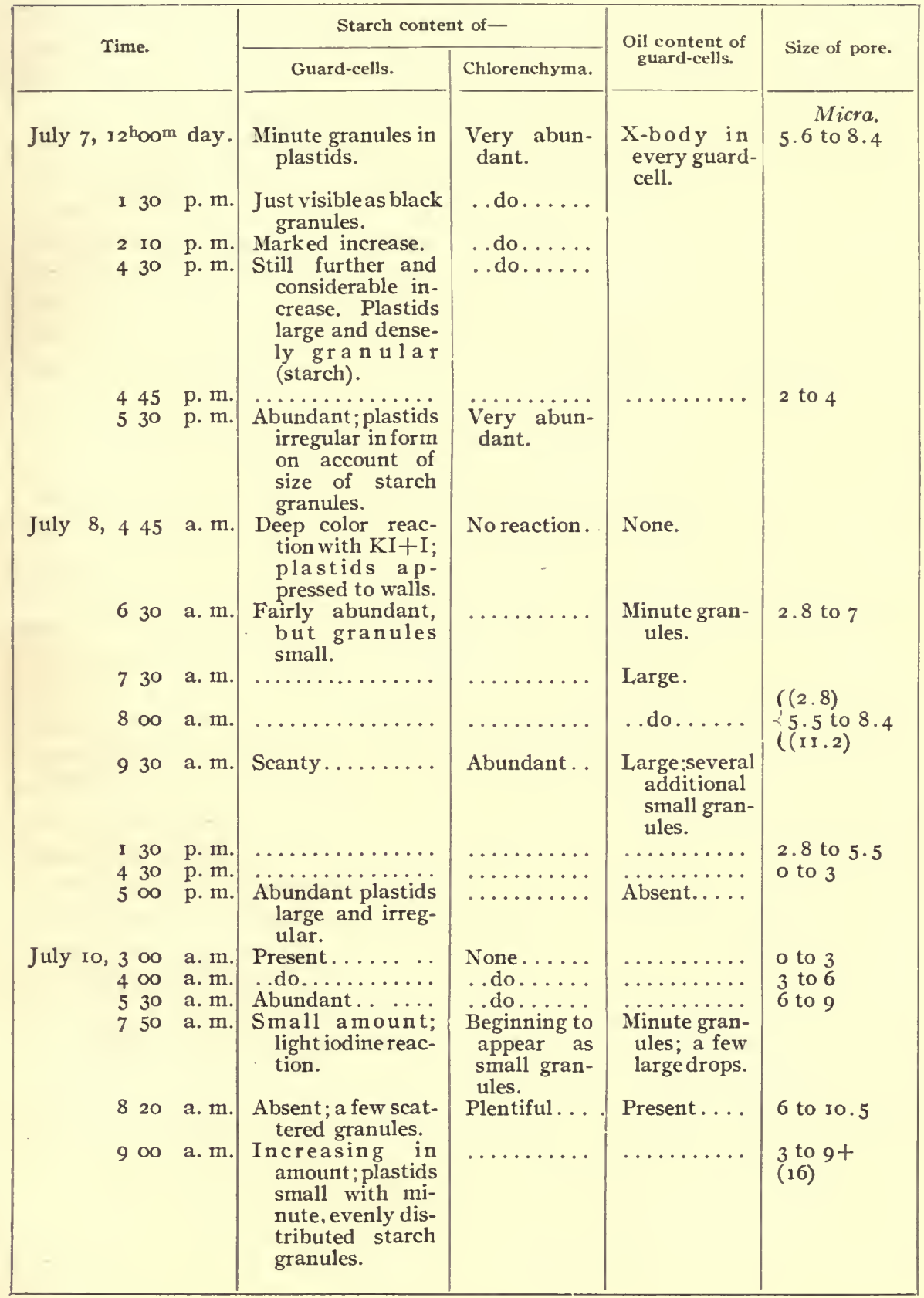


TABLE 48.-Changes in contents of guard-cells and of pore-Continued.

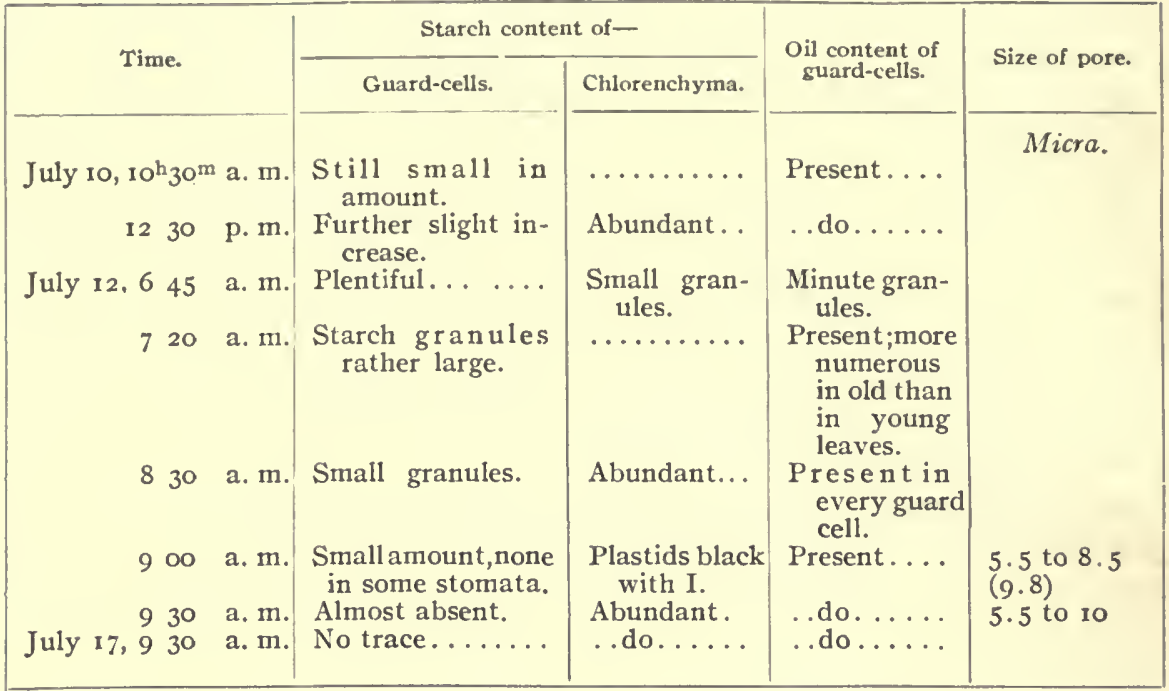

TABLE 49--Verbena ciliata. Observations of condition of stomata and chlorenchyma on four days with relatively low and high temperature conditions. Reduced from notes.

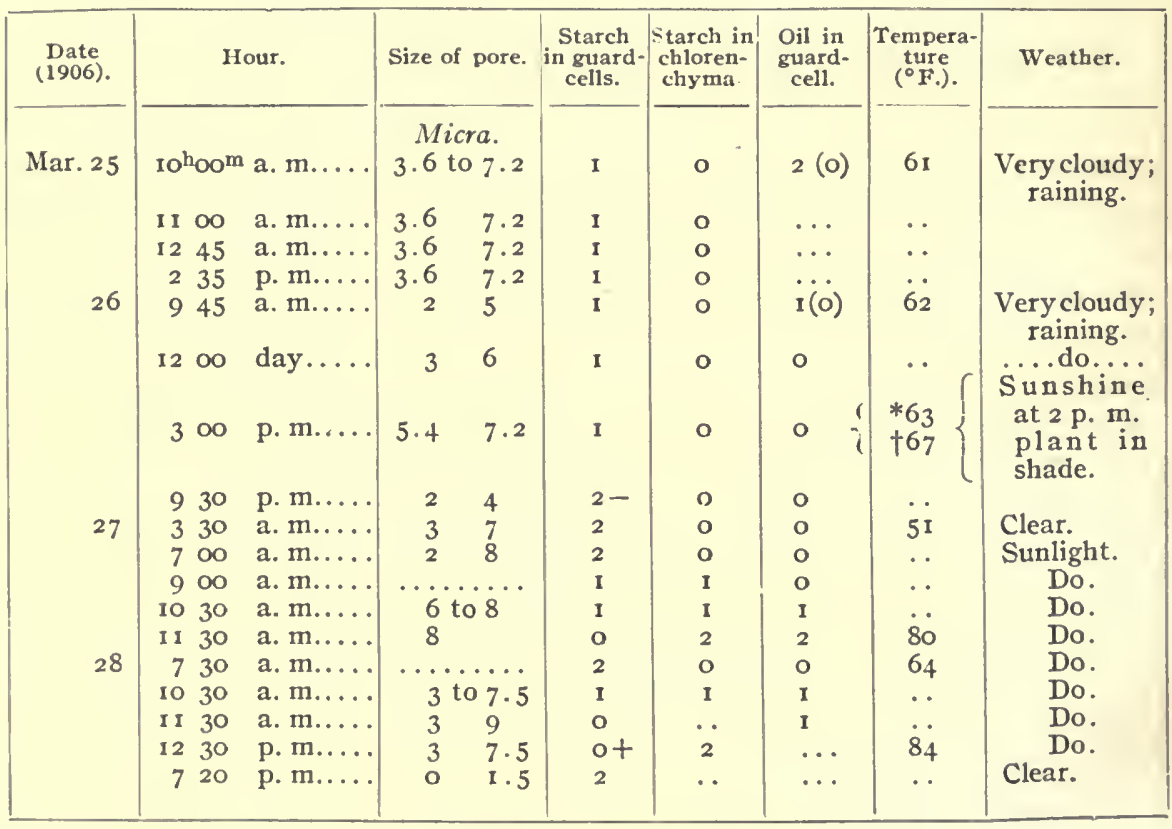

* Shade.

t Sun. 
In table 49 is given a series of observations made in the year I 906 in March. The data were entered in tabular form at once, and for the sake of convenience and brevity a rough grading of the quantity of starch and oil present was used, o meaning the absence and I a medium amount, and 2 the apparently full amount. When it was difficult to decide readily the signs minus ( - ) and plus $(+)$ were used to modify the grading.

The facts presented in this table indicate a slower opening movement and a longer period of starch dissolution than is shown in the notes made in the summer. I have attributed this difference to the lower temperature prevalent in March.* Making due allowance for such variation, due to this and probably other causes, we may regard as beyond doubt the conclusion that the starch and oil vary in amount, their quantitative fluctuations being complementary to each other. The minimum starch content occurs during the latter part of the morning, at the time when maximum. oil content occurs. Before and after this period the amounts of starch and oil vary in inverse order.

The diurnal movements of the stomata are such as to lead to the suggestion that the variations of amount of the starch and oil content are closely connected with them. I have made an attempt to test this view observationally in the following manner: As has been pointed out, the sizes of the stomatal openings are not

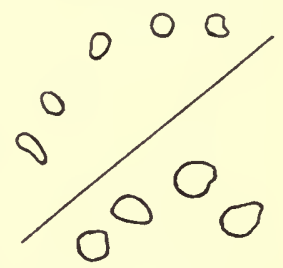

FIG. 32a.-Verbena ciliata, experiment 220. uniform, and it thus happens that two adjacent stomata may be in quite different physiological condition-the one open and the other closed. On two occasions I have found one stoma quite closed and the other, very close to it, widely open, at about ro a. $\mathrm{m}$. By applying iodine under constant observation, the open stoma was found to possess distinctly less starch than the closed stoma. Fig. $32 a$ shows the difference in the size of the plastids, due to different amounts of starch, in two neighboring stomata, 30 micra apart, one widely open ( 12 micra), the other about one-third ( 4 micra) open, taken from. preparation at $\mathrm{II}^{\mathrm{h}} 3 \mathrm{O}^{\mathrm{m}}$ a. m., May 3, I906. From this it would seem that the above suggestion is sustained, as far as concerns the starch. The evidence to be shown beyond does not, however, favor the same view as regards the oil, the rôle of which remains problematical.

\footnotetext{
* Observations made at the end of December, I906, when the temperatures were still lower, showed a still less active physiological condition of the guard-cells.
} 


\section{FOUQUIERIA SPLENDENS.}

VARIATION IN THE STARCH CONTENT OF THE GUARD-CELLS.

After satisfying myself that the observations on the increase and decrease of starch in the guard-cell of Verbena were, so far as I could judge, correct, I very naturally hoped that I might succeed in finding instances among other plants which would afford evidence of the same kind. With this in mind I examined at various times of the day a number of species (Amaranthus, Jatropha, Nicotiana, Euphorbia, etc.) without finding sufficiently constant differences to afford a basis for comparison with Verbena. Upon confining my attention exclusively to one species, the ocotillo, and comparing series of observations made at considerable intervals of time, the conviction grew upon me that in this plant, too, there is a regular, though less obvious, change in the amount of starch, the maximum being reached in the night (or perhaps the early hours of the morning before sunrise) and the minimum during the latter half of the forenoon. The data in table 50 were gathered by examining pieces of epidermis taken from the same plant at $3^{\mathrm{h}} 2 \mathrm{O}^{\mathrm{m}}$ a. m., $8^{\mathrm{h}} 3 \mathrm{O}^{\mathrm{m}}$ a. m., and $6^{\mathrm{h}} 3 \mathrm{O}^{\mathrm{m}}$ p. m., and grading the stomata with reference to the amount of starch found in them.

TABLE 50.-The change in amount of starch in guard-cells of ocotillo, July 27, 1906.

\begin{tabular}{|c|c|c|c|c|c|c|}
\hline Time. & $\begin{array}{c}\text { No. of } \\
\text { stomata. }\end{array}$ & $\begin{array}{c}1 \\
\text { (meager). }\end{array}$ & 2 & 3 & 4 & $\begin{array}{c}5 \\
\text { (very abun- } \\
\text { dant). }\end{array}$ \\
\hline $3^{\mathrm{h}} 2 \mathrm{O}^{\mathrm{m}}$ a. m.... & 59 & $\cdots$ & $\ldots$ & $\ldots$ & 15 & 44 \\
\hline 830 a.m.... & 82 & 5 & 34 & .. & 38 & 5 \\
\hline 630 p. m.... & 53 & . & $\ldots$ & 27 & Io & 16 \\
\hline
\end{tabular}

It was found that the stomata could be grouped in five groups in a series from "starch meager" to "starch very abundant." The maximum amount of starch in the ocotillo stoma is very much greater than in the verbena. The groups were numbered, for convenience, from $\mathrm{I}$ to 5 . The counts were made by chance by moving the slide in one general direction and estimating the condition of all the stomata in the field at one time. The summations of counts only are given.

The figures in table 50 must be regarded as representing approximation only. It is difficult to distinguish always between the condition of the stomata in any two grades, and one must make counts at random, judging as he goes. But it is not difficult to distinguish between grades 1 or 2 and 4 or 5 . The accompanying figures (plate 8 ) show the extreme observed contrast between $3^{\mathrm{h}} 2 \mathrm{O}^{\mathrm{m}}$ a. $\mathrm{m}$. and $8^{\mathrm{h}} 3 \mathrm{O}^{\mathrm{m}}$ a. $\mathrm{m}$. The table shows that in the $3^{\mathrm{h}} 2 \mathrm{O}^{\mathrm{m}}$ a. m. piece there were no stomata approaching the $8^{\mathrm{h}} 3 \mathrm{O}^{\mathrm{m}}$ a. m. condition; while in the $8{ }^{\mathrm{h}} 3 \mathrm{0}^{\mathrm{m}} \mathrm{a} . \mathrm{m}$. piece there was a small majority approaching or equaling the condition of the $3^{\mathrm{h}} 2 \mathrm{O}^{\mathrm{m}}$ a.m. stomata. In the $6^{\mathrm{h}} 3 \mathrm{o}^{\mathrm{m}} \mathrm{p} . \mathrm{m}$. piece a general change towards the $3^{\mathrm{h}} 2 \mathrm{O}^{\mathrm{m}}$ a. $\mathrm{m}$. condition is evident, as no 

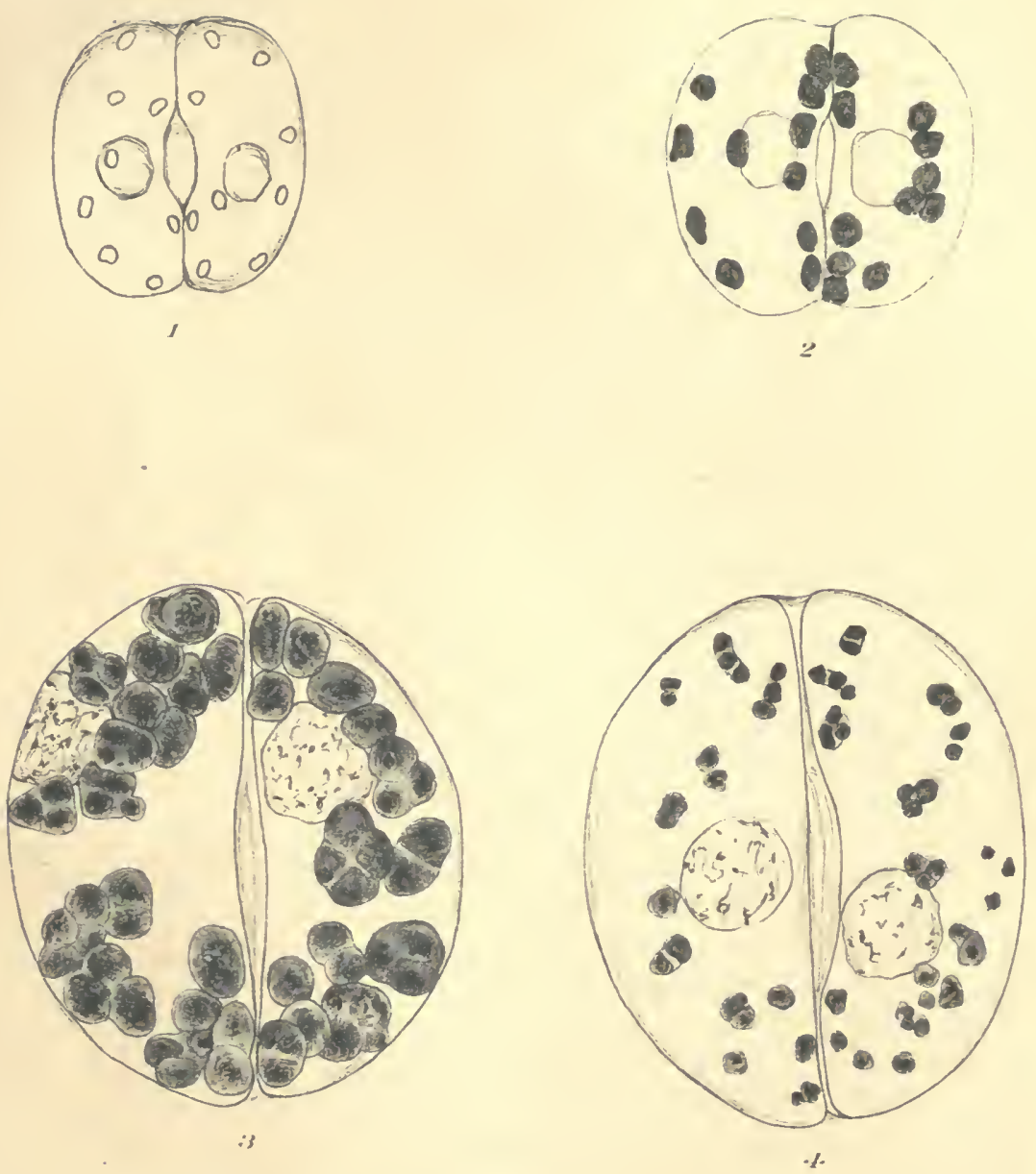

Explanation of Plate.

1 and 2. On the left (figure 1) a stoma which overlay normal tissue. This contained no starch. On the right (figure 2) one which overlay dead chlorenchyma, and contained an abundance of starch. (Experiment 201b.)

3 and 4. Stomata of Fouquieria splendens showing the starch content at $3 \mathrm{a.} \mathrm{m}$. (figure 3) and at 8 a. $\mathrm{m}$. (figure 4). 

stomata were observed which could be said to belong to $\mathrm{x}$ or 2 . These general differences can be told at a glance, when the mind is not prejudiced, for the preparations were examined by an observer who did not know what the objects were, and he recognized the differences at a glance.

Just as it is difficult to distinguish between two adjacent grades of starch dissolution in neighboring stomata, so also is it difficult to recognize any difference in stomata taken at short intervals apart. The difference between stornata taken at $3 \mathrm{a}$. m. and 8 or 9 a. m. is marked enough, but between 3 and $5 \mathrm{a} . \mathrm{m}$. the difference is more difficult of recognition. There is a difference, however, recognizable under the lower power of magnification, as a difference in depth of staining, and in part to the smaller size of the starch granules, which therefore do not crowd upon each other as densely (approximately as seen in plate 8 , fig. 3 ), thus allowing more light to fall between the plastids, and also between the granules within the plastids.

That these differences are real and of significance is indicated by the following observations made October 18, I906, at $9^{\text {h }} 30^{\mathrm{m}}$ a. m., on the stomata of a potted plant of ocotillo, on leaves a few days old but still tender. The stomata were all in the young condition, showing little secondary development, and were open from 3 to 6 micra. I plotted a group of 8 or ro stomata, two of which in the center were 6 micra open, while those surrounding were 3 micra open. Upon irrigating with water they all closed, and upon adding iodine, all under continual observation, the reactions in the two 6-micra stomata were sensibly less marked than in the surrounding ones.

Wortmann regards corrosion of the starch grains as necessary evidence to the conclusion that starch is being digested. I was, however, not able to observe any pittings such as are usually observable in large starch grains (e. g., potato) on digestion by diastase. It is possible that the starch grains of the guard-cells are not corroded irregularly, as is often the case, but are gradually dissolved from without with the same rapidity at all points. This is what appears actually to occur in the guard-cells. In dead guard-cells, for instance, the starch granules are frequently perfectly spherical in form, while their appearance otherwise indicated clearly that they are in an arrested state of partial dissolution, and I have noted similar appearances in the normal guard-cells at about $9 \mathrm{a} . \mathrm{m}$. The individual granules of a plastid are separated from each other by double-concave masses of the plastid matrix, as if the starch disappeared before the plastid became reduced in size; while, when the starch granules are growing, these are separated by plane masses of the plastid matrix, suggesting that the centers of starch accumulation were close together at first, thus bringing the starch granules into close juxtaposition. The very small size of the starch granules, however, makes their observation in this regard very difficult, and these statements must therefore be regarded as tentative. 


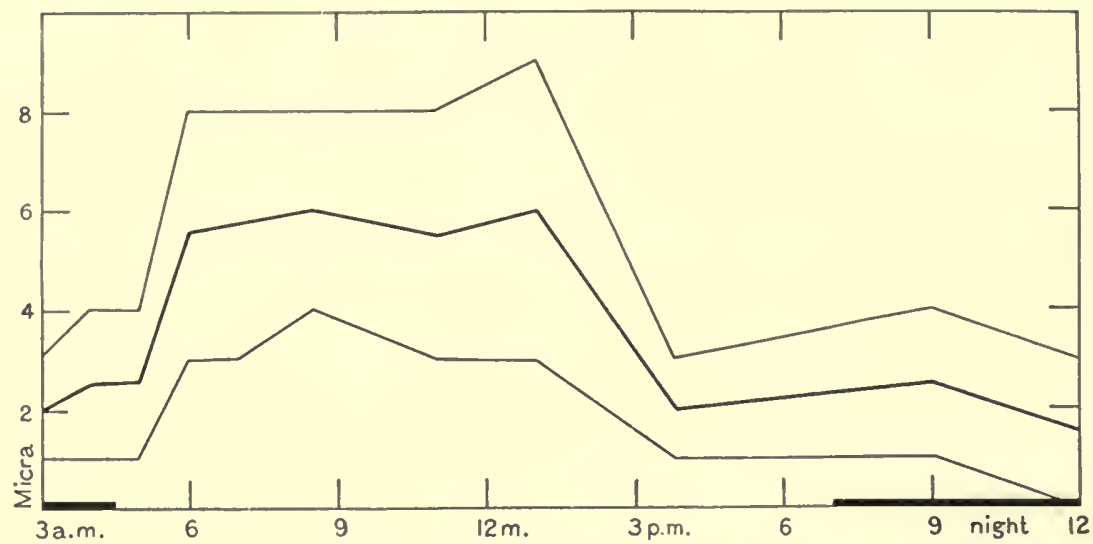

Fis. 33.-Daily periodicity in movements of stomata of Fouquieria splendens. Extreme sizes plotted in thin lines; means in heavy line. July 10, 1904.

TABLE 51.-Stomatal movement, Fouquieria splendens, July 10, 1904. (Fig. 33.)

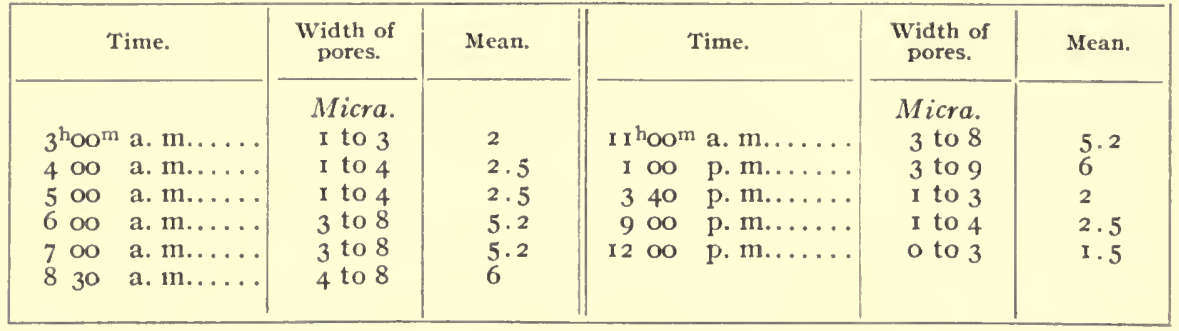

TABLE 52.- Size of stomatal openings under normal conditions, material growing on $U n i$. versity of Arizona campus, July 27-28, 1906. Well-watered plants of Fouquieria splendens, in irrigated (Toumey) garden. (Figs. 34 to 37 , inclusive.)

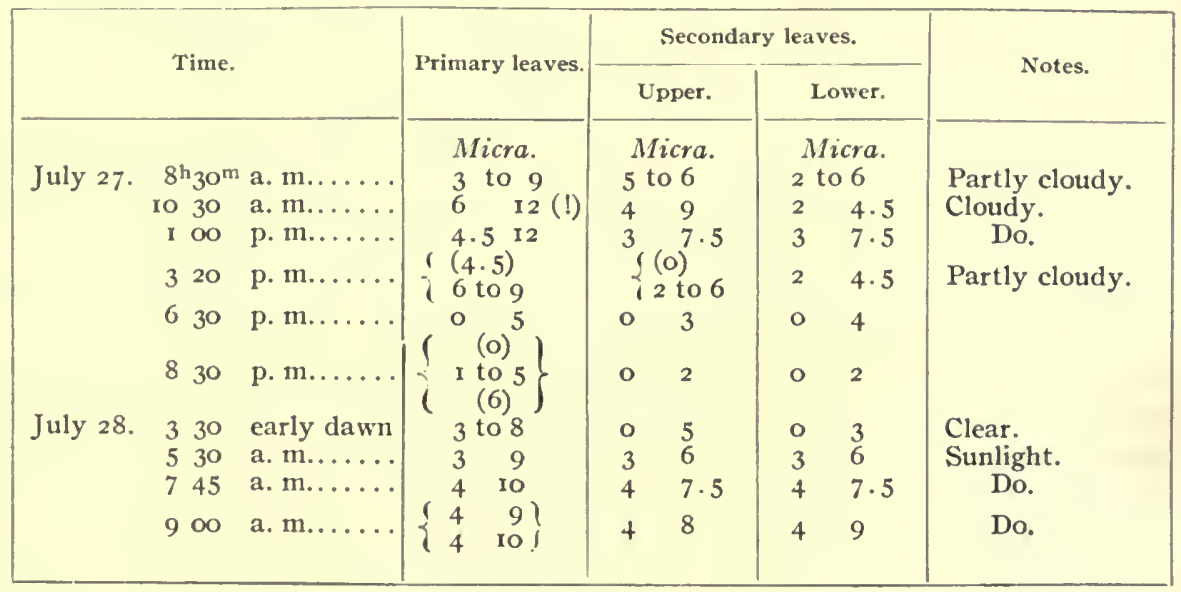




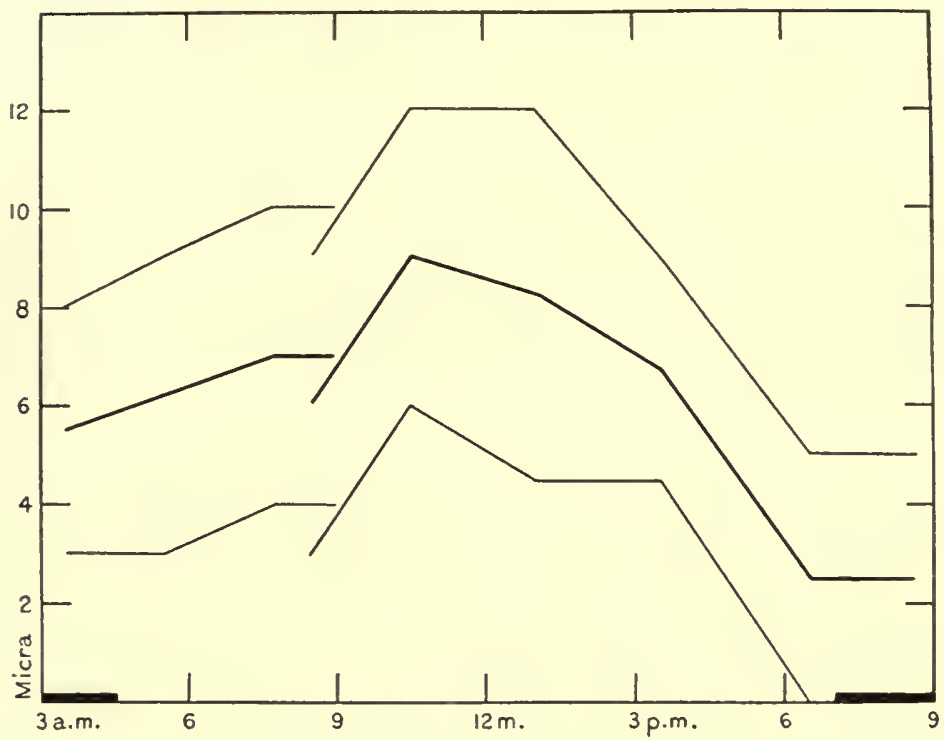

Fig. 34.-Daily periodicity of stomatal movement in Fouquieria splendens. Stomata, upper surface of primary leaves. (Curve $a$, fig. 37.)

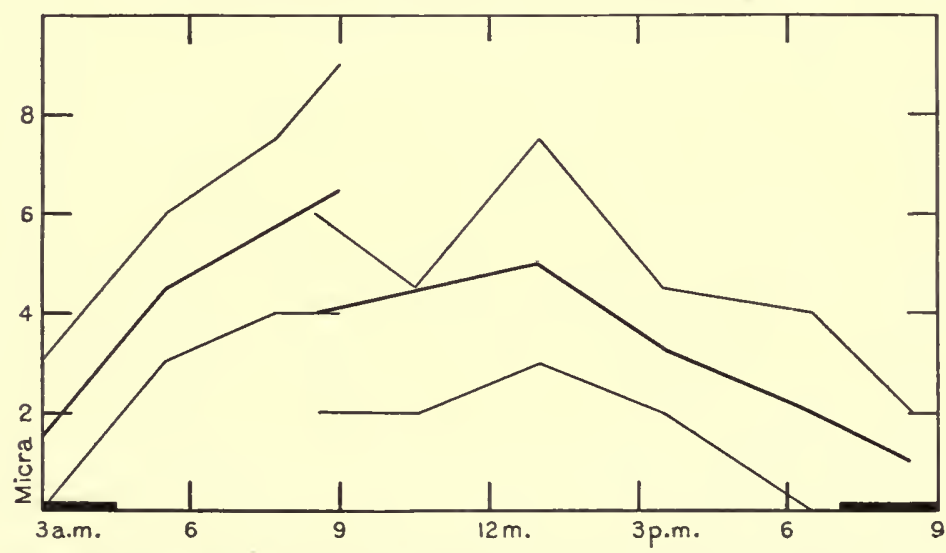

F1G. 35.-Stomata, lower surface, secondary leaves of Fouquieria splendens, July 2728, 1906. Curves of extreme and mean transverse diameter. (Curve b, fig. 37.)

NORMAL STOMATAL MOVEMENT.

The amplitude of movement in the stomata of the ocotillo is not as great as in Verbena, a transverse diameter of 12 micra, when fully open, being reached usually only by the stomata found on the primary leaves. The usual maximum pore fully open does not often exceed Io micra. As in Verbena, the period of minimum starch content is that of maximum opening. Tables $5^{1}$ and $5^{2}$ and the curves in figs. 33 to 37 will give a fair idea of the usual 
course of events. In these figures the extreme measurements are plotted in thin lines and their means in heavy lines. These latter are again plotted, together with a grand mean, $d$, in fig. 37. A portion of the curve of grand means is theoretical, this being represented by a broken line.

The large proportion of stomata which failed to open is to be explained by their immature condition. The leaves were young, and were forced in the glass-house. Clearly, the maximum measurements are the more nearly normal for fully active stomata.

The stomata in ocotillo commence to open before dawn and continue to open steadily till the maximum is reached at $10^{\mathrm{h}} 3 \mathrm{O}^{\mathrm{m}} \mathrm{a} . \mathrm{m}$. The stomata of the lower surface of the secondary leaves appear to be somewhat less uniform in their behavior. Part of this appearance of the curve may very well

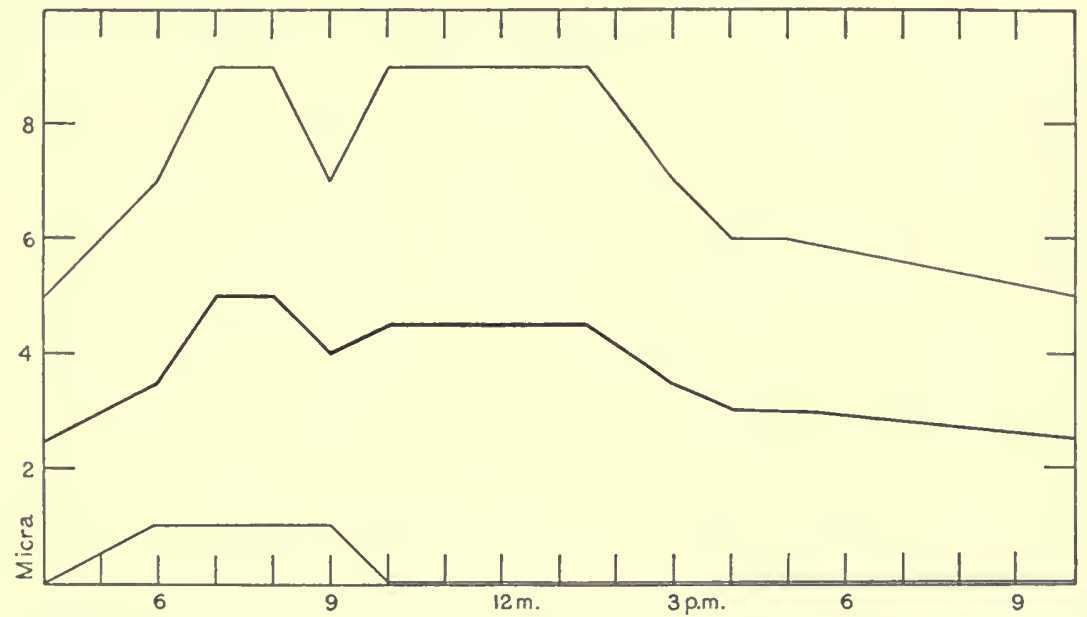

F1G. 38.-Daily periodicity of stomatal movement in Fouquieria splendens, December 17-18, 1906, from data derived from rather young leaves. Extreme measurements in thin lines; means in a heavy line.

be due to error in measurement. The position of the leaves, however, tends to render the illumination of their lower surfaces much more irregular than the upper, and this may be the explanation. The amplitude of movement of the stomata of the primary leaves is one-fourth greater than that of the stomata of the upper surface of the secondary leaves. Francis Darwin (1898, p. 589) was unable to arrive at any more definite conclusion as regards the stomata of upper and lower surfaces of the leaf of Narcissus.

After the maximum opening is attained, the stomata begin to close, at first rather slowly and later (after 3 p. m.) more rapidly. The rise in the curves from 9 p. m. on is due, I believe, to the lack of observations between that hour and $3 \mathrm{a} . \mathrm{m}$. The differences in the size of the openings on clear and cloudy days are small. 


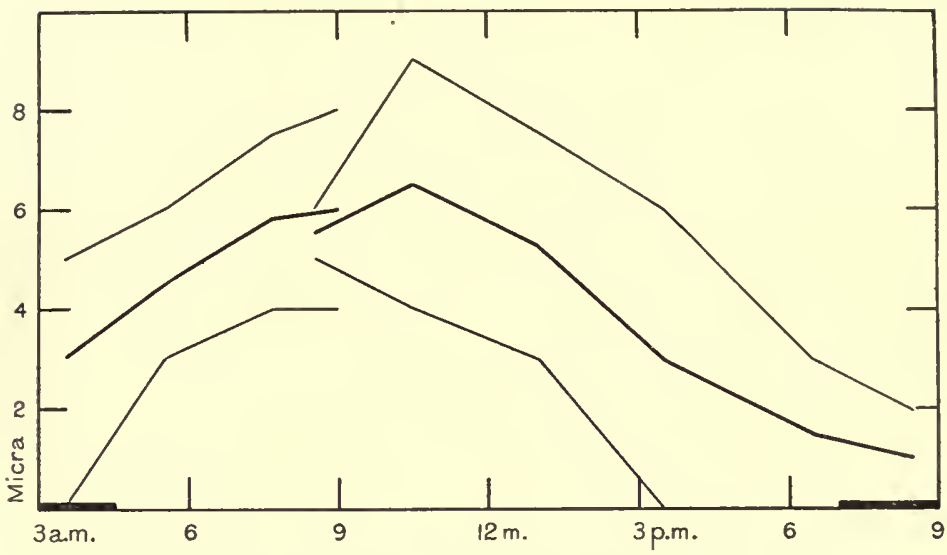

Fig. 36.-Stomata, upper surface, secondary leaves of Fouquieria splendens, July 27-28, 1906. (Curve $c$, fig. 37.)

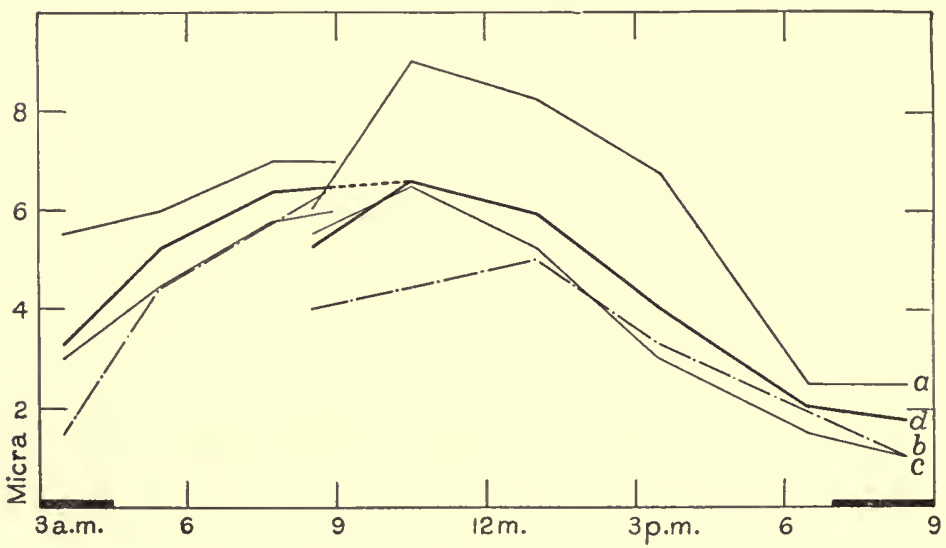

Fig. 37.-Curves of means in figs. 34,35 , and 36 , with grand mean of same (d).

TABLE 52a.-Sizes of stomatal openings under normal conditions. Tumamoc Hill, December 17-18, 1906. (Fig. 38.) Fouquieria splendens. Measurements in micra.

\begin{tabular}{|c|c|c|c|c|c|c|}
\hline $4^{\mathrm{h}} \mathrm{OO}^{\mathrm{n}}$ & p. m.......... & o to 4 & I to 4 & I to $6(7)$ & o to 6 & Sundown. \\
\hline 500 & p. m.......... & & & - 6 & $\ldots \ldots$ & \\
\hline 600 & p. m.......... & o & $6(7)$ & $\ldots \ldots$ & $\ldots \ldots$ & \\
\hline Io 00 & 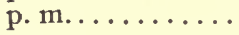 & $5(6)$ & $3(4)$ & $\ldots \ldots$ & $\ldots \ldots$ & \\
\hline 400 & a. m.......... & $5(7)$ & 3 & o to 3 & o to $5(6)$ & \\
\hline 500 & a. $m \ldots \ldots \ldots \ldots$ & 4 & 0 & o 6 & $\ldots \ldots$ & \\
\hline 600 & a.m.......... & $0 \quad 3(7)$ & o & (o) 2 to 6 & $\ldots \ldots$ & Sunrise. \\
\hline 700 & a. m......... & (o) I to 7 & 2 & $\cdots \cdots$ & $\ldots \ldots$ & \\
\hline 800 & a.m.......... & I to 6 & $\mathbf{I}$ & 3 to 6 & $\ldots \ldots$ & \\
\hline 900 & 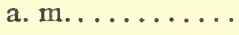 & I 7 & 2 & $\ldots \ldots$ & $\cdots \cdots$ & \\
\hline Io 00 & 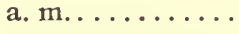 & 7 & & o to 9 & $\ldots \ldots$ & \\
\hline I 30 & p. m......... & o & $\ldots \ldots$ & $\ldots \ldots$ & $\ldots \ldots$ & \\
\hline 300 & p. m......... & o & $\ldots \ldots$ & $\ldots \ldots$ & $\ldots \ldots$ & \\
\hline
\end{tabular}


SUMMARY.

The chief conclusions to be drawn from the above observations are:

(I) The starch content of the stomata in the plants studied fluctuates between a maximum quantity in the early morning and in the evening and a minimum at about 9 to $1 \mathrm{r}$ a. $\mathrm{m}$.

(2) Oil is also present (in Verbena) in complementarily fluctuating quantities, the maximum amount being present at 9 to $1 \mathrm{I}$ a.m., with minimum amounts during the night.

(3) The stomata open and close rather slowly and maintain a maximum opening for about 3 hours from 9 a. $\mathrm{m}$. to 12 day. This maximum can not be said to be strictly constant, but the differences are but slight and within the personal error of observation.

Stomatal closure occurs in the early afternoon, advancing steadily till nightfall. It is difficult to correlate this with changes in the surrounding media.

The disappearance of starch during the earlier part of the day is out of accord with present views of stomatal metabolism. The plastids of the guardcells have been regarded as strictly photosynthetic (except when non-green), and the movements of stomata have been connected with this process. The above observations have made necessary, therefore, experimentation directed to test the photosynthetic theory, and these are now to be presented.

\section{RELATION OF STOMATA TO CERTAIN PARTS OF THE SPECTRUM, TO DARKNESS AND TO AIR DEVOID OF CARBON DIOXID.}

In view of the theory enunciated by von Mohl and supported by Schwendener and others, that the movements of the stomata are dependent upon the changes in turgor of the guard-cells, and these in turn upon the photosynthetic activity of the chloroplasts of the guard-cells, the behavior of stomata, and in particular the internal activities of the guard-cells under the conditions implied in the wording of the above caption, are of prime importance. 'This was recognized by Francis Darwin, who, in 1898, investigated in this field as regards stomatal movement; and his results, together with the earlier ones of Leitgeb (1888), Kohl (1895), and Schellenberg (1896), are those which must be especially noticed in connection with the following data.

\section{METHOD.}

In carrying out the experiments either cuttings were employed or branches of the experimental plant still attached were inclosed within a large bell-jar, either single-walled or double-walled, or, when it was desired to exclude the light, a good sized "olla," the local Papago Indian water-jar, was used (see plate 5). The interior temperatures were controlled within normal limits by 
swathing the bell-jars on one side with cloths kept wet by irrigation, the rapid evaporation having a sufficiently cooling effect. In but few instances did the temperature get beyond normal limits, and then not sufficiently high to vitiate the results of the experiments. The objections which might be raised to the use of cuttings are disposed of by the uniformity of results obtained by both methods employed. The high humidity of the interior, which may be objected to, may, I believe, be disregarded, since there is no evidence that this condition materially modifies the processes within the guardcells; while its influence upon the size of the stomatal openings is exerted only indirectly, as in the case of wilted plants. In the $\mathrm{CO}_{2}$-free air experiments the composition of the air within the bell-jars was controlled by means of caustic potash and lime or baryta water.

The data obtained include not only the size of the stomatal openings, but the conditions of the starch and oil content of the guard-cells and the starch content of the near-by chlorenchyma. Observations of the chlorenchyma adjacent to the stomata have been made in every case, since it offers a convenient and very necessary standard by which to judge the condition of the starch content of the guard-cell. The estimation of the amount of starch present in the plastids is purely a matter of judgment, based upon constant experience. The stomata were examined after proper treatment with potassium iodide-iodine by means of a Leitz I / 6 oil immersion, which was used also in making the photomicrographs. For clearing, which is not always necessary but preferable for photography, glycerine or chloral hydrate was used. In order to swell the starch grains I had recourse to boiling, or chloral hydrate or potash. The latter two reagents, however, as is well known, disorganize the starch, so that their use is not to be depended upon, especially when very small granules are to be examined. Experience taught me that even boiling was of little value, as one then has to depend upon a more or less vague color effect merely, while in the unaltered material the size of the granules of starch is quite apparent after some practice in observation. Material in the fresh condition and after treatment with absolute alcohol has in all cases been used, the latter being better, inasmuch as the iodine reaction is not then masked by the presence of the chlorophyll in the adjacent cells. The photographs were, for the greater part, made from specimens of epidermis mounted in temporary fashion in absolute alcohol or in glycerine-iodine solution, the former for the size of the stomatal apertures and the latter for the starch content. In all cases epidermis of the same collection was examined at least twice, and usually three times, at considerable intervals of time, in some cases after the lapse of a year. In this way a valuable check on one's personal judgment may be obtained. 


\section{THE RED AND BLUE REGIONS OF THE SPECTRUM.}

The relation of the various parts of the spectrum to stomatal activity has been studied by Kohl (1895) and by Francis Darwin (1898). According to Kohl, the rays between $\mathrm{B}$ and $\mathrm{C}$ and the rays near $\mathrm{F}$ (from $\mathrm{F}$ up to the edge of the violet) in the blue are alone effective. In his experiments he used Trianea, the stomata of which opened in the red light between $\mathrm{B}$ and $\mathrm{C}$ in 9 minutes, completing the opening in 17 minutes, and in the blue light in 7 minutes, completing the movement in 25 minutes. In the yellow-violet, ultra-red, and ultra-violet no movement took place.

Darwin's results accord with Kohl's so far as the red end of the spectrum is concerned. He failed to find the blue end had any decided effect, but his results are not to be interpreted as militating against Kohl's, for reasons stated by Darwin.

In carrying forward the following experiments, I have paid attention only to the two ends of the visible spectrum, using bichromate of potash and ammoniacal copper sulphate solution modified by suitable colors, so that, when examined spectroscopically, there was a complete separation of the red and blue ends of the spectrum. The solutions were contained in Sach's double-walled bell-jars.

\section{RED LIGHT.*}

Experiment 212.-Verbena ciliata, April 24, 1906. Twig remaining attached to the plant arranged under double-walled bell-jar holding modified potassium-bichromate mixture. Set up $4^{\mathrm{h}} 30^{\mathrm{m}}$ a. m., irrigated with water to prevent overheating.

$4^{\mathrm{h}} 3 \mathrm{O}^{\mathrm{m}}$ a. m., temperature $56^{\circ} \mathrm{F}$. Starch absent from chlorenchyma. Present in abundance in guard-cells; plastids large and densely staining; separate starch grains scarcely distinguishable; no oil; o to 3 micra (plate 9, fig. 1).

I $\mathrm{I}^{\mathrm{h}} 3 \mathrm{O}^{\mathrm{m}} \mathrm{a}$. m.: Experiment concluded. Maximum temperature during experiment, $93^{\circ} \mathrm{F}$; air temperature, $80^{\circ}$.

Control: Starch in chlorenchyma abundant; starch in guard-cells reduced in amount, though not absent; oil present; 2 to 6,2 to 8 , o to 6 micra (plate 9, fig. 3 ).

Experimental part: Starch absent from chlorenchyma. The absence of starch appears to be due to the reduced amount of light contingent on the use of the thick layer of fluid and double glass wall, and not the result of cessation of photosynthesis. Starch is reduced in amount in guard-cells, the plastids lakey and granular with chloral-iodine; occasionally deeply staining, but in these cases the granules of starch are readily distinguishable, o to 8 micra (plate 9, fig. 2).

Experiment 214.-Verbena ciliata, April 24, 1006. Conditions as in experiment 212, but hegun at $11^{\mathrm{h}} 3 \mathrm{O}^{\mathrm{m}}$ a. m., and carried through till $6^{\mathrm{h}} 3 \mathrm{O}^{\mathrm{m}} \mathrm{p} . \mathrm{m}$.

$1 \mathrm{I}^{\mathrm{h}} 3 \mathrm{O}^{\mathrm{m}}$ a. m., control: As in experiment 212 at the same hour (plate 9, fig. 3).

$6^{\mathrm{h}} 3 \mathrm{O}^{\mathrm{m}}$ p. m., control: Starch abundant in guard-cells and in chlorenchyma; no oil; o to 2 micra.

* Between 0.54 and 0.70. 

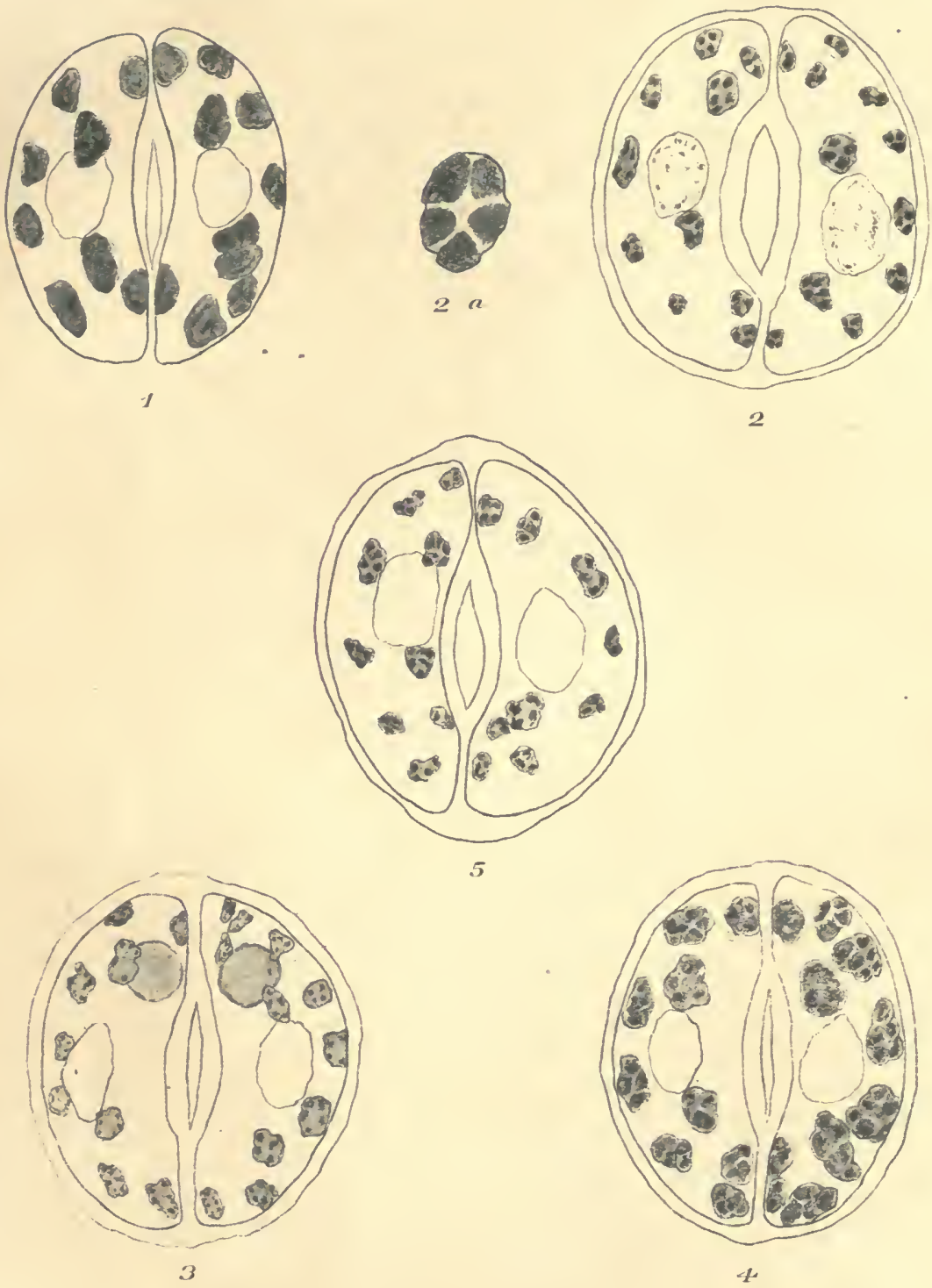

Explanation of Plate.

Stomata of Verbena ciliata at various times, under red light.

1. $4^{\text {h } 30^{\mathrm{m}}}$ a. m. Experiment 212.

2. $11^{\mathrm{b}} 30^{\mathrm{m}} \mathrm{a}$ a. $\mathrm{m}$.

2a. A single plastid from figure 2 .
3. 11 a. $\mathrm{m}$.

4. $6^{\mathrm{h}} 30^{\mathrm{m}}$ p. $\mathrm{m}$.

5. $11^{\mathrm{b} 30^{\mathrm{m}}}$ a $\mathrm{m}$.
Experiment 214, control.

" 214. 


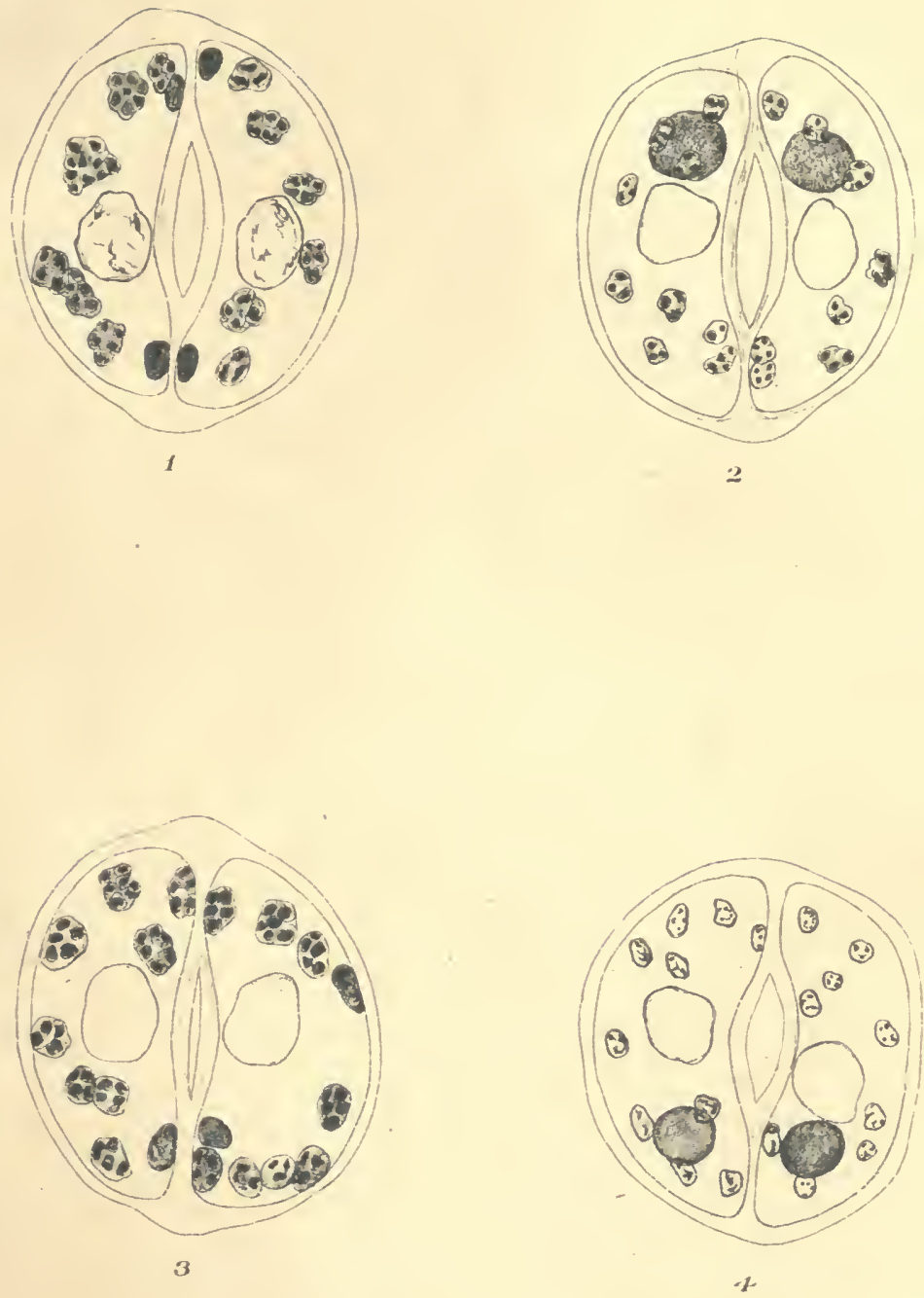

Explanation of Plate.

Stomata of Verbena ciliata under red light.
1. 6 a. m. Experiment 220, April 30.
3. 5 a. m. Experiment 220, May 3.
2. $11 \mathrm{a} . \mathrm{m}$. " " " - 

Experimental part: Starch in guard-cells as abundant as in the blue-violet test, and as abundant as in the control; abundant in the chlorenchyma; o to 2.5 micra (plate 9, fig. 4).

Allowed to remain under the bell-jar all night and experiment continued as experiment 218 on April 25.

\section{Experiment 218.-Verbena ciliata, April 25.}

Set up at $6^{\mathrm{h}} 3 \mathrm{o}^{\mathrm{m}}$ p. m., April 24, remaining upon the same twigs as were used in the previous experiment (214). Night temperature minimum, $50^{\circ} \mathrm{F}$.

$6^{\mathrm{h}} 3 \mathrm{O}^{\mathrm{m}}$ p. m., April 24, control: See 214 at the same hour.

$4^{\mathrm{h}} 3 \mathrm{o}^{\mathrm{m}}$ a. m., April 25, control: Starch absent from chlorenchyma; abundant in guardcells; no oil; o to 3 micra.

$10^{\text {h }} 3 \mathrm{O}^{\mathrm{m}}$ a. m., control: Oil drops large; starch plentiful in chlorenchyma; starch in guardcells depleted but not absent; 2 to 4 micra.

$\mathrm{II}^{\mathrm{h}} 3^{\mathrm{m}}$ a. m., control: Oil drops very large; 4 to 8 micra; starch content of guard-cells low, presumably at the minimum.

Experimental part: Bell-jar maximum temperature, $95^{\circ} \mathrm{F}$; air temperature maximum, $95^{\circ} \mathrm{F}$; starch in guard-cells plentiful; plastids do not stain deep black usually, but the granules are often indistinguishable; no oil. In many stomata the starch is in very reduced amounts. Average condition shown in the illustration (plate 9, fig. 5); 4 to (8) 10 micra.

$$
\text { Experiment 220.--Verbena ciliata. }
$$

Red bell-jar set over twigs attached to plants at 6 a. m., April 27, and allowed to remain for several days. Irrigated to keep cool.

April 3o, 6 a.m.: Oil drops small, but at normal size for this time of the morning; 2 to 7 micra; starch absent from the chlorenchyma, but moderately abundant in guard-cells; plastids large usually, but not deeply staining; based on three examinations, the last with KI-I, using oil immersion $\mathrm{I} / \mathrm{I} 6$ and oc. 3 ; maximum temperature for period, $95^{\circ} \mathrm{F}$. (plate Io, fig. I).

April 30, II a. m., control: 4 to Io micra; starch abundant in chlorenchyma; in small amount in guard-cells.

Experimental part: Starch in guard-cells rather meager, in about the same amount as in the control; plastids smaller than at 6 a. m., otherwise appearing equally dense in staining; occasional stomata with deep-staining, large plastids; starch meager in chlorenchyma; 4 to I micra (plate ro, fig. 2).

May 3, 6 a. m.: Oil drops as before, viz, small or not evident; 2 to 7 micra; moderate amount of starch in guard-cells; none in chlorencliyma (plate ro, fig. 3).

Control: Starch plentiful in guard-cells; a little in chlorenchyma.

II $^{\mathrm{h}} 3 \mathrm{O}^{\mathrm{m}}$ a. m.: Maximum temperature for period, $95^{\circ} \mathrm{F}$.

Control: As usual at this hour.

Experimental part: 6 to I 3 micra; little or no starch in guard-cells; moderate amount in chlorenchyma (plate 10, fig. 4).

SUMMARY, RED LIGHT.

Experiments begun early in the morning, when the starch content is at the maximum, and concluded at the time of the normal starch minimum, show that in red light-

(I) The starch in the guard-cells is reduced in amount.

(2) Oil drops are not formed in the guard-cells.

(3) Starch is formed in the chlorenchyma.

(4) The stomata open. 
When begun at the time of starch minimum, as the day advances-

(I) Starch is increased in amount in the guard-cells.

(2) Oil is reduced in amount.

(3) The starch content of the chlorenchyma continues to increase.

(4) The stomata gradually close.

The conclusion to be drawn is, therefore, that the course of events is normal as regards both the guard-cells and chlorenchyma and as regards the movements of the stomata. Such quantitative differences as were observed may be referred to the reduced amount of illumination available under the conditions of the experiments. Differences of this kind become more marked when the experimental conditions are long sustained, as in experiment 220 displayed above. As there shown, the starch in the guard-cells and chlorenchyma appears to become somewhat depleted, and this is referable to a slight general starvation. The same thing, but more pronounced, has been shown to occur in the corresponding experiment with the blue light, for which see beyond (fig. 39).

\section{BL,UE I,IGHT.*}

Experiment 217.-Verbena ciliata, April 25.

Set up at $6^{\mathrm{h}} 3 \mathrm{o}^{\mathrm{m}}$ p. m., Apri! 24 , bell-jar remaining upon the same twigs as were used in experiment 215 , beyond; night minimum temperature, $50^{\circ} \mathrm{F}$.

$6^{\mathrm{h}} 3 \mathrm{o}^{\mathrm{m}}$ p. m., April 24, control: Starch in guard-cells approaching its maximum; no oil; starch in chlorenchyma plentiful; o to 2 micra.

$4^{\mathrm{h}} 3 \mathrm{o}^{\mathrm{m}}$ a. m. April 25, control: Starch abundant in guard-cells, but no oil; minute granules of starch in chlorenchyma (chloral-iodine); o to 3 micra.

$\mathrm{IO}^{\mathrm{h}} 3^{\mathrm{O}} \mathrm{m}$ a. m., control: Oil drops; starch plentiful in chlorenchyma; starch depleted but not absent from guard-cells; 2 to 4 micra.

I $^{\mathrm{h}} 3 \mathrm{o}^{\mathrm{m}}$ a. m., control: Oil drops very large; 4 to 8 micra; starcls content of guard-cells low, presumably at minimum.

Experimental part: 2 to 8 micra; no oil; bell-jar maximum temperature, $90^{\circ} \mathrm{F}$; air temperature, $95^{\circ} \mathrm{F}$. (plate $\mathrm{ir}$, fig. 6 ).

The starch in the guard-cells is entirely absent from certain stomata which are wide open and their plastids small. Some stomata, however, have rather large plastids and appear lakey, while a few are deeply-staining. An average stoma, as regards starch, appears as at the same hour on the $24^{\text {th }}$ (experiment 2 I 2, plate 9, fig. 2). The a mount of starch appears to be correlated with the degree of opening. No starch in chlorenchyma.

A particular stoma with a very wide opening (8 micra) was noted; the plastids were very small and but little starch was present, in minute granules. 

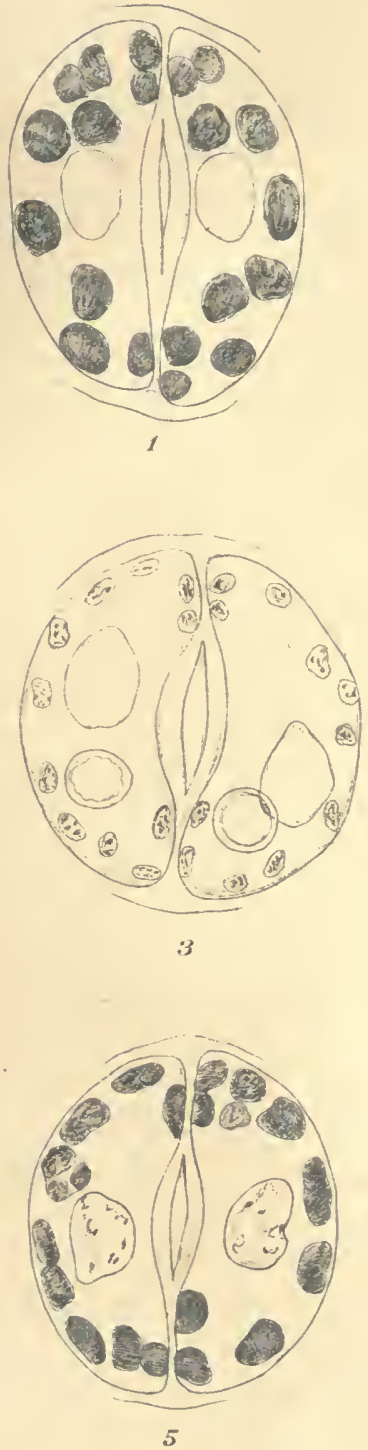
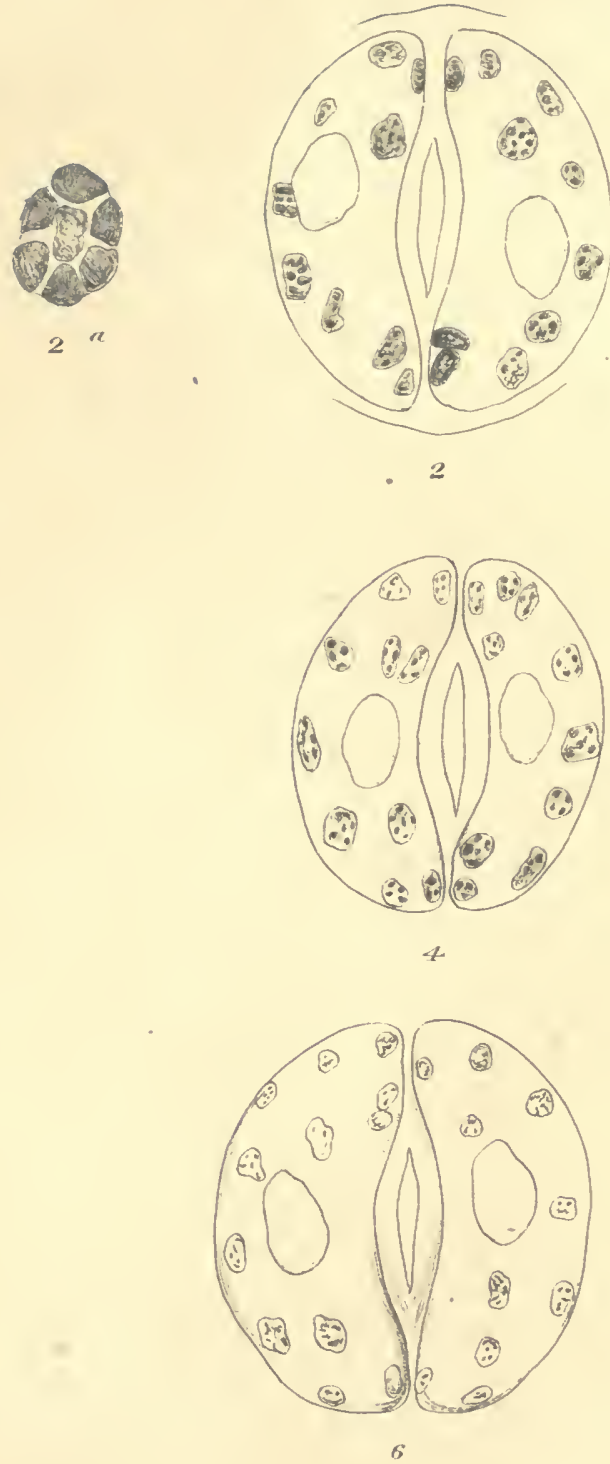

Explaxatiox of Plate.

Stomata of Verbena ciliata at various times, under blue light.

1. $4^{\mathrm{b}} 30^{\mathrm{m}}$ a, m. Experiment 213 .

2. $11^{\mathrm{b}} 30^{\mathrm{m}}$ a. $\mathrm{m}$. " "

2a. A plastid from figure 2 .

3. $11^{\text {b } 30^{\mathrm{m}}}$ a. $\mathrm{m}$. Experiment 213 , cuntrol.
4. $11^{\mathrm{t}} 30^{\mathrm{m}}$ a. m. (Cf. figure 3.) Experiment 215 .

5. $6^{\mathrm{b}} 30^{\mathrm{m}}$ p. in. " " " " "

6. $11^{\mathrm{h}} 30^{\mathrm{m}}$ a. m. Experiment 217. 

Experiment 213.-Verbena ciliata, April 24, 1906. Twig remaining attached to plant arranged under double-walled bell-jar holding ammoniated copper solution, modified by gentian violet. Spectrum shows blue and violet. Set up at $4^{\mathrm{h}} 3 \mathrm{o}^{\mathrm{m}} \mathrm{a}$. m.; irrigated with water to prevent overheating.

$4^{\mathrm{h}} 3 \mathrm{O}^{\mathrm{m}}$ a. m.; temperature $56^{\circ} \mathrm{F}$; control: Starch abundant in guard-cells; no oil; minute granules in chlorenchyma (chloral hydrate-iodine); o to 3 micra (plate I I, fig. 1).

$6^{\mathrm{h}} 3 \mathrm{om}^{\mathrm{m}}$ a. m., control: Oil drops begin to be formed and appear large and abundant at 9 a. $\mathrm{m}$; starch reduced in amount, as evidenced by the distinctly granular appearance of the plastids when iodine is applied.

I $\mathrm{I}^{\mathrm{h}} 3 \mathrm{O}^{\mathrm{m}}$ a. m.: Experiment concluded; maximum temperature during experiment, $79^{\circ} \mathrm{F}$.

Control: Starch in quite small quantities in guard-cells; abundant in chlorenchyma; oil drops large; 2 to 8 micra (plate I I, fig. 3 ).

Experimental part: No starch in chlorenchyma; reduced amount in the guard-cells; 2 to 6 micra; oil absent. In some guard-cells the amount of starch is almost if not quite as great at $4^{\mathrm{h}} 3 \mathrm{o}^{\mathrm{m}}$ a. m., but in others it is absent or nearly so. In an average one the plastids are lakey and evidently granular; o to 3 micra, o to 5 micra (plate 11 , fig. 2 ).

Experiment 215.-Verbena ciliata, April 24, 1906. Conditions as in experiment 213, but begun at $I^{\mathrm{h}} 30^{\mathrm{m}}$ a. m., and continued till $6 \mathrm{p}$. $\mathrm{m}$.

$I^{\mathrm{h}} 3 \mathrm{O}^{\mathrm{m}}$ a. $\mathrm{m}$., control: Starch present in guard-cells, but in reduced amount, as indicated by the weak reaction; abundant in some stomata; starch in chlorenchyma abundant; oil present in guard-cells; 2 to 9 micra (plate I I, fig. 4).

$6^{\mathrm{h}} 3 \mathrm{om}^{\mathrm{m}}$ p. m., control: Starch present in guard-cells in much greater quantity than at $1 \mathrm{I}^{\mathrm{h}} 3 \mathrm{O}^{\mathrm{m}}$ a. $\mathrm{m}$.; an increased quantity of starch in chlorenchyma over that at $1 \mathrm{I}^{\mathrm{h}} 3 \mathrm{O}^{\mathrm{m}} \mathrm{a} . \mathrm{m}$.; no oil present; o to 2 micra.

Experimental part: Plastids densely-staining, indicating an increased amount over the normal at $\mathrm{I}^{\mathrm{h}} 3 \mathrm{O}^{\mathrm{m}}$ a. m.; no oil; $\mathrm{I}$ to 6 micra; a small amount of starch in the chlorenchyma, certainly less than at $\mathrm{II}^{\mathrm{h}} 3 \mathrm{O}^{\mathrm{m}}$ a. m. (plate $\mathrm{II}$, fig. 5).

Allowed to remain under bell-jar all night and experiment continued on April 25 as experiment 217 , on the preceding page.

Experiment 219.-Blue bell-jar set over twigs attached to plants at 6 a. m., April 27, to be allowed to remain thus for several days. Irrigated to keep cool. Maximum and minimum thermometer within.

April 30, 1906, 6 a. m., o to 2 (3) micra; oil drops present but quite small, i. $e_{\text {., normal }}$ for this time of the morning; starch meager or absent in guard-cells, but variable in amount, sometimes plentiful, $i$. $e_{\text {., }}$ in very occasional and for the most part young stomata; no starch in chlorencliyma. These results are based on four separate examinations, the last two examinations with $\mathrm{KI}+\mathrm{I}$ under oil immersion I/I6 and oc. 3. Occasionally a young stoma having one guard-cell with abundant starch and the other with none. Maximum temperature for period, $86^{\circ} \mathrm{F}$.

April 30, I I a. m., control: Guard-cell starch rather meager but evenly distributed in all the stomata; starch in chlorenchyma plentiful.

Experimental part (two samples): Starch entirely absent from both guard-cells and chlorenchyma, not a trace being visible; 2 to 8 micra.

May 3, 6 a. m.: Oil drops as on April 30 at the same hour; no evidence of starch in chlorenchyma or guard-cells; o to 2 micra.

$\mathrm{II}^{\mathrm{h}} 3 \mathrm{O}^{\mathrm{m}}$ a. m.: Maximum temperature for period, $100^{\circ} \mathrm{F}$. 
Control: Guard-cell plastids appearing more granular than at 6 a. m., and smaller; starch less in amount, but not very much difference; oil drops large; starch in chlorenchyma plentiful.

Experimental part: No starch in guard-cells or chlorenchyma; 2 to 6 micra; scarcely one ent irely closed.

SUMMARY, BLUE LIGHT.

In plants exposed to blue-violet light during the early part of the morning, between the time of normal maximum and minimum starch content-

(I) The starch content of the guard-cells is reduced.

(2) The oil is not formed.

(3) Starch is not formed in the chlorenchyma.

(4) The stomata open, but not so much as normally or as in red light.

When the experiment is started at the time of normal starch minimum-

(I) The starch content increases in the guard-cells.

(2) The oil is reduced to the minimum.

(3) The starch content of the chlorenchyma decreases.

(4) The stomata gradually close.

With the exception of the smaller amplitude of stomatal movement as compared with red or normal illumination, the course of events is normal and is so as regards the behavior of starch. The failure to form oil in the early part of the day is to be noted.

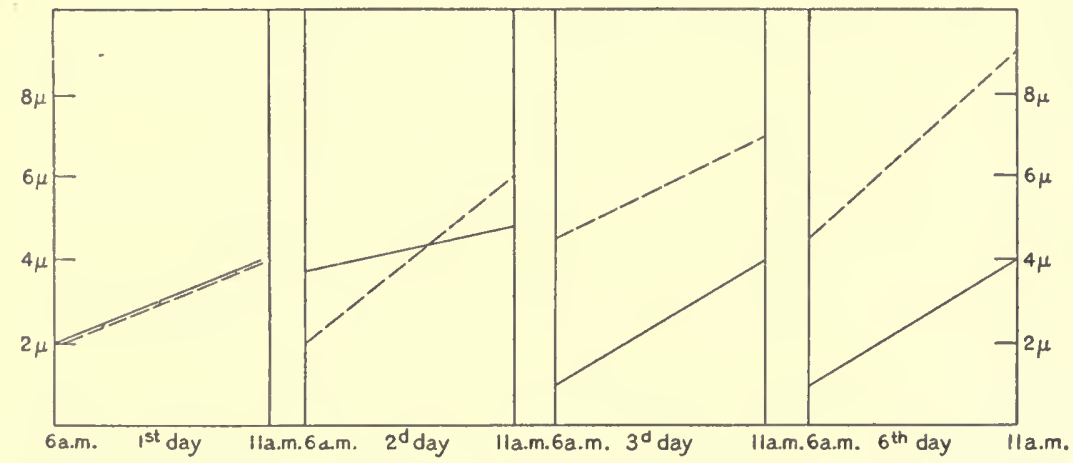

Fic. 39.-Effect of prolonged exposure to red (broken line) and to blue light on the amplitude of stomatal movement, Verbena ciliata.

When the period of experimentation is extended over several days, the gradual disappearance of starch from the stomata is to be noted, and this may be referred to the generally starved condition of the leaf. Movements of the stomata continue, however. They open toward i i a. m. and gradually close toward evening. The maximum opening is, however, slowly reduced (see fig. 39). 
DARKNESS.

Concerning the relation of prolonged darkness to the physiological activity of stomata we have some data, but the effect of this condition upon the contents of the guard-cells has received scant attention. Francis Darwin (1898), by means of the horn hygroscope, came to the conclusion that "there is a tendency to a gradual opening of the stomata in continued darkness, " though with the "same irregularity" that he had "noted in regard to nocturnal closure."

Sachs (1862, p. 369; Beilage, 1863 , p. 4), pointed out that starch occurs in the guard-cells of etiolated plants, and that stomata develop completely in entire darkness. Similarly, Leitgeb (I 888) found that, in the etiolated petioles of Crambe cordifolia, in the complete absence of chlorophyll, and entirely without the influence of light, the stomata were wide open, and that the guard-cells were filled with starch. MacDougal (I903), also, noted that the stomata in many plants which had been grown in total darkness were open. It seems clear from previous studies that stomata may perform movements, at least the opening movement, and that starch may accumulate in the guard-cells, in the entire absence of light.

As in the case of the other experiments to determine the effect of the several factors upon the changes in the character of the contents of the guardcells, I have taken advantage of the presence and absence of starch in the early and late hours of the morning, respectively, to begin experiments at these times, thus enabling me to determine if the amount of starch and of oil will decrease in the dark, and also if it will increase, and what is the behavior of the stomata as to movement.

\section{VERBENA.}

Experiment 208.-Cutting placed in dark at II a. m., March 28, till 3 p. m., March 29.

A moderate amount of starch in the chlorenchyma, but none in the stomata at the beginning of the experiment. At the close of 28 hours' exposure to darkness, a medium amount of starch is found in the guard-cells, but no trace in the chlorenchyma. Stomata closed, but as the leaves were slightly wilted no conclusion may be drawn.

Experiment 144.-July 4, 1905. In darkness from 8 a. m. on.

July 4,8 a. $\mathrm{m}$. Cutting placed in the dark, 2.8 to $8.4 ; 5.5$ to 8.4 micra.

II a. m. Little or no starch in guard-cells; 2 to 3 micra.

I p. m. Starch in the guard-cells; 2 to 3 micra.

$3^{\mathrm{h}} 5^{\mathrm{m}} \mathrm{p} . \mathrm{m}$. Starch plentiful in the guard-cells, but none in the palisade tissue.

7 p. m. Starch plentiful in the guard-cells, but none in the palisade tissue.

July $5,8 \mathrm{a}$. m. Stomata contain plenty of starch and are 2 to 5.5 micra open.

NorE.-Apparently a slight opening at the close of 24 hours. 
Experiment ${ }_{154}$ - -Verbena, July 10, 1905. Cutting placed in the dark room at $8^{\mathrm{h}} 55^{\mathrm{m}}$ a. $\mathrm{m}$.

July $10,8^{\mathrm{h}} 55^{\mathrm{m}}$ a.m. Starch in very small amount, appearing as minute granules in the pale plastids; 5.5 to 10 micra.

$1 \mathrm{O}^{\text {h }} 3 \mathrm{O}^{\mathrm{m}}$ a. $\mathrm{m}$. No increase of starcl $\mathrm{observable;} 2.8 ; 2.8$ to 5.5 micra.

Control: 2.8 to $7 ; 4$ to $7 ; 2.8$ to 5.5 micra. Little if any increase of starch observable.

$\mathrm{I}^{\mathrm{h}} 5^{\mathrm{m}} \mathrm{p} . \mathrm{m}$. Small increase of starch; if anything more in the dark-room plant than in the control. Abundant starch in the chlorenchyma of control, but in the experimental plant no more than at $8^{\mathrm{h}} 55^{\mathrm{m}}$ a. m.; 2 to 5 micra. A few extreme measurements: closed and 5.5 micra; control, o to 3 micra.

July 11,8 a.m. 2 to 5.5 ; o to 5 micra. Comparison with the control shows a distinctly greater starch content in the guard-cells of the experimental plant. Experimental cutting placed in strong diffused light at this time.

$\mathrm{II}_{\mathrm{I}} \mathrm{O}^{\mathrm{m}} \mathrm{a} \cdot \mathrm{m}$. Closed; o to 3 ; o to 4 micra. The younger stomata are those chiefly closed, while the mature ones are usually open to 2 to 4 micra. Very little starch in the mature stomata, but considerable amounts in the young ones. The specimens taken turned out to be rather young and had in consequence a large number of undeveloped stomata. The large proportion of closed stomata is attributed in part to this. Starch granules in the chlorenchyma quite obvious.

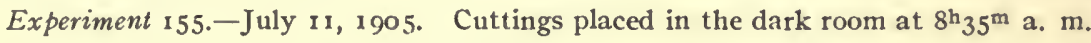

July $\mathrm{II}, 8^{\mathrm{h}} \mathrm{r} 5^{\mathrm{m}}$ a. $\mathrm{m}$. Control: Little starch in guard-cells; oil present.

$8^{\mathrm{h}} 35^{\mathrm{m}}$ a. m. Control: No starch in guard-cells; oil bodies at maximum; cuttings placed in the dark; control pieces taken also from the cuttings showed no starch in guard-cells, and oil drops large; starch in chlorencliyma; 4 to $9 ; 2.8$ to $8.4 ; 2.8$ to 8.4 micra.

July $12,8^{\mathrm{h}} 5^{\mathrm{m}}$ a. $\mathrm{m}$. No oil drops; starch abundant in guard-cells in large granules, the plastids appearing wholly stained with iodine; none in the chlorenchyma; o to 2.8 (7) micra, 80 per cent closed; o to 4 micra, 70 per cent closed.

I p. $\mathrm{m}$. Starch still present in guard-cells.

July 13, 8 a. m. Only an occasional stoma has starch; 90 per cent closed, the rest open to a slit of 1 or 2 micra; no starch in chlorenchyma; in malformed guard-cells a large amount of starch is to be found, and this is true also of perfect guard-cells when they are paired with imperfect ones. Part of the material placed in the strong diffused light of a north window at this time $(8 \mathrm{a} . \mathrm{m}$.) with the following results:

$9^{\mathrm{h}} 45^{\mathrm{m}}$ a. m., in diffused light. Minute granules have appeared in the clilorenchyma, but none as yet in the guard-cell plastids.

${ }_{1} 2^{\mathrm{h}}{ }_{1} 5^{\mathrm{m}}$ p. m. in diffused light. Stomata closed, save for a few which are opened to a slit of $\mathrm{I}$ or 2 micra; the plant is partly wilted; stem trimmed; stomata of leaves which are submerged in the water of the vessel in which the cutting stands are widely open, but no starch is to be seen in them.

3 p. m. in diffused light. Distinctly deeply-stained starch grains in the chlorenchyma; a small amount in fine granules in the guard-cell plastids.

6 p. m. Light. A distinct increase of starch in the guard-cell, though not abundant.

July 14,7 a. m. Part of experimental material, after 3 days in the dark room, has stomata ranging from o to 4 micra in width, 50 per cent being 2 micra; starch content of guard-cells varies from a little to abundance; none in cllorenchyma.

Summary of 144, 154, and 155.-When material is taken at the time of minimum starch content, maximum oil content, and maximum opening, and placed in the dark the oil apparently does not reappear. Starch increases during the first 24 hours, and shows a decrease at the end of 48 hours. In the 

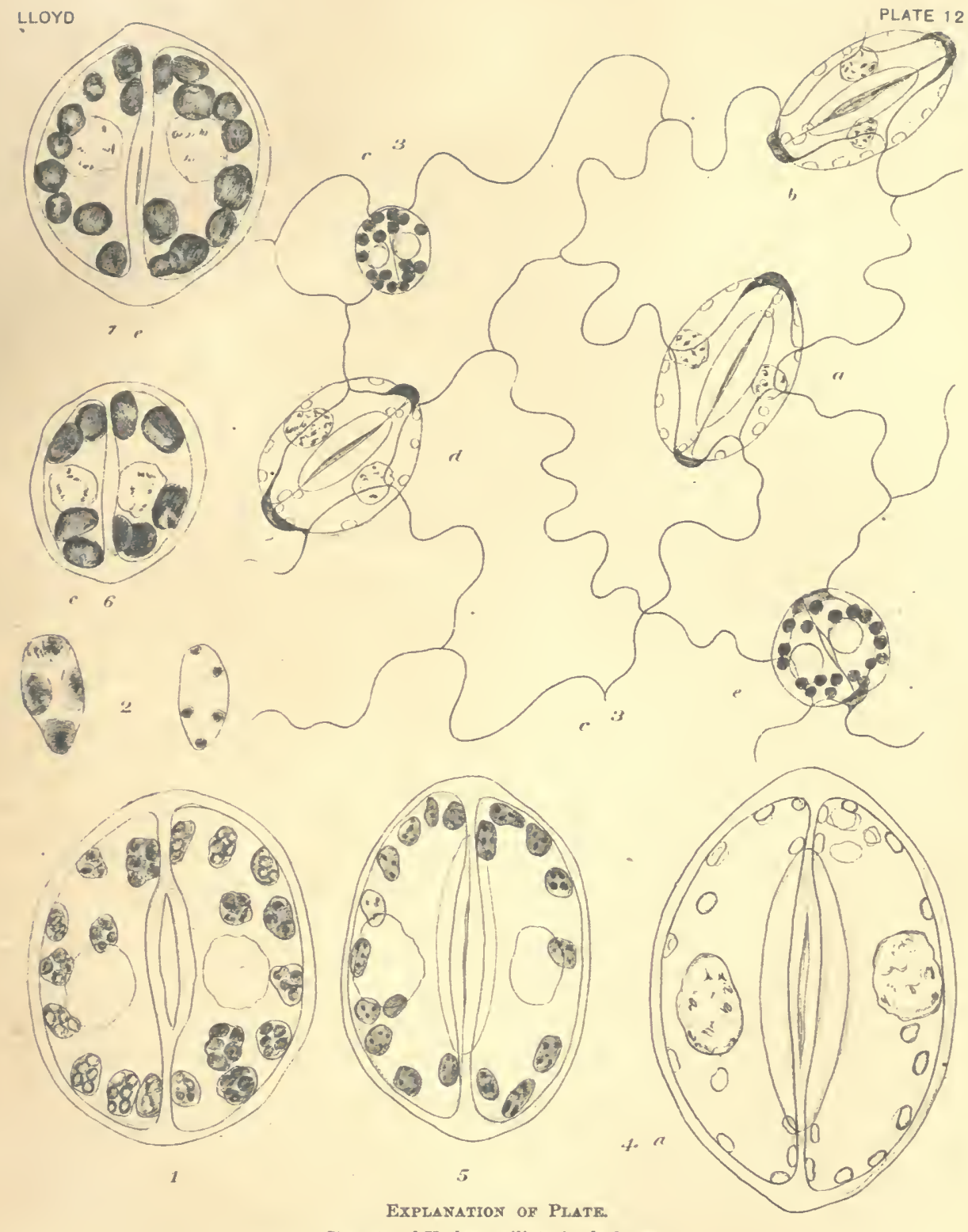

Stomata of Verbena ciliata in darkness.

1. $11^{\mathrm{h}} 30^{\mathrm{m}} \mathrm{a} . \mathrm{m}$., March 30 . Experiment 210.

2. Two plastids showing extremes of starch content at 6 a. m. Experiment 210.

3. A group of stomata, $11 \mathrm{a}$. m., January 11. Starch is absent from the mature stomata, $a, b$, and $d$, but is present in abundance in the young ones, $c$ and $e$ (tgures 6 and 7 ).

4. A mature stoma containing no starch, 11 a. m., January 11.

5. Stoma at 11 a. m., January 12 , after 24 hours of darkness. Cf. figure 4 , which is the control. 6 and 7. Young stomata containing an abundance of starch. 

subsequent 24 hours, the third day in the dark, the starch content increases irregularly as regards different stomata.

After placing in the dark the stomata close as normally and remain so. A slight opening may occur between sunrise and $8 \mathrm{a} . \mathrm{m}$. on the second day. The starch content of the guard-cells is uneven at this time and the slight opening of some stomata may be correlated with this condition. The starch content of the chlorenchyma disappears once for all after a few hours.

When stomata, taken at any time in the progress of the experiment, are placed in water, they open to from 2.8 to 8.4 micra.

When, after exposure to darkness for 24 and 48 hours, the plant is placed in strong diffused light, the starch appears in the chlorenchyma more rapidly than in the plastids of the guard-cells. Assuming that the guard-cell plastids are capable of photosynthesis, this may mean that the products of this activity are used too rapidly to allow accumulation of starch, or on the contrary assumption, that the stomata have to draw upon the chlorenchyma for the materials which they use. There remains the possibility that both of these conditions obtain in part. It remains clear that the stomata are less starved than the chlorenchyma.

Experiment 2 10.-Verbena, March 30 , I906. Cutting taken $5^{\mathrm{h}} 3 \mathrm{O}^{\mathrm{m}}$ a. m. and placed in dark.

$5^{\mathrm{h}} 3 \mathrm{O}^{\mathrm{m}}$ a. m. Normal; starch in abundance in the guard-cells; absent from the majority of the chlorenchyma cells but found in some, due probably to a small amount of photosynthesis. (See also experiment 209.)

$1 \mathrm{I}^{\mathrm{h}} 3 \mathrm{O}^{\mathrm{m}}$ a. $\mathrm{m}$. Experimental. o to 5 micra; starch abundant in the guard-cells; none in chlorenchyma (plate 12, fig. I).

Experiment 151 Ia.-Verbena ciliata, July 9, 1904. Prolonged darkness. Cutting in water, placed in dark room at $6 \mathrm{p}$. m.; starch in chlorenchyma and in guard-cells.

July $10,7^{\mathrm{h}} 5 \mathrm{O}^{\mathrm{m}}$ a. m. Starch abundant in stomata; o to $3 ;$ I to 7 ; o to $3 ; 50$ per cent closed; no starch in chlorenchyma.

${ }^{\mathrm{h}} 3 \mathrm{O}^{\mathrm{m}} \mathrm{p} . \mathrm{m}$. Starch reaction in mature stomata as marked in control; reaction is not equal in all stomata, and is more pronounced in young ones; 2 to 5.5 micra.

July II, 7 a. m. o to 3 ; o to 5 ; o to 2 micra, 90 per cent closed; starch plentiful in mature stomata; absent from very young ones; smaller amounts in half-grown ones; none in chlorenchyma; no oil.

8 a. $\mathrm{m}$. Cutting placed in strong diffused light.

I I a. m. 2 to 5.5 micra. Very little starch in guard-cells, except in those of very young stomata, which show a little; no starch in the chlorenchyma; no oil in the guard-cells.

When stomata which are plentifully supplied with starch were subjected to darkness, the starch was retained, so that even at the end of a period of 36 hours the quantity was not observably different from the amount in the stomata of the control. They opened but little, if at all. When after prolonged exposure to the darkness such stomata were exposed to light at $8 \mathrm{a} . \mathrm{m}$. there followed, during the ensuing 3 hours, a reduction of the amount of starch in the guard-cells. 
The stomata, being less than half open at the beginning of the experiment, remained so, though closures become more pronounced during 36 hours. Placed, at the end of 36 hours, for 3 hours in diffused light, a measurable though not a great amount of opening movement occurred, while the starch was reduced.

Experiment 221.-Verbena ciliata, April 27-May 3, 19c6. Twig in situ covered with an olla, and irrigated; twig kept in dark for 6 days. Set up on April 27, 1907, at 6 a. m.

April 30, 6 a. m. Oil drops small but normal; stomata closed, or a mere slit; starch absent fron chlorenchyma; starch present in guard-cells in meager but variable amount; sometimes plentiful; three examinations; the last with $\mathrm{KI}+\mathrm{I}, \mathrm{I} / \mathrm{I} 6 \mathrm{oil}$ imm., oc. 3 .

April 30, is a. m. Control (see experiment 219, p. I 13).

Experimental part: Starch in guard-cells absent or in very minute quantities; none in chlorenchyma.

May 3, 6 a. m. Oil drops as before, viz, small or not evident; no evidence of starch in guard-cells or chlorenchyma; an occasional stoma 3 micra in diameter; others closed.

Control: Starch abundant in guard-cells; a little in the chlorenchyma.

II a. m. Control (see experiment 219).

Experimental part: No starch in the guard-cells or chlorenchyma.

The following three experiments were carried out to determine especially if oil accumulates in the guard-cells in the dark:

Experiment $160 .-J u l y ~ 14,1905$. Taken at $6^{\mathrm{h}} 5 \mathrm{O}^{\mathrm{m}}$ a. m., at which time no oil drops were visible; starch in guard-cells in fine granules; 2 to 5 , mean about $4 ; 2$ to 11 ; mean about 6 to 7 micra (the latter piece had very large stomata).

$\mathrm{I}_{1}^{\mathrm{h}} 3 \mathrm{O}^{\mathrm{m}}$ a. m. Control: Oil drops large; no obvious change in starch content; 8.5 to 14 micra.

Experimental part: No oil visible, nor change in starch content; 2 to $6 ; 2$ to $8.5 ; 4$ to 8 micra.

No oil was formed in the dark during the period when, under normal conditions, this occurs. The similar amounts of starch in the control is shown by other experiments not to be due to the absence of change in the amount, but to the return, after the minimum, which occurs about 8 to $9 \mathrm{a} . \mathrm{m}$., to the increased, but not maximum amount.

Experiment 168.-Verbena ciliata, July 15, 1905.

$5^{\mathrm{h}} 3 \mathrm{o}^{\mathrm{m}}$ a. m. Cuttings placed in the dark room. 5.5 to $8 ; 2.8$ to 8.5 micra; no oil drops. $9^{\mathrm{h}} 4^{\mathrm{m}} \mathrm{a}$. m. Starch plentiful in guard-cells, but no oil drops; no starch in chlorenchyma; 2.8 to 7 micra, a few with openings 8.5 micra.

Control: 5.5 to 8.5 micra; oil present.

Experiment 202a.-Verbena ciliata, March 17, 1906.

$5^{\mathrm{h}} 3 \mathrm{o}^{\mathrm{m}}$ a. m. Cuttings placed in the dark room. Starch abundant in guard-cells; absent from chlorenchyma; no oil in guard-cells.

i a. m. Control: Starch absent from guard-cells: abundant in chlorenchyma; oil drops large in guard-cells.

Experimental part: Starch present in guard-cells; absent from chlorenchyma; no oil. (See experiment 201a.) 
The conclusion reached was that the accumulation of oil does not take place in the absence of light. The retention of starch and the inhibition of opening in the absence of light is to be noted.

$$
\text { Experiment 300.-Verbena ciliata, January II, } 1907 .
$$

II a. m. Control showed no starch in the guard-cell, though a considerable amount in the chlorenchyma. The guard-cell plastids were very small (plate 12 , figs. $3, a, b, d$, and 4 ). Jan. I2, I a. m., after darkness for 24 hours. Guard-cell plastids fully twice the diameter and showing a distinct though not very pronounced general reaction. The black granules, however, very distinct. Stomata 1 to 7 micra open; no starch in the chlorenchyma; no starch in guard-cells of control (plate 12, fig. 5).

The accumulation of starch at this time of the year is not as rapid as in the warmer months. The same experiment was tried on December 27, 1906, but the temperature was too low and the result of the trial was negative. January I I was unusually warm and the opportunity was used to repeat the experiment, with the above result.

SUMMARY FOR VERBENA.

When the experimental conditions are imposed upon the plant in the early morning, when the starch content is at its maximum and the oil at the minimum, we find that during the following few hours, during which the starch is normally reducing and the oil increases to a maximum-

(I) The starch content of the guard-cells is not reduced.

(2) The oil does not increase in quantity.

(3) Starch is not formed in the chlorenchyma.

(4) The stomata open little if at all.

On the other hand, if the experiments are begun late in the morning, at a time when the starch is absent and oil is present, and when a certain amount of starch has already appeared in the chlorenchyma, we find that-

(I) The starch is reformed more or less rapidly in the guard-cells.

(2) The oil disappears.

(3) The starch disappears from the chlorenchyma.

(4) The stomata gradually close.

During prolonged exposure for 3 days to darkness, starch continues to be found, but no oil. After 6 days the general starvation of the leaf becomes so pronounced that little or no starch may be found in the stomata. After such extended subjection to darkness, upon being placed in the light starch appears first in the chlorenchyma. The stomata do not, taken collectively, become wide open, although, as Francis Darwin noticed, some opening does take place. There is, however, considerable variation in the size of the stomata. In one instance a maximum width of Io micra (Verbena) was seen after 7 hours of darkness. 


\section{ADDITIONAL, EXPERIMENT'S.}

Experiment I5I, Fouquieria splendens.-After 20 hours in total darkness, the stomata were open about 3 micra, some as wide as 9 micra.

On a shoot kept in constant darkness for 3 days young etiolated leaves formed. The stomata of these leaves were open, though not widely, since they were too young.

After 5 days the mature leaves of the same shoot continued to show plenty of starch in the guard-cells till the leaves commenced to drop off. Even during abscission the starch is not removed from the stomata.

Experiment 164.- After constant darkness for 15 hours, the stomata measure, at $\mathrm{I}^{\mathrm{h}} \mathrm{O}_{\mathrm{O}} \mathrm{m}$ a. m., 2 to 6 micra.

Experiments 163 and 165.- After 15 hours' darkness, the stomata are 2 to 4 micra. Scarcely any wholly closed.

Experiment, Iris sp.-A plant was etiolated for 30 days (June 12 to July 12 , 1906) and at the end of this period both young and mature stomata were found abundantly supplied with starch. No change in the form of the stoma could be observed, either in this or some other experiments made with the same species.

The constant occurrence of a considerable amount of starch in the stomata after so long an exposure to darkness, as here observed, and as noted also by others elsewhere mentioned, appears to be contingent, in part at least, upon the possession by the plant of a store of food material.

Analogous is the occurrence of starch in the guard-cells on the underground parts of the leaves of Brodica, which are found abundantly supplied with starch, and the stomata open (January 5, 1907).

\section{CONCLUSION.}

The conclusion may be drawn that the absence of light does not result in the loss of starch by the guard-cells as by the chlorenchyma, nor in the inhibition of its accumulation, if the necessary materials are available in the leaf-tissues, or elsewhere. The possession of chlorophyll by the stomata of many plants under complete or much prolonged etiolation (Sachs, MacDougal) as in the Iris sp. studied, may be explained by the availability of starch in storage organs, which are a source of energy for plants deprived of light. Thus seedlings grown in feeble light or deprived of carbon dioxid have been shown to transfer their starch from one point to another (Böhm, 1874; Schimper, 1880 ).

The opening of stomata is not entirely inhibited when the usual stimulus is removed and darkness is more or less prolonged, though the cause for such movement is obscure, as was observed by Leitgeb and Francis Darwin. Darwin criticized Leitgeb's explanation that the opening is due to the moist atmosphere, and justly. The same thing occurs at low humidities. It is, however, not obvious how Darwin's own explanation, that the guard-cells are 
"less resistant" than the epidermal cells, losing their turgor earlier, may be applied to much prolonged darkness, unless there is something going on within the guard-cell to keep up the supply of osmotic materials beyond the amount occurring in the epidermal cells. The point will be referred to later.

\section{EXPERIMENTS WITH AIR FREE OF CARBON DIOXID.}

\section{BEGINNING AT SUNRISE.}

Experiment 167.-Verbena ciliata, in air deprived of carbon dioxid. July 15, 1905.

A good-sized sprig was placed, shortly after sunrise, at $5^{\mathrm{h}} 5^{\mathrm{m}}$ a. m., under a bell-jar, together with a vessel of strong potassium-hydrate solution offering a large surface to the air. The whole was exposed to the light, but the interior kept at normal temperature by means of a wet cloth on the outside of the bell-jar. Starch abundant and oil absent from the guard-cells.

July I $5,8^{\mathrm{h}} 4 \mathrm{O}^{\mathrm{m}}$ a. m. Control piece: Oil present, starch abundant in chlorenchyma; a small amount of starch in the guard-cell plastids.

Experimental piece: Oil absent, excepting in very small droplets in some cells; no trace of starch in the majority of guard-cells, although in very young stomata there is plenty of starch; starch absent from the chlorenchyma cells.

July 17,9 a. m. The cutting taken at sunrise on July ${ }_{5} 5$ has been kept under the bell-jar till this time, $i$. e., for 52 hours, during the day time in the diffused light of the laboratory; starch absent from chlorenchyma but present in abundance in guard-cells, from which, however, oil is absent. ( $C f$. experiments $20 \mathrm{I} a$ and $20 \mathrm{I} b$, which gave similar results.)

Experiments 201 a and 201b.-March 17, 1906. Cuttings of Verbena placed in bell-jar in air deprived of $\mathrm{CO}_{2}$ and $(a)$ placed in the light, (b) placed in the dark. Set up at $5^{\mathrm{h}} 3 \mathrm{om}^{\mathrm{m}} \mathrm{a} . \mathrm{m}$. Oil in large drops in guard-cells or entirely absent. (See table 53.)

Conclusion.-Starch disappaars from the guard-cells in the absence of $\mathrm{CO}_{2}$ in the light, as it does normally; it is not formed in the chlorenchyma. Oil is apparently not formed as uniformly, although it occasionally appears. The stomata opened. In the dark, in absence of $\mathrm{CO}_{2}$, the starch is not removed from the guard-cells, nor does oil appear in them. Starch is not formed in the chlorenchyma, as is to be expected.

Experiment 209.-March 29, I906. Cutting placed under bell-jar in air- $\mathrm{CO}_{2}$ at $5^{\mathrm{h}} 3 \mathrm{O}^{\mathrm{m}}$ a. $\mathrm{m}$. The condition of the air in the bell-jar was controlled by potassium hydrate and lime water; concluded at $\mathrm{II}^{\mathrm{h}} 3 \mathrm{O}^{\mathrm{m}}$ a. m., bell-jar $25^{\circ}$ to $30^{\circ} \mathrm{C}$.

$5^{\text {h }} 30^{\mathrm{m}}$ a. m. Normal; starch present in abundance in guard-cells; absent from many chlorenchyma cells, but found in small grains in many; o to 3 micra; plastids large.

$\mathrm{II}^{\mathrm{h}} 3 \mathrm{O}^{\mathrm{m}}$ a. m. Normal; oil drops, usually 2 in guard-cells, and of good size; 4 to 8 micra; starch in small amount in the guard-cells; plentiful in the chlorenchyma; plastids small.

Experimental: No oil; 6 to 8 micra; starch in small amount in the guard-cells, but none in the chlorenchyma.* Plastids small.

* The occurrence of starch in the stomata in the $1 \mathrm{Ih} 3 \mathrm{O}^{\mathrm{m}}$ material, similar amounts in both experimental and control, is due, I believe, to the fact that the material was, unavoidably, not taken at the critical period. 
Conclusion.-The stomata behaved alike in the presence and in the absence of $\mathrm{CO}_{2}$. In the absence of $\mathrm{CO}_{2}$, oil failed to appear in the guard-cells.

TABLE 53.-Data of experiments $201 a$ and 201 .

\begin{tabular}{|c|c|c|c|}
\hline Time. & Control. & $\begin{array}{l}\text { Experiment } 201 a \text {, in } \\
\text { the light without } \\
\mathrm{CO}_{2} \text {. }\end{array}$ & $\begin{array}{l}\text { Experiment 201b, in } \\
\text { the dark without } \\
\text { CO. }\end{array}$ \\
\hline $5^{\mathrm{h}} 3 \mathrm{O}^{\mathrm{m}}$ a. m. & $\begin{array}{l}\text { Starch abundant in guard- } \\
\text { cells; starch absent from } \\
\text { chlorenchyma; oil ab- } \\
\text { sent from guard-cells; } \\
\text { o to } 3 \text { micra. }\end{array}$ & & \\
\hline $\begin{array}{c}9^{\mathrm{h}} \mathrm{I}^{\mathrm{m}} \text { a.m. } \\
\text { t. } 20^{\circ} \mathrm{C} .\end{array}$ & $\begin{array}{l}\text { Starch abundant in chlor- } \\
\text { enchyma; starch nearly } \\
\text { gone from guard-cells; } \\
\text { oil in small drops. }\end{array}$ & & \\
\hline${ }_{10}{ }^{h} \mathrm{O}^{m}$ a. $\mathrm{m}$. & $\begin{array}{l}\text { Starch absent from guard- } \\
\text { cells; starch abundant } \\
\text { in chlorenchyma; oil in } \\
\text { small drops. }\end{array}$ & & \\
\hline I I hoom a. $\mathrm{m}$. & $\begin{array}{l}\text { Starch absent from guard- } \\
\text { cells. } \\
\text { Starch abundant in chlor- } \\
\text { enchyma. } \\
\text { Oil drops large in guard- } \\
\text { cells. }\end{array}$ & $\begin{array}{l}\text { Starch absent from } \\
\text { guard-cells. } \\
\text { No starch in chlo- } \\
\text { renchyma. } \\
\text { Oil in large drops } \\
\text { in few stomata. } \\
\\
5 \text { to ro micra..... }\end{array}$ & $\begin{array}{l}\text { Starch abundant in } \\
\text { guard-cells. } \\
\text { No starch in chloren- } \\
\text { chyma. } \\
\text { No oil in guard-cells. } \\
\text { Control (normal air } \\
\text { in dark): Starch in } \\
\text { guard-cells; no oil; } \\
\text { no starch in chloren- } \\
\text { chyma. } \\
\text { o to } 3 \text { micra. }\end{array}$ \\
\hline
\end{tabular}

Experiment 211.-March 31, 1906. Cutting placed in air deprived of $\mathrm{CO}_{2}$; potassium hydrate, and lime water under bell-jar. Set up at $6^{\mathrm{h}} 3^{\mathrm{m}} \mathrm{a} . \mathrm{m}$.

$6^{\text {h }} 3 \mathrm{om}^{\mathrm{m}}$ a. $\mathrm{m}$. Normal; starch abundant in the guard-cells; very minute granules visible in the chlorenchyma plastids; no oil in stomata; 2 to 6 (8) micra (plate 13, figs. 2 and 3 ; plate I 4 , fig. I).

II a. m. Normal; starch in chlorenchyma; little or none in guard-cells; oil; 4 to 8 micra (plate 13 , figs. 4 and 5 ).

Experimental: Moderate amount of starch in chlorenchyma, none in stomata; oil drops large; bell-jar temperature $42^{\circ} \mathrm{C}$; 3 to in micra; no trace of precipitate in the lime water (plate 13 , figs. 6 and 7 ; plate 14, fig. 2).

Conclusion.-In the absence of $\mathrm{CO}_{2}$ the reduction of starch during the early hours of the day took place as under normal conditions. In this case oil was formed also, as is true under normal conditions. As should be expected, starch was not formed in the chlorenchyma in excess of the amount already present at $6^{\mathrm{h}} 3 \mathrm{O}^{\mathrm{m}}$ a.m., I.5 hours after sunrise. 


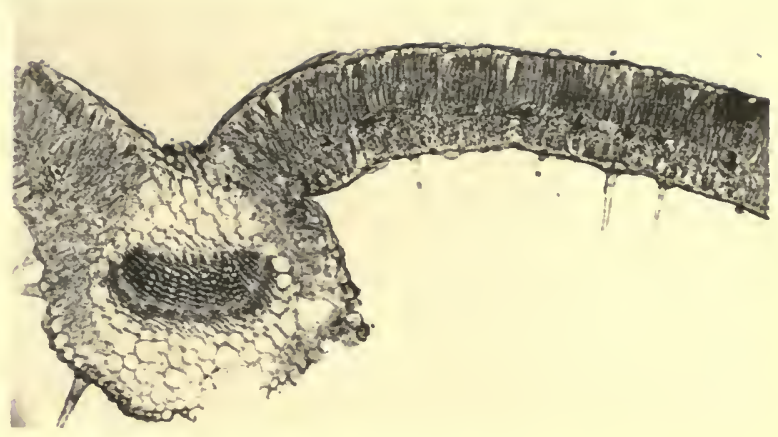

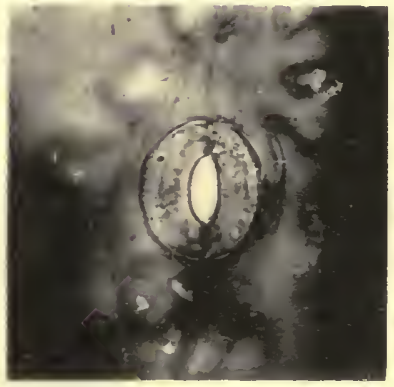

2

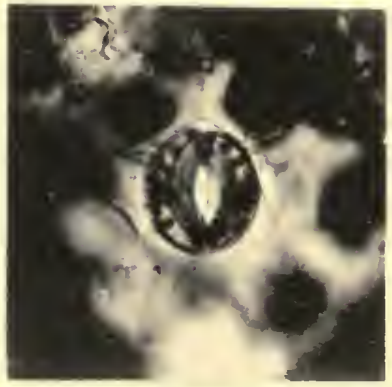

5

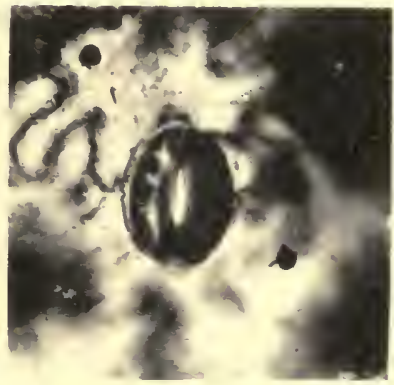

3

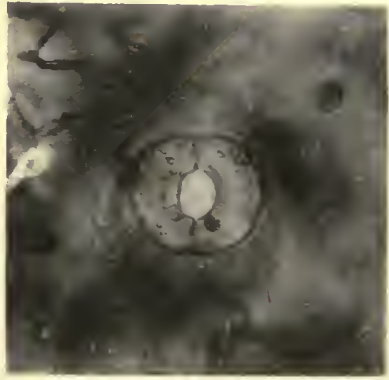

6

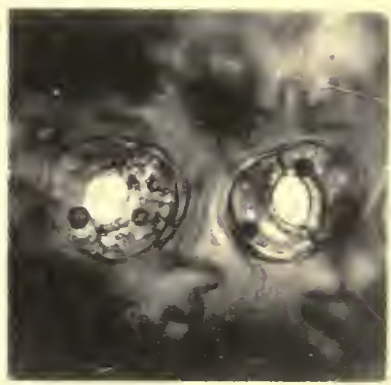

4

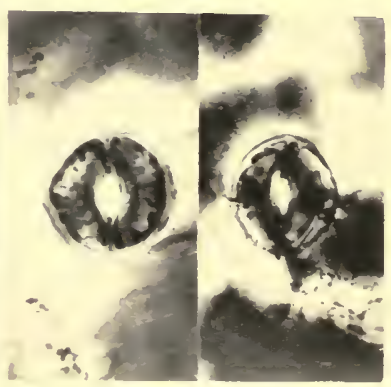

7

1. Transverse section of leaf of Verbena ciliata. The substomatal spaces below stomata of upper surface may readily be seen.

Figs. 2-7. Stomata of Verbena ciliata in air deprived of carbon dioxid.

2. Normal condition at $6 \mathrm{~h} 30 \mathrm{~m}$ a. $\mathrm{m}$. Fixed with absolute alcohol. No oil is visible. The starch content may be seen in fig. 3 .

3. Normal starch content at $6 \mathrm{~h} 30^{\mathrm{m}}$ a. $\mathrm{m}$. Stained with iodine after boiling.

4. Normal condition at 11 a. m. Fixed with absolute alcohol. Oil drops may be seen. The starch content may be seen in fig. 5 .

5. Normal starch content at 11 a. $\mathrm{m}$. Stained with iodine after boiling.

6. Stoma in air deprived of carbon dioxid at $11 \mathrm{a} . \mathrm{m}$. Fixed with absolute alcohol. Compare with fig. 4. Oil drops are present. The starch content is small, as is seen in fig. 7 .

7. Stoma in air deprived of carbon dioxid at $11 \mathrm{a} . \mathrm{m}$. Boiled, and then stained with iodine The plastids are small. 


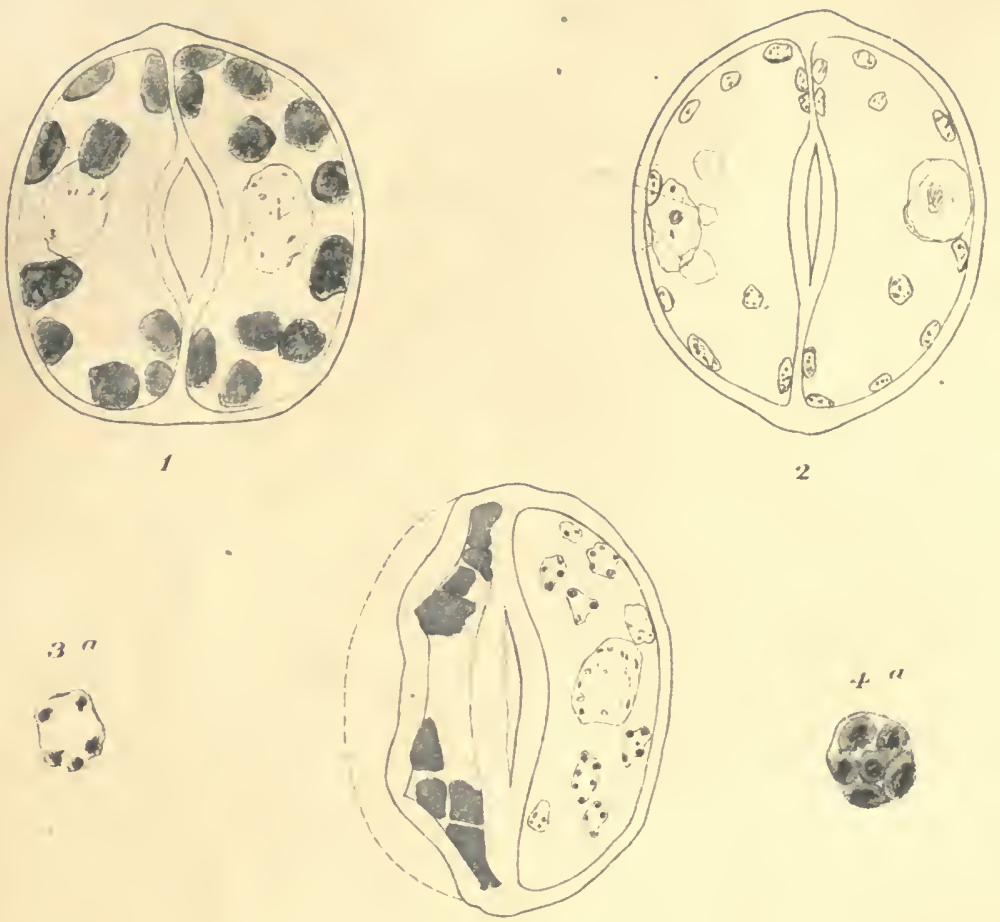

5
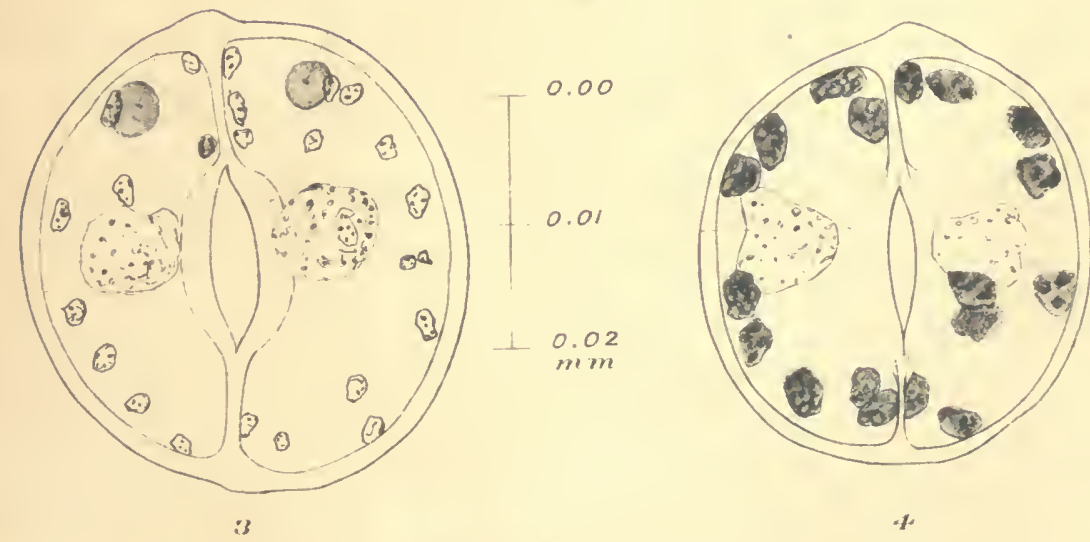

Explanation of Plate.

Stomata of Verbena ciliata in air deprived of carbon dioxid.
1. $6^{\mathrm{h}} 30^{\mathrm{m}}$ a. m. Experiment 211.
2. 11 a. $\mathrm{m}$.
4. $7^{\text {b }} 30^{\mathrm{m}}$ p. m. Experiment 207.
3. 11 a. $\mathrm{m}$.
"4
3a. A plastid from figure 3 .
4a. A plastid from tigure 4.
5. 6 a. m. April 30 and May 3. Stoma with . one dead guard-cell, this containing an abundance of starch. 

The formation of oil may be connected with the high temperature which occurred in the bell-jar, which was $15^{\circ} \mathrm{F}$. higher than outside.

\section{EXPERIMENTS COMMENCING AT TIME OF MINIMUM STARCH CONTENT OF THE GUARD-CELLS.}

Experiment 161.-Verbena ciliata, July 13, 1905. A shoot remaining attached to the experimental plant covered by a bell-jar, and a vessel of potassium hydrate introduced. The interior temperature kept normal by wet paper on the outside of the bell-jar.

$9^{\mathrm{h}} 2 \mathrm{O}^{\mathrm{m}}$ a. $\mathrm{m}$. Temperature, $3 \mathrm{I}^{\mathrm{o}}$ in bell-jar; starch in guard-cell plastids in minute granules; stomata open wide; otherwise as in experiment 162 , at the same hour.

$9^{\mathrm{h}} 45^{\mathrm{m}}$ a.m. Temperature, $30.5^{\circ}$ in bell-jar.

$12^{\mathrm{h}} 45^{\mathrm{m}}$ p. m. Temperature, $30.5^{\circ}$; oil present in a few cells; little or no change apparent in the starch content of the guard-cell plastids, if anything a little more; no observable difference between experimental and control leaves.

Conclusion.-Oil disappeared slowly; starch formed slowly if at all; change not marked in 3 hours.

Experiment $162 .-$ Verbena ciliata, July 14,1905 . A good-sized cutting was placed under a bell-jar, together with a vessel of potassium-hydrate solution, with large surface exposed. Set up at $9^{\mathrm{h}} 3^{\mathrm{m}}$ a. m.

$9^{\mathrm{h}} 2 \mathrm{O}^{\mathrm{m}}$ a. $\mathrm{m}$. Starch in minute granules in the guard-cell plastids; oil drops large; pore 4 to 8 micra wide, mean about 6 micra; starch in chlorenchyma abundant.

$5^{\mathrm{h}} 45^{\mathrm{m}} \mathrm{p}$. m. Starch abundant in guard-cells, but no oil; the guard-cells of control contain perhaps a trifle more starch; openings 4 to 8 micra wide; when placed in water they open to 8 to II micra; starch in chlorenchyma much reduced.

July 15,5 a. $\mathrm{m}$. Starch in guard-cell plastids very abundant, and the grains so large that they can not be delimited from each other; ro oil; starch in chlorenchyma; openings o to 8.5 micra. Of the material taken for examination, one large piece shows many stomata closed entirely, but about to per cent rather widely open ( 8.5 micra); another piece shows the same range of size, but with numerous intermediate sizes. In the various pieces a few stomata are found as wide as II micra.

In carrying out the above experiment the temperature was kept normal and fairly constant by keeping wet a jacket of thick bibulous paper on the outside of the bell-jar. The whole was exposed to strong diffused light.

Conclusion.-In absence of $\mathrm{CO}_{2}$ the oil disappears; starch is formed to, or near to, the maximum amount in 8 hours. In this instance closure of stomata was not prompt.

\section{Experiment 203.}

A cutting, taken on March 17 , I906, at ${ }^{10}{ }^{\text {h}} 30^{\mathrm{m}}$ a. m., was placed in $\mathrm{CO}_{2}$ free air and allowed to remain for 52 hours. At the close of the period the stomata in general did not contain starch. Starch is, however, found in abundance in those stomata which lie near to the vascular strands.

Experiment 203a, March 19, 1906.

Duplicate of 203 , giving identical results. 
Experiment 204.-Verbena. Cutting placed in air deprived of $\mathrm{CO}_{2}$ at $10^{\mathrm{h}} 30^{\mathrm{m}}$ a. m., March 24, 1906. Normal: little or no starch in the guard-cells; entirely absent from many; oil drops large; starcl in small amounts in chlorenchyma.

8 p. m., experimental part: o to 8 micra; amount of starch in guard-cells distinctly greater and evenly distributed in the different stomata, though maximum amount is not present.

Experiment 205.-March 24, 1906 . Cutting in air deprived of $\mathrm{CO}_{2}$ in the dark at $10^{\mathrm{h}} 3 \mathrm{om}^{\mathrm{m}} \mathrm{a} . \mathrm{m}$.

At 5 p. m., the results are identical with those of the foregoing experiment, except as regards to the size of the pores, viz, 2 to 4 micra.

Experiment 207.-Air deprived of $\mathrm{CO}_{2}$ in the light. Large bell-jar luted with vaseline, with a vessel of potassium hydrate. Set up at ir a. m., March 28, r9o6. Starch abundant in chlorenchyma, but none or meager amounts of starch in the guard-cells. Oil present (plate 14, fig. 3).

$7^{\mathrm{h}} 3 \mathrm{o}^{\mathrm{m}}$ p. m. Starch very abundant in guard-cells, and present in the chlorenchyma; o to 7 micra. Maximum temperature for the period: in the foliage $28^{\circ} \mathrm{C}$.; in bell jar, $30^{\circ} \mathrm{C}$. Temperature at $7^{\mathrm{h}} 3 \mathrm{o}^{\mathrm{m}}$ p. m. $15^{\circ} \mathrm{C}$. without and within (plate 14 , figs. 4 and $4 a$ ).

Summary.-If the stomata are exposed to air robbed of the $\mathrm{CO}_{2}$ at the time of minimum starch content, reformation of starch takes place as in the normal. The starch in the chlorenchyma was undoubtedly that formed carlier in the day.

For the normal course of events on this day, see table 49, page roo, March 26-28.

Farmer \& Chandler (1902) found that the stomata of Kalanchoe grown in an atmosphere containing about 3.5 times the normal amount of $\mathrm{CO}_{2}$ (I I.47 parts per I000) were gorged with starch and were always widely open, whilst they were closed in the control. "This points to a permanent alteration of form, seeing that the material throughout was killed and preserved in spirit." They emphasized the point that in the plants treated with $\mathrm{CO}_{2}$ the chlorenchyma invariably shows an accumulation of starch, except in Kalanchoe, which is a succulent, the succulents being noted by them as having a peculiar physiology. In this plant, however, the stomata were gorged with starch, a fact of significance. At first glance the greater amount of starch in the stomata of the treated plant would appear to be due to a greater photosynthetic activity, but this conclusion does not follow of necessity. The experiment, which was, however, designed for another purpose, does not enable us to draw any conclusion as to the direct dependence of the guardcell upon the presence of $\mathrm{CO}_{2}$. The matter of a "permanent alteration of form" may be seriously questioned.

Francis Darwin (1898) concluded that "when illuminated, stomata remain open in the absence of $\mathrm{CO}_{2}$," and took issue with Schellenberg (I 896), who held the opposite view. The reason assigned by Schellenberg is that with the loss of photosynthesis there is a consequent loss of turgor. Darwin con- 
cluded that the opening of stomata is not due to the formation of osmotic materials due to photosynthesis.

I am able to agree with Darwin. Not only this, but if the plant is subjected to the experimental conditions at sunrise, before the stomata are open, they open as they would normally. And, vice versa, when they are open, they close as normally. Furthermore, the increase and decrease of starch, and probably oil, go on as in the normally conditioned plant. My conclusion is, therefore, that the presence or absence of $\mathrm{CO}_{2}$ has no direct influence on stomata, and that, physiologically, they are not at all dependent upon photosynthetic processes within the guard-cells. If this be true, the guardcell is set off as distinct physiologically from the chlorenchyma-cell. Schellenberg's explanation is therefore incorrect, and the whole prevailing theory of the relation of stomatal activity to photosynthesis is thus called into question. The mere fact that stomata open in the absence of $\mathrm{CO}_{2}$ shows conclusively that the movement is not directly connected with photosynthetic activity, even if the process takes place normally in stomata.

The reduction and increase of starch in the guard-cells, in the absence of carbon dioxid, points rather clearly to the activity of an enzyme, presumably a sort of diastase, as a factor in the mechanism, a view in accord with that of Kohl.

\section{DISCUSSION AND CONCLUSIONS.}

The facts obtained by experimentation under the above conditions, namely, in air free of carbon dioxid, in total darkness, in red light, and in blue light, accord well with the general theory that photosynthesis, even in stomata, whose plastids are well supplied with chlorophyll, plays a secondary rôle in their physiology, and is connected only indirectly with their movements $(c f$. Francis Darwin, r898, p. 615), and that, therefore, there is a marked quantitative difference between the physiology of the typical chlorenchyma-cell and that of the guard-cell. This difference lies in the quantitatively different nature of the plastids. In support of this contention the following arguments may be advanced:

(I) The formation of starch in the stoma plastids takes place in the dark, and, of course, in the absence of either red or blue light and in the absence of carbon dioxid. In the plastids (chloroplastids) of the chlorenchyma, on the contrary, in accordance with our general understanding, the accumulation of starch occurs only when carbon dioxid is available, in white light and in red light.* In Verbena ciliata no accumulation of starch has been

*Bohm (1874-7) showed that, in seedlings, starch may appear in the chloroplasts under feeble illumination and in the absence of $\mathrm{CO}_{2}$. The behavior of the chloroplasts, when starch is available, may under special conditions be very similar to that of the stoma plastids. In the present connection, we find, under the same conditions, a different behavior, which can not be referred to the "isolated" position of the stomata, since, after all, this isolation is more apparent than real. 
observed in the blue, though photosynthesis may occur to some extent. The quantitative differences noted hold for blue as well as for red light.

(2) The accumulation of starch in the guard-cells in the darkness and, it seems highly probable, in $\mathrm{CO}_{2}$-free air also, is contingent upon the presence of starch or related substances in the subjacent portions of the chlorenchyma. Following the complete removal of all carbohydrates from the leaf when subjected to suitable conditions, there ensues a gradual reduction of the starch content of the stomata. This loss is irregular as regards different stomata, those being more favorably placed as, $e . g$., near the vascular tissues, showing a less rapid loss of starch. This starvation of the leaf, and the consequent starvation of the stomata, has been shown to occur in prolonged darkness, in prolonged exposure to blue light, and we may infer also, in the continued absence of carbon dioxid, under the conditions, namely, which prevent any accumulation of starch (blue light), or prevent photosynthesis entirely, in the cells of the chlorenchyma.

When a plant in a thoroughly starved condition is exposed to diffused light, the formation of starch appears to occur less rapidly in the stomata than in the chlorenchyma.

That the guard-cells derive their starch chiefly from the underlying tissues rather than through the photosynthetic activity of their own plastids is a view strengthened by the observation that young stomata which are not yet functional, and frequently long before they are exposed to light, are found to be richly supplied with starch. The very young though completely formed stomata which are to be found near the bases of the leaves still inclosed within the terminal bud of Agave contain starch, while none of this may be detected in the leaf chlorenchyma. At this time there is no trace of chlorophyll either in the chlorenchyma or stomata. Even at an early period in the development of the leaf, therefore, the difference between the chlorenchyma and stoma plastids becomes apparent, and other evidence shows that this difference continues to obtain through the whole life of the stoma.

Starch has been shown to occur in mature stomata which have never been exposed to the light, by Sachs, Leitgeb, and MacDougal, and I have observed this to be true of other plants than those examined by these authors. It occurs also in stomata devoid of chlorophyll, according to Leitgeb (1888), and when this substance is very meager in amount, by myself.

(3) The movements of stomata take place under conditions which prevent photosynthesis, as in the absence of carbon dioxid; and in blue light ( $c f$. Kohl, I 895), when, if it takes place, it is reduced to a small amount. There is evidence also that movements occur in prolonged darkness (Francis Darwin, I 898), and the open condition has been observed in total etiolation experiments in many plants (MacDougal). There is, in addition, evidence that in 
Verbena and ocotillo prolonged darkness results in the opening and possibly the repeated opening and closing of small amplitude, of stomata (see fig. 40).

Further, the accumulation of starch in moribund cells has been observed (Dandeno) in the cells of ripe apples when affected by disease. The same result may frequently be seen in leaves ( $V$ erbena) in which, through one cause or another, portions of the chlorenchyma have been damaged and killed. When the epidermis is removed many of the cells of such dead areas are removed and stain black with iodine. It very frequently happens that the

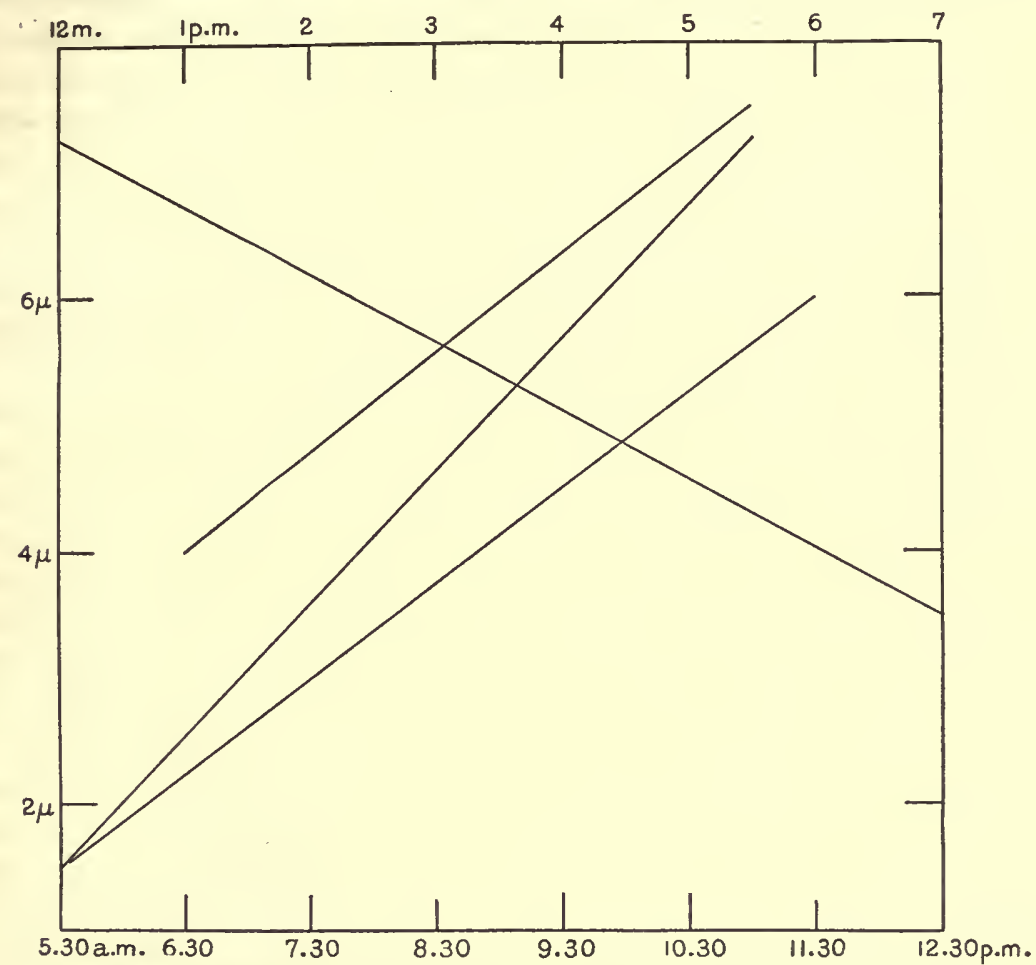

FIG. 40.-Opening (in the morning) and closing (in the afternoon) of stomata in air devoid of carbon dioxid. Verbena ciliata.

epidermis over such areas, including the stomata, is quite normal. I have noted in several instances that such stomata may be supplied with starch under conditions, as, $e . g$., in the absence of carbon dioxid, which preclude the accumulation of starch in the chlorenchyma, and when, also, the stomata above normal chlorenchyma do not contain starch (see plate 8, figs. I and 2). The stomata may have taken up materials from the underlying moribund cells. The transfer of starch from one cell to another in injured leaves (Bain, 1902) appears to be analogous behavior invoked under special conditions. 
The contrary explanation, that the moribund tissue prevented the loss of starch from the stomata, would be weakened by the fact that the materials could readily escape into the adjacent epidermal cells.

The foregoing argument, showing that stomata may be largely independent of photosynthesis, however, does not account for the function of chlorophyll in the guard-cell. According to the theory of von Mohl, the chlorophyll is fundamentally important, and Kohl, following Schwendener and Schellenberg, has strongly supported this view, having shown the opening of stomata to occur in the regions of the spectrum where the maxima of "assimilation" (photosynthesis) occur. But Darwin has met this argument by pointing out that the opening of stomata in the absence of $\mathrm{CO}_{2}$ and the persistent occurrence of starch in the guard-cells do not accord with the general view which makes the physiology of the chlorenchyma and of the guard-cell identical, though he remarks with real pertinence that "no reason has ever been given for the guard-cells behaving differently to other chlorophyllous tissues." Kohl further (r886, p.39) speaks of the "Bewegungslosigkeit" of chlorophyllfree stomata, and expresses the belief that the stimulus of light is made effective through the chlorophyll ("dass eine Reizwirkung auf das farblose Plasma der Schliesszellen nicht die Bewegung verursacht, sondern dass das Chlorophyll die Oeffungsbewegung im Lichte vermittelt"). Kohl's evidence is, however, not convincing. Leitgeb (1888) showed that the stomata in the etiolated petiole of Crambe cordifolia open, though they possess no chlorophyll, and light is completely absent. They were seen, furthermore, to be filled with starch, though this is absent from the tissues. I have confirmed Leitgeb's observations in a species of Brodicea in all points. Arguments which have been based upon observations on the white parts of leaves, assuming that the stomata lack chlorophyll, are negatived by the fact that they do possess this material, in many cases, at least. The stomata on albino shoots of Sequoia sempervirens, however, are said to lack plastids, and it would be of interest to know whether they are motile or not (G. J. Peirce, I90I).* The amount of chlorophyll in the active stomata of different plants, disregarding albinism, is so various, however, that this fact also may well be regarded as throwing doubt on the photosynthetic theory as a complete explanation of stomatal activity.

In view of the evidence that the guard-cells do behave differently from the chlorophyllous tissues under the same circumstances, $\uparrow$ for the support of

* Since writing this I have had theopportunity of examining some preserved material kindly sent me at the cost of much trouble by Dr. Peirce. I find plastids to be present in the guard-cells, and in shoots exposed to the light; that chlorophyll is formed in the plastids. I infer that the stomata are motile even in white shoots, but this conjecture needs the support of direct observation of the living material.

$\dagger$ Molisch (1897) observed that, in many plants, the guard-cells and trichomes resist lower freezing temperatures than the remaining epidermal and chlorenchyma cells. And Leitgeb (1888) adduced evidence that the stomata are able to resist higher temperatures and other 
which conclusion the evidence of the present contribution has been arraigned, we are forced to believe that the chlorophyll of the guard-cells is of relatively minor importance. The admission that the chlorophyll is active, as in the chlorenchyma cell, involves the further one that during the early part of the day, when opening takes place, photosynthesis and the dissolution of the stored starch within the chloroplasts occur at the same time in the same plastids. We must therefore favor the explanation that the products of photosynthesis, (relatively small in amount as compared with the amount available from the starch derived by translocation, and already in the plastids) do not immediately take the form of starch; but that when the maximum opening has passed they may, along with the other osmotic substances, then be formed into starch, except, of course, a part which may have escaped by diffusion. The ability of the chloroplastid to secrete starch if supplied with the appropriate materials (Meyer, r 883 ) suggests the view that, as regards their functions, the plastids of the guard-cell and of the chlorenchyma-cell differ quantitatively in that while both are capable of both photosynthesis and secretion, their normal activities in these two directions are in inverse relation. The guardcell plastid is normally and chiefly a leucoplast, while the chlorophyll-cell plastid is, in like manner, a photosynthetic organ. The relative importance of the photosynthesis in the stoma is small enough so that the movements of the stomata are affected but little by its cessation, as must in all probability intervene under conditions which are known to make photosynthesis impossible.

This view makes it possible to harmonize results such as those of Kohl on the one hand and those of Leitgeb and Francis Darwin on the other. If turgor-raising substances are present in sufficient amounts the stoma must open; and while these will be normally present, even if the appropriate conditions for photosynthesis are not supplied, yet, if photosynthesis may occur, the osmotic turgor-raising substances may thereby be additionally formed. Whether, however, the amount formed by photosynthesis is sufficient alone to effect the opening in the blue light to the extent indicated by the experiments of Kohl and those recorded by myself is not yet to be answered.

In the case of stomata with a large amount of chlorophyll, if we may assume that the effectiveness of a plastid is related to the amount of chlorophyll present in it (which is said by Pfeffer not to be of necessity the case), it may be argued that the products of photosynthesis would be sufficient to bring about

conditions generally unfavorable to the remaining tissues of the leaf. Thus in Galtonia, after an interval surprisingly long, nanely, one month, during which time the underlying tissues had become discolored and impregnated by the mycelia of fungi, the stomata remained living and were shown by him to be capable of photosynthesis. According to Molisch the "concentration of the cell sap, the size of the cells, capillarity, and the specific constitution of the plasma" all probably contribute to this result. The results of both these authors afford general support to the present contention, but are open to various interpretations, none of which are as yet proven to be true. 
the opening in blue light; but in the event that the amount of chlorophyll is small we may justifiably doubt that the substances which effect the opening are produced in great enough quantities by photosynthesis alone. The question opens a distinct and well-defined field for research which should enable us to get exact information leading to the solution of the problem at large.

The dissolution of the starch contained within the plastids of the guardcells, in regard to which there can be no doubt, introduces another phase of the problem-that, namely, as to the cause of this dissolution and of the conditions under which it may proceed. The question concerns the intimate physiology of the stoma, and is one upon which we have at present far too little light to enable us to do more than to formulate a working theory. The only contribution in this direction is that of F. G. Kohl (1895), whose argument is as follows: Recognizing that stomatal movements are caused by changes in turgor, he points out that the direct cause of these changes remained till that moment undiscovered. The fact that the guard-cells always contain an abundance of starch indicates that this plays an important rôle. The ever-present chlorophyll bodies produce in the course of their development a continually increasing amount of starch,* which is quickly changed under appropriate stimuli into powerfully osmotic substances. That these are sugars, or organic acids, failed of proof, because the former can not be demonstrated to be present in the guard-cells, and the latter are not more abundant in them than in the epidermal cells. That sugar takes a part may perhaps be inferred from the opening of stomata on being treated with a solution of diastase.

The change of starch into the problematical osmotic substances takes place for the most part in consequence of the effect of light. Kohl now asks what conditions favor stomatal opening. He shows that a rise in temperature will do so while relative humidity does not. Also the dark heat rays, and light deprived of these, cause opening. $\dagger$ Of the visible spectrum, he found that the effective light is that which lies between $B$ and $C$ and between $F$ and the beginning of the violet. In the yellow, green, violet, and ultra-violet, no movement whatever occurred. This behavior brings the stomatal movement and the maxima of photosynthesis into coincidence.

The failure of the stomata to open in the region of the violet is referred to the destructive effect of this light upon diastase, as held by J. R. Green (I897) to be the case, while the red light, especially, has the contrary effect.

\footnotetext{
* Not all of this is, however, the product of photosynthesis within the guard-cell, as above shown.

$\dagger$ Pfeffer, however, had previously shown that the dark heat rays are not "assimilatory" and, therefore, can not effect the opening of stomata by their being used in this way by the chlorophyll (Kohl, I885, p. 77). The effectiveness of the dark rays may, however, be related to their effect upon the enzyme.
} 
Kohl's conclusion is then-

Da nun an diesen Stellen des Spectrums auch die Turgorsteigerung in den Schliesszellen, welche zur Oeffinung des Spaltes führt, eintritt, folgere ich, dass es auch in erster Linie die in den Chloroplasten der Schliesszellen die Production der Stärke sowohl als auch die der Stärke-umsetzenden Fermente in den Schliesszellen der Stomata bewirken (p. 4).

The case as presented by Kohl is suggestive, but the explanation, plausible as it appears, is not beyond criticism. Starch being "always present," it is difficult to see why the supposedly present amylolytic ferments are not stimulated to activity by all the light except that in the region of the violet (Green, loc. cit.), since in the present state of our knowledge we may not confine the fermentative activity solely to the red and the blue. Indeed, even the presence of an appropriate ferment in the guard-cells has not yet been demonstrated, although there is every reason to believe it to be present. Moreover, Kohl's theory appears to lead to the view that the amylolytic ferment is active at the time of photosynthesis, but does not explain how both processes may take place at once. The actual disappearance of starch during the early part of the day, as observed by myself, indicates, however, that a ferment is indeed active; and, as I have said above, if photosynthesis takes place, the products must in all probability not assume the form of starch until later, thus adding them to the osmotic substances obtained from the stored starch. That by photosynthesis alone the starch of the guard-cell is obtained, we may not believe, in view of the facts presented by Leitgeb (1888), Francis Darwin, and myself, relating to the accumulation of starch in the stomata in the absence of carbon dioxid and under other conditions which do not result in the formation or accumulation of starch in the chlorenchyma, and to the opening of the stomata under these conditions, with the concurrent disappearance of starch leading, except in darkness, to as full an amplitude of movement as under normal conditions. To these must be added the reformation of starch in the latter part of the day, even when light is excluded (Verbena). The objection that, in experiments in which the carbon dioxid is excluded, there may be a sufficient amount available for the use of the stomata as a product of respiration, may be met in part by the observation that no trace of photosynthesis has been noted to occur in nearby chlorenchyma cells, to which the excreted gas has access equally with, if not even more directly than, the stomata.

Kohl's suggestion that there is present in the guard-cell an amylolytic ferment is of especial interest, but the mere fact that in a solution of diastase the stomata open can hardly be said to prove anything in this regard, since diastase is highly non-diffusive, and, moreover, many stomata open in water.

As already said, the presence of a ferment has not demonstrated, and myown attempts in this direction have failed. Leitgeb's observations on Galtonia 
candicans in the isolated moribund stomata of which he observed the disappearance of starch and oil, and my own on Verbena, in the stomata of which there is a daily reduction of starch, * leads irresistibly to the conclusion that there is a protoplasmic activity to which this is due, and the natural assumption is that the mechanism involved is a ferment. Wortmann championed the view that the dissolution of starch in the cell is not affected by a ferment, but by the direct action of the protoplasm (1890); but the trend of research has unceasingly favored the belief that there is an intermediate mechanism, the ferment. $\dagger$

Here, however, we tread on very debatable ground, and, in the case of the stoma, almost purely theoretical. J. R. Green ( 1899, p. 74), in his generally excellent summary of our knowledge of enzymes, points out in regard to stomata merely the teleological aspect of the question, and does not attempt to explain why the "diastase" in the stomata should act differently from the diastase of the chlorenchyma. As already pointed out, Kohl supposes an enzyme to be present whose activity, in the light of Green's later studies (1894) on the influence of light on diastase, is in some obscure way connected with photosynthesis. It seems that it will serve the best purpose in this connection to point out as clearly as may be the facts which must be considered in any attempt to formulate a theory of enzymatic activity in the stoma. The most fundamental difference to be noted as between leaf diastase and of the stoma is in the normal relation to light. Leaf diastase does its work ordinarily in the dark. $\neq$ If stoma diastase did so, there would be a disappearance of the starch in the night. This, however, is not the case. This inhibition of the process of starch dissolution can not be due to the presence of sugars or other osmotic substances (Wortmann) since the stomata are almost or quite closed, and in this condition these substances can not be present in quantities greater than those in the adjacent epidermal cells (Kohl, I895). Whatever the amount, it is not great enough to inhibit the action of the supposed diastase at dawn, until which hour the starch content remains unaffected. This leads to the next consideration, namely, that the secretion of the ferment or its activity is stimulated by light. If the relation of the stoma ferment to the rays of different refrangibility be the same as that of ordinary diastase (Green, loc. cit.), we may suppose that the early morning light would be stimu-

\footnotetext{
* The behavior of the oil in the stomata of this plant need not be considered in this connection.

$+\mathrm{G}$. Krabbe (1890) believed that diastase originates in the cell that uses it, as it can not pass, unless chemically changed and rechanged, from one cell to another. This certainly seems to be the case, since the starch in dead chlorenchyma cells does not appear to be digested even at points in close contiguity to adjacent living cells. This is true also of the stoma, in which, when one of the guard-cells is dead, this may be found richly loaded with starch, though the other guard-cell may contain no starch at all in consequence of digestive activity (plate 14, fig. 5). From this observation we may conclude that the special ferment of the guard-cell, if it exists, originates in that cell, and may not escape from it.

$\ddagger$ Though light does not inhibit its activity (Brown \& Morris, 1893, p. 624).
} 
lating, and we may further suppose that the quality of the light may become such in a few hours that the activity of the ferment, or the ferment itself, is destroyed. Whatever the cause, accumulation of starch begins at a certain time approximately each day, whether the whole of the starch content is depleted or not. The action of the ferment is not, therefore, so closely related to the presence or absence of starch as it is to some other factor, possibly light. The stimulus of light in the early morning may, however, be directed toward secretion, rather than the activity, of an enzyme already present; and here again the early morning light may affect the protoplasm positively, while the light of midday may be such as to inhibit the secretion of the ferment. The continued presence of starch in the night seems to warrant the view that the ferment as such is not present in the night, though the zymogen may be. And the increase of starch in the latter part of the day, even though the plant be in darkness, indicates that the ferment has disappeared by the time the minimum starch content is reached, though it remains possible that the cessation of its activity is due to the accumulation of the products of amylolysis. The activity of the ferment in the stoma seems, then, to be confined to the early part of the day, during which time the starch content of the plastids is depleted, and its absence at night strengthens the view that the light of the early morning stimulates the secretion of the ferment. We are, then, led to the conclusion that the stomatal activity of the morning is due to the secretion of an enzyme by the protoplasm in response to the light stimulation, and not to the view that the light, through the chlorophyll, causes the accumulation of osmotic substances by photosynthesis. The response differs, however, from the usual phototropic responses in that the protoplasm of the stoma does not differentiate between blue and red light (Francis Darwin, I 898, p. 6r5), and we are drifting toward the "nutritive theory" of stomatal activity, though not wholly in the sense conceived by Kohl. I would hold that the opening of the stoma is due to the stimulation of the protoplasm, or of some part of the protoplasm, by the secretion of an enzyme which digests the starch present. The cessation of this process is followed by a period of stasis, in which there is little change in the dimensions of the stomata. The closing of the stomata during the afternoon is due to the withdrawal of the osmotic substances by reformation of starch (and by outward diffusion) and is therefore passive in part. This reformation of starch may occur in the dark, but if the plant is exposed to light the loss of material may be made up in part by photosynthesis, which may be more active in the stomata of some plants than of others.

Further study may show that photosynthesis supplements the peculiar processes of the stomata to a greater extent in those having a large amount of chlorophyll, but the fact that they are not directly dependent upon light must be reckoned with. 
If the theory above outlined is, in its chief conception, true, the temperature and moisture relations are not difficult of understanding, although the behavior of stomata in prolonged darkness still offers some difficulty. The gradual disappearance of starch when the plant is starved is possible only if an agent of starch dissolution is present, and the appearance of this material may be the result of this starvation. The probable slight movement of stomata in darkness demands also the presence of the ferment in small quantities, though it is possible that the osmotic adjustments between the cells of the stomata and epidermis on the one hand and the cells of the epidermis and chlorenchyma on the other during darkness may account for the movement.

The behavior of the stomata which do not close at night, belonging, according to Darwin, to perhaps 3 per cent of land plants, remains to be explained, but it seems clear that these difficulties are less troublesome on the theory that photosynthesis is of relatively less importance than has hitherto been thought. And there is no real objection to supposing that the ferment which is normally rendered active in the early part of the day is present in small quantities and is proportionally active during the night, and more so in some plants than in others. These points, while they must ultimately be explained, are of subsidiary importance to the main question.

The higher normal temperatures, according to Kohl and Francis Darwin, favor the opening of the stomata. I have not, for my own part, examined by experimentation ad hoc into this relation, but my observations of the rates of stomatal opening and starch dissolution at different times of the year seem to leave little doubt that the lower normal temperatures of spring delay these processes from 2 to 3 hours. This may be understood in the light of the conditions under which enzymatic processes take place. In the spring, when the minimum temperatures range near $45^{\circ} \mathrm{F}$. and the daily maxima are $40^{\circ}$ to $50^{\circ}$ lower than in the summer, the whole action of the plant is sluggish, as is evidenced by the slower growth. The difference in the quality of the insolation may, however, be in part responsible for these differences, and it will require further research to separate these factors.

As regards the effect of relative humidity, the case seems to be comparatively simple with respect to the principle involved. So long as the tissues of the plant are supplied with a sufficient water content, the stomata may be expected to behave normally. If it happens that the vapor-tension is so low as to make it difficult for the plant to keep up the supply, or, what amounts to the same thing physiologically, if the water-supply at the roots is reduced too far, wilting ensues, and the stomata close concomitantly. The stomata do not prevent wilting; they only manage to conserve the water after wilting has occurred. Although Francis Darwin's results and mine are not wholly in accord on certain other points, especially matters of fact, I may express my own views in this regard in his words- "they [the stomata] close or 
open according as the leaf as a whole is badly or well supplied with water, either owing to the variation in the psychrometric conditions or in water supply." The secondary stomatal characters and those of the cuticle in many cases conserve the water supply so that wilting does not progress rapidly, and, further, the mechanical conditions found in the leaf may be such that wilting may progress so far that the stomata are closed before the effect is rendered visible in flaccidity. These phenomena are apart from the main issue, however, which is the relation of psychrometric conditions on the physiology of the guard-cells proper, and there is no evidence that this relation is any different for the stomatal than for the epidermal or chlorenchyma-cell.

Concerning the function of the oil in the guard-cells little at present may be said. The earlier mentioned suggestion, which was prompted by the apparent correlation of the starch and oil, their behaviors being in inverse relation, that there might be some causal connection between the oil and stomatal movement, is borne to the ground by the force of the experimental evidence. A change of a diffusible carbohydrate into a hydrocarbon is a possible mechanism for bringing about closure, but this is not in accord with the observed facts. At low temperatures, such as occur in December and January, the oil fails to appear in the guard-cells at the usual time, though this does not seem to result from external conditions, as oil does occur in the chlorenchyma at all times during the winter. We might regard it as a by-product, as has been done, but this does not save us from our ignorance. 


\section{GENERAL SUMMARY.}

The material chiefly studied for the purpose of the foregoing paper was derived from two distinct types of desert plants, Fouquieria splendens and Verbena ciliata. The former is possessed of a water-storage tissue, while the latter has no obvious adaptive character related to desert conditions. Both plants have leaves of rather unspecialized character, especially as regard the stomatal apparatus, which conforms to a widely generalized type. There are no pits, plugs, or other contrivances which might be regarded as having an accessory modification on the rate of water-vapor diffusion through the stomatal pore. The problem of the regulation of transpiration by the stomata has therefore not been complicated by such "adaptations," but is confined wholly to the possible degree of correlation of the transpiration rate and the movements of the stomata which result in the change in the size of the pores. It has also occurred that the stomata of Verbena ciliata have proved of especial value in the study of the internal economy of the guard-cell, and the experiments carried out on this plant have, it is believed, thrown light on the cause and regulation of stomatal movement. The investigation has then been directed along these two lines of thought, namely, the alleged regulation of water loss by the stomata and the physiological causes of stomatal movement.

Methods of probable wide application, to which, however, exceptions have been noted, have been devised for the more accurate estimation of the physical condition of the stomata at any given moment, by direct examination of these organs, not in situ upon the plants. By means of absolute alcohol the walls of the guard-cells are rendered rigid by the rapid extraction of the imbibed water. With the exercise of due precaution the stomata may then be made into permanent preparations if that is desirable. For the quantitative determination of changes in transpiration rate in successive periods of time, potometers, in a modified form and arranged in batteries so as to become mutual controls, have been used. By weighing, the probable error for the absorption of water by the tissues, or its loss by wilting, may be discovered.

\section{TRANSPIRATION AND STOMATAL MOVEMENT.}

On the theory of stomatal regulation of water loss by the plant we should expect a close correlation between the daily periodicities of transpiration and of stomatal movement. The rate of transpiration, however, continues to increase for a considerable period of time after the maximum stomatal opening has been reached. The diminution in the rate of transpiration during the latter part of the day may be interrupted by intervals of increase, without 
any interruption of the diminution of the stomatal dimensions. Such conclusions afforded sufficient evidence to throw real doubt on the accuracy of the view of stomatal regulation as above indicated, and the problem was then attacked from the vantage-ground of experiment.

By this means it has been found that the rate of transpiration may undergo sudden and wide changes without the accompaniment of a sufficient change in the dimensions of the stomata to account for them on the theory of stomatal regulation of transpiration. This generalization is in full accord with the conclusions of Brown \& Escombe in regard to the diffusion capacity of stomata, which, in the particular plant studied by them (Helianthus), is 6 times that of the actual maximum transpiration rate observed. A comparison of the physical characters of the stomata of Fouquieria splendens and Helianthus annuus shows that the diffusion capacities of the stomata of these two plants are nearly the same. From this fact and from the observed maximum transpiration rate of Fouquieria, it appears that the possible diffusion capacity of the stomata for water-vapor is probably never reached in this plant. And from the observation that wide positive changes in the transpiration rate may occur at any particular size of the stomatal pore, it must be further concluded that the full diffusion capacity at such dimensions is in excess of the actual diffusion. It appears, therefore, that stomatal regulation of transpiration does not occur, though, of course, conservation of the contained water follows on complete closure of the stomata. It is open to doubt, however, if this condition ever obtains. As a corollary to the above it must be held that the vapor pressure within the leaf varies from time to time, and that it does not remain constantly at the point of saturation.

\section{INDUCED RHYTHM IN TRANSPIRATION.}

Observation of changes in the rate of transpiration during constant conditions of temperatures and relative humidity, and in total darkness, brought to light evidence that there exists in Fouquieria splendens an induced rhythm in transpiration. The rhythm maximum falls at an early hour in the morning at, or somewhat later than, the hour of normal stimulation by the rising sun. The evidence is lacking that this maximum is related to stomatal movement, as, on the grounds stated above, the amount of change in the rate of transpiration involved in the attainment of the rhythm maximum is too small to be attributed to change in the dimensions of the stomatal pores; and inductive evidence has been brought to the support of this. The conclusion follows that the observed induced rhythm is a true phenomenon of transpiration, the cause for which is quite obscure. It may be remarked that the relegation of this behavior to the category of rhythm is the best disposition that we may make at this time. 


\section{INDUCED RHYTHM IN STOMATAL MOVEMENT.}

The question of induced rhythm in stomatal movement has been attacked, but with conflicting and, for the greater part, with negative results.

WILTING.

During the progress of wilting there ensues a gradual closure of the stomata without any preliminary opening such-as was believed to occur by Francis Darwin. The beginning of closure occurs somewhat later than initial wilting and seems to be a result of water loss by the leaf as a whole. There is no adaptive closure, meaning by this a closure in anticipation of wilting. Closure "before visible wilting" has no meaning, inasmuch as the progress of wilting and concomitant stomatal behavior must be investigated in each particular plant by quantitative methods. For this purpose a suitable method, as applied to Verbena ciliata, has been devised.

There can be little doubt that a high relative humidity favors the opening of stomata indirectly, by the suppression of water loss, when the supply of water is reduced toward the point of danger to the plant. Aside from this condition, however, there seems to be no relation between the degree of relative humidity and the condition of the stomata. The plants of the desert about Tucson are subjected to extremely low relative humidities, without any apparent effect upon the stomata. Changing a plant from one extreme to another is not followed by closure or opening, although the rate of transpiration may be greatly affected, since in a saturated space the transpiration rate may be reduced to a very low value and the stomata remain open; while at a low relative humidity, as, $e . g$., of 5 per cent, the stomata do not close, provided there is a sufficient supply of water for the plant. There appears to be no regulation of transpiration by the stomata correlated with changes of relative humidity.

These conclusions, taken together with those of Brown \& Escombe with reference to the relation between the diffusion capacity of stomata for carbon dioxid, indicate strongly that these organs in the plants studied are not adaptive in the active sense. They are means of communication between the interior of the plant and the gaseous environment, but the amount of water-vapor which escapes is to a very marked degree independent of the size of the pores. If a regulation of water loss exists, it is more probably brought about by some other means. Their ability to conserve the water content of the plant is a function of their size and numbers, and in many plants of such adjunctive anatomical characters as have been copiously described by many observers (especially Porsch, 1905). None of these features, however, are regulatory in their function, but are effective only through the dampening effect of constant value upon transpiration. 
PHYSIOLOGY OF THE GUARD-CELLS.

There is in Verbena ciliata a fluctuation of the amount of starch within the plastids of the guard-cells, accompanied by a complementary fluctuation of the oil content. The origin and the conditions contributory to the formation of the oil content have not been determined, but such evidence as has been afforded indicates that this substance is of secondary importance. The starch content is at its minimum during the later hours of the morning, being reached earlier in the warm weather. During the earlier hours of the morning this material is dissolved and disappears from the plastids of the guard-cells, beginning at sunrise. The increase to the maximum occupies the afternoon and probably the earlier part of the night, the maximum amount being observable in the hours of the night. The movements and periods of stasis of the stomata are closely correlated with this appearance and disappearance of starch, and this appears to be the case also in the ocotillo (Fouquieria splendens) both in regard to the fluctuation of the starch content and the stomatal movements. This behavior, and the extremely small amount of chlorophyll present in the guard-cell plastids, together with the accumulation and remarkable persistence of starch in the guard-cell during darkness, strongly suggest the hypothesis that the physiological activities within the guard-cell are quantitatively different from those of the ordinary chlorenchyma cell, a view at variance with the conclusions generally held, but which are not accepted by all students of the problem without objection.

In detail, it would appear that the plastids of the stoma, which present certain morphological differences needing further investigation, normally accumulate starch under conditions during the continuance of which the chlorenchyma plastids do not normally do so, namely, when exposed to the blue end of the spectrum, to darkness, and to air devoid of carbon dioxide. Beginning with an initial condition of the entire absence of starch, this substance has been observed to be formed, and to materially increase in quantity, when photosynthesis was impossible. This phenomenon is dependent upon the presence of available carbohydrates within the chlorenchyma, since it is possible to prolong the conditions of experimentation sufficiently to induce starvation of the stomata and a consequent reduced amplitude of movement. In this case the stomata most favorably placed are last to lose their starch content, and when again placed in the light reform their starch more slowly than the chlorenchyma. It follows that the guard-cell plastid not only is able to accumulate starch in the dark and without a supply of carbon dioxid (as are also the chlorenchyma plastids under special conditions), but normally does so by drawing upon the general supply of the leaf. The function of the chlorophyll in the plastids within the stomata of many plants is probably complementary to the secretion, otherwise than by photosynthesis, 
of starch by the same plastids, and the ratio between the two functions may and probably does vary with the amount of chlorophyll present. On this view it may be seen that the movements of the stoma are not wholly and directly dependent upon the process of photosynthesis within the guard-cell plastid, and there are thus brought into harmony the dissenting explanations of various workers in this field; and the activity of stomata which have no chlorophyll, or very little, is thus explained. The disappearance of starch from the guard-cell in the early part of the morning, and its oft-observed persistence in darkness, especially in plants in which a supply of food materials is available, compels the assumption of a mechanism of digestion of a different kind from the ordinary diastase of the leaf. The presence of such an agent has not been demonstrated, though its existence had been previously suspected (Kohl). The difference lies in its absence or inactive condition during the night, and its marked activity in the early part of the day, in sharp contrast to the inverse order of activity shown by leaf diastase. It is believed that a clear understanding of this assumed ferment will enable us to account for the movements of stomata which have remained unexplained by the generally prevalent photosynthetic theory.

The relation of stomatal activity to normal, though high, temperatures and to the very low and presumably trying relative humidities of the desert appears to be the same as to these conditions anywhere, and there is nothing which may be seized upon as affording an illustration of adaptive behavior particularly suited to the supposedly unkind climate to which the plants studied are subject. Ewart (1897) in his studies of the effect of tropical insolation, came to a somewhat analogous result with reference to other matters. As long as a water-supply is available, and so long as the plant is kept cool by transpiration, it suffers no more in the tropics than in temperate regions. The same may be said of desert plants. There is at present, at any rate, no evidence that the behavior of the stomata tends to mollify the rigor of the environment. Many plants of the desert have, to be sure, many peculiar anatomical features connected with the stoma, to which, however, no regulatory behavior may be attributed. By virtue of such characters, the plants of the desert may claim their lease of existence where many others would succumb. That the activities of such apparently very important organs as the stomata, though subject to the exigencies of the desert, have not changed adaptively in the course of uncounted centuries makes it appear improbable that plants have become gradually fitted to this environment, but that, being fitted, they have survived. 


\section{BIBLIOGRAPHY.}

[This list is not intended to be exhaustive, since the bibliography of the subject is easily accessible in certain of the works mentioned below, marked with an asterisk. The remainder are papers which have been found pertinent, but which are not usually included elsewhere. For the sake of indicating the papers referred to, even though they may not be included in the list below, the year of publication has been inserted, and the paper may thus be found in one or other of the asterisked articles.]

BAIN, S. M.

1902. A simple method for demonstrating the translocation of starch. Univ. Tenn.

BERGEN, J. Y. Record 5: 259-262.

1904a. Transpiration of sun leaves and shade leaves of Olea europaa and other broad-leaved evergreens. Bot. Gaz. 38: 285-296.

rgot $b$. Relative transpiration of old and new leaves of the Myrtus type. Bot. Gaz.

BESSEY, C. E. 38: $446-45$ I.

1898. Some considerations upon the functions of stomata. Science, II, 7: $13-16$.

BlaCKMAN, J. F.

1895. Experimental researches on vegetable assimilation and respiration. Phil. Trans. Roy. Soc. London B. 186: 503-562.

Brown, H. T., and MorRIS, G. H.

1893. * A contribution to the chemistry and physiology of foliage leaves. Jour. Chem. Soc. Trans. Isondon 63: 604-477.

Brown, H. T., and Escombe, F.

1900. Static diffusion of gases and liquids in relation to the assimilation of carbon and translocation in plants. Ann. Bot. 14: 537-542.

$1900 a$. Static diffusion of gases and liquids in relation to the assimilation of carbon and translocation in plants. Phil. Trans. Roy. Soc. London B. 193: 223-291.

1902. The influence of varying amounts of carbon dioxide in the air on the photosynthetic process of leaves and in the mode of growth in plants. Proc. Roy. Soc. London $70: 397-418$.

1905. Researches on some of the physiological processes in green leaves with spccial reference to the interchange of energy between the leaf and its surround-

BURGERSTEIN, A. ings. Proc. Roy. Soc. B. 76: 29-111.

1887. * Materialien zu einer Monographie betreffend die Erscheinung der Transpiration der Pflanzen. Wien.

1904. * Die Transpiration der Pflanzen. Jena.

Cannon, IV. A.

1905. On the transpiration of Fouquieria splendens. Bull. Torr. Club $32: 397-4$ I 4 .

$1905 b$. A new method of studying the transpiration of plants in place. Bull. 'Torr. Club 32: 5 I $5-529$.

1906. The effects of high relative humidity on plants. Torreya $6: 2 \mathrm{I}-25$.

Clements, F. E.

1905. Research methods in ecology. Lincoln, Nebraska.

1907. Abstract, Science, 11, 26: 440, 44I.

COPELAND, E. B.

1902. The mechanism of stomata. Ann. Bot. 16: 327-364.

Covilite, F. V., and MAcDougaL, D. T.

1903. The Desert Botanical Laboratory of the Carnegie Institution of Washington.

Curtis, C. C.

Carnegie Institution of Washington Publication No. 6.

1902. Some observations on transpiration. Bull. Torr. Club $29: 360-373$.

Dandeno, J. B.

A stimulus to the production of cellulose and starch. Ann. Rpt. Mich. Acad. Sci. 8: $40-44$. 
DARWIN, FRANCIS.

1897. Observations on stomata by a new method. Proc. Cambridge Phil. Soc. 9: 303-308.

1898. * Observations on stomata. Phil. Trans. Roy. Soc. London B. 190: 531-621.

EWART, A. J.

1897. The effects of tropical insolation. Ann. Bot. $11: 439-480$.

1905. The ascent of water in trees. Phil. Trans. Roy. Soc. London B. 198: 41-85.

Farmer, J. B., and Chandler, S. E.

1902. On the influence of an excess of carbon dioxide in the air on the form and

GreEN, J. R. internal structure of plants. Proc. Roy. Soc. London $70: 413-423$. I 899. The soluble ferments and fermentation. Cambridge.

Greenman, J. M. (See Wilson, WV. P., and Greenman, J. M., 1892.)

HABERLANDT, G. 1904. * Physiologische Pflanzenanatomie. Leipzig.

KонL, F. G.

1886. Die Transpiration der Pflanzen und ihre Einwirkung auf die Ausbildung

Livingston, B. E pflanzlicher Gewebe. Braunschweig.

1906. The relation of desert plants to soil moisture and to evaporation. Carnegie

LLOYD, F. E. Institution of Washington Publication No. 50. August.

1902. Movements of leaflets in Onoclea sensibilis, p. 178, in Vacation Observations, Torreya, 2: 177-180.

1901. Some points in the anatomy of Chrysoma pauciflosculosa. Bull. Torr. Club 28: 445-450. August.

1905. The artificial induction of leaf formation in the ocotillo. Torreya 5: 175-r79.

MacDougal, D. T.

1903. The influence of light and darkness upon growth and development. Mem.

MCGEE, IV J N. Y. Bot. Gard. 2.

1906. Climatology of Tinajas. Altas, Arizona: A preliminary report. Science, II,

Molisch, H. 23: $721-736$. 11 May.

1896. Eine neue mikrochemische Reaction auf Chlorophyll. Ber. D. Bot. Gesellsch. 14: $16-18$.

1897. Untersuchungen über das Ërfrieren der Pflanzen. Jena.

Peirce, G. J.

I901. Studies on the coast redwood, Sequoia sempervirens Endl. Proc. Cal. Acad.,

PORSCh, OtTO. III, Bot., 2 : 83-106.

I905. * Der Spaltöffnungsapparat im Lichte der Phylogenie. Ein Beitrag zur phylo-

RoBINSON, W. J. genetischen Pflanzenhistologie. Jena, $196 \mathrm{pp}$

1904. The spines of Fouquieria. Bull. Torr. Club 31: 45-50.

SCHIMPER, A. F. IV.

1903-4. Plant geography upon a physiological basis. (Translation.) Oxford.

WIESNER, J.

I 876. Untersuchungen über den Einfluss des Lichtes und der strahlenden Wärme auf die Transpiration der Pflanze. Sitzungsber. d. K. Akad. d. Wiss. Vien 74: $(1-55)$

Wilson, IV. P., and GreEnMan, J. M.

1892. Preliminary observations on the movements of the leaves of Melilotus alba $\mathrm{I}$. and other plants. Contr. Bot. Lab. Univ. Penn. 1: 66-72. 





\section{PLEASE DO NOT REMOVE CARDS OR SLIPS FROM THIS POCKET \\ UNIVERSITY OF TORONTO LIBRARY}

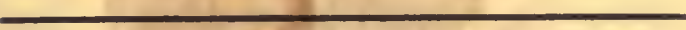
Bot Lloyd, F. E.
L The Physiology of Stomata

BioMed. 
